\title{
Observations and Modelling of Precipitation in the Southern Alps of New Zealand
}

\author{
by \\ Stephen John Stuart
}

A thesis

submitted to the Victoria University of Wellington in fulfilment of the requirements for the degree of Master of Science in Physical Geography.

Victoria University of Wellington 2011 



\begin{abstract}
Precipitation in the central Southern Alps affects glaciation, river flows and key economic activities, yet there is still uncertainty about its spatial distribution and primary influences. Long-term and future patterns of New Zealand precipitation can be estimated by the HadRM3P regional climate model (RCM) - developed by the United Kingdom Met Office - but orographic rainfall in the steep and rugged topography of the Southern Alps is difficult to simulate accurately at the $30-\mathrm{km}$ resolution of the RCM. To quantify empirical relationships, observations of surface rainfall were gathered from rain gauges covering a broad region of the South Island. In four transects of the Hokitika, Franz Josef and Haast regions, the mean annual precipitation maxima of objectively interpolated profiles are consistently located $7-11 \mathrm{~km}$ southeast of the New Zealand Alpine Fault. The magnitude and shape of the rainfall profile across the Southern Alps are strongly influenced by the $850-\mathrm{hPa}$ wind direction to the north of the mountain range, as determined by comparing rain-gauge observations to wind vectors from NCEP/NCAR Reanalysis 1 . The observed profile of orographically enhanced rainfall was incorporated into a trivariate spline in order to interpolate precipitation simulated by the RCM. This downscaling method significantly improved the RCM's estimates of mean annual rainfall at stations in the Southern Alps region from 1971 to 2000, and RCM projections of future rainfall in mountainous regions may be similarly refined via this technique. The improved understanding of the observed rainfall distribution in the Southern Alps, as gained from this analysis, has a range of other hydrological applications and is already being used in 'downstream' modelling of glaciers.
\end{abstract}




\section{Acknowledgments}

First and foremost, I must thank my primary supervisor, Sam Dean, for giving me much of his time, patience and valuable advice throughout my time at NIWA. Many thanks also to my secondary supervisor, Andrew Mackintosh, for guidance, insight and encouragement during the three years since I returned to university, and for careful consideration of the text. Brian Anderson has been of great assistance with glacial matters. I must acknowledge Tim Kerr, whose $\mathrm{PhD}$ thesis on precipitation in the Pukaki catchment provided the basis for much of my research from the outset. Discussions with Lawrence Kees have been enlightening, and his work with ground-penetrating radar in the Aoraki Mount Cook region has been valuable. Anthony Clark and Andrew Tait from NIWA have kindly helped me to improve my knowledge of splines. Thanks also to Nick Golledge, Heather Purdie, Martyn Clark, David Wratt, Abha Sood, Duncan Ackerley, Kathy Walter and Jim McGregor. I am grateful to the Victoria University of Wellington for awarding me a VUW Master's by Thesis Scholarship. Observational data from rain gauges were sourced from the New Zealand National Climate Database and the Water Resources Archive, both of which are hosted by NIWA. NCEP/NCAR reanalysis data were provided by the NOAA/OAR/ESRL PSD, Boulder, Colorado, USA. Digital elevation data were provided by Geographx in Wellington, New Zealand. Finally, thanks to my family for being good people. 


\section{Contents}

List of Figures vi

List of Tables $\quad x$

Symbols and abbreviations used in the text xii

1 Introduction 1

$\begin{array}{lll}2 & \text { Background } & \mathbf{7}\end{array}$

2.1 Topography of the central Southern Alps . . . . . . . . . . 7

2.2 Formation of precipitation . . . . . . . . . . . . . . . 10

2.3 Precipitation in mountainous regions . . . . . . . . . . . . . 12

2.3.1 Southern Alps of New Zealand . . . . . . . . . . . . . 12

2.3.2 International studies of orographic precipitation . . . 16

2.4 Dynamic modelling of the atmosphere . . . . . . . . . . . . . . 18

2.4.1 Numerical weather prediction . . . . . . . . . . . 18

2.4.2 Reanalyses . . . . . . . . . . . . . . . . . . . . . . . . 19

2.4.3 Global climate models . . . . . . . . . . . . . . 20

2.4.4 Regional climate models . . . . . . . . . . . . 20

2.5 Statistical downscaling . . . . . . . . . . . . . . 27

2.6 Methods of estimating historical precipitation . . . . . . . 28

2.6.1 Spatial interpolation of observations . . . . . . . . . 28

2.6.2 Weather radar and satellite observations . . . . . . . 32

2.6.3 Models of orographic precipitation . . . . . . . . . . 32

2.6.4 Water balance within catchments . . . . . . . . 33

2.7 Summary . . . . . . . . . . . . . . . . . . . . . 33 
3 Observational data $\quad 35$

3.1 South Island rain gauges . . . . . . . . . . . . . . 35

3.1 .1 Domain of rain gauges . . . . . . . . . . . . 36

3.1 .2 Period of observation . . . . . . . . . . . . 40

3.2 Atmospheric properties in global reanalyses . . . . . . . . . 42

3.3 Precipitation in the Pukaki catchment . . . . . . . . . . . 44

3.4 Summary . . . . . . . . . . . . . . . . . . . 46

4 Methodology $\quad 47$

4.1 Spatial interpolation of observations . . . . . . . . . . 48

4.1.1 Interpolated profiles of observed precipitation . . . . . 48

4.1.2 Interpolated surfaces of observed precipitation . . . . . 50

4.2 Downscaling of simulated precipitation . . . . . . . . . . 51

4.3 Software . . . . . . . . . . . . . . . . . . 52

4.4 Summary . . . . . . . . . . . . . . . . . 54

5 Results $\quad 55$

5.1 Direct influence of topographic elevation . . . . . . . . 55

5.2 Profiles of precipitation . . . . . . . . . . . . 57

5.2 .1 Mean annual profiles . . . . . . . . . . . 57

5.2.2 Comparison of daily profiles with atmospheric properties 63

5.3 Surfaces of observed precipitation . . . . . . . . . . . 69

5.3.1 Surface of mean annual precipitation . . . . . . . 70

5.3.2 Surfaces of mean daily precipitation, categorised by wind direction . . . . . . . . . . . . . . . . 77

5.4 Simulation of precipitation from 1971 to 2000 . . . . . . . 82

5.4.1 Distribution of simulated precipitation . . . . . . . 84

5.4.2 Comparison of simulated precipitation with observations 89

5.5 Case study: precipitation on 5 November 1994 . . . . . . . 97

5.5.1 Observed weather during the Guy Fawkes storm . . . . 97

5.5.2 Simulated precipitation on 5 November 1994 . . . . . 98

5.6 Summary of key results . . . . . . . . . . . . . 105

$\begin{array}{lll}6 & \text { Discussion } & 107\end{array}$ 
$\begin{array}{lll}7 & \text { Conclusion } & 117\end{array}$

$\begin{array}{ll}\text { References } & 120\end{array}$

$\begin{array}{ll}\text { A Rain gauges in the Southern Alps } & 131\end{array}$

B Simulated precipitation vs rain gauges 143 


\section{List of Figures}

1.1 A crevasse field on the upper regions of the Franz Josef Glacier in the Southern Alps . . . . . . . . . . . . . 3

1.2 Topography of the central Southern Alps, as represented by a digital elevation model . . . . . . . . . . . . . . 5

2.1 MODIS satellite image of the South Island of New Zealand on $11 \mathrm{Jul} 2003 \ldots \ldots$

2.2 Topography of the central Southern Alps, including the New Zealand Alpine Fault and the Main Divide. . . . . . . . . . 9

2.3 MTSAT-1R satellite image of New Zealand and the Tasman Sea on 21 Aug $2009 \ldots \ldots$. . . . . . . . . . . . . . . . 13

2.4 Orography of New Zealand, as represented by a GCM and the HadRM3P regional climate model . . . . . . . . . . . . 22

2.5 Topographic elevations of HadRM3P grid cells in the central Southern Alps . . . . . . . . . . . . . . . . . 23

2.6 A grid cell in the HadRM3P regional climate model. . . . . . . 25

2.7 Median annual rainfall in the South Island of New Zealand from 1971 to 2000 (Tait and Zheng 2007) . . . . . . . . . . . 31

3.1 Topography of the South Island and study baseline . . . . . . 37

3.2 Transects and rain gauges in the South Island from 1971 to 200038

3.3 Elevation of rain gauges versus distance northwest of baseline 39

3.4 Grid points near the Southern Alps in NCEP/NCAR Reanalysis $1 \ldots \ldots \ldots \ldots \ldots$. . . . . . . . . . . . . . 43 
3.5 Mean daily zonal wind velocity at $850 \mathrm{hPa}$ on 5 Nov 1994, as represented in NCEP/NCAR Global Reanalysis 1. . . . . . . . 44

3.6 Isohyets of estimated mean annual precipitation in the Pukaki catchment from 1971 to 2000 (Kerr 2009) . . . . . . . . . . 45

4.1 Coordinate grid aligned with the main axis of the Southern Alps 49

4.2 Domains and HadRM3P grid points used during the downscaling of simulated precipitation in the Southern Alps . . . . 53

5.1 Mean annual precipitation observed at Southern Alps stations from 1971 to 2000 , versus elevation of stations . . . . . . 56

5.2 Mean annual precipitation observed at Southern Alps stations from 1971 to 2000, versus distance northwest of baseline . . . 58

5.3 Mean daily precipitation observed at Southern Alps stations from 1971 to 2000, versus distance northwest of baseline . . . 63

5.4 Frequency of mean daily wind direction at $850 \mathrm{hPa} 42.5^{\circ} \mathrm{S}$ $170^{\circ} \mathrm{E}$ from 1971 to 2000 in NCEP/NCAR Reanalysis 1 . . . 64

5.5 Mean daily precipitation observed at Southern Alps stations from 1971 to 2000, versus distance northwest of baseline, categorised by wind direction at $850 \mathrm{hPa} 42.5^{\circ} \mathrm{S} 170^{\circ} \mathrm{E}$. . . . 66

5.6 Mean daily precipitation at Southern Alps stations on northwesterly days with $850 \mathrm{hPa}$ temperature less than or equal to $0{ }^{\circ} \mathrm{C}$, from 1971 to 2000 , versus distance northwest of baseline

5.7 An oblique aerial view of observed mean annual precipitation in the central Southern Alps from 1971 to 2000 . . . . . . . . 71

5.8 Isohyets of interpolated observations of mean annual precipitation in the central Southern Alps from 1971 to 2000 . . . . . 72

5.9 Contours of differences in mean annual precipitation in the central Southern Alps: Surf Obs.A minus Surf $_{\text {Obs.BA }}$. . . . . . 74

5.10 Differences in mean annual precipitation in the Pukaki catchment from 1971 to 2000: Surf Obs.A minus Surf Obs.TK.M, and

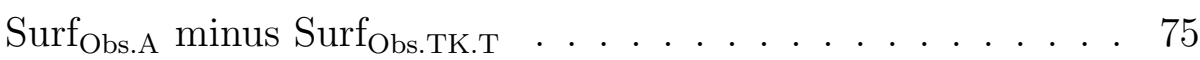


5.11 Snapshot of the flux and extent of glacial ice in the central Southern Alps, as simulated by the Parallel Ice Sheet Model under possible LGM cooling of $5-6{ }^{\circ} \mathrm{C} \ldots$. . . . . . . . . 78

5.12 Isohyets of interpolated observations of mean daily precipitation in the central Southern Alps from 1971 to 2000 . . . . . . 80

5.13 Isohyets of interpolated observations of mean daily precipitation in the central Southern Alps on northwesterly days from 1971 to $2000 \ldots \ldots$. . . . . . . . . . . . . 81

5.14 Isohyets of interpolated observations of mean daily precipitation in the central Southern Alps on southwesterly days from 1971 to $2000 \ldots \ldots$. . . . . . . . . . . . . . 83

5.15 Mean annual precipitation in the central Southern Alps from 1971 to 2000, as simulated by HadRM3P at 30-km resolution . 85

5.16 Isohyets of mean annual precipitation the central Southern Alps from 1971 to 2000, simulated by HadRM3P and downscaled using a square-root transformation . . . . . . . . . . . 87

5.17 Isohyets of mean annual precipitation in the central Southern Alps from 1971 to 2000, simulated by HadRM3P and downscaled without transformation . . . . . . . . . . 88

5.18 Stations in the central Southern Alps used to validate precipitation simulated by HadRM3P from 1971 to 2000 . . . . . . . 90

5.19 Mean annual precipitation simulated by HadRM3P versus observations from rain gauges from 1971 to 2000 . . . . . . 92

5.20 Mean annual precipitation simulated by HadRM3P, minus estimated 'true' mean annual precipitation (Surf $f_{\text {Obs.TK.T }}$ ) in the Pukaki catchment, from 1971 to 2000 . . . . . . . . . . . 94

5.21 ECMWF mean sea level pressure and 850-hPa isotachs at 00:00 5 Nov 1994 and 00:00 6 Nov 1994 UTC (Sinclair et al.

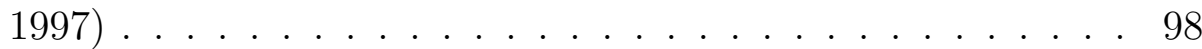

5.22 Precipitation in the central Southern Alps on 5 Nov 1994 UTC, as simulated by HadRM3P at 30-km resolution . . . . . . . . 100

5.23 Stations in the central Southern Alps used to validate precipitation simulated by HadRM3P on 5 Nov 1994 . . . . . . . . . 101 
5.24 Isohyets of downscaled HadRM3P-simulated precipitation in the central Southern Alps on 5 Nov 1994 UTC . . . . . . . . . 104

6.1 Mean annual precipitation in the Franz Josef transect from 1971 to 2000, versus distance southeast of the Alpine Fault, with topographic elevations . . . . . . . . . . . . . 109

6.2 Mean annual precipitation in the Franz Josef transect from 1971 to 2000, versus distance northwest of baseline, with GPRbased estimates by Kees (2011) . . . . . . . . . . . . . . . 111 


\section{List of Tables}

3.1 Number of rain gauges in transects of the Southern Alps from 1971 to 2000 . . . . . . . . . . . . . . . . 4 40

3.2 Time periods of rain gauges, NCEP/NCAR Reanalysis 1 and HadRM3P-simulated precipitation . . . . . . . . . . . 42

5.1 Atmospheric properties from NCEP/NCAR Renalysis 1 and observed precipitation in the Southern Alps from 1 Jan 1971 to 31 Dec $2000 \ldots \ldots$. . . . . . . . . . . . . . 67

5.2 Mean annual precipitation simulated by HadRM3P, minus observations from rain gauges, from 1971 to 2000 . . . . . . . 91

5.3 Comparison between HadRM3P-simulated and estimated 'true' precipitation in the Pukaki catchment from 1971 to 2000 . . . 96

5.4 HadRM3P-simulated precipitation compared with observations from rain gauges on 5 Nov 1994 . . . . . . . . . . . . . 102

A.1 Rain gauges in the northeast Hokitika transect of the Southern Alps from 1971 to 2000 . . . . . . . . . . . . . . . . 132

A.2 Rain gauges in the southwest Hokitika transect of the Southern Alps from 1971 to 2000 . . . . . . . . . . . . . . . 135

A.3 Rain gauges in the Franz Josef transect of the Southern Alps from 1971 to 2000 . . . . . . . . . . . . . . 137

A.4 Rain gauges in the Haast transect of the Southern Alps from 1971 to 2000 . . . . . . . . . . . . . . . . . 139

A.5 Rain gauges in the Milford transect of the Southern Alps from 1971 to $2000 \ldots \ldots$. . . . . . . . . . . . . . 141 
B.1 Observations from rain gauges in the Southern Alps, compared with precipitation simulated by HadRM3P, from 1971 to 2000. 144

B.2 Observations from rain gauges in the Southern Alps, compared with precipitation simulated by HadRM3P, on 5 Nov 1994 . . 146 


\section{Symbols and abbreviations used in the text}

\begin{tabular}{ll}
\hline ARC & Antarctic Research Centre \\
CliDB & National Climate Database \\
DEM & digital elevation model \\
EBM & energy-balance model \\
ECMWF & European Centre for Medium-Range Weather Forecasts \\
ENSO & El Niño Southern Oscillation \\
GCV & generalised cross validation \\
GCM & general circulation model \\
GPR & ground-penetrating radar \\
HadRM3P & a regional climate model developed by the Hadley Centre \\
LBC & lateral boundary condition \\
LGM & Last Glacial Maximum \\
NHD & National Hydrometric Database \\
NCAR & National Center for Atmospheric Research \\
NCEP & National Centers for Environmental Prediction \\
NIWA & National Institute of Water and Atmospheric Research \\
NOAA & National Oceanic and Atmospheric Administration \\
NWP & numerical weather prediction \\
NZLAM & New Zealand Limited Area Model \\
NZMG & New Zealand Map Grid \\
PISM & Parallel Ice Sheet Model \\
RCM & regional climate model \\
RMSE & root mean square error \\
& \\
&
\end{tabular}




$\begin{array}{ll}\text { UTC } & \text { Coordinated Universal Time } \\ \text { UKMO } & \text { United Kingdom Met Office } \\ \text { UM } & \text { Unified Model } \\ \text { VUW } & \text { Victoria University of Wellington } \\ \text { WRA } & \text { Water Resources Archive } \\ \text { WRF } & \text { Weather Research and Forecasting }\end{array}$

Surf Obs.A $_{\text {Surface of interpolated observations of mean annual }}$ precipitation in the Southern Alps from 1971 to 2000

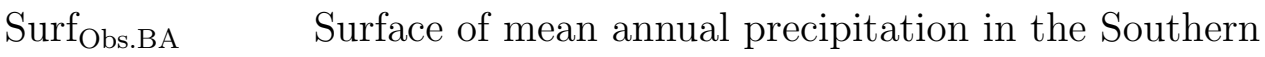
Alps, produced by Dr Brian Anderson of the ARC

Surf $f_{\text {Obs.D }} \quad$ Surface of interpolated observations of mean daily precipitation in the Southern Alps from 1971 to 2000

Surf $_{\text {Obs.D.NE }} \quad$ Surface of interpolated observations of mean daily precipitation in the Southern Alps on northeasterly days from 1971 to 2000

Surf Obs.D.Nw Surface of interpolated observations of mean daily precipitation in the Southern Alps on northwesterly days from 1971 to 2000

Surf $_{\text {Obs.D.SE }} \quad$ Surface of interpolated observations of mean daily precipitation in the Southern Alps on southeasterly days from 1971 to 2000

Surf $f_{\text {Obs.D.SW }} \quad$ Surface of interpolated observations of mean daily precipitation in the Southern Alps on southwesterly days from 1971 to 2000

Surf $_{\text {Obs.TK.M }} \quad$ Surface of mean annual measured precipitation in the Pukaki catchment from 1971 to 2000, produced by Kerr (2009)

Surf Obs.TK.T Surface of mean annual 'true' precipitation in the Pukaki catchment from 1971 to 2000, produced by Kerr (2009)

Surf $f_{\text {Rcm.A.Ds }} \quad$ Surface of mean annual precipitation in the Southern Alps from 1971 to 2000, simulated by the RCM and then 
downscaled

Surf $_{\text {Rcm.A.DsT }} \quad$ Surface of mean annual precipitation in the Southern Alps from 1971 to 2000, simulated by the RCM and then downscaled using a square-root transformation

Surf $f_{\text {Rcm.A.Raw }} \quad$ Surface of mean annual precipitation in the Southern Alps from 1971 to 2000, simulated by the RCM at 30-km res.

Surf $_{\text {Rcm.D.Ds }} \quad$ Surface of precipitation in the Southern Alps on 5 Nov 1994, simulated by the RCM and then downscaled using $\operatorname{Surf}_{\text {Obs.D }}$

Surf $_{\text {Rcm.D.Ds.NW }}$ Surface of precipitation in the Southern Alps on 5 Nov 1994, simulated by the RCM and then downscaled using Surf Obs.D.NW

Surf $_{\text {Rcm.D.Raw }}$ Surface of precipitation in the Southern Alps on 5 Nov 1994, simulated by the RCM at $30-\mathrm{km}$ res.

$\mathrm{g} \mathrm{kg}^{-1} \quad$ grams per kilogram

$\mathrm{m} \mathrm{a}^{-1} \quad$ metres per annum

$m$ a.s.l. metres above sea level

$\mathrm{m} \mathrm{dy}^{-1} \quad$ metres per day

$\mathrm{m} \mathrm{s}^{-1} \quad$ metres per second

$\mathrm{m}^{2} \mathrm{a}^{-1} \quad$ square metres per annum

$\mathrm{mm} \mathrm{a}^{-1} \quad$ millimetres per annum

$r \quad$ linear Pearson correlation coefficient

$r^{2} \quad$ coefficient of determination

$\rho \quad$ smoothing parameter of a thin-plate smoothing spline 


\section{Chapter 1}

\section{Introduction}

The Southern Alps are the most dominant topographic feature of New Zealand. These mountains strongly influence the South Island climate, and more precipitation falls here than in any other part of the country. This precipitation feeds glaciers and provides snow to ski fields. Rivers which flow from the Southern Alps generate almost half of New Zealand's electricity (Leyland and CAE 1998) and irrigate much of the South Island. Both the quantity and the distribution of precipitation in the Southern Alps are critical to key national industries such as energy, agriculture and tourism.

Observed changes in global climate during the last century are very likely to be at least partially due to anthropogenic emissions of greenhouse gases (Hegerl et al. 2007), and projected increases in the variability of precipitation have lead to regional concerns over water security (Kundzewicz et al. 2007). Scientists have developed sophisticated climate models in recent years, in an effort to improve our understanding of the physics that underlie such changes (Randall et al. 2007). Climate models can simulate the interaction of different atmospheric and oceanic processes at a range of spatial scales over both land and sea. One goal of present research is to accurately simulate and predict global and regional climatic variability.

Using an ensemble of general circulation models (GCMs), which simulate global climate, scientists have predicted further rises in global mean surface air temperature by the end of this century (Meehl et al. 2007). The amount of the projected increase is strongly related to the quantity of greenhouse 
gases emitted by anthropogenic activity over the next few decades. Simulations run under the mid-range $\mathrm{A} 1 \mathrm{~B}$ emissions scenario have predicted a mean increase of $2.8^{\circ} \mathrm{C}$ in global mean surface air temperature by 2100 , relative to the period from 1980 to 1999 (Meehl et al. 2007). While such projections are only estimates, the use of GCMs has gained general acceptance among the scientific community as the most effective means of predicting future variations in global climate (Randall et al. 2007).

In the mid-latitudes, GCMs simulate a future poleward shift of the westerlies and primary storm tracks (Yin 2005). This is likely to increase rainfall in the southwest of the South Island of New Zealand and in the western Southern Alps, while reduced rainfall is expected in northeastern parts of the North Island (Christensen et al. 2007). However, precipitation in mountainous regions is not well represented by GCMs, partly due to their coarse representation of topography (Schmidli et al. 2006).

A regional climate model (RCM), nested within a GCM, provides a means of downscaling global climatic projections. This downscaling provides finer meteorological detail within a designated region of interest, usually measuring a few thousand kilometres in both length and breadth (Jones et al. 2004). To date, the main application of RCMs has been to estimate the likely impacts of global increases in greenhouse gases upon regional climates. HadRM3P is a regional climate model that has been developed by the United Kingdom Met Office (UKMO) (Jones et al. 2004). This model is currently being adapted by the National Institute of Water and Atmospheric Research (NIWA) for use in New Zealand (Drost et al. 2007). The NIWA RCM will be used to quantify potential changes to the New Zealand climate during the next century. It can also be used to drive models of other environmental processes, such as river flows, snow accumulation and glaciation.

The two strongest climatic influences upon the behaviour of glaciers are temperature and precipitation. Anderson and Mackintosh (2006) found temperature to be the dominant influence in the Southern Alps, but South Island glacial advance has also been linked to the higher levels of precipitation associated with increased westerly circulation (Hessell 1983; Hay and Fitzharris 1988; Fitzharris et al. 1992). High rates of accumulation and ablation make 


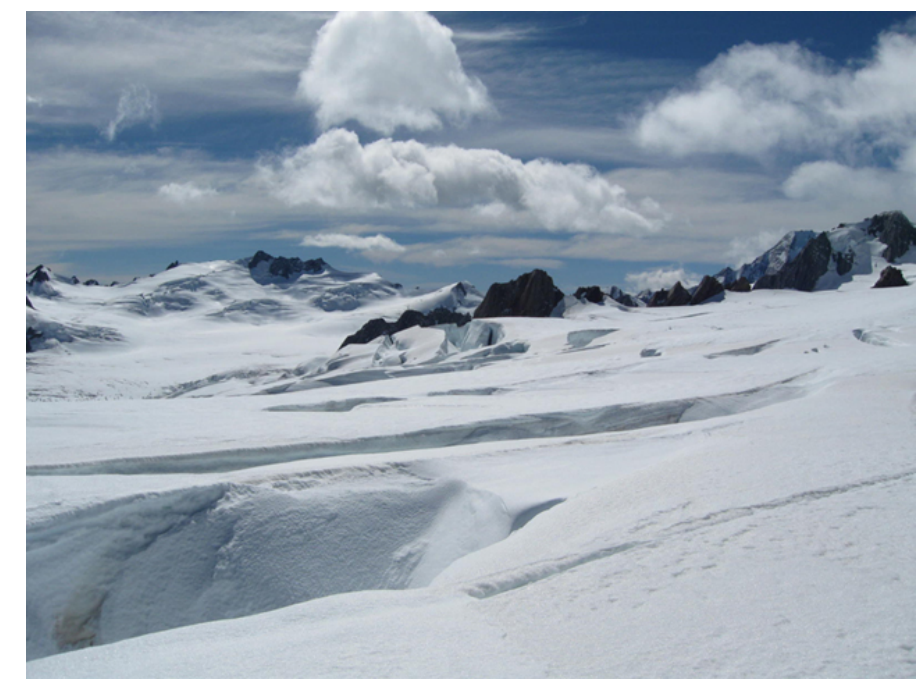

Figure 1.1 A crevasse field on the upper regions of the Franz Josef Glacier in the Southern Alps. Photograph taken by S. Stuart in March 2009.

temperate maritime glaciers particularly sensitive to climatic fluctuations (Oerlemans 1997), and debris-free glaciers in the Southern Alps, such as the Franz Josef Glacier (Figure 1.1), are important indicators of climate change (Chinn 1996; Anderson et al. 2008). The accumulation and melt of glacial ice and snow also affect the water balance of downstream catchments in the South Island.

Researchers from the Antarctic Research Centre (ARC), based at the Victoria University of Wellington (VUW), aim to gain a greater understanding of the past, present and future behaviour of glaciers in New Zealand. Various glacial mass-balance and ice-flow models are in development, including an energy-balance model (EBM) of glaciers in the central Southern Alps (Anderson et al. 2010). A key motivation for the research in this thesis was to aid the coupling of NIWA's RCM to this EBM. Linking these two models will provide insight into New Zealand glacial processes and help scientists predict future changes to glacial volumes, runoff and water availability in South Island alpine catchments. ARC researchers also aim to link the EBM to an instance of the Parallel Ice Sheet Model (PISM) (Bueler et al. 2010), in order to simulate the flow and extent of glaciers in the Southern Alps during the last 40,000 years. The PISM requires a surface of precipitation across 
the area being modelled. One of the results of this thesis was a surface of observed mean annual precipitation in the central Southern Alps from 1971 to 2000, which was subsequently used to drive glacial simulations by the PISM (Section 5.3.1).

The current horizontal resolution of NIWA's RCM is around $30 \mathrm{~km}$, but downstream environmental models often require meteorological data, such as temperature and precipitation, at a much finer spatial resolution. For example, the EBM operates on a grid which has a resolution of just over $100 \mathrm{~m}$. Since air temperature has a strongly negative correlation with altitude, mesoscale temperatures simulated by the RCM can be approximated at smaller scales via a fine representation of topography, such as a highresolution digital elevation model (DEM) (Barry 2008).

Topography also strongly influences the spatial distribution of precipitation in the Southern Alps. The upward forcing of saturated air by these high mountains - described in more detail in Section 2.3.1 — produces extremely steep rainfall gradients at the surface (Chinn 1979; Griffiths and McSaveney 1983; Henderson and Thompson 1999). However, the steep and rugged topography of the Southern Alps is smoothed at the $30-\mathrm{km}$ resolution of the RCM, and this impairs the simulation of orographic precipitation at finer spatial scales (Drost et al. 2007). A suitable method of downscaling the simulated precipitation needs to somehow incorporate orographic processes at a scale below that of the RCM's 30-km grid.

Observations in highly elevated regions of the Southern Alps are sparse. This makes it difficult to ascertain the actual distribution of rainfall in the central Southern Alps, and hinders the development of downscaling techniques. Previous research has shown that the direct correlation between local topographic elevation and precipitation is not strong in this region (Wratt et al. 2000), and employing a direct dependence upon elevation is not an accurate method of downscaling rainfall in New Zealand (Tait et al. 2006). However, a two-dimensional approach to the modelling of precipitation may be appropriate in the Southern Alps, since the orographic forcing of air moving across the mountain range produces a distinctly shaped profile of rainfall (Chinn 1979; Griffiths and McSaveney 1983; Henderson and Thompson 1999; 


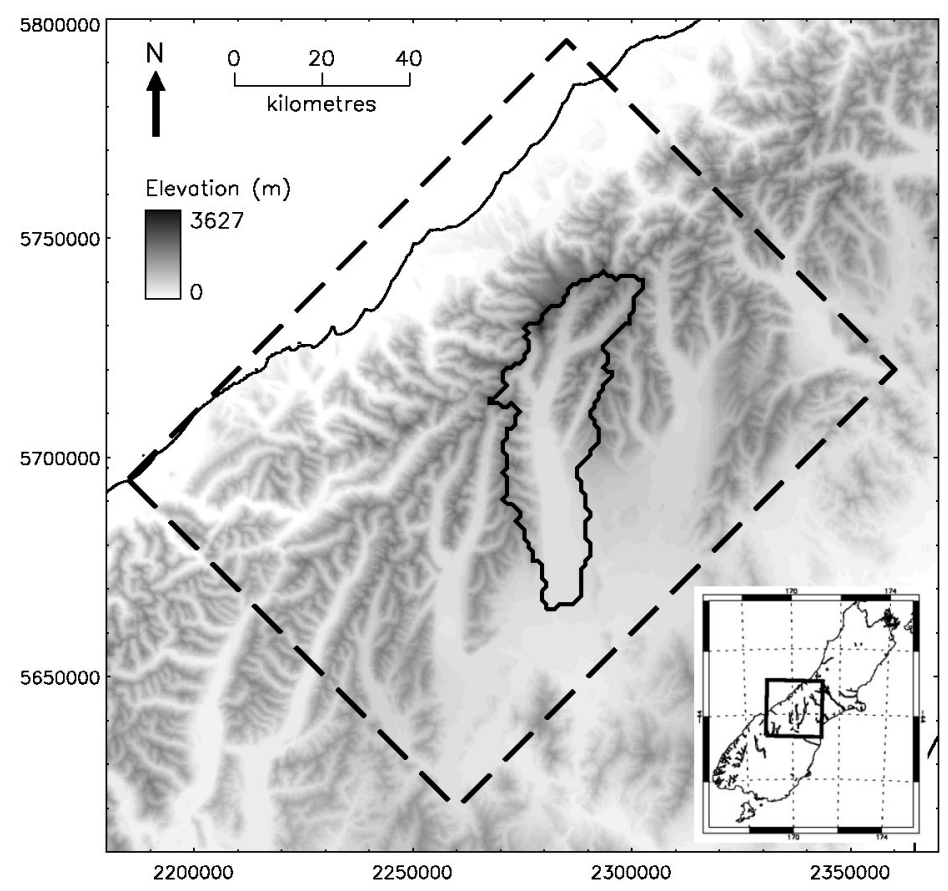

Figure 1.2 The topography of the central Southern Alps, as represented by a digital elevation model. The dashed line outlines the domain of the ARC energy-balance glacial model, which is the primary study region for this thesis. The Pukaki catchment is outlined by a thick solid line within the primary study region.

Wratt et al. 2000).

In this thesis, I ask the research question:

- What is the spatial distribution of precipitation in the central Southern Alps, and how is it influenced by topography and wind direction?

The domain of the ARC energy-balance model was designated the primary region of study (Figure 1.2). This is the most highly elevated and heavily glaciated region of New Zealand, and occupies approximately 14,000 km² of land. My objectives in this thesis are to:

1. derive profiles of historical rainfall across the Southern Alps, using observations from rain gauges;

2. identify the strongest influences upon the spatial distribution of precipitation in the central Southern Alps; 
3. incorporate observed profiles of rainfall into the downscaling of precipitation simulated in the central Southern Alps by the NIWA regional climate model;

4. validate the simulated and downscaled precipitation by comparisons with observations of rainfall.

An improved correlation between observed and simulated precipitation, after downscaling, will help identify the primary determinants of rainfall distribution in the Southern Alps. In addition, the accurate simulation of historical climate instils greater confidence in future projections from both the RCM and other environmental models to which it is linked.

The next chapter describes the topography of the central Southern Alps, and reviews existing literature relating to orographic rainfall, dynamic atmospheric models and the estimation of precipitation. The observational data used in this thesis, including rain gauges in the Southern Alps and atmospheric properties from historical reanalyses, are described in Chapter 3. Many of these data have not been previously been included in such an analysis. Chapter 4 details the methods used to interpolate observations and downscale the simulated rainfall. The results of the analysis, including profiles and surfaces of observed and simulated precipitation, are presented in Chapter 5. These results are discussed within a wider research context in Chapter 6, before conclusions are presented in Chapter 7. Rain gauges in the Southern Alps from 1971 to 2000 are catalogued in Appendix A, and comparisons between individual rain gauges and the RCM are listed in Appendix B. 


\section{Chapter 2}

\section{Background}

The predominantly westerly airflow of the mid-latitudes may be vertically displaced in the lower troposphere by local topographic variations, such as the steep mountains in the South Island of New Zealand. The orographically enhanced rainfall which arises from these effects has been studied in the Southern Alps and in a number of other mid-latitude mountain ranges around the world. The underlying physics of atmospheric motion and rainfall processes may be approximated by numerical equations, which are integrated in time within dynamic models. The distribution and influences of precipitation can also be modelled using interpolative and statistical techniques, in order to produce continuous rainfall surfaces, but empirical methods may be hindered in remote regions by a shortage of observational data. This chapter provides background information about alpine precipitation in the South Island, and documents previous work in related regions of study.

\subsection{Topography of the central Southern Alps}

The Southern Alps extend over $500 \mathrm{~km}$ along the west side of the South Island of New Zealand, with latitudes of $42-45^{\circ} \mathrm{S}$ and longitudes of $167-173^{\circ} \mathrm{E}$. Figure 2.1 shows the South Island after a heavy blizzard in July 2003; the major mountain ranges are marked out by snow, though significant snow cover is also present in some catchments east of the mountains. The main orographic axis of the Southern Alps runs northeast-to-southwest, approxi- 


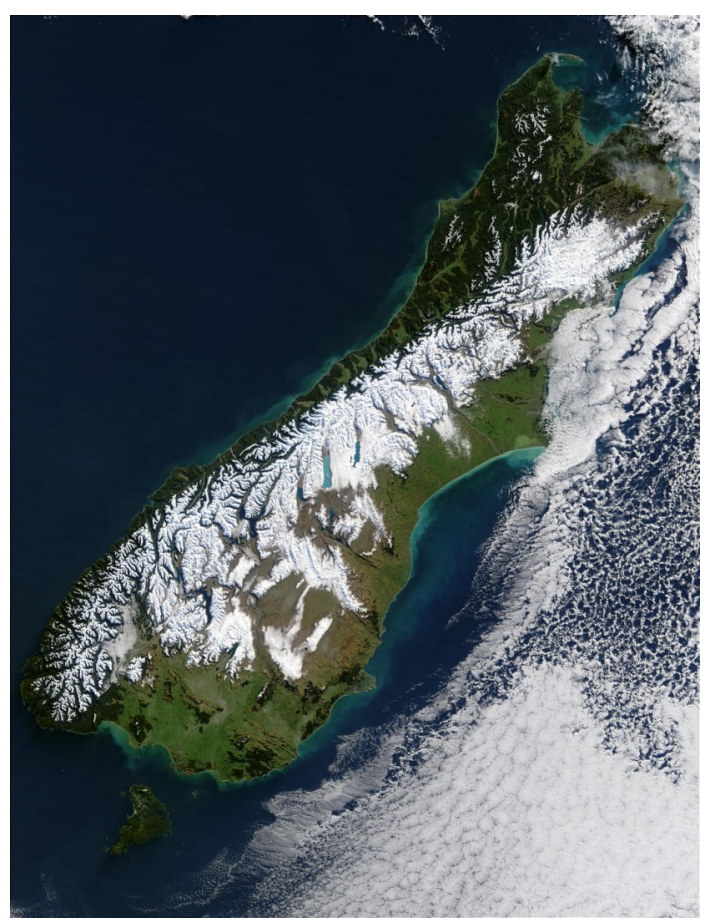

Figure 2.1 The South Island of New Zealand after a heavy blizzard. Image taken on 11 Jul 2003 by the Moderate Resolution Imaging Spectroradiometer (MODIS), Terra Satellite, NASA.

mately parallel to the New Zealand Alpine Fault (Figure 2.2). The Southern Alps have formed at the boundary of the Pacific and Indo-Australian plates, where oblique convergence has caused tectonic uplift during the last 5-6 million years (Walcott 1998; Batt et al. 2000). The Main Divide of the Southern Alps generally lies $15-30 \mathrm{~km}$ southeast of the Alpine Fault. The Southern Alps culminate at Aoraki Mount Cook (3754 m, 43.6 $\mathrm{S}$ ), which lies just south of the Main Divide. Mount Tasman (3491 m) is $4 \mathrm{~km}$ north of Aoraki and many other peaks also exceed $2500 \mathrm{~m}$. Aoraki Mount Cook National Park and Tai Poutini Westland National Park occupy the most highly elevated region of the central Southern Alps, which contains all but one of New Zealand's peaks higher than $3000 \mathrm{~m}$ a.s.l.

Southwest of Aoraki, toward Haast, the Main Divide deviates further southeast of the Alpine Fault and reduces in height. Northwest of the Main Divide in this region, the Hooker Range lies on the northwest flank of the 


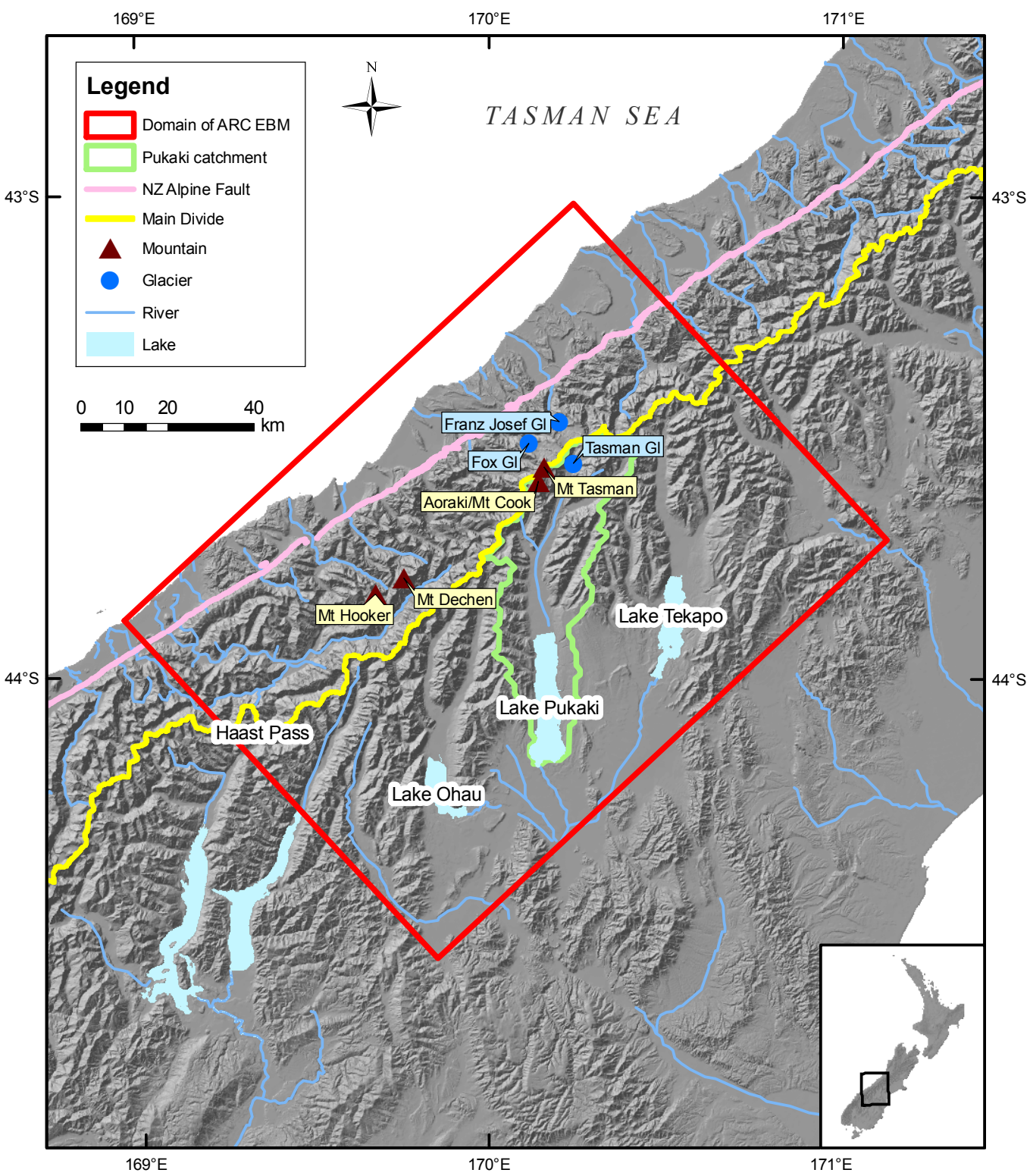

Figure 2.2 The topography of the central Southern Alps. Also shown on this map are the New Zealand Alpine Fault, the Main Divide, the domain of the ARC energybalance glacial model, the Pukaki catchment and other geographic features mentioned in the text. 
Landsborough Valley. This range contains significant peaks such as Mount Hooker (2640 m) and Mount Dechen (2643 m).

Glacial erosion has carved steep troughs and valleys through the landscape during multiple glaciations since the late Pleistocene (Suggate 1990), and the Southern Alps currently contain over 3000 glaciers (Chinn 1995). The Fox and Franz Josef glaciers are located on the western slopes north of Aoraki Mount Cook. The length of the Franz Josef Glacier is around $11 \mathrm{~km}$ and its elevation ranges from $2900 \mathrm{~m}$ a.s.l. near the Main Divide (Anderson et al. 2008) to less than $300 \mathrm{~m}$ a.s.l. at the glacial terminus. The upper regions of the glacier consist of wide, shallow snowfields which funnel down through the valley, in a northwest direction, to the steep tongue. The Franz Josef Glacier drains into the Waiho River in the Waiho Valley.

The Pukaki catchment lies southeast of the Main Divide in the Aoraki Mount Cook region, and has an area of $1359 \mathrm{~km}^{2}$. The upper catchment contains 133 glaciers (Chinn 2001), including the largest glacier in New Zealand - the Tasman Glacier — which is currently $23 \mathrm{~km}$ long (Dykes and Brook 2010). Tasman Saddle is located in the upper regions of the glacier at an altitude of $2435 \mathrm{~m}$ a.s.l. The glacial tongue extends southwest into the Tasman Valley, where a proglacial lake drains into the Tasman River. This river

flows south into Lake Pukaki, which covers an area of $168 \mathrm{~km}^{2}$. Other large glaciers in the Pukaki catchment include the Murchison, Hooker and Mueller. The Ben Ohau and Sealy ranges form the steep west flank of the catchment, and the Jollie River flows through a subcatchment to the east. East of the Pukaki catchment, the Godley and Macaulay rivers flow into Lake Tekapo. Southwest of the Pukaki catchment, the Dobson and Hopkins rivers feed Lake Ohau.

\subsection{Formation of precipitation}

In this section, the basic physical processes that lead to precipitation are described. The two major constituent gases of the homosphere are nitrogen and oxygen; these gases are well mixed within the homosphere. The atmospheric concentration of water vapour, however, is variable, since cooler air has a 
reduced capacity to hold water vapour in its gaseous state. Water vapour constitutes up to $4 \%$ of the volume of the homosphere (Sturman and Tapper 2006).

Within the troposphere, the pressure of air decreases logarithmically with height, as the accumulated weight of the compressed atmosphere decreases. This reduction in atmospheric pressure causes the temperature of air to also decrease with height - as air rises, it decompresses and becomes cooler (Barry and Chorley 2003). Rising air cools at the dry adiabatic lapse rate of $9.8^{\circ} \mathrm{C} \mathrm{km}^{-1}$ if no condensation of water takes place. Given a sufficient increase in altitude, rising moist air will eventually cool to the extent that its water vapour condenses to become particles of liquid water or ice (Barry and Chorley 2003).

If condensation of water vapour does occur, then latent heat is released. This latent heat partially counters the cooling of the rising air, causing the temperature of the air to decrease at a lower rate. This reduced rate is the saturated adiabatic lapse rate, which is usually $4-7{ }^{\circ} \mathrm{C} \mathrm{km}^{-1}$ (Wallace and Hobbs 2006). If condensation continues, then cloud may form. Once the droplets or ice particles reach a certain size, the weight of their mass is sufficient to counter the upward force caused by the vertical pressure gradient. The water particles are then no longer in hydrostatic balance and gravity forces them to fall down toward the Earth as hydrometeors.

As the hydrometeors fall downward, the ambient atmospheric temperature usually rises, which may cause them to evaporate. Water droplets or ice particles that fall at least $100 \mathrm{~m}$ below the cloud base are regarded as precipitation (Sturman and Tapper 2006). If the precipitation lands in the phase of liquid water, then rain occurs. The presence of ice in the hydrometeors results in the precipitation falling in the form of snow, sleet or hail.

Precipitation is typically caused by some form of upward atmospheric motion. The three main drivers of upward atmospheric motion that leads to precipitation are convection, cyclonic lifting and orographic forcing. Convection is caused by the thermodynamic transfer of heat within the atmosphere, resulting in the vertical movement of air parcels. Convective precipitation can occur when a warm surface heats the lower troposphere and destabilises 
the atmosphere, or within tropical cyclones as warm air rises near the centre of the depression.

Cyclonic precipitation forms as air is forced upward by the convergence of air masses in a region of low pressure. Along warm and cold fronts in the mid-latitudes, this causes the uplift of the warmer and more buoyant of the two air masses (Barry and Chorley 2003).

Orographic precipitation occurs as moist air travelling horizontally is forced upward by mountains. The amount of orographic precipitation that is experienced by a particular point on land is influenced by a number of factors. These include the humidity and temperature of the atmosphere upwind of the mountains (Wratt et al. 2000). Warmer air can hold more precipitable water, and a steep environmental lapse rate leads to atmospheric instability and more vigorous vertical movement of air parcels. A steep horizontal pressure gradient is associated with an increase in horizontal wind speed, leading to enhanced orographic uplift of air. The slope and height of the topography affect the rate and extent of atmospheric ascent. Land exposed to the direction of the wind is likely to receive more orographic precipitation (Barry 2008).

\subsection{Precipitation in mountainous regions}

\subsubsection{Southern Alps of New Zealand}

The Southern Alps lie on the northern edge of the zone of mid-latitude westerlies, which predominate between the subtropic belt of high pressure to the north and the polar trough to the south (Sturman and Tapper 2006). The proximity of the Southern Alps to the west coast of the South Island exposes these mountains to weather systems approaching from the Tasman Sea (Figures 2.3 and 5.21). The combination of westerly winds, moist oceanic air and orographic forcing typically causes annual precipitation on the upper west flank of the Southern Alps to exceed $10 \mathrm{~m}$ (Henderson and Thompson 1999). Lee side warming regularly causes a föhn effect over the eastern plains of the South Island, where precipitation drops to around $0.5 \mathrm{~m} \mathrm{a}^{-1}$. 


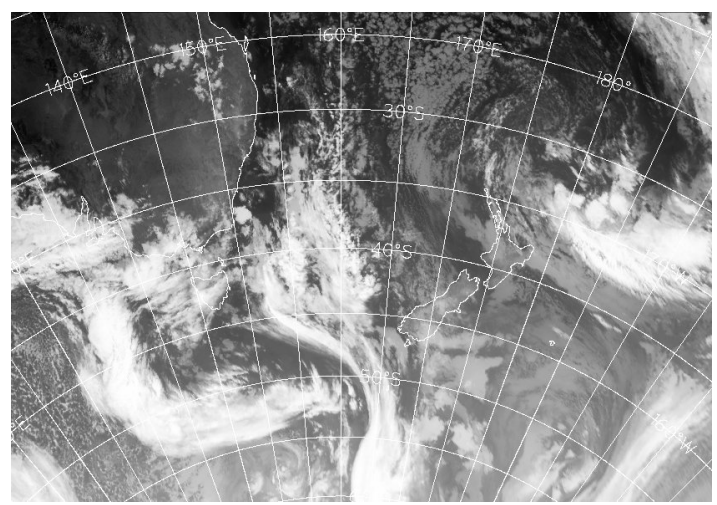

Figure 2.3 A front approaches New Zealand from the Tasman Sea on 21 Aug 2009. Image taken by the MTSAT-1R satellite and provided courtesy of the Japanese Meteorological Agency, the New Zealand Meteorological Service and MetVUW.com.

The observed distribution of precipitation exhibits a distinct profile across the Southern Alps (Chinn 1979; Griffiths and McSaveney 1983; Henderson 1993; Henderson and Thompson 1999), though the direct correlation between elevation and precipitation is not strong (Wratt et al. 2000). Henderson and Thompson (1999) analysed observations from rain gauges, which were arranged into four transects across the Southern Alps. They concluded that storm rainfall along the Southern Alps peaks within a slender zone, approximately $10 \mathrm{~km}$ southeast of the Alpine Fault and 10-20 km northwest of the highest ground. Additionally, across each section of the Southern Alps, the magnitude of the precipitation maxima and the height of the Main Divide showed some correlation (Henderson and Thompson 1999).

The Main Divide is not always the line of maximum elevation in the Southern Alps; subranges form the major windward barrier along some sections. At and around Aoraki Mount Cook, however, the Main Divide is at its highest and is also only around $30 \mathrm{~km}$ southeast of the western coastline, with little intervening topography. Precipitation in the Southern Alps may peak just upwind of the Main Divide in the vicinity of Aoraki Mount Cook (Griffiths and McSaveney 1983; Henderson and Thompson 1999).

The Franz Josef Glacier lies $13 \mathrm{~km}$ to the northeast of Aoraki Mount Cook and less than $20 \mathrm{~km}$ from the western coastline. The upper catchment of the glacier experiences up to $12 \mathrm{~m}$ of precipitation each year (Anderson 
et al. 2008). However, it is difficult to maintain observational instruments at high altitude in such steep and icy terrain, and in such a harsh climate. A shortage of observations at high elevation makes it difficult to ascertain whether mean annual precipitation does indeed peak in this region.

Precipitation in the Southern Alps is particularly intense during northwesterly storms (Chinn 1979). Air from lower latitudes tends to be warmer and therefore can usually hold more moisture. Warm air to the northwest of New Zealand often becomes saturated as it travels southeastward over the Tasman Sea. Moreover, northwesterly airflow approaches the Southern Alps at an angle perpendicular to their axis, which enhances orographic uplift (Chater and Sturman 1998; Wratt et al. 2000).

The influence of atmospheric variables upon the distribution of precipitation in the Southern Alps has been investigated in a number of previous studies, such as the Southern Alps Experiment (SALPEX) (Wratt et al. 1996; Sinclair et al. 1997; Wratt et al. 2000), Chater and Sturman (1998) and Kerr (2009). Among the atmospheric properties analysed in these studies were wind direction, wind magnitude, temperature and humidity, at various altitudes of the atmosphere. Wratt et al. (2000) constrained their analysis of the relationship between air mass properties and rainfall in the Southern Alps to times at which wind direction, in the horizontal plane and at the $850 \mathrm{hPa}$ pressure level, blew from between the bearings of $245^{\circ}$ and $25^{\circ}$, that is, from a northwestern segment of the compass. The average height of the $850 \mathrm{hPa}$ pressure level is around $1460 \mathrm{~m}$ a.s.l (NOAA et al. 1976), though the actual height depends upon the current atmospheric temperature and pressure. Air that displays a strong vertical temperature gradient upwind of the Southern Alps is more easily destabilised as it encounters the first windward ranges, encouraging upward motion (Wratt et al. 2000).

Sinclair et al. (1997) studied a long, intense northwesterly storm in the Southern Alps from 4 to 9 November 1994. This was nicknamed the 'Guy Fawkes storm', in recognition of the anniversary of the 'Gunpowder plot' to blow up the English House of Lords on 5 November 1605. As this storm progressed, the profile of precipitation moved southeastward across the mountains. A comparison to rawinsonde observations indicated that this move- 
ment was associated with stronger wind speeds and a reduction in atmospheric stability during the latter periods of the storm (Sinclair et al. 1997).

Precipitation that falls east of the Main Divide during westerlies and northwesterlies is often termed 'spillover'. Past studies have noted a negative - though not always strong - correlation between air temperature and spillover (Sinclair et al. 1997; Chater and Sturman 1998; Wratt et al. 2000). Cool air is often associated with a reduction in the height of the freezing level, which can increase the amount of ice in the lower atmosphere. As hydrometeors, ice crystals fall more slowly than raindrops and thus travel further downwind, leading to more precipitation east of the Main Divide (Wratt et al. 1996; Sinclair et al. 1997; Chater and Sturman 1998; Wratt et al. 2000). Additionally, cool air masses can be destabilised by surface heating, which in turn reduces the blocking effect of the mountains and leads to increased spillover of precipitation. Kerr (2009) found that the distribution of precipitation in the Pukaki catchment was most strongly affected by distance from the axis of maximum orographic uplift and synoptic wind direction.

Annually, snowfall forms only 10-20\% of the precipitation in the Southern Alps (Barry 2008), though this proportion increases during winter and early spring. Overall volumes of precipitation in the vicinity of the Main Divide show relatively little seasonal or annual variation (Hessell 1982; Henderson and Thompson 1999), but are influenced by changes in synoptic circulation. Annual precipitation in the south and west of the South Island correlates positively with the Trenberth (1976) Z1 index of westerly flow (Salinger 1982). The correlation between seasonal precipitation in the southwest South Island and the Southern Annular Mode (SAM) index is negative during summer and positive during winter (Kidston et al. 2009). During the El Niño (negative) phase of the El Niño Southern Oscillation (ENSO), cooler sea surface temperatures in the west Pacific introduce anomalous southwesterly airflow to New Zealand. This leads to cooler temperatures and a seasonally varying effect upon precipitation in the south and west of the South Island (Gordon 1986). The advance of reactive glaciers in the Southern Alps, such as the Franz Josef Glacier, is negatively correlated with the Southern Oscillation Index (SOI) and positively correlated with westerly circulation (Fitzharris 
et al. 1992, 1997; Hooker and Fitzharris 1999).

\subsubsection{International studies of orographic precipitation}

Climatic conditions similar to those of the Southern Alps are to some extent encountered in other mountain ranges that also trend north-to-south and intersect the westerlies. Such ranges include the Patagonian Andes, the Scandinavian Mountains, and the Cascade Range and Sierra Nevada in the United States. The European Alps differ from these other ranges in some aspects of geography, but they have been the subject of much research into processes of orographic precipitation.

The Patagonian Andes are aligned approximately north-to-south, lie in the southern mid-latitude westerlies and are exposed on their windward side to the Pacific Ocean. High precipitation rates and the low temperatures associated with high latitudes and topographic elevation lead to significant glacierization in the Patagonian icefields. Fujiyoshi et al. (1987) studied precipitation over San Rafael Glacier in Chile, at around $47^{\circ} \mathrm{S}$. At the glacial terminus, which lies at sea level on the western coastline, mean annual rainfall over 4 years was $3.7 \mathrm{~m} \mathrm{a}^{-1}$. From 5 months of observations during the austral summer, Fujiyoshi et al. (1987) estimated that in the middle of the Northern Patagonia Icefield, $12 \mathrm{~km}$ east of the San Rafael terminus and at an altitude of $640 \mathrm{~m}$ a.s.l., mean annual precipitation was around $10 \mathrm{~m} \mathrm{a}^{-1}$. To the south, Schneider et al. (2003) analysed 3 years of observations of precipitation across a mountainous section of the Patagonian archipelago at $53^{\circ} \mathrm{S}$, in which elevation climbed to a maximum of around $1500 \mathrm{~m}$ a.s.l. Mean annual precipitation was estimated to be $4.4 \mathrm{~m} \mathrm{a}^{-1}$ at sea level west of the main divide, and $10.9 \mathrm{~m} \mathrm{a}^{-1}$ at a station toward the middle of the profile. At the leeward site of Punta Arenas, mean annual precipitation at sea level dropped to around $0.5 \mathrm{~m} \mathrm{a}^{-1}$ (Schneider et al. 2003). The west-to-east profile of precipitation in the Patagonian Andes thus shows some similarities to that of the Southern Alps.

The Scandinavian Mountains run approximately southwest to northeast along the length of Norway from $58-71^{\circ} \mathrm{N}$. The maximum elevation of this mountain range is $2469 \mathrm{~m}$ a.s.l. Over the North Atlantic Ocean, westerlies 
and southwesterlies form between the subtropical Azores High to the south and the Icelandic Low to the north. Moist air blowing in from the North Atlantic Ocean and Norwegian Sea leads to around $3.5 \mathrm{~m}$ of precipitation on the western Norwegian coastline each year, while orographic forcing contributes to over $5 \mathrm{~m} \mathrm{a}^{-1}$ in elevated and glaciated regions further inland (Chinn et al. 2005). Some valleys in the lee of the Scandinavian Mountains receive less than $0.5 \mathrm{~m}$ of precipitation each year (Barry and Chorley 2003).

The European Alps lie at $43-48^{\circ} \mathrm{N}$ and are somewhat less exposed to westerly winds. This is due to the lower latitude of the mountain range, a more inland location and the variable orientation of the main orographic axis. Certain situations of surface pressure occasionally force air from the Mediterranean northward over the Swiss Alps, causing a föhn wind to develop north of the main Alpine Ridge. The relationship between elevation and precipitation varies within the European Alps. South of the main Alpine Ridge in Switzerland, no correlation exists between precipitation and elevation, while north of the ridge the correlation is strong (Sevruk 1997). Although the highest regions of the Swiss Alps are over $4000 \mathrm{~m}$ a.s.l., precipitation reaches only around $2.3 \mathrm{~m}$ each year (Frei and Schär 1998; Weingartner and Pearson 2001). Snowfall typically constitutes $60-80 \%$ of total precipitation in the European Alps (Barry 2008).

Panziera and Germann (2010) used weather radar to analyse orographic precipitation in the southern European Alps, between Switzerland and Italy. The dominant factor in determining the intensity and frequency of orographic precipitation was wind velocity upstream of the Alps. Instability in the lower atmosphere was also correlated with more intense rainfall, though to a lesser extent than wind velocity. Wind direction was the primary determinant of the location of the maximum accumulations of precipitation. These atmospheric properties were found to be most influential at around $1000 \mathrm{~m}$ a.s.l. upwind of the Alps and $3000 \mathrm{~m}$ above the first windward mountains (Panziera and Germann 2010). 


\subsection{Dynamic modelling of the atmosphere}

Dynamic numerical models of the atmosphere are based on the physical laws which govern the thermodynamics, pressure and movement of fluid, such as the equations of motion and state (Holton 1992). Improvements in our understanding of the atmosphere and the advent of high-speed computing in recent decades have led to the development of increasingly complex and realistic models. Simulations can be performed over a range of spatial and temporal scales, in order to provide weather forecasts, reproduce palaeoclimate and make predictions about future climate (Randall et al. 2007).

\subsubsection{Numerical weather prediction}

Numerical weather prediction (NWP) models assimilate output from a global or regional model with a range of observational data, in order to produce an approximation of the state of the atmosphere at a particular point in time. These observational data may include imagery from geostationary and polar-orbiting satellites, as well as meteorological measurements from aircraft, ships, radiosondes and surface climate stations. The assimilated data are then used as the starting point for the next run of the model, from which a prognosis and forecast are produced, usually for a period of up to 10 days (Kalnay 2003). Sophisticated NWP models have been developed by organisations such as the European Centre for Medium-Range Weather Forecasts (ECMWF), the UKMO and the US National Center for Atmospheric Research (NCAR).

The Hadley Centre of the UKMO has developed a suite of atmospheric and oceanic numerical modelling software called the Unified Model (UM). The UM can be run in a number of different configurations: as a global NWP model, regional NWP model (Uddstrom et al. 2007), general circulation model (Johns et al. 2006), or regional climate model (Jones et al. 2004). The UM was first introduced into operation in 1991 and was originally written in the Fortran 77 programming language (United Kingdom Met Office 1998), but much of the model has subsequently been rewritten in Fortran 90. For numerical weather prediction in the United Kingdom, the UKMO runs 
the UM at a resolution of $4 \mathrm{~km}$ (United Kingdom Met Office 2009).

The Weather Research and Forecasting (WRF) Model is a freely available mesoscale NWP model. WRF has been developed via a collaborative partnership between many organisations, including NCAR and the National Oceanic and Atmospheric Administration (NOAA) in the United States. The WRF model can be used for both weather prediction and atmospheric research. Dravitzki (2009) used WRF to simulate three heavy precipitation events in the Waikato River catchment between 2005 and 2007, with the spatial resolution of the innermost domain of the model set to $3 \mathrm{~km}$. WRF consistently underestimated the magnitude of precipitation during these events. During a continuous two-year simulation of precipitation across New Zealand from 2005 to 2007, run at 12-km resolution, WRF displayed a common tendency of NWP models to underestimate heavy precipitation and overestimate light precipitation (Dravitzki 2009).

The New Zealand Limited Area Model (NZLAM) is an instance of the UM used at NIWA for numerical weather prediction (Uddstrom et al. 2007). In a case study, NZLAM simulated a severe weather event over the South Island of New Zealand at a spatial resolution of up to $1 \mathrm{~km}$ and with time steps as short as 15 seconds (Webster et al. 2008). At this resolution, NZLAM simulated up to $500 \mathrm{~mm}$ of precipitation in the Southern Alps during a 24hour period. However, NZLAM is currently run operationally at a resolution of $12 \mathrm{~km}$. NZLAM, WRF and other NWP models are designed for relatively short-term weather prediction; excessive computational requirements currently make NWP unsuitable for the approximation of long-term spatial patterns of precipitation (Tait et al. 2006).

\subsubsection{Reanalyses}

Reanalyses are descriptions of the past state of the atmosphere that have been produced by specialised dynamic atmospheric models that are genetically related to NWP models. Reanalysis models assimilate historical meteorological observations from aircraft, ships, satellites, ground stations and rawindondes around the world. Guided by the observational data, the models simulate atmospheric processes and produce meteorological diagnostics at regular time 
intervals on a regular spatial grid. These diagnostics include atmospheric pressure, wind velocity, air temperature, specific humidity, relative humidity and precipitation. Global reanalyses have been produced by the National Centers for Environmental Prediction (NCEP) and NCAR (Kalnay et al. 1996), as well as the ECMWF (Uppala et al. 2005).

\subsubsection{Global climate models}

Climate models simulate atmospheric processes over much longer periods of time than NWP models - typically decades, and sometimes centuries or even millennia (Eby et al. 2009). Over longer time scales, the atmosphere is significantly influenced by its interaction with other geophysical components, such as the ocean, cryosphere and biosphere. Climate models are therefore often coupled with models of these other processes in order to simulate climate more realistically (Weaver et al. 2007).

Given finite computing power, global climate models must be simplified in some way to make long-term simulations feasible. General circulation models usually have considerably coarser spatial and temporal resolution than NWP models, which significantly reduces the amount of computing power required to simulate atmospheric processes over any given length of time. The spatial resolution of current GCMs is typically in the order of hundreds of kilometres (Randall et al. 2007). At this resolution, GCMs provide little detail of regional climatic variations, especially within a topographically diverse country such as New Zealand. In Earth System Models of Intermediate Complexity (EMICs), the model physics are simplified. For example, in the University of Victoria (UVic) Earth System Climate Model (Weaver et al. 2001), the atmosphere is simplified to an energy-moisture balance model, while the ocean retains a high degree of complexity.

\subsubsection{Regional climate models}

Regional climate models run at a higher spatial resolution than GCMs, typically 30-50 km (Christensen et al. 2007). RCMs are essentially limited-area GCMs, but usually do not have an ocean component. An RCM receives its 
lateral boundary conditions (LBCs) from the GCM or reanalyses in which it is embedded. LBCs include atmospheric pressure, temperature and humidity. From these, an RCM simulates atmospheric circulation and climatic processes within its domain. The LBCs of an RCM are usually updated by the GCM or reanalysis at regular intervals, such as every 6 hours.

\section{HadRM3P regional climate model of New Zealand}

HadRM3P is an RCM configuration of the Unified Model. NIWA is currently adapting HadRM3P for use in New Zealand. The NIWA version of HadRM3P uses the existing UM Fortran code, but the execution of the model over the New Zealand domain necessitates the development of new input data and parameterisations appropriate for the region. In order to downscale global climatic projections for New Zealand, HadRM3P is nested within a GCM version of the Unified Model known as HadAM3P (Anagnostopoulou et al. 2008). HadRM3P has already simulated New Zealand climate from 2070 to 2100 under the A2 and B2 emissions scenarios (Meehl et al. 2007). Alternatively, the RCM can be tested and calibrated via the use of control runs, during which the LBCs are provided by historical reanalyses such as ERA-40 (Uppala et al. 2005) or NCEP/NCAR (Kalnay et al. 1996). Past control runs of the RCM have simulated New Zealand climate from 1970 to 2000 .

During RCM simulations, the geographic coordinates of the model are rotated so as to straddle the equator. This minimises the convergence of the meridians and allows the model to operate within grid cells that are almost square. To analyse output from the RCM in true geographic coordinates, the longitudes and latitudes first need to be rotated back to the mid-latitudes.

HadRM3P contains 19 vertical levels and has a horizontal spatial resolution of around $30 \mathrm{~km}$. The increase in spatial resolution, relative to that of a typical GCM, greatly improves the representation of New Zealand topography, as illustrated in Figure 2.4. Different orographic surfaces can be used in each simulation. Figure 2.5 shows the orography of HadRM3P in the central Southern Alps during the simulations used this thesis. In this image, the RCM elevations overlay a $500 \mathrm{~m}$ digital elevation model of the area. To 


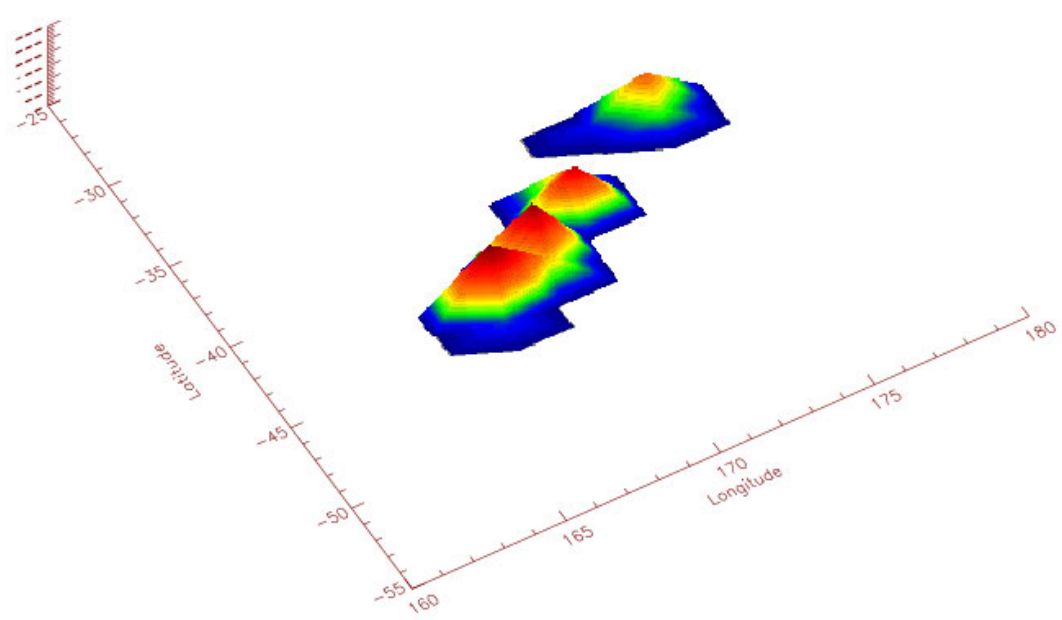

(a) General circulation model, resolution: 140 km

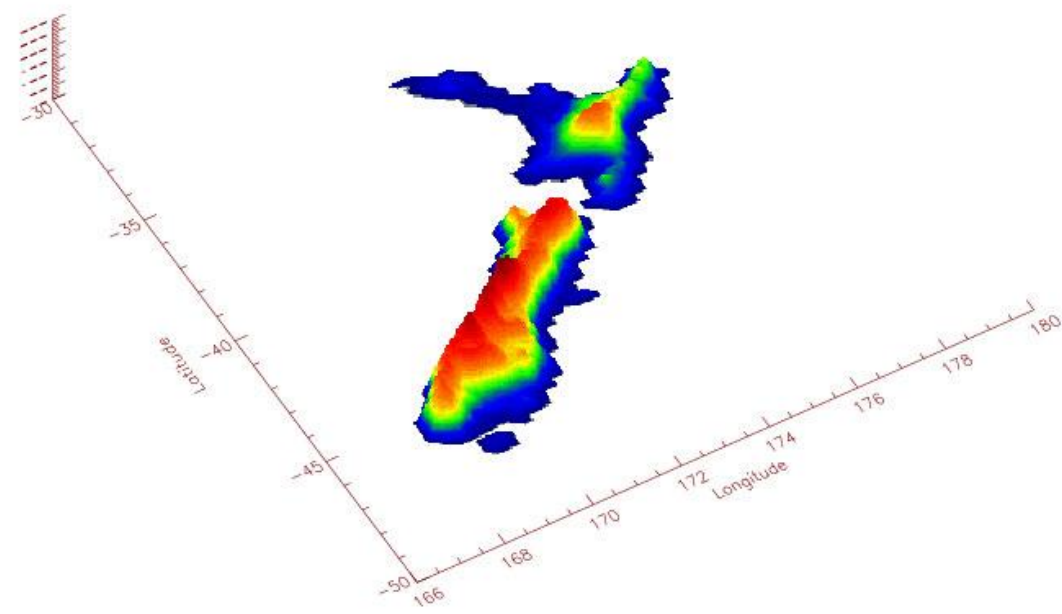

(b) Regional climate model, resolution: $\sim 30 \mathrm{~km}$

Figure 2.4 Orography of New Zealand, as represented by a general circulation model (upper image) and the HadRM3P regional climate model (lower image). Images produced by Dr Sam Dean of NIWA in Wellington, New Zealand. 


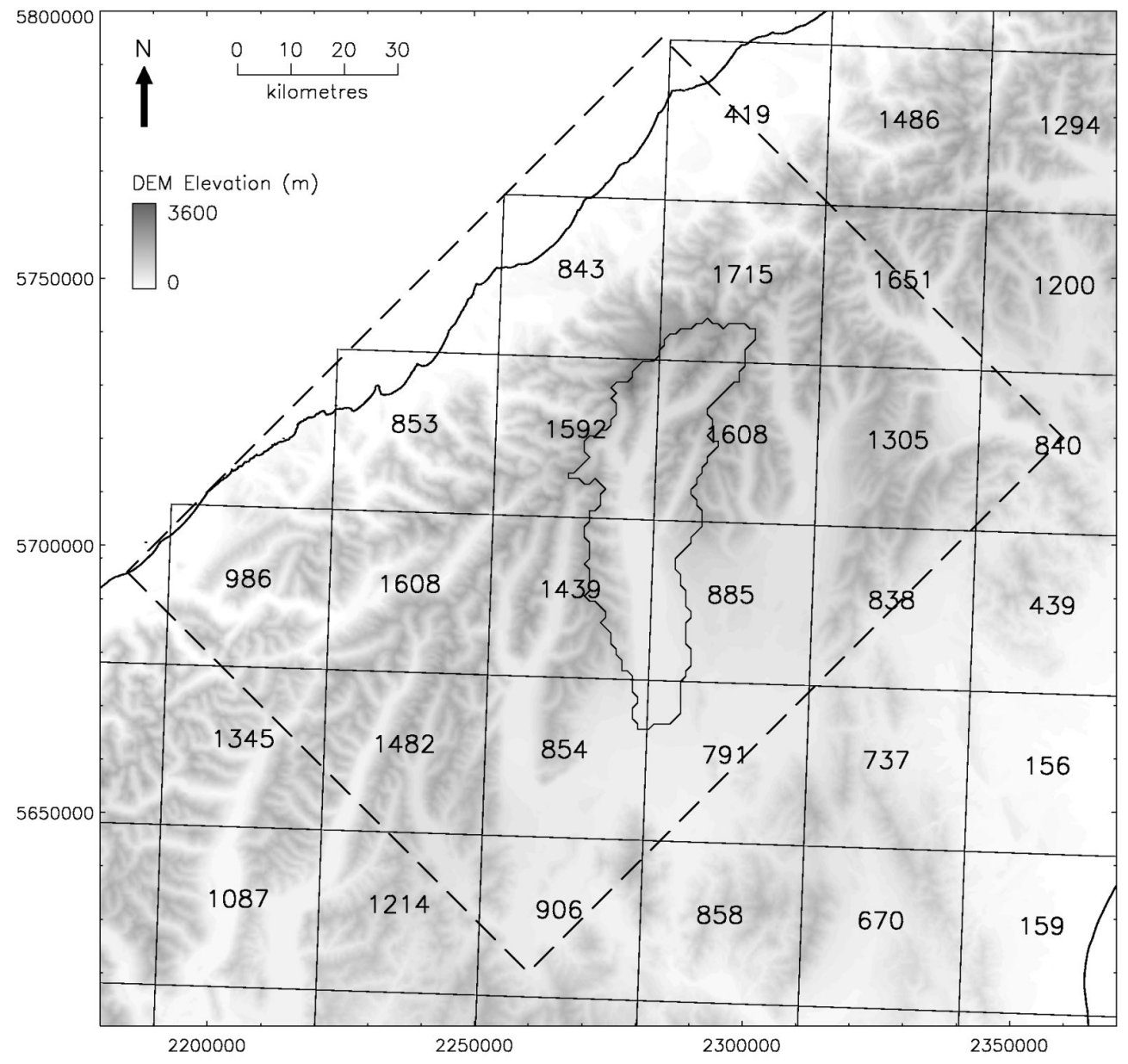

Figure 2.5 Topographic elevations of HadRM3P grid cells ( $m$ a.s.I.) in the central Southern Alps. Squares outline the HadRM3P grid cells within the land mask of the model. The dashed line outlines the primary study region, within which Pukaki catchment is outlined. Shading indicates topographic elevations from a $500 \mathrm{~m}$ digital elevation model. 
produce the orography for the RCM, the topographic elevation of each RCM grid cell is estimated from a DEM of similarly high resolution. However, regions of steep and rugged topographic relief, such as the Southern Alps, cannot be accurately represented at the $30-\mathrm{km}$ resolution of the RCM. For example, at the boundary between the Tasman Sea and the West Coast of the South Island, the orography of the RCM rises sharply and unrealistically from sea level to almost $1000 \mathrm{~m}$ a.s.l.

Figure 2.6 represents a single grid cell of the HadRM3P model. The thermodynamic variables of atmospheric pressure, temperature and water content are calculated at a point in the centre of the cell: point ' $\mathrm{P}$ '. Zonal and meridional wind vectors $(u$ and $v$ ) are calculated at the cell vertices. The model has two precipitation schemes: large-scale and convective. The large-scale scheme resolves precipitation at the $30-\mathrm{km}$ scale of the model grid, and briefly described here is the implementation of this scheme during the RCM simulations used in this thesis (see Sections 5.4 and 5.5). The amount of liquid or ice precipitation within the whole of each grid cell - centred at point $\mathrm{P}$ in Figure 2.6 - is diagnosed from the cell's water content, temperature and saturation vapour pressure (Jones et al. 2004). The precipitation subsequently falls at a parameterised fall speed (United Kingdom Met Office 1998). While the simulated rainfall analysed in this thesis is the sum of both large-scale and convective rainfall, large-scale rainfall is dominant in the Southern Alps.

In order to provide a 'faithful' visual representation, the simulated precipitation is often presented as a map containing $30-\mathrm{km}$ squares, with each square cell containing uniform precipitation. However, due to the relatively coarse resolution of the model, this cannot be regarded as an accurate representation of precipitation in the real world.

\section{Previous regional climate models of New Zealand}

Renwick et al. (1998) embedded the Division of Atmospheric Research limitedarea model (DARLAM) RCM within the output of the 'Mark 2' Commonwealth Scientific and Industrial Research Organisation nine-level atmosphere (CSIRO9) GCM. In this study, an RCM of New Zealand at 50-km resolu- 


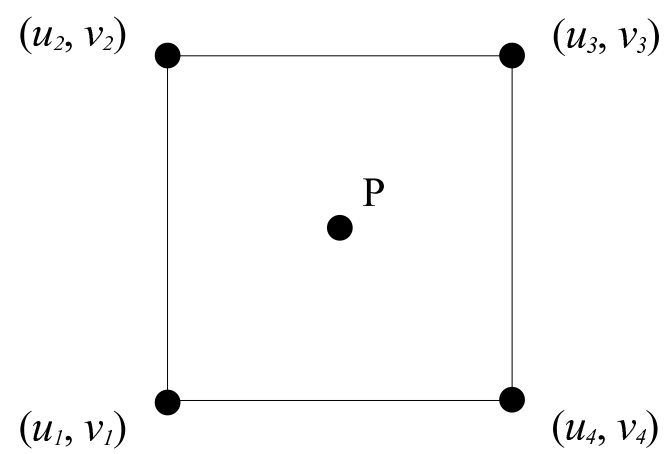

Figure 2.6 A grid cell in the HadRM3P regional climate model. ' $P$ ' is the centre of the cell, where atmospheric pressure, temperature and water content are calculated. Zonal and meridional wind vectors $(u$ and $v)$ are calculated at the cell vertices.

tion (RCM50) was driven by an RCM of the Australasian region at $125-\mathrm{km}$ resolution (RCM125), which in turn was nested within the GCM. The RCMs simulated 10-year periods within multidecadal GCM simulations under both present-day (control) and doubled $\mathrm{CO}_{2}$ conditions. The output of the control simulation was compared to observations of temperature and precipitation at 60 climate stations around the country. However, most of these stations were either coastal or located in relatively low terrain; little data from the Southern Alps was used. The increased horizontal resolution of RCM50 allowed orography to be modelled more accurately. This led to significantly more accurate spatial patterns of mean simulated surface temperature and precipitation. There was a general bias towards excess precipitation at $50-\mathrm{km}$ resolution, though RCM50 performed better than RCM125 at estimating daily variations in rainfall. RCM50 also provided better resolution of the west-east precipitation gradient in the South Island. The doubling of $\mathrm{CO}_{2}$ resulted in slight changes to the frequency of precipitation extremes in most locations.

Drost et al. (2007) simulated 20-year periods of New Zealand's climate by embedding a previous version of the Unified Model RCM, HadRM3H, within the global HadAM3H model, also based on the Met Office UM. The tropospheric chemistry of each model was fixed at pre-industrial levels. Each model operated using similar dynamics and physics settings, except for some 
parameters of the regional model which were altered to suit its higher spatial resolution of $40 \mathrm{~km}$.

HadRM3H adequately simulated major components of regional and seasonal climatic variation around the country. However, anomalous initial and lateral boundary conditions provided by the GCM, such as excessively strong mid-latitude westerlies, lead to certain inaccuracies in the RCM. In parts of the east coasts of both the North and South Islands, this contributed to underestimates of precipitation and excessive temperatures. RCM estimates of precipitation were generally fairly accurate over regions with low or smooth orography. However, precipitation simulated in the west and south of the South Island was significantly different from that recorded in the National Climate Database (CliDB). In mountainous areas, the simulated precipitation was too high and temperatures too low, particularly in the Southern Alps. Drost et al. (2007) believed that the simulation of precipitation might be improved by tuning the RCM's parameterisations of precipitation to the steep orography of New Zealand. The spatial resolution of the model was expected to increase in the future, and this was also likely to help make the model more accurate. Despite the mismatches between simulated climate and observations, the researchers concluded that the overall results from the RCM were promising and that future work would produce increasingly accurate and useful climatic predictions.

\section{Regional climate models in international studies}

During research into scenarios of regional climatic change over the United States, Giorgi et al. (1994) found that an RCM provided better estimates of spatial and seasonal variation of precipitation than the GCM in which the RCM was embedded. However, the representation of mountainous terrain within the RCM, at its horizontal resolution of $60 \mathrm{~km}$, lead to overestimates of orographic precipitation, particularly over the more mountainous western regions.

Jones et al. (1995) nested an RCM of Europe within a GCM. The RCM had a horizontal resolution of around $50 \mathrm{~km}$, while the resolution of the GCM in the vicinity of Great Britain was around $270 \mathrm{~km}$. Both models 
were versions of the UKMO Unified Model. The RCM simulated a greater amount of precipitation than the GCM, and in mountainous regions this increase correlated strongly with orographic height. The finer resolution and topography of the RCM greatly improved the spatial correlation of simulated and observed precipitation in Great Britain. Regional climate models have also been employed in many other international studies (e.g. Hudson and Jones 2002; da Rocha et al. 2009; Saeed et al. 2011).

\subsection{Statistical downscaling of simulated precipitation}

Statistical techniques can be employed to increase the spatial resolution of precipitation simulated by dynamic climate models (Mullan et al. 2001; Haylock et al. 2006; Christensen et al. 2007; Ministry for the Environment 2008). During empirical statistical downscaling, observational data are first analysed in order to determine statistical relationships between large-scale predictors and local climatic variables, such as precipitation. The predictors are usually developed from synoptic-scale atmospheric variables such as pressure, wind direction, humidity and temperature. Synoptic situations can be classified using indices such as those developed by Trenberth (1976) or Kidson (2000) for New Zealand. Empirical orthogonal functions can be used to isolate and quantify the key factors which influence the distribution of precipitation in a given area.

Statistical methods are usually less computationally intensive than dynamic climate modelling (Wilby et al. 2004). GCM projections of future global climate have been downscaled for New Zealand using a bivariate linear regression model (Ministry for the Environment 2008). This statistical model is based on relationships between the Trenberth (1976) indices and interpolated grids of daily climate observations in New Zealand. However, statistical downscaling can suffer from insufficient data in isolated regions, and the daily grids can significantly underestimate precipitation in the Southern Alps (Tait et al. 2006). 
Kidson and Thompson (1998) compared statistical regression and regional modelling techniques for downscaling GCM output over New Zealand. The RCM used in this study was the Regional Atmospheric Modeling System (RAMS) developed at Colorado State University (Pielke et al. 1992). While both methods had comparable skill in estimating regional anomalies in rainfall and temperature, statistical methods required considerably less computational effort and would therefore be the preferred method in many instances. Peak precipitation rates in the RCM were limited by the $50-\mathrm{km}$ resolution of the model grid and orography. However, Kidson and Thompson (1998) found that convective model-based interpolation better simulated daily precipitation over parts of New Zealand, including the area west of the Southern Alps. The RCM was also inclined to provide estimates superior to those of statistical methods if climatic variations lay significantly beyond the 'normal' range of values from which the regression equations had been developed. Since future climate may be perturbed by increased greenhouse gases and other forcings, these findings suggest that dynamic modelling may be a preferable means of downscaling climatic projections for New Zealand.

\subsection{Methods of estimating historical precipitation}

The spatial distribution of historical precipitation over a particular area can be estimated via a number of different empirical techniques, some of which are described in this section. Such methods may be based on direct observations of precipitation by rain gauges, weather radar or satellites. Alternatively, the amount of rainfall within a catchment may be inferred from observations of river flows.

\subsubsection{Spatial interpolation of observations}

Observations from point-based rain gauges can be interpolated via a number of different techniques, in order to produce a surface of areal-average precipitation. Theissen polygons are a relatively simple method of interpola- 
tion, but one which results in sharply stepped plateaux of rainfall. Another approach is for a meteorologist to draw, by hand, isoyets of equal rainfall, taking into account the available observations, as well as his or her expert knowledge of the weather patterns of the region. This technique is often more accurate than simpler methods but is also more time-consuming. The New Zealand Meteorological Service (1985) used this method to produce a map of mean annual rainfall over the whole of New Zealand for the 30-year period from 1951 to 1980 . The interpolation was necessarily more subjective in regions where observational data were sparse, such as the Southern Alps (Tait et al. 2006).

Alternatively, observations from rain gauges can be interpolated via more mathematical techniques such as kriging and splines. While such methods still encounter problems resulting from a shortage of observations in remote regions, the subjectivity associated with hand-drawn contours can be removed. A spline comprises piecewise polynomial functions which connect a number of data points. The polynomial pieces have continuous derivatives at the data points, making the composite spline function smooth. The bending energy of the composite curve is minimised; the curvature of a spline is thus analogous to that of a rubber strip forced through certain breakpoints. As a function of a single independent variable, a spline forms a two-dimensional curve of the dependent variable; functions of two or more independent variables can produce a surface (de Boor 1978; Wahba 1990).

A thin-plate smoothing spline is fitted to a set of data points by minimising both the roughness and the residuals of the fitted function. The balance between smoothness and fidelity is controlled by a 'smoothing parameter' $(\rho)$ : a larger value of $\rho$ results in more smoothing and a looser fit to the supplied data points. A common way to determine the optimum value of $\rho$ is to minimise a measure of the predictive error of the fitted spline known as the generalised cross validation (GCV) (Craven and Wahba 1979). A useful diagnostic of a thin-plate smoothing spline model is the 'signal', which is the effective number of degrees of freedom of the fitted spline (Hutchinson and Gessler 1994). Minimising the GCV may result in very small values for both $\rho$ and the residuals, accompanied by a signal equal to the number of 
supplied data points. This indicates that the spline is effectively an exact interpolant and normally means that the value of $\rho$ has not been genuinely optimised. A signal equal to more than half the number of data points can indicate that the thin-plate smoothing spline has been supplied with insufficient data to adequately represent the true surface (Hutchinson and Gessler 1994; Hutchinson 2000).

The frequency distribution of short-term precipitation is typically positively skewed, with fewer instances of high amounts of precipitation. A square-root transformation is often employed to decrease the skewness of daily precipitation, bringing its distribution more into line with the upper tail of a normal distribution (Hutchinson 1998a,b; Tait et al. 2006; Hutchinson et al. 2009). This can improve the accuracy of a thin-plate smoothing spline model. Using this transformation, the square roots of the dependent variable - that is, the precipitation - are interpolated; the fitted values are then squared to produce the final surface. The accuracy of the surface can be estimated by comparison to withheld data points. When interpolating observations of daily precipitation using a thin-plate smoothing spline, a square-root transformation has been shown to significantly improve estimates of withheld data points (Hutchinson 1998a; Tait et al. 2006).

In addition to the available observations, other predictors of the spatial distribution of precipitation can be mathematically incorporated into a spline interpolation (Hutchinson 1995). Such predictors may include grids of topographic elevation and aspect. These predictors may be used as independent variables or linear covariables within the interpolation. The inclusion of additional predictors can significantly improve the accuracy of the interpolated surfaces of precipitation (Hutchinson 1998b).

Daily and annual climatic surfaces for New Zealand from 1960 to 2010 have been produced by interpolating observations at stations using a trivariate thin-plate smoothing spline (Tait et al. 2006) (Figure 2.7). The precipitation surfaces formed by this interpolation have a relatively high spatial resolution of 0.05 degrees of latitude and longitude, which equates to around $4.2 \mathrm{~km}$ by $5.5 \mathrm{~km}$, respectively. The trivariate spline employs the 1951-1980 mean annual rainfall surface — produced by the New Zealand Meteorologi- 


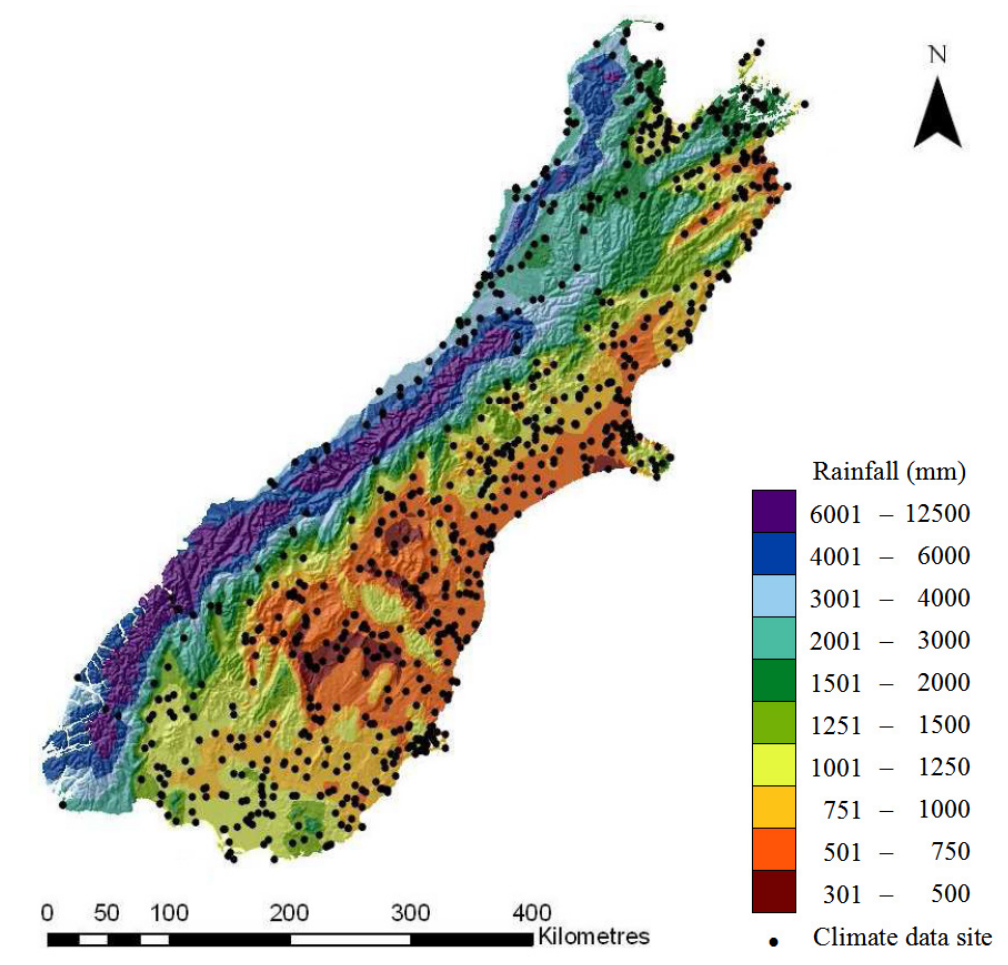

Figure 2.7 Median annual rainfall in the South Island of New Zealand from 1971 to 2000. Image reproduced from Tait and Zheng (2007).

cal Service (1985) — as a third independent variable, in addition to latitude and longitude. The assumption of this technique is that over the period for which the surface is being constructed, the precipitation experienced by a particular area is a function of both its horizontal location and the mean annual precipitation previously experienced at that location, as specified by the 1951-1980 rainfall surface. The inclusion of the mean annual rainfall surface helps guide the spline toward 'realistic' values in areas in which observational data is sparse.

A shortage of observations in mountainous areas can lead to significant uncertainty during the interpolation. When validated against observations from rain gauges during a 36-day period, the interpolated surface underestimated rainfall by up to $46 \%$ in some highly elevated regions of the Southern Alps (Tait et al. 2006). The locations of precipitation maxima in these climatic surfaces of the Southern Alps are known to have a bias toward the 
crest of the Main Divide. Additionally, since a single map of mean annual precipitation is used in the interpolations, and westerlies predominate in New Zealand, interpolated precipitation during non-westerly days is likely to be biased toward a westerly climatology. Tait et al. (2006) suggested that the accuracy of the interpolated daily precipitation surfaces for New Zealand could be improved by incorporating, as a third independent variable, different mean precipitation surfaces, each tailored to a typical synoptic situation for the country. Tait and Turner (2005) improved estimates of rainfall in remote New Zealand catchments by integrating mesoscale weather simulations into a trivariate spline interpolation.

\subsubsection{Weather radar and satellite observations}

Reflectivity from weather radar can be used to estimate precipitation, but few weather radar sites operate in the South Island and radar is obstructed by mountains (New Zealand Meteorological Service 2010). This precludes the use of radar for the accurate estimation of precipitation in the Southern Alps. Microwave sensors in polar-orbiting satellites can directly estimate precipitation over very wide areas, but these satellites take snapshots over any given surface area only two or three times a day. Such low temporal sampling limits the amount of data available for accurate estimates of precipitation in any particular region (Tait et al. 2006).

\subsubsection{Models of orographic precipitation}

Models can be developed specifically for the estimation of orographic precipitation. Griffiths and McSaveney (1983) formulated equations which describe the logistic growth of precipitation across two-dimensional profiles of topography in mountainous regions of New Zealand. In their model, the precipitation estimated at a particular location within a transect is a function of both local elevation and the distance to the crest of the main topographic ridge. The model can be calibrated using observations from rain gauges, in order to improve the accuracy of isohyets of rainfall in remote mountainous catchments (Griffiths and McSaveney 1983). 
Both short-term and long-term orographic precipitation have been estimated in parts of New Zealand using a diagnostic model developed by Sinclair (1994) and Thompson et al. (1997). This model is based on the wind velocity upstream of mountains, $V$, and the topographic gradient, $\nabla Z$, and is thus known as VDEL. VDEL can be initialised with data from global reanalyses or local atmospheric soundings. The model was validated against precipitation estimated from catchment runoff in a mountainous region of the southern North Island, with errors generally lying between 5 and 10 per cent (Thompson et al. 1997).

\subsubsection{Water balance within hydrological catchments}

Precipitation can be estimated by quantifying the major downstream components of the overall water balance in a catchment: evapotranspiration and runoff. Rates of evapotranspiration can be estimated from the climate, vegetation and albedo of the catchment (Zhang et al. 2004), and runoff can be gauged from observations of river flows. Variations in groundwater are often treated as negligible over periods of a decade or more (Thompson et al. 1997; Tait et al. 2006). In elevated catchments of the central Southern Alps, such as Tekapo and Pukaki, changes in the volume of water stored in glaciers and snow also need to be taken into account (McKerchar et al. 1998). Tait et al. (2006) validated surfaces of interpolated daily precipitation in New Zealand against river flows. Kerr (2009) also used a water balance approach to validate surfaces of mean precipitation in the Pukaki catchment from 1971 to 2000 .

\subsection{Summary}

- The Southern Alps are highly exposed to moist air carried across the Tasman Sea by the mid-latitude westerlies, and orographic forcing leads to extremely high levels of precipitation.

- A scarcity of observations at high elevations contributes to considerable uncertainty about the magnitudes and processes of precipitation in the 
more remote regions of these mountains.

- The distribution of precipitation may be estimated via a number of different empirical methods, including interpolative and statistical techniques, though these approaches may be hindered if data are sparse.

- Dynamic atmospheric models, such as RCMs, can perform well in areas of low topographic relief, but precipitation is difficult to simulate accurately in mountainous regions of the South Island.

- While both interpolative and dynamic downscaling techniques have drawbacks when applied to remote mountainous regions, such modelling, combined with the available observational data, does offer a way to gain a better understanding of the distribution and influences of orographic precipitation. 


\section{Chapter 3}

\section{Observational data}

To fulfil the objectives of this thesis - listed earlier in Chapter 1 - it is necessary to describe the spatial distribution of historical rainfall in the Southern Alps. With this aim, observations were compiled from several hundred rain gauges across a broad region of the South Island, as detailed in Section 3.1. These observations were used to construct profiles and surfaces of rainfall, and to validate precipitation simulated by the regional climate model. To help identify primary influences upon the spatial distribution of historical precipitation, the rainfall profiles were compared to reanalyses of atmospheric properties, which are described in Section 3.2. An independently developed surface of mean annual precipitation in the Pukaki catchment (Section 3.3) was used to further validate the simulated precipitation.

\subsection{South Island rain gauges}

Observations from rain gauges in the South Island were retrieved from the National Climate Database (CliDB) (NIWA 2010a). CliDB is administered by NIWA and includes observations of daily rainfall from over 3500 sites in or near New Zealand, the earliest of which date back to 1852. Most of these sites have since closed, but more than 700 CliDB stations recorded observations of rainfall during 2010. Rainfall is not recorded in many mountainous areas and observations at high elevations in the Southern Alps are particularly sparse.

During the past few decades, rain gauges have been have been installed 
at a number of sites in the Southern Alps by local governmental organisations - such as the West Coast and Canterbury regional councils - and hydroelectric companies, such as Meridian Energy. Both manual and automatic gauges have been installed, and data from many of these sites are not currently present in CliDB. Dr Martyn Clark, formerly of NIWA, extracted these additional data from the Water Resources Archive (WRA) (Walter 2000; NIWA 2007) using the Tideda software package (NIWA 2010b). The WRA is also managed by NIWA and includes rainfall data from the National Hydrometric Database and regional archives.

\subsubsection{Domain of rain gauges}

The domain of rain gauges used in this thesis extends over much of the South Island (Figure 3.1), and is based on the grid used by Henderson and Thompson (1999). The domain's baseline is aligned with — and approximately $85 \mathrm{~km}$ southeast of - the New Zealand Alpine Fault. The baseline originates in Cape Providence at the southwestern tip of Fiordland, and extends to its northeastern terminus near the town of Oxford in central Canterbury. The line of the Main Divide has been significantly deformed by tectonic activity, and ranges from $40 \mathrm{~km}$ northwest of the baseline in the Milford region, to $70 \mathrm{~km}$ northwest of the baseline near Franz Josef. The domain itself measures $400 \mathrm{~km}$ from southwest to northeast, beginning $150 \mathrm{~km}$ northeast of Cape Providence. From the baseline, the domain extends northwest over the Southern Alps to the Tasman Sea. The domain shown in Figure 3.1 extends $20 \mathrm{~km}$ southeast of the baseline, so as to encompass the entire domain of the ARC energy-balance glacial model.

The domain was further extended to $120 \mathrm{~km}$ southeast of the baseline (Figure 3.2) to encompass 572 rain gauges and a greater number of RCM grid points (Figure 4.2). The inclusion of the additional RCM grid points aided the downscaling of precipitation simulated in the central Southern Alps, as described in Section 4.2.

The domain was originally divided into four transects of the Southern Alps, each 100 km wide: Hokitika, Franz Josef, Haast and Milford. This division facilitates the analysis of spatial variations in precipitation along the 


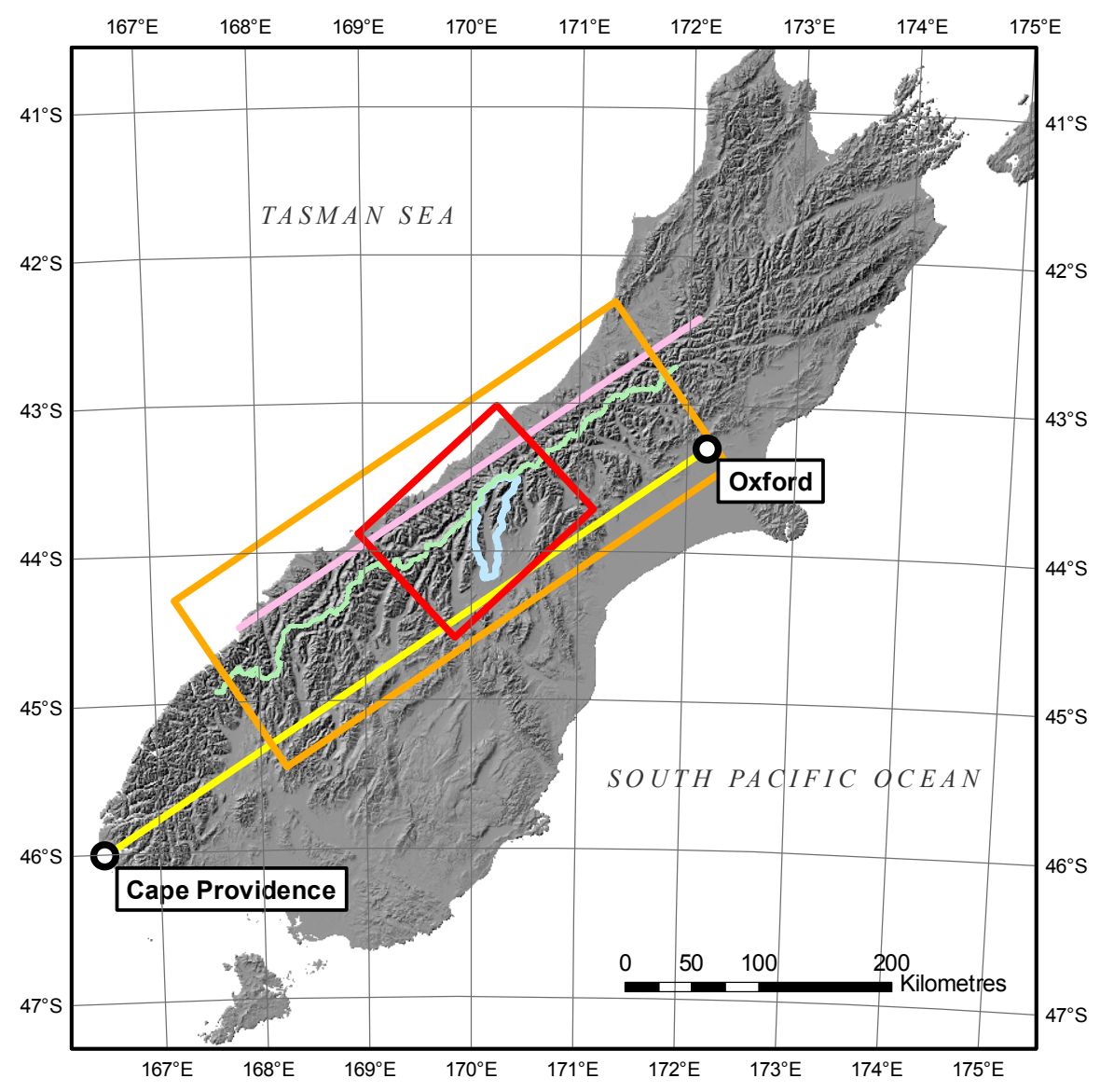

Figure 3.1 Topography of the South Island. The New Zealand Alpine Fault is approximated in the Southern Alps region by the pink line. The study baseline (yellow line) extends from Cape Providence northwest to near Oxford, in a line parallel to the Alpine Fault. The orange line outlines the domain of rain gauges from $20 \mathrm{~km}$ southeast of the baseline northwest to the Tasman Sea. The Main Divide of the Southern Alps within this domain is shown by the light green line. The red line outlines the primary study region. The light blue line outlines the Pukaki catchment. 


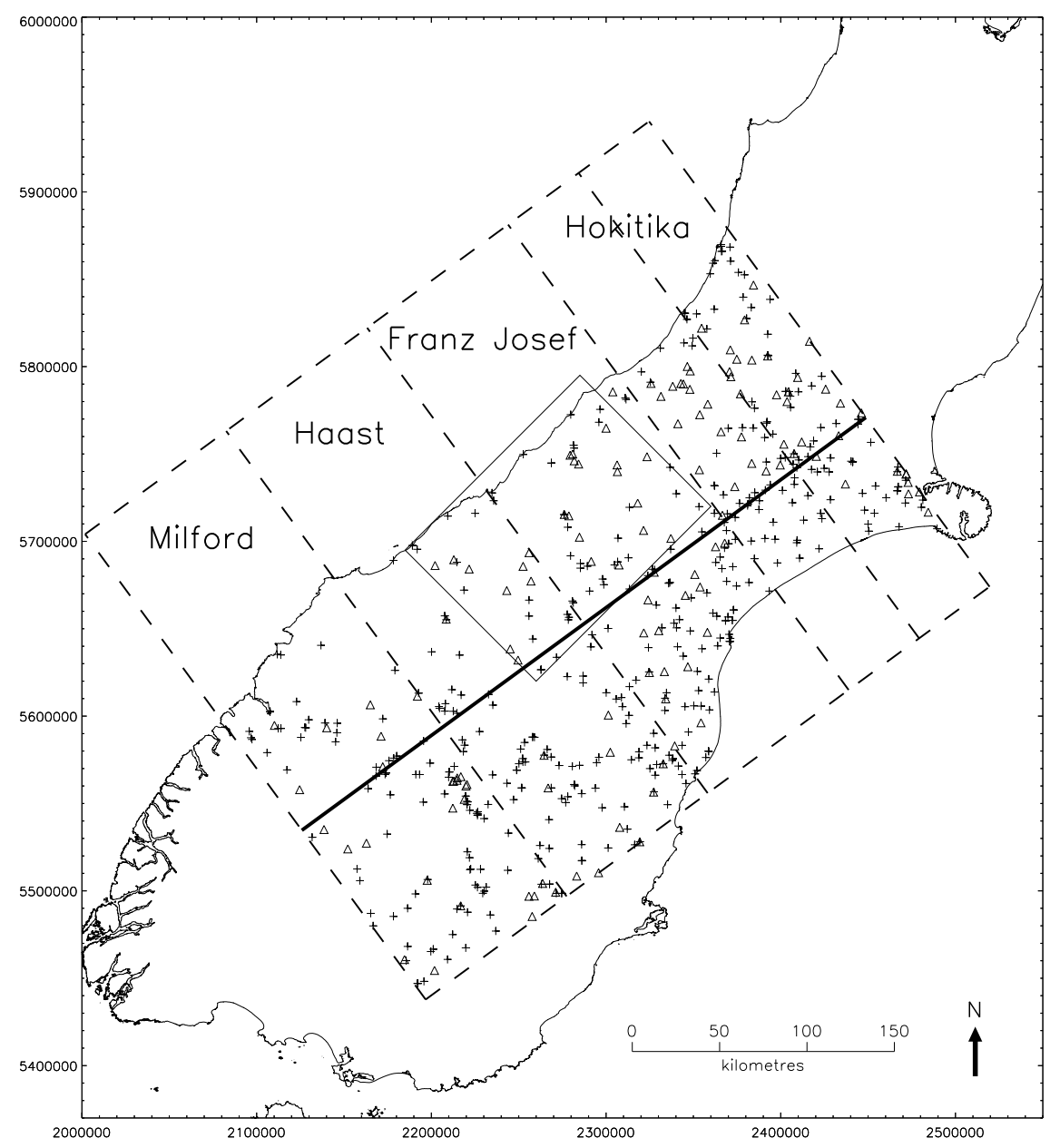

Figure 3.2 Transects and rain gauges in the South Island from 1971 to 2000 . '+' symbols denote CliDB gauges, ' $\triangle$ ' symbols denote WRA gauges. The primary study region is within the rectangle outlined by a solid line in the centre of the map. The transects are delineated by dashed lines. The baseline is represented by the thick solid black line running from southwest to northeast. The domain is based on that used in Henderson and Thompson (1999). 


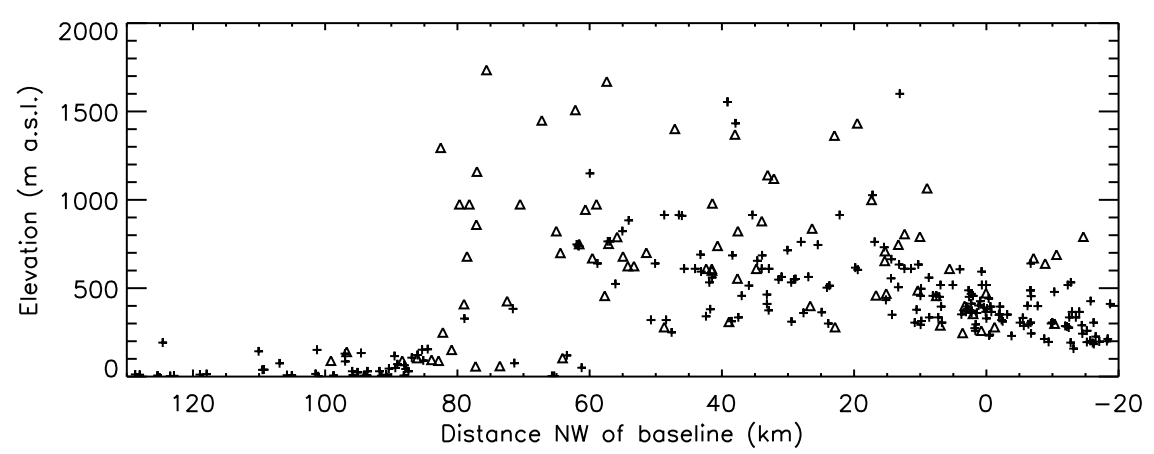

Figure 3.3 Elevation of rain gauges ( $m$ a.s.l.) versus distance northwest of baseline $(\mathrm{km})$. ' + ' symbols denote CliDB gauges, ' $\triangle$ ' symbols denote WRA gauges.

northeast-to-southwest axis of the mountain range. The original Hokitika transect contained a large number of gauges (177), relative to the number of gauges in each of the other transects (Franz Josef: 137; Haast: 131; Milford: 127). Therefore in order to further resolve spatial variations in precipitation along the main axis of the Southern Alps, the Hokitika transect was divided into a northeast transect and a southwest transect, each of which was $50 \mathrm{~km}$ wide. Details of rain gauges in each of these transects of the Southern Alps, including the total precipitation recorded at each gauge from 1971 to 2000, are listed in Appendix A.

Figure 3.3 shows the elevation of rain gauges across the profile of the Southern Alps. Moving from northwest to southeast, the elevation of the gauges increases suddenly a few kilometres southeast of the New Zealand Alpine Fault, which is around $85 \mathrm{~km}$ northwest of the baseline. The WRA gauges are generally more elevated than those in CliDB. Within the extended domain, $29 \%$ of the WRA gauges, and only $4 \%$ of the CliDB gauges, are at elevations over $750 \mathrm{~m}$ a.s.l. (Table 3.1).

Undercatch of precipitation by rain gauges at high elevations in the Southern Alps has been estimated to be over 20\% (Kerr 2009). However, given the difficulty of accounting for such errors in a large data set, no error corrections were applied to observations from rain gauges in this thesis. 
Table 3.1 Number of rain gauges in each transect of the Southern Alps from 1971 to 2000 . '> $750 \mathrm{~m}$ a.s.l.' refers to gauges located more than $750 \mathrm{~m}$ a.s.l. The domain of the rain gauges extends $120 \mathrm{~km}$ southeast of the baseline.

\begin{tabular}{lrrrrrrrrr}
\hline \multirow{2}{*}{ Transect } & \multicolumn{3}{c}{$>750$ m a.s.l. } & & & \multicolumn{3}{c}{ All Elevations } \\
\cline { 2 - 3 } \cline { 8 - 9 } & CliDB & WRA & Total & & CliDB & WRA & Total \\
\hline Northeast Hokitika & 4 & 6 & 10 & & 81 & 31 & 112 \\
Southwest Hokitika & 1 & 10 & 11 & & 46 & 19 & 65 \\
Franz Josef & 5 & 12 & 17 & & 104 & 33 & 137 \\
Haast & 1 & 4 & 5 & & 111 & 20 & 131 \\
Milford & 7 & 6 & 13 & & 99 & 28 & 127 \\
\hline All & 18 & 38 & 56 & & 441 & 131 & 572 \\
\hline
\end{tabular}

\subsubsection{Period of observation}

The standard period of climatological normals is 30 years, usually beginning in the first year of a calendar decade (World Meteorological Organization 1983). Observations from rain gauges in the Southern Alps were compiled over the most recent 30-year period that conformed to this standard at the commencement of this thesis, that is, 1 January 1971 to 31 December 2000. The use of the 1971-2000 period also allowed the compiled observations to be directly compared to a 1970-2000 control run by the RCM, which is described in Section 4.2.

As stated in Chapter 1, one of the objectives of this research is to identify the strongest influences upon the spatial distribution of precipitation in the Southern Alps. To this end, observations from rain gauges were compared with atmospheric properties from NCEP/NCAR Reanalysis 1. The reanalyses and RCM data had both previously been aggregated into 24-hour periods from 00:00-00:00 Coordinated Universal Time (UTC), which is equivalent to the period from 12:00-12:00 New Zealand Standard Time (NZST).

Since the austral summer of $1974 / 75$, daily rainfall at CliDB gauges has usually been measured over 24-hour periods from 08:00-08:00 NZST during New Zealand Daylight Saving, and 09:00-09:00 NZST at other times of the 
year. This equates to observational periods of 20:00-20:00 UTC during the austral summer months, and 21:00-21:00 UTC during the austral winter months. The 24-hour periods covered by the daily reanalyses and RCM data were thus either 3 or 4 hours later than those of the daily CliDB observations (Table 3.2). This time lag could be resolved by the use of hourly observations of rainfall, but fewer CliDB sites provide hourly rainfall data. The temporal resolution of daily rainfall data poses no problem to the calculation of 30year normals. Daily rainfall was therefore retrieved from the CliDB database. CliDB gauges were compared to the NCEP/NCAR reanalyses, but were not used to validate short-term precipitation simulated by the RCM. Rainfall at some CliDB stations is occasionally observed over a period of several days rather than a single day. Such observations were not compared with daily reanalyses, but were included in the calculation of 30-year normals.

The WRA data were received in hourly format and then aggregated into UTC days, that is, 24-hour periods from 00:00-00:00 UTC. The 24-hour periods of observation at WRA gauges and CliDB gauges were therefore slightly inconsistent, with the CliDB observation days being either 3 or 4 hours earlier than those of the WRA gauges. However, compiling the WRA observations into UTC days allowed the WRA gauges to be directly compared to both the NCEP/NCAR reanalyses and the HadRM3P-simulated precipitation. The inconsistency between the daily observation periods of the CliDB and WRA gauges was therefore considered acceptable. For the 30-year normals, the difference between the observation periods of the CliDB and WRA gauges equates to only 3 or 4 hours in a period of 30 years; the influence of this difference was considered negligible.

It must be noted that in the raw WRA data, successive hourly amounts of precipitation occasionally repeat for several hours or even days, which suggests that a multi-hour reading may have been split into equal hourly amounts. In one noted instance, the amount of precipitation observed at a particular WRA gauge recurs hourly for a period of 25 consecutive days. Such repetition is not common in this data set, but it must be acknowledged. In future analysis, it may be possible to reaggregate these data into their original periods of observation. In this thesis, however, all WRA observations were 
Table 3.2 Time periods of rain gauges, NCEP/NCAR Reanalysis 1 and HadRM3Psimulated precipitation.

\begin{tabular}{ll}
\hline Name & Time Period (UTC) \\
\hline Rain gauges, CliDB & 21:00 - 21:00 (austral winter); \\
& 20:00 - 20:00 (austral summer) \\
Rain gauges, WRA & 00:00 - 00:00 \\
NCEP/NCAR Reanalysis 1 & $00: 00-00: 00$ \\
HadRM3P-simulated precipitation & 00:00 - 00:00 \\
\hline
\end{tabular}

simply aggregated into 24-hour UTC days.

The mean daily precipitation observed at each gauge from 1971 to 2000 was calculated by dividing the total recorded precipitation by the total number of daily observations. Of the 306 gauges located in the domain from $20 \mathrm{~km}$ southeast of the baseline northwest to the Tasman Sea, only 14 had recorded less than 1 year of data. Due to the relatively small number of short-term sites, a minimum observational period was not enforced. Thus all daily precipitation recorded within the domain from 1971 to 2000 was used in the analysis. Mean annual precipitation observed at each rain gauge was calculated by multiplying the mean daily precipitation by the number of days in a Julian year: 365.25. Mean annual precipitation at short-term sites was not normalised to observations from long-term stations.

\subsection{Atmospheric properties in global reanalyses}

Mean daily wind velocity, air temperature and specific humidity were extracted from Reanalysis 1 of the NCEP/NCAR global reanalyses (Kalnay et al. 1996). NCEP/NCAR have interpolated these reanalyses on to a global regular grid at a horizontal resolution of $2.5^{\circ}$ latitude and longitude. The locations of 6 reanalysis grid points in the region of the Southern Alps are shown in Figure 3.4. For simplicity, data from only one reanalysis grid point 


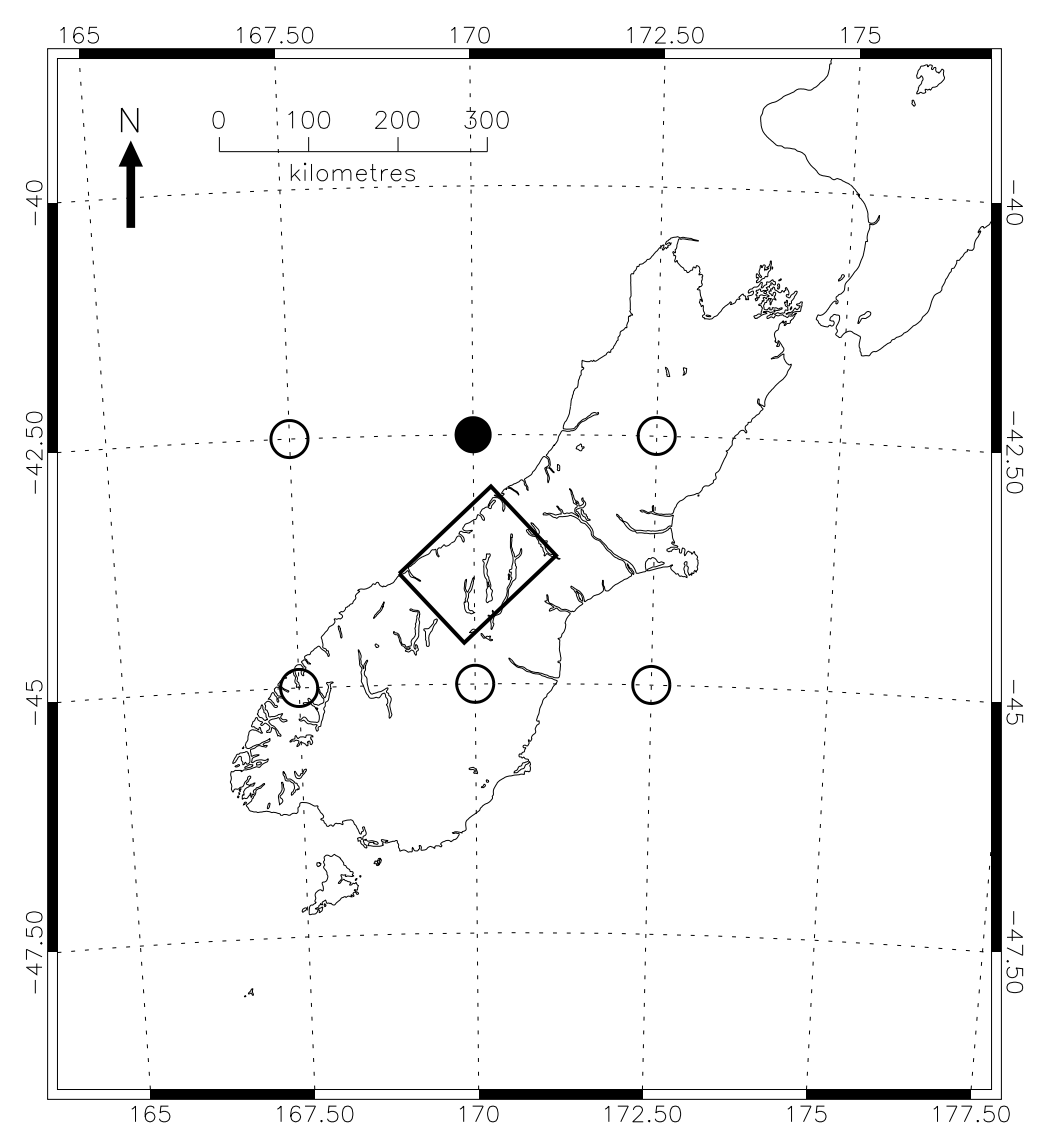

Figure 3.4 Grid points near the Southern Alps in NCEP/NCAR Reanalysis 1. denotes the grid point at $42.5^{\circ} \mathrm{S} 170^{\circ} \mathrm{E}$, which was used in this thesis; ' $\mathrm{O}$ ' symbols denote unused additional grid points.

was used in this thesis. Data were retrieved from the grid point immediately to the north of the primary study region, at $42.5^{\circ} \mathrm{S} 170^{\circ} \mathrm{E}$. Given the predominance of westerlies in the mid-latitudes, this is the grid point on the 'upwind' side of the Southern Alps that lies nearest to the central Southern Alps. Data was extracted from the single pressure level of $850 \mathrm{hPa}$. Reanalyses from 1 January 1971 to 31 December 2000 were used in this thesis.

Horizontal wind velocity in NCEP/NCAR Renalysis 1 is divided into zonal and meridional wind vectors. Figure 3.5 shows mean zonal wind velocity at the $850 \mathrm{hPa}$ pressure level on 5 November 1994 UTC, the first day of the 'Guy Fawkes Storm' in the Southern Alps. The mid-latitude westerlies are clearly visible, and particularly so in the Southern Hemisphere where the 


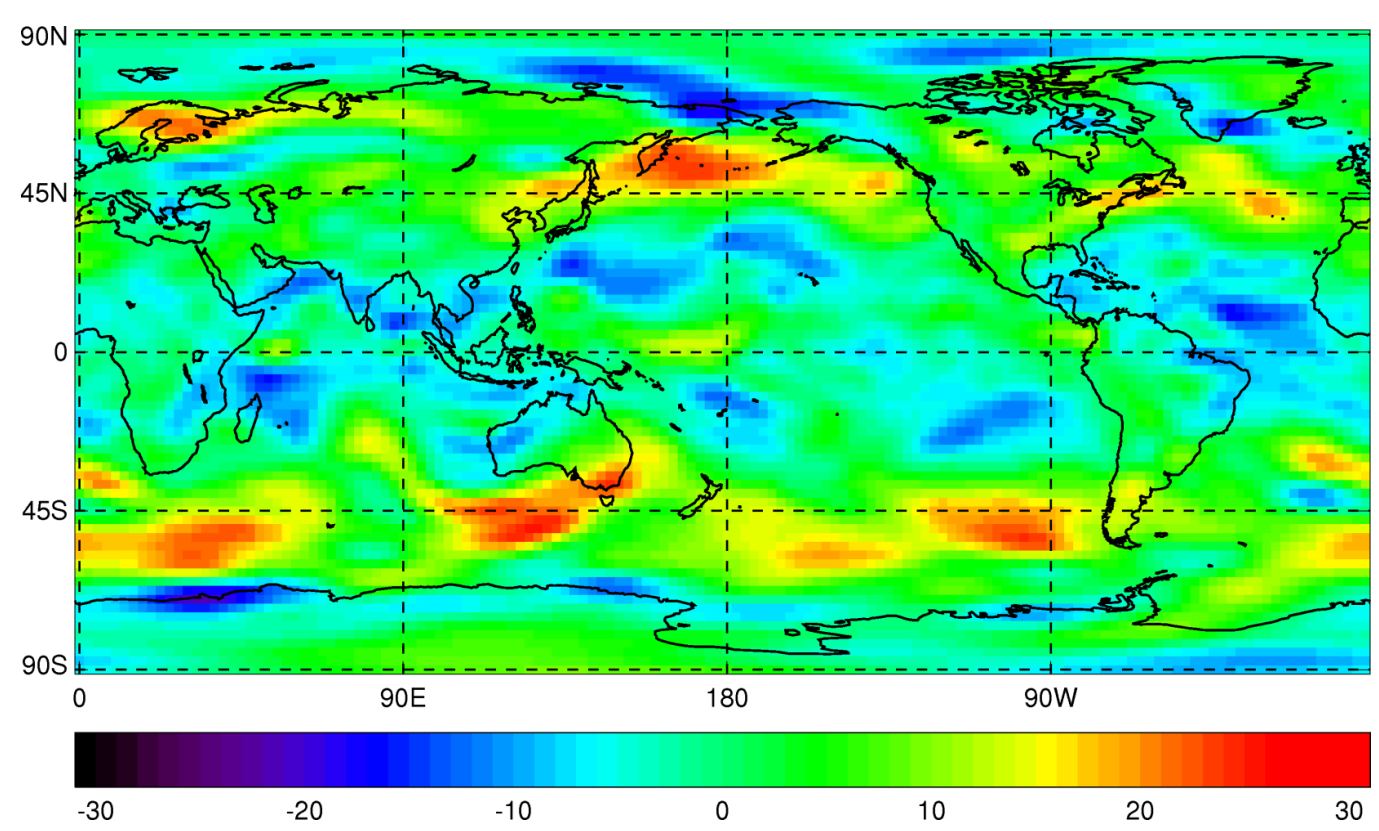

Figure 3.5 Mean daily zonal wind velocity $\left(\mathrm{m} \mathrm{s}^{-1}\right)$ at $850 \mathrm{hPa}$ on $5 \mathrm{Nov} 1994$ UTC, as represented in NCEP/NCAR Global Reanalysis 1 . Westerly flow is positive and is indicated by warm colours.

zonal flow of air experiences less obstruction from land masses.

\subsection{Mean annual precipitation in the Pukaki catchment}

The Pukaki catchment occupies around $10 \%$ of the land within the primary study region. Kerr (2009) produced surfaces of mean annual precipitation in the Pukaki catchment from 1971 to 2000. These surfaces are shown in Figure 3.6. Surf Obs.TK.M (Figure 3.6a) is based on the amount of precipitation

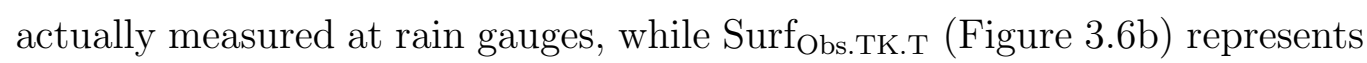
the estimated 'true' precipitation by also taking into account the estimated undercatch at rain gauges. The horizontal precipitation gradient of both surfaces is very steep in the northern part of the catchment near the Main Divide, where it reaches $1 \mathrm{~m} \mathrm{a}^{-1} \mathrm{~km}^{-1}$. Precipitation in Surf Obs.TK.т peaks at over $13 \mathrm{~m} \mathrm{a}^{-1}$ in this region. 


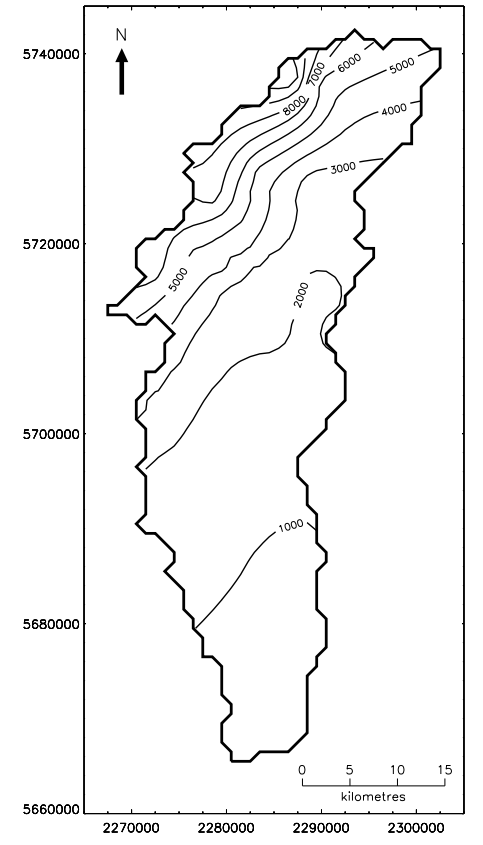

(a) Measured precip. (Surf Obs.TK.M)

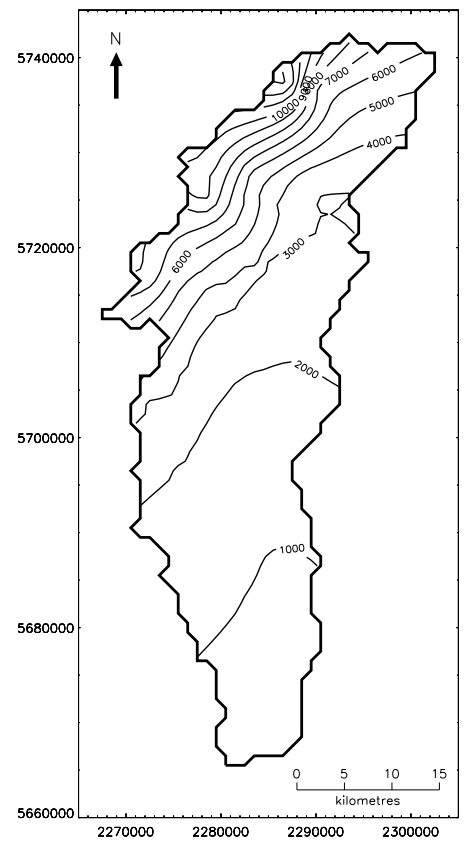

(b) 'True' precip. (Surf Obs.TK.T)

Figure 3.6 Isohyets $\left(\mathrm{mm} \mathrm{a}^{-1}\right)$ of estimated mean annual precipitation in the Pukaki catchment from 1971 to 2000 , as determined via ordinary kriging of observations from rain gauges (Kerr 2009). The left surface (Surf Obs.TK.M) is based on measured precipitation, while the right surface (Surf Obs.TK.T) also takes into account the estimated undercatch at rain gauges. 
As part of the research by Kerr (2009), new rain gauges were installed in highly elevated regions of the catchment. These additional rain gauges are not present among the CliDB and WRA gauges described in the previous section. The construction of these surfaces of precipitation in Pukaki was rigorous and independent of the present research. The surfaces produced by Kerr (2009) were therefore used to validate the precipitation simulated by the RCM in the Pukaki catchment. Surf $f_{\text {Obs.TK.m }}$ and Surf Obs.TK.T were received in ESRI ASCII grid format at a spatial resolution of $1 \mathrm{~km}$ (Kerr 2010).

\subsection{Summary}

The observational data used in this thesis comprise:

- precipitation recorded by 572 rain gauges in the South Island during the 30-year period from 1971 to 2000, compiled from the New Zealand National Climate Database and the Water Resources Archive managed by NIWA.

- wind velocity, air temperature and specific humidity at $850 \mathrm{hPa} 42.5^{\circ} \mathrm{S}$ $170^{\circ} \mathrm{E}$, north of the central Southern Alps, from 1971 to 2000, extracted from NCEP/NCAR Reanalysis 1;

- surfaces of mean annual precipitation in the Pukaki catchment from 1971 to 2000, developed by Kerr (2009).

Many of these data have not previously been included in such an analysis. 


\section{Chapter 4}

\section{Methodology}

As stated in Chapter 1, the focus of this thesis is the spatial distribution of precipitation in the central Southern Alps, and the manner in which it is influenced by topography and wind direction. A better understanding of the rainfall distribution in the central Southern Alps, and its primary determinants, has many potential applications. One such application is to help improve the spatial resolution of dynamically simulated precipitation in this region, which may in turn provide insight into glacial and hydrological processes. However, as mentioned in previous chapters, there is a shortage of observational data in elevated parts of the Southern Alps; this makes it difficult to produce an accurate surface of historical precipitation via a simple two-dimensional interpolation of the available point-source rain gauges. Adopted in this thesis is an alternative approach, which utilises the distinct cross-mountain profile of orographically enhanced precipitation, following and extending the work of Henderson and Thompson (1999). The construction of these profiles is described in Section 4.1.1. As noted in Chapter 1, one of the objectives of the present research is to incorporate the cross-mountain profile into the downscaling of precipitation simulated in the central Southern Alps by the HadRM3P regional climate model. This was achieved by first joining the rainfall profiles together to produce surfaces of observed precipitation in the Southern Alps (Section 4.1.2). The subsequent integration of the observed precipitation surfaces into the downscaling of simulated precipitation is described in Section 4.2. 


\subsection{Spatial interpolation of observations from rain gauges}

\subsubsection{Interpolated profiles of observed precipitation}

In order to create profiles of observed precipitation across the Southern Alps, it was necessary to first define the position of each rain gauge on a coordinate grid aligned with the main axis of the mountain range. As described in Section 3.1.1, the domain used in this analysis is based on that used by Henderson and Thompson (1999). This domain runs approximately parallel to the New Zealand Alpine Fault, and the axes of the grid are shown in Figure 4.1. The y-axis of the grid forms the domain's baseline, which extends from Cape Providence in Fiordland, northeastward through the town of Oxford in Canterbury. The x-axis represents distance across the Southern Alps, which equates to the distance northwest of, and perpendicular to, the baseline.

The mean annual precipitation observed at each rain gauge from 1971 to 2000 was calculated, as described in Section 3.1.2, and then plotted against its distance northwest of the baseline. Examples of these profile plots are presented in Figure 5.2 of the Results chapter. Precipitation recorded across the transects can vary significantly between individual stations in the most mountainous regions, around 40-90 km northwest of the baseline (Figure 5.2a). In these areas, airflow may be modified by local topographic variations to produce localised peaks and troughs of rainfall. A form of approximation is necessary to produce a line of 'best fit' to the profile, but interpolative methods may ignore important local variations entirely if the data are too 'noisy'. Neither a cubic spline nor a B-spline (de Boor 1978, chap. 13) of the individual gauges produced, upon visual inspection, a good fit to the general trend of the profile. To help guide the spline toward observations from longterm stations - which ought to have lower standard errors of mean annual precipitation than short-term stations - each individual gauge was assigned a weighting proportional to the number of observation days at that gauge. The weighted gauges were then interpolated using a least-squares B-spline 


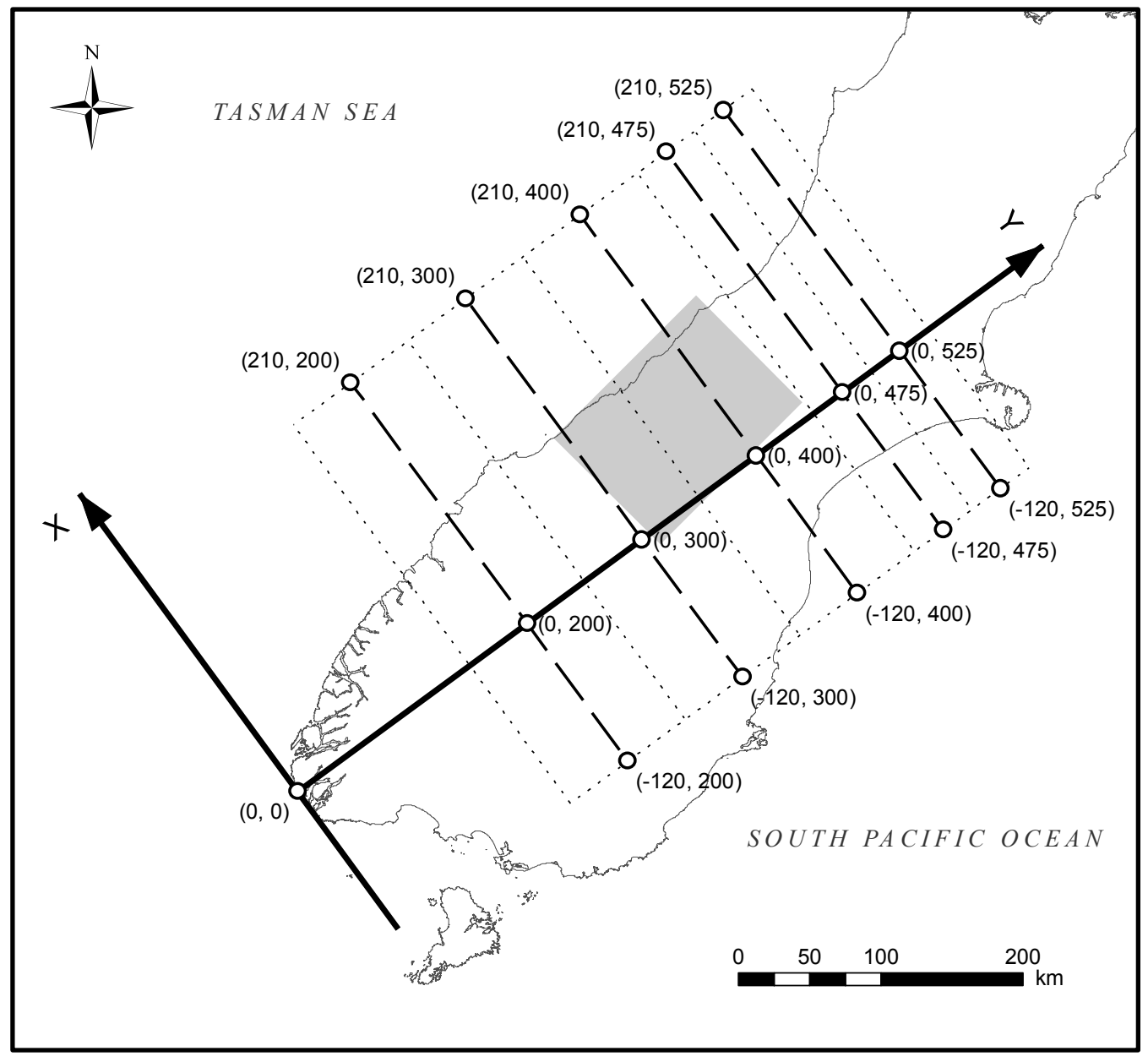

Figure 4.1 Coordinate grid aligned with the main axis of the Southern Alps. The thick solid lines, terminated by arrow-heads, represent the axes of the grid: $Y$ is the baseline; $X$ is the distance northwest of, and perpendicular to, the baseline. The dotted lines outline the domains of the five transects used in this analysis: (from northeast to southwest) northeast Hokitika, southwest Hokitika, Franz Josef, Haast and Milford. The dashed lines bisect the domain of each transect. 'o' symbols mark the grid origin, the end-points of each transect, and the intersections of each transect with the baseline. The coordinates of these points are indicated in $(x, y)$ format. The grey shaded area is the primary study region. 
(de Boor 1978, chap. 14). However, the use of weightings made no discernible improvement to the poor fit of the individual gauges.

The $\mathrm{x}$-axis of each profile was therefore separated into 5-km divisions. The mean annual precipitation within each division was calculated by taking a simple average of the mean annual precipitation observed at all the individual stations within each division. The averages within each division were then interpolated across the Southern Alps using a one-dimensional cubic spline (de Boor 1978, chap. 4) to create the line of best fit. No weightings were applied. If no gauges were present in a particular division, then that division was omitted from the interpolation. This combination of averaged $5-\mathrm{km}$ divisions and a cubic spline produced the precipitation profile that, upon visual inspection, best fitted the general trend of the observations from individual rain gauges. This method was therefore adopted for the construction of all precipitation profiles for the remainder of the analysis.

Profiles were constructed for the Southern Alps as a whole, and individually for the northeast Hokitika, southwest Hokitika, Franz Josef, Haast and Milford transects. To enable the profiles to be combined into a single surface, the lengths of the five profiles first needed to be made equal. This was achieved by extrapolating the profiles over the Tasman Sea and South Pacific Ocean. Extrapolated values were set to the mean annual precipitation in the 5 -km divisions at the tails of each profile. The extrapolated values exerted little influence on the splined surface, other than to provide reasonable boundary conditions with which to constrain the spline.

\subsubsection{Interpolated surfaces of observed precipitation}

The domains of each of the five transects (northeast Hokitika, southwest Hokitika, Franz Josef, Haast and Milford) are outlined by the dotted lines in Figure 4.1. These domains were bisected, as indicated by the dashed lines in Figure 4.1, and the five corresponding interpolated profiles of precipitation were georeferenced to these bisecting lines. The profiles were then merged into a single three-dimensional surface using a two-dimensional, tensor-product B-spline (de Boor 1978, chap. 17). The spatial resolution of this interpolated surface was $100 \mathrm{~m}$. 


\subsection{Downscaling of simulated precipitation}

The downscaling method could be applied to precipitation simulated during an historical control run, or to precipitation simulated under a future climatic scenario. The analysis in this thesis focuses on precipitation simulated by HadRM3P during the period from 1971 to 2000. The use of this historical period allowed the skill of the downscaling method to be subsequently assessed via comparisons with observations. Dr Sam Dean of NIWA performed the simulation, which was executed on the Cray T3E1200e supercomputer at NIWA in Wellington, New Zealand. HadRM3P and its topography during this simulation are described in more detail in Section 2.4.4. The unrotated $\mathrm{RCM}$ domain has latitudes of $31-52^{\circ} \mathrm{S}$, longitudes from $160^{\circ} \mathrm{E}$ to $168^{\circ} \mathrm{W}$, and a spatial resolution of approximately $30 \mathrm{~km}$. Lateral boundary conditions from 1970 to 2000 were provided at 6-hourly intervals from NCEP/NCAR Reanalysis 1 (Kalnay et al. 1996). Dr Dean aggregated the simulated precipitation into 24-hour periods from 00:00-00:00 UTC. These data were stored in netCDF format (Rew and Davis 1990).

A trivariate thin-plate smoothing spline was used to downscale the spatial resolution of the simulated precipitation from $30 \mathrm{~km}$ to $100 \mathrm{~m}$. The trivariate interpolation was performed using version 4.36 of the ANUSPLIN software package (Hutchinson 2011). The first two independent variables of the spline were two horizontal spatial coordinates: NZMG easting and northing. The third independent variable was mean daily precipitation observed in the Southern Alps from 1971 to 2000. The dependent variable of the spline was precipitation simulated by HadRM3P between 1971 and 2000 .

To perform the interpolation, the values of the three independent variables and the one dependent variable need to be known at each of the RCM grid points supplied to the spline. The values of the two spatial independent variables were determined by simply converting the unrotated longitudes and latitudes of the RCM grid points into NZMG eastings and northings. The third independent variable - observed mean daily precipitation from 1971 to 2000 - was determined from points on the surface described in Section 4.1.2. This required the cropping of the RCM domain to 57 grid points (' $\bullet$ 'sym- 
bols in Figure 4.2) within the domain of the mean daily precipitation surface (outlined by the dotted line in Figure 4.2). Fourteen of these RCM grid points lie over ocean, making it necessary to sample values from the extrapolated section of the observed precipitation surface at these locations. The inclusion of these ocean-based points helps to limit the dependent variable to reasonable values at the boundaries of the primary study region.

The interpolation itself involves two main steps. The first step is to calculate the coefficients of the polynomials that link the breakpoints of the spline. These coefficients were calculated by the ANUSPLIN SPLINA program, using the values of the independent and dependent variables at the grid points of the RCM. Once the coefficients of the splined surface are defined, the value of the dependent variable over the domain of the spline has been defined as a function of the three independent variables.

The second step of the interpolation is to create a surface of the dependent variable - the simulated precipitation — on a $100 \mathrm{~m}$ regular grid (outlined by the dashed line in Figure 4.2) using the ANUSPLIN LAPGRD program. To perform this step, each independent variable must first be defined at all points on this regular grid. Grids of the spatial independent variables of easting and northing are easily calculated by the software. The grid of the third independent variable - observed mean daily precipitation from 1971 to 2000 — was constructed as per the methodology described in Section 4.1. Once the grids of the three independent variables are defined, the LAPGRD program can calculate the values of the dependent variable at all points on the same grid. This results in a high-resolution surface of simulated precipitation in the central Southern Alps. The assumption of this technique is that the precipitation at any given point in the central Southern Alps is a function of both its horizontal spatial position and the mean daily precipitation previously experienced at that location. This issue is discussed in Chapter 6 .

\subsection{Software}

Most of the spatial and numerical analysis in this thesis was performed within IDL (Interactive Data Language) Version 7.0, a product developed by ITT 


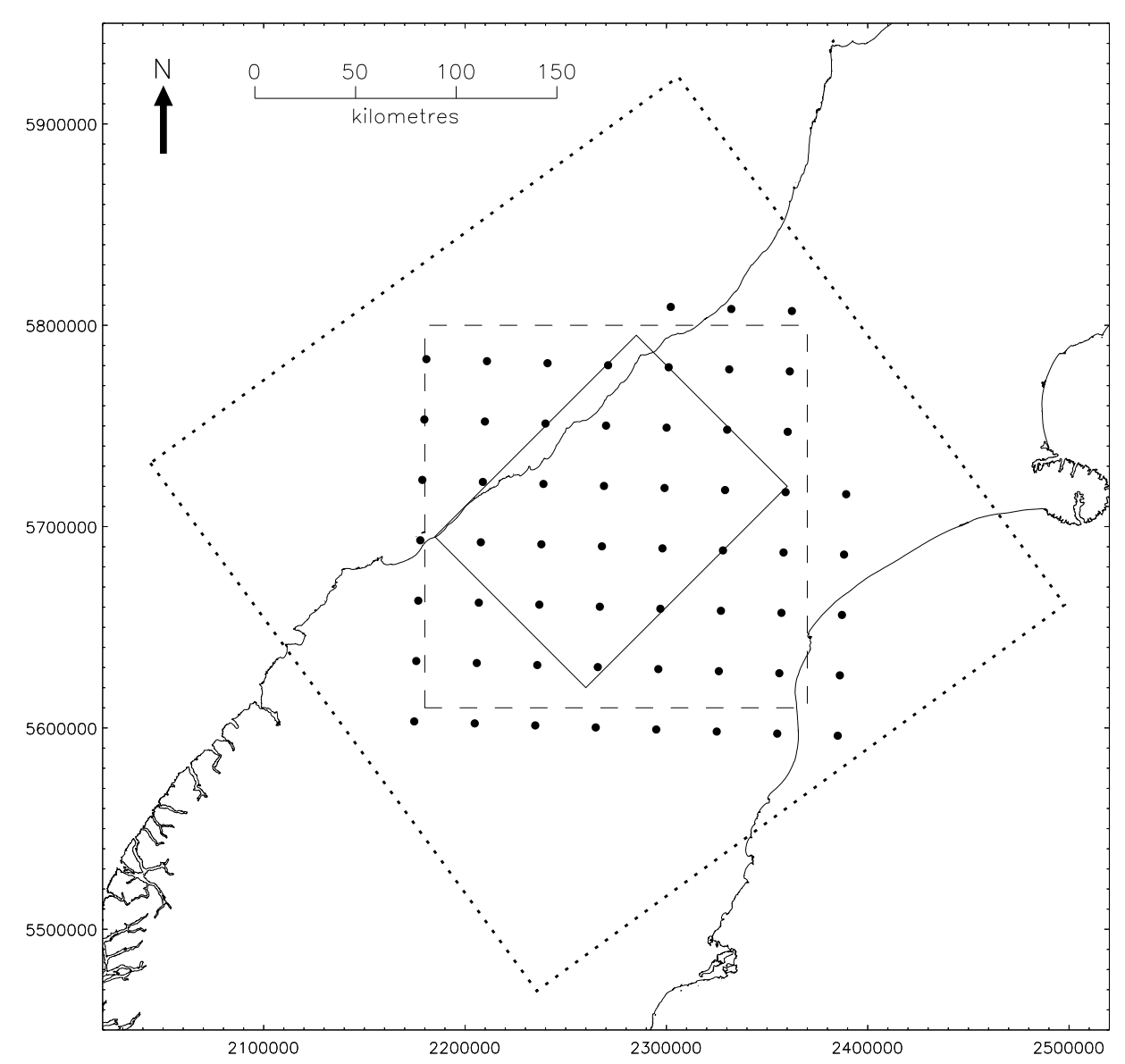

Figure 4.2 Domains and HadRM3P grid points used during the downscaling of simulated precipitation in the Southern Alps. The dotted line outlines the domain of the observed precipitation surface, which was produced by combining transects of observed precipitation from 1971 to 2000 . ' $\bullet$ ' symbols denote HadRM3P grid points used during the downscaling. The region of downscaled HadRM3P precipitation is outlined by the dashed line. The primary study region is outlined by the tilted rectangle in the centre of the map. 
Visual Information Solutions. The precipitation simulated by the HadRM3P regional climate model was interpolated and downscaled using version 4.36 of the ANUSPLIN software package (Hutchinson 2011). Some of the maps in this thesis were produced in ESRIC) ArcGIS Version 9.3.1.

\subsection{Summary}

Observations from rain gauges across transects of the Southern Alps were interpolated to produce profiles of precipitation, which were subsequently combined into surfaces of observed precipitation. In order to downscale precipitation simulated by the HadRM3P regional climate model, these surfaces of observed precipitation were employed as independent variables within a trivariate thin-plate smoothing spline. The next chapter describes the results of this analysis. 


\section{Chapter 5}

\section{Results}

A greater understanding of natural phenomena can be gained from both empirical analysis and dynamic modelling, but models cannot be developed without first observing physical interrelationships. This chapter initially focuses on the observed distribution of precipitation in the central Southern Alps, and its primary influences. Firstly, to assess the extent to which mean annual precipitation at any given location in the Southern Alps is directly correlated with the local topographic elevation, these two variables are very briefly compared. A two-dimensional approach is then adopted, in which profiles of observed precipitation are constructed, compared to atmospheric properties, and then combined to form surfaces of precipitation in the Southern Alps. In Sections 5.4 and 5.5, these surfaces are used as predictors of rainfall at fine spatial scales, via their employment as independent variables in the downscaling of precipitation simulated by the HadRM3P regional climate model. The downscaled surfaces are subsequently validated against observations, both during a 30-year period and on a single day.

\subsection{Direct influence of topographic elevation upon precipitation}

One of the initial objectives of this thesis is to identify the strongest influences upon the spatial distribution of precipitation in the Southern Alps. To 


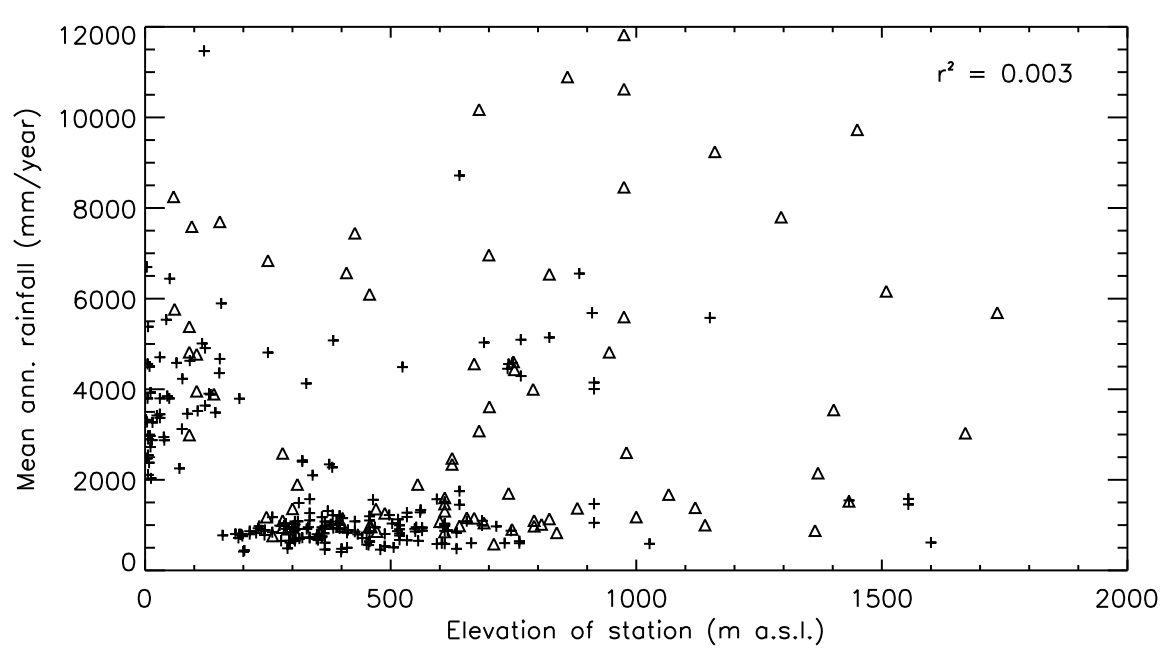

Figure 5.1 Mean annual precipitation $\left(\mathrm{mm} \mathrm{a}^{-1}\right)$ observed at Southern Alps stations from 1971 to 2000, versus elevation of stations ( $m$ a.s.l.). '+' symbols denote CliDB gauges, ' $\triangle$ ' symbols denote WRA gauges.

this aim, the mean annual precipitation at each rain gauge was compared to its elevation above mean sea level (Figure 5.1). The spatial domain of this comparison was limited to the more mountainous area that extends from $20 \mathrm{~km}$ southeast of the study baseline, northwest to the Tasman Sea (Figure 3.1). One can see from Figure 5.1 that the WRA gauges (' $\triangle$ ' symbols) have a wider range of both topographic elevation and recorded mean annual precipitation than the CliDB gauges ('+' symbols).

The direct correlation between local topographic elevation and precipitation observed by rain gauges is weak in the Southern Alps. The linear Pearson correlation coefficient $(r)$ of observed mean annual precipitation versus elevation is 0.059 and the coefficient of determination $\left(r^{2}\right)$ is only 0.003 . Variations in the topographic elevation of rain gauges thus explain very little of the variation in mean annual precipitation observed at those gauges. It is therefore impossible to simply use local topographic elevation as an accurate means of downscaling long-term precipitation in the Southern Alps, and an alternative method is necessary. 


\subsection{Profiles of precipitation}

This section describes two-dimensional profiles of mean annual precipitation observed in the Southern Alps during the 30-year period from 1971 to 2000. The profile of observed mean daily precipitation is subsequently compared to atmospheric properties and is classified by wind direction.

\subsubsection{Mean annual profiles}

\section{Southern Alps transect}

Figure 5.2a shows the mean annual precipitation observed at each gauge in the Southern Alps versus the distance of the gauge northwest of the study baseline. The curved line in Figure 5.2a is the line of 'best-fit', produced by the one-dimensional cubic spline, as described in Section 4.1.1. The Alpine Fault is located $85-87 \mathrm{~km}$ northwest of the baseline. As has been shown in previous studies, the distribution of precipitation exhibits a distinct profile across the Southern Alps. Around 2-4 m of precipitation is experienced by sites on the West Coast of the South Island each year. Moving southeastward, precipitation rises sharply, reaching $10-12 \mathrm{~m} \mathrm{a}^{-1}$ at some stations located a few kilometres southeast of the Alpine Fault. The wettest gauges in this region are generally sourced from the WRA, vividly illustrating the value of these data. The spline fitted to the observations peaks at $9.0 \mathrm{~m} \mathrm{a}^{-1}$. The location of this peak is $78.1 \mathrm{~km}$ northwest of the baseline and $7-9 \mathrm{~km}$ southeast of the Alpine Fault. Continuing southeastward, precipitation drops to less than $1 \mathrm{~m} \mathrm{a}^{-1}$ in the lee of the Southern Alps.

Separate profiles of mean annual precipitation were subsequently constructed across the northeast Hokitika, southwest Hokitika, Franz Josef, Haast and Milford transects. The locations of these transects within the South Island are shown in Figure 3.2. Details of individual gauges in each transect, including the amount of recorded mean annual precipitation, are listed in Appendix A. 


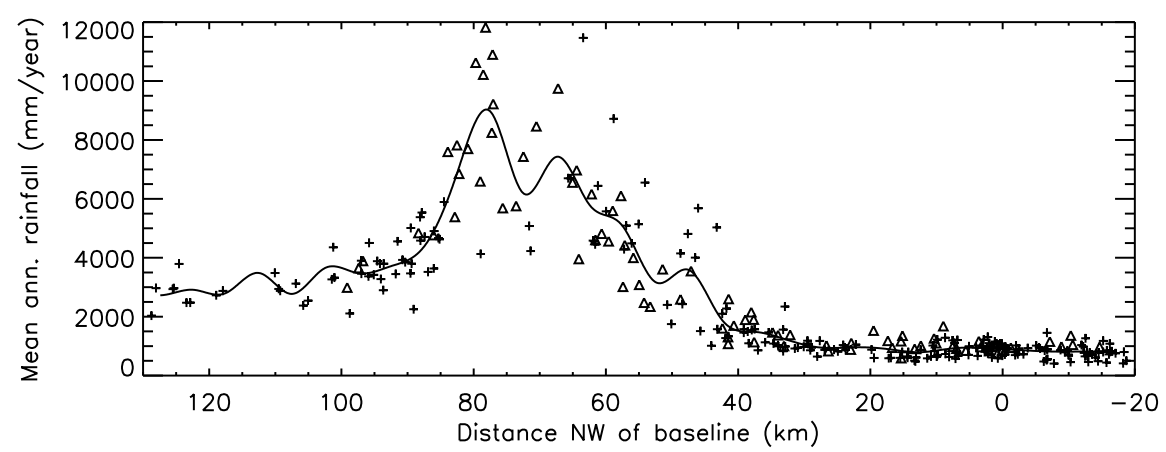

(a) Southern Alps

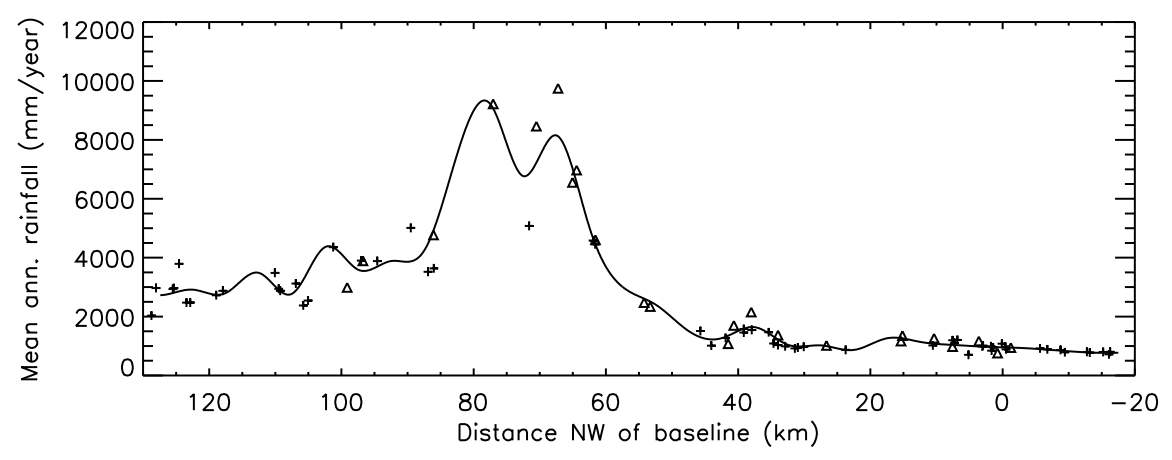

(b) Northeast Hokitika

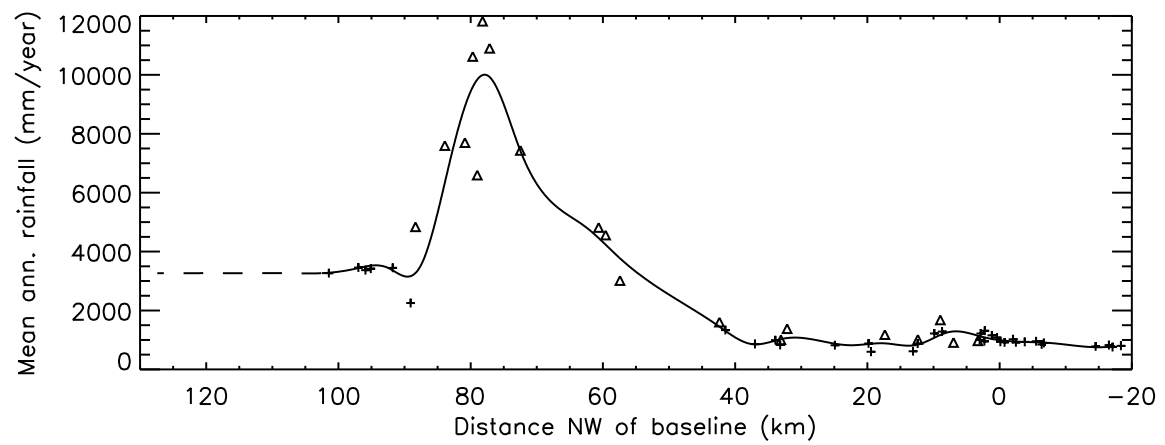

(c) Southwest Hokitika

Figure 5.2 Mean annual precipitation $\left(\mathrm{mm} \mathrm{a}^{-1}\right)$ observed at Southern Alps stations from 1971 to 2000, versus distance northwest of baseline $(\mathrm{km})$. ' + ' symbols denote CliDB gauges, ' $\triangle$ ' symbols denote WRA gauges. The curved line shows the cubic spline fitted to the profile. The dashed line represents extrapolated values, which are equal to the mean annual precipitation observed in the 5-km division at the northwestern tail of each profile. 


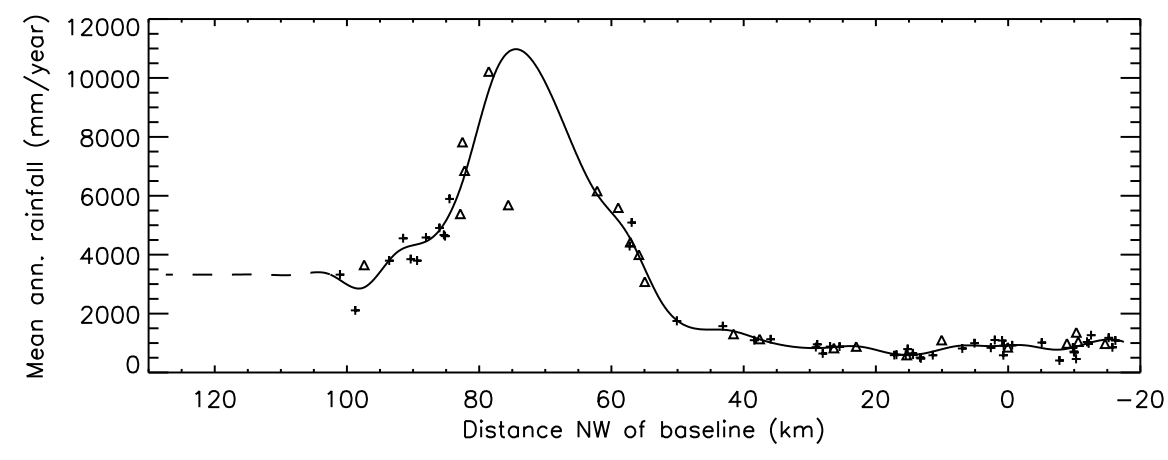

(d) Franz Josef

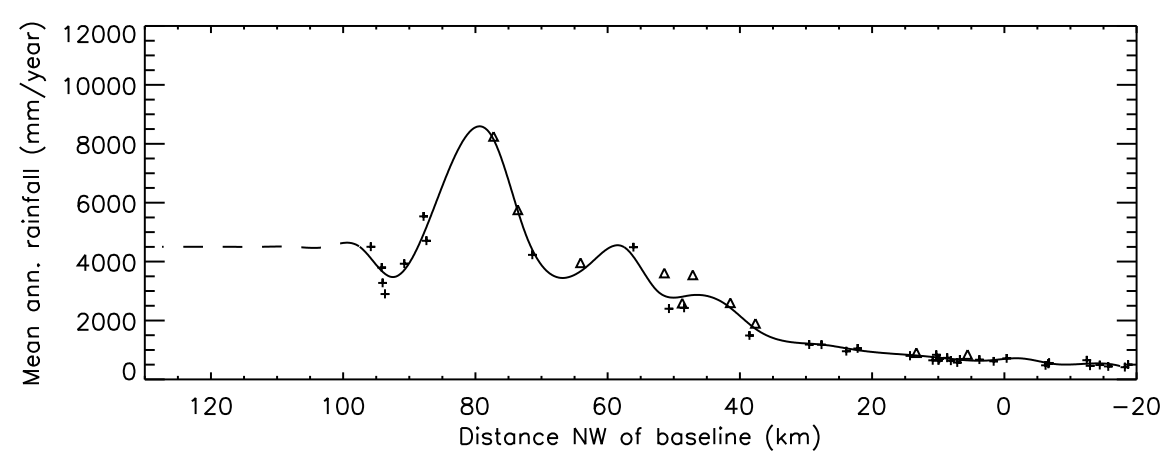

(e) Haast

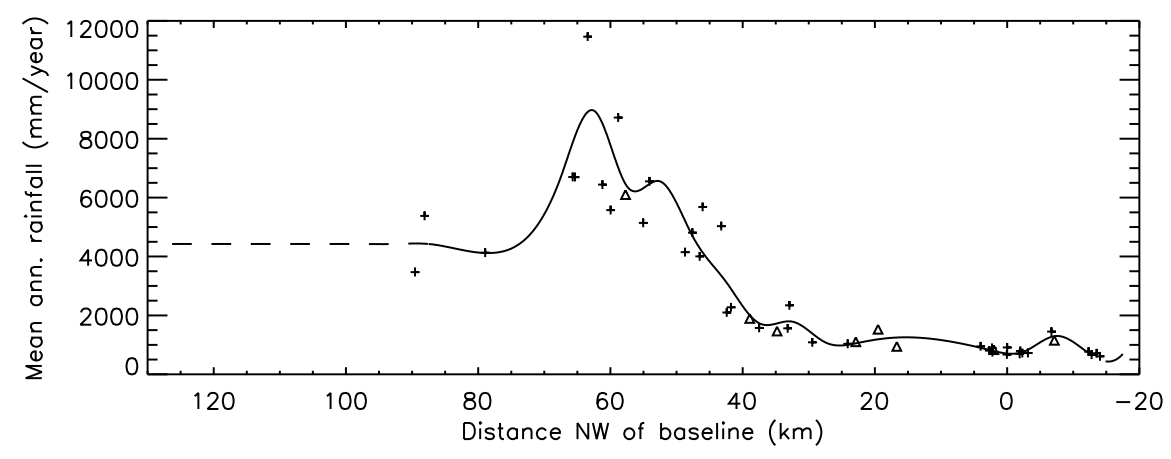

(f) Milford

Figure 5.2 (continued). 


\section{Northeast Hokitika transect}

The spline fitted through the averaged divisions of the northeast Hokitika transect peaks at $9.4 \mathrm{~m} \mathrm{a}^{-1}$ (Figure $5.2 \mathrm{~b}$ ). This maximum is located $78.4 \mathrm{~km}$ northwest of the baseline and $8 \mathrm{~km}$ southeast of the Alpine Fault. The location and magnitude of the peak is largely defined by the sole station within the 75-80 km division: Mount Browning (1160 m a.s.l.) at the head of the Styx River, where $9.2 \mathrm{~m} \mathrm{a}^{-1}$ of precipitation was recorded. However, Cabot Ridge (1450 m a.s.l.), just east of the Wilberforce River and $67.2 \mathrm{~km}$ northwest of the baseline, is the individual station that recorded the maximum mean annual precipitation across the northeast Hokitika transect: $9.7 \mathrm{~m} \mathrm{a}^{-1}$. The spline through this transect has a second, smaller peak of $8.1 \mathrm{~m} \mathrm{a}^{-1}$ at $67.7 \mathrm{~km}$.

\section{Southwest Hokitika transect}

The spline through the southwest Hokitika transect peaks at $10.0 \mathrm{~m} \mathrm{a}^{-1}$ (Figure 5.2c). This maximum is located $77.9 \mathrm{~km}$ northwest of the baseline and $7 \mathrm{~km}$ southeast of the Alpine Fault. The wettest 5 - $\mathrm{km}$ division of the southwest Hokitika transect extends from $75-80 \mathrm{~km}$ northwest of the baseline. This division contains stations in the Tuke and Cropp catchments. However, one station within this division, Moonbeam Torrent (410 m a.s.l.) on the Waitaha River, recorded average precipitation of only $6.6 \mathrm{~m} \mathrm{a}^{-1}$.

\section{Franz Josef transect}

The wettest individual gauge within the Franz Josef transect is Luncheon Rock (680 m a.s.l.), near the lower tongue of the Franz Josef Glacier and $78.5 \mathrm{~km}$ northwest of the baseline (Figure $5.2 \mathrm{~d}$ ). $10.2 \mathrm{~m} \mathrm{a}^{-1}$ of precipitation was recorded at Luncheon Rock during 3.7 years of observations between 1982 and 1986. Almer Hut (1735 m a.s.l.) lies just $3 \mathrm{~km}$ to the southeast, near the upper tongue of the Franz Josef Glacier. Only $5.7 \mathrm{~m} \mathrm{a}^{-1}$ of precipitation was recorded at Almer Hut during 4.5 years of observation between 1991 and 1996.

No observations are recorded between Almer Hut and the next gauge to 
the southeast, Panorama Ridge (1509 m a.s.l.) at the head of the Godley River. Panorama Ridge is $22 \mathrm{~km}$ to the east of Almer Hut, and the distance between these two stations along the northwest-southeast axis normal to the baseline is $13 \mathrm{~km}$. $6.2 \mathrm{~m} \mathrm{a}^{-1}$ of precipitation was recorded at Panorama Ridge over 7.0 station years.

Initially, all the stations in the Franz Josef transect were included in the interpolation, and the peak of the spline reached $8.2 \mathrm{~m} \mathrm{a}^{-1}$. This peak was located $74.4 \mathrm{~km}$ northwest of the baseline, $11 \mathrm{~km}$ southeast of the Alpine Fault and 4-5 km northwest of the Main Divide above the Franz Josef névé. Almer Hut was then removed from the interpolation and the spline was recalculated. The location of the peak of the spline remained at $74.4 \mathrm{~km}$ northwest of the baseline. However, the maximum magnitude of the spline with Almer Hut excluded was $10.9 \mathrm{~m} \mathrm{a}^{-1}$ - an increase of $2.7 \mathrm{~m} \mathrm{a}^{-1}$. This illustrates the sensitivity of the spline to individual gauges located in data-sparse areas. Figure 5.2d shows the spline with Almer Hut excluded from the interpolation, but mean annual precipitation recorded at Almer Hut is still represented on the plot by the ' $\triangle$ ' symbol located at $75.6 \mathrm{~km}$ northwest of the baseline.

The available observations form a distinctly shaped profile across the Franz Josef transect, but observations of precipitation at Almer Hut appear to be anomalously low. A high proportion of the precipitation experienced at Almer Hut is likely to fall in the form of snow, due to the high elevation of the site. The combination of the reduced fall-velocity of snowflakes and deformation of the wind field around rain gauges can lead to significant undercatch of precipitation in exposed, highly elevated locations (Goodison et al. 1998). The low precipitation recorded at Almer Hut was suspected to be at least partially due to undercatch. Observations from Almer Hut were therefore excluded from the interpolation for the remainder of the analysis. With Almer Hut excluded, the peak of the spline through the Franz Josef transect $\left(10.9 \mathrm{~m} \mathrm{a}^{-1}\right)$ is higher than the peak of the spline through the other 4 transects. Measurements of snow accumulation on the Franz Josef Glacier appear to support this level of precipitation, as discussed in Chapter 6 . 


\section{Haast transect}

The spline through the Haast transect peaks at $8.6 \mathrm{~m} \mathrm{a}^{-1}$ (Figure 5.2e). This peak is located $79.4 \mathrm{~km}$ northwest of the baseline, around $7 \mathrm{~km}$ southeast of the Alpine Fault. Of the 5 transects - northeast Hokitika, southwest Hokitika, Franz Josef, Haast and Milford - Haast has the lowest peak. The peak of the Haast profile is $2.3 \mathrm{~m} \mathrm{a}^{-1}$ lower than that of the Franz Josef profile. The Haast region has lower topographic elevation than other parts of the Southern Alps. This may lead to reduced orographic uplift of air and explain the lower magnitude of precipitation across this transect. The wettest gauge across the Haast transect is Cron Creek (58 m a.s.l.), near the Haast River, which lies $77.3 \mathrm{~km}$ northwest of the baseline and $8 \mathrm{~km}$ southeast of the Alpine Fault. An average of $8.2 \mathrm{~m} \mathrm{a}^{-1}$ of precipitation was observed at Cron Creek during 9.0 years of observation between 1991 and 2001. No stations are located in the $80-85 \mathrm{~km}$ interval of the Haast transect. The southeastern tail of the spline fitted through the Haast transect drops away at a lower rate than the tails of the other 4 transects. This gives some support to the low peak of the spline, since there may be more spillover of precipitation to compensate.

\section{Milford transect}

The wettest gauge in the Milford transect (Figure 5.2f) is Dumpling Hut (120 m a.s.l.). $11.5 \mathrm{~m} \mathrm{a}^{-1}$ of precipitation was recorded at Dumpling Hut between 1982 and 1987, though the number of daily readings from this site equates to only 1.7 years of observation over this time. The spline through the Milford transect peaks at $9.0 \mathrm{~m} \mathrm{a}^{-1}$. This peak is located $62.8 \mathrm{~km}$ northwest of the baseline, $11.6 \mathrm{~km}$ southeast of the peak across the Franz Josef transect. The peaks of splines fitted to the northeast Hokitika, southwest Hokitika and Haast transects all lie yet further to the northwest. This could be partially due to the topography of the Milford region, where the Main Divide lies furthest to the southeast. However, there are large observational gaps in the profile through the Milford transect, with only 3 stations located more than $66 \mathrm{~km}$ northwest of the baseline. The observations are insufficient to describe 


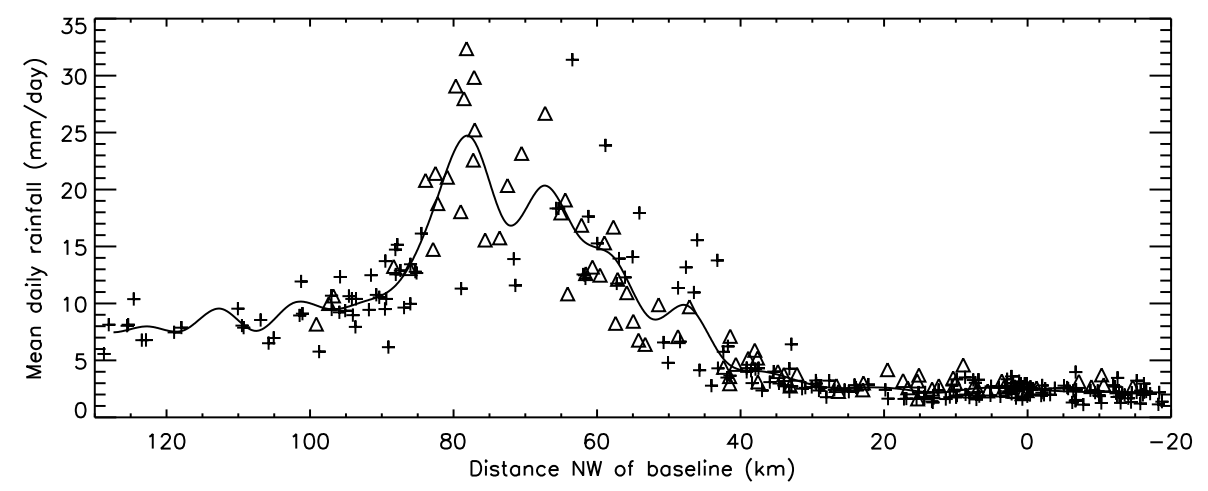

Figure 5.3 Mean daily precipitation $\left(\mathrm{mm} \mathrm{dy}^{-1}\right)$ at Southern Alps stations from 1971 to 2000 , versus distance northwest of baseline $(\mathrm{km})$. '+' symbols denote CliDB gauges, ' $\triangle$ ' symbols denote WRA gauges. The curved line shows the cubic spline fitted to the profile.

the distribution of precipitation in this region, and the northwest section of the Milford profile must be viewed with caution.

\subsubsection{Comparison of daily profiles with atmospheric properties}

One of the basic aims of the methodology was to use the two-dimensional profile of orographically enhanced rainfall as a predictor of rainfall distribution at high spatial resolution. Since the profile of observed rainfall could be expected to vary under different atmospheric conditions, it was hypothesised that incorporating such variations of the profile might improve the skill of the downscaling method. The profile of mean daily precipitation across the Southern Alps on all days from 1 January 1971 to 31 December 2000 is shown in Figure 5.3. The shape of the daily profile is the same as that of the annual profile in Figure 5.2a, but the units of the ordinate axis are instead millimetres of precipitation per day $\left(\mathrm{mm} \mathrm{dy}^{-1}\right)$.

Using data from NCEP/NCAR Reanalysis 1, the mean direction and magnitude of wind - diagnosed at $42.5^{\circ} \mathrm{S} 170^{\circ} \mathrm{E}$, north of the central Southern Alps (see Figure 3.4) — was calculated on all days from 1 January 1971 to 31 December 2000. The direction and magnitude of the wind 


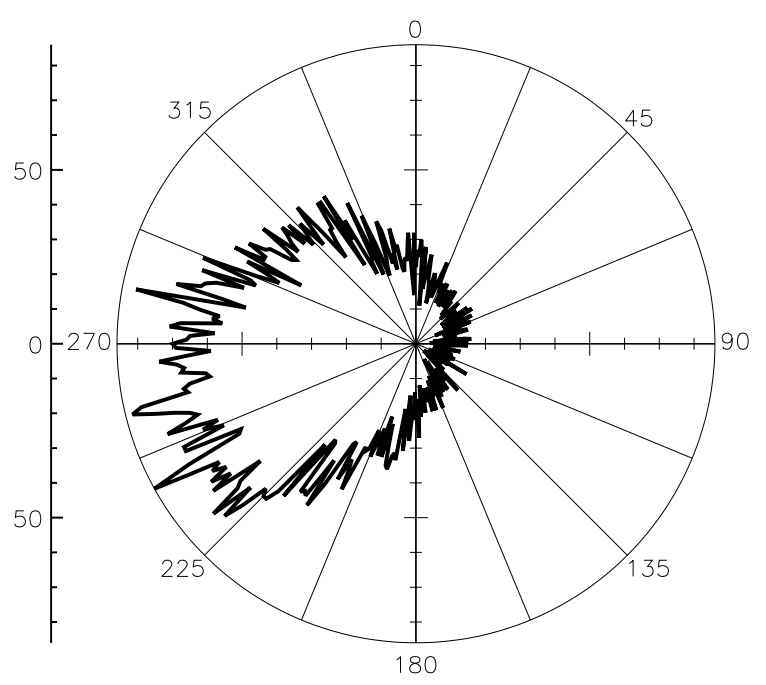

Figure 5.4 Frequency of mean daily wind direction at $850 \mathrm{hPa} 42.5^{\circ} \mathrm{S} 170^{\circ} \mathrm{E}$ from 1 Jan 1971 to 31 Dec 2000 in NCEP/NCAR Reanalysis 1 . Frequency is measured by the total number of days on which the mean horizontal wind direction blew from each $1^{\circ}$ segment of the $360^{\circ}$ compass.

in the horizontal plane was calculated via a vector sum of the zonal and meridional wind vectors at the $850 \mathrm{hPa}$ pressure level. The resultant wind vectors were then rotated by $180^{\circ}$ in the horizontal plane, so as to point in the source direction of the wind.

Figure 5.4 shows the frequency of mean daily wind direction at $42.5^{\circ} \mathrm{S}$ $170^{\circ} \mathrm{E}$, at a height of $850 \mathrm{hPa}$. Westerlies are dominant at this height and location: the wind blows from the western half of the compass on $78.4 \%$ of all days from 1971 to 2000 . The wind most commonly blows from the southwest (42.4\% of days), west (50.8\%) and northwest (36.0\%) quadrants. Winds from the eastern half of the compass are infrequent $(21.6 \%)$ and winds from the eastern quadrant are particularly rare $(8.4 \%)$.

The source wind directions were initially categorised into 4 quadrants (90 segments) of the compass: northwest, northeast, southeast and southwest. Quadrants were used for simplicity; the use of smaller segments, such as $45^{\circ}$ segments, would have necessitated a greater number of different windclassifications, thereby complicating the downscaling process. An additional 4 quadrants were however used to analyse the relationships between precip- 
itation and wind direction, but these were not used during the downscaling process. These additional 4 quadrants were: north, east, south and west, each with quadrant again forming a $90^{\circ}$ segment of the compass.

The profile of daily precipitation across the Southern Alps was then categorised by the quadrant from which the wind blew on each UTC day. The profile of precipitation across the Southern Alps varies considerably during different wind directions (Figure 5.5). The greatest amount of precipitation falls on days during which the wind blows from the northwest, north and west quadrants. The highest precipitation is experienced on 'northwesterly days', when the spline fitted through the transect of observations peaks at $53.2 \mathrm{~mm} \mathrm{dy}^{-1}$. When the wind blows from the southwest, west, northwest, north or northeast quadrant, the average location of peak precipitation is $77-81 \mathrm{~km}$ northwest of the study baseline, that is, on the northwest flank of the Southern Alps.

The peak precipitation of the spline across the Southern Alps is lowest on days when the wind blows from the south $\left(3.1 \mathrm{~mm} \mathrm{dy}^{-1}\right)$, southeast $\left(4.3 \mathrm{~mm} \mathrm{dy}^{-1}\right)$ and east $\left(4.2 \mathrm{~mm} \mathrm{dy}^{-1}\right)$ quadrants. Wind from these quadrants produces a very flat distribution of precipitation. The average location of peak precipitation on such days is on the southeast side of the Southern Alps, approximately $5 \mathrm{~km}$ northwest of the baseline. This is around $72-75 \mathrm{~km}$ southeast of the peak that occurs on days the wind blows from the other quadrants.

Air temperature and specific humidity from NCEP/NCAR Reanalysis 1 were also analysed. Table 5.1 presents a summary of atmospheric variables and precipitation, classified according to the source direction of the mean daily wind at $42.5^{\circ} \mathrm{S} 170^{\circ}$ E. Mean air temperature, specific humidity and peak precipitation are all highest on days when the wind blows from the north and northwest quadrants. Conversely, these properties are all lowest when the wind blows from the south quadrant. Mean wind magnitude is strongest on days when wind blows from the west $\left(9.7 \mathrm{~m} \mathrm{~s}^{-1}\right)$ and northwest $\left(9.4 \mathrm{~m} \mathrm{~s}^{-1}\right)$ quadrants, and is weakest when wind blows from the east $\left(5.1 \mathrm{~m} \mathrm{~s}^{-1}\right)$ quadrant.

The distribution of precipitation across the Southern Alps was also clas- 

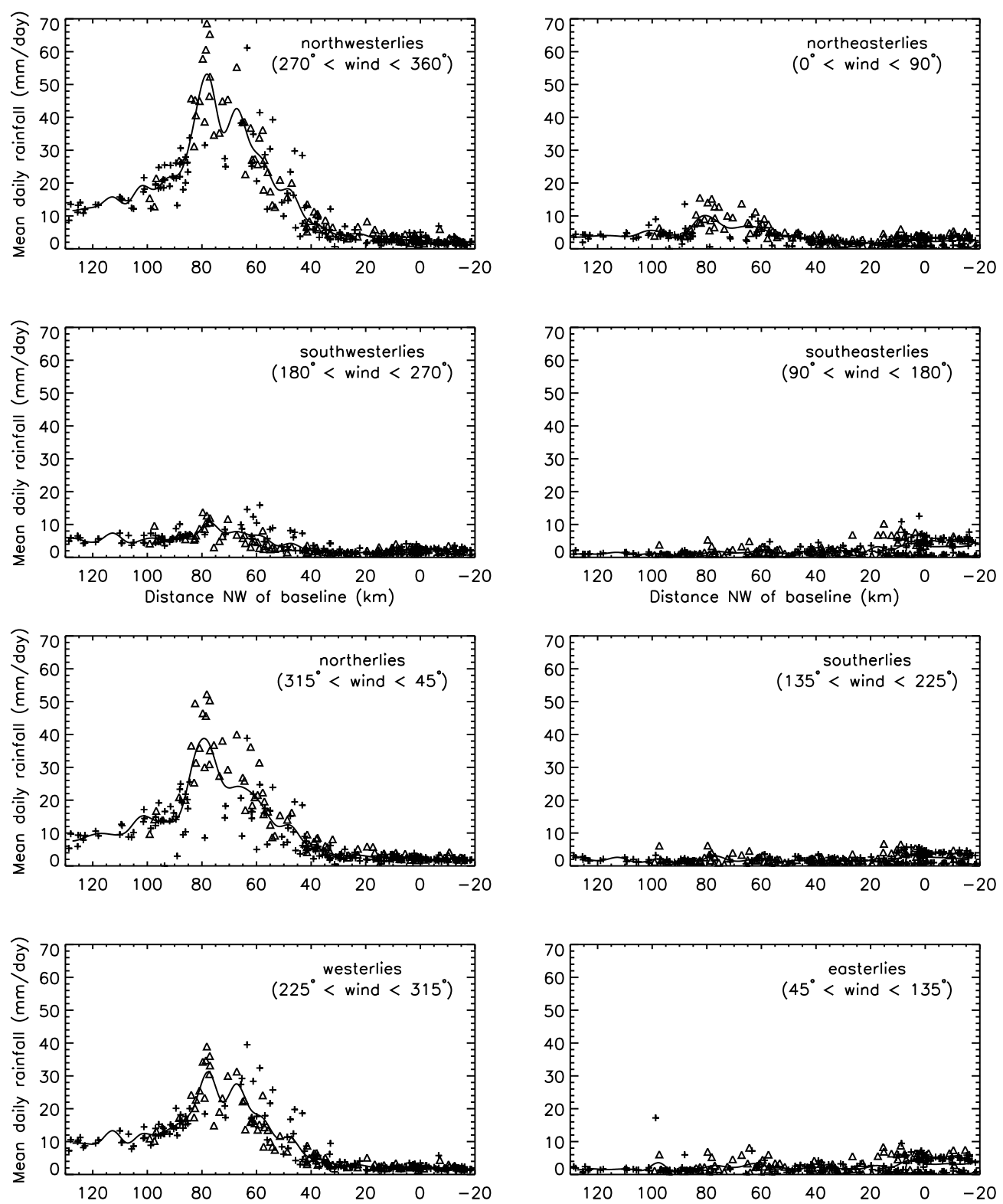

Figure 5.5 Mean daily precipitation $\left(\mathrm{mm} \mathrm{dy}^{-1}\right)$ observed at Southern Alps stations from 1971 to 2000, versus distance northwest of baseline $(\mathrm{km})$, categorised by wind direction at $850 \mathrm{hPa} 42.5^{\circ} \mathrm{S} 170^{\circ} \mathrm{E}$. '+' symbols denote CliDB gauges, ' $\triangle$ ' symbols denote WRA gauges. The curved line shows the cubic spline fitted to each profile. 
Table 5.1 Atmospheric properties and observed precipitation in the Southern Alps from 1 Jan 1971 to $31 \mathrm{Dec} 2000$. Wind, air temperature and specific humidity are taken from $850 \mathrm{hPa} 42.5^{\circ} \mathrm{S} 170^{\circ} \mathrm{E}$ in NCEP/NCAR Reanalysis 1. Precipitation was observed by rain gauges located in the Southern Alps. All data are categorised by the source direction of the mean daily wind in the horizontal plane. [Column 1] quadrant from which the wind originates, and in parentheses, the minimum and maximum bearings that enclose the quadrant; [2] mean magnitude of the sum of the zonal and meridional mean daily wind velocities $(|\overline{u+v}|)$; [3] mean daily air temperature $(\bar{T})$; [4] mean daily specific humidity $(\bar{q})$; [5] maximum value of spline fitted to the profile of observed precipitation across the Southern Alps $\left(p_{\max }\right)$; [6] distance from the study baseline northwest to the location of $p_{\max }$ (NW Dist.); [7] number of days on which the wind blew from within the quadrant; [8] number of days on which the wind blew from within the quadrant, expressed as a percentage of the total number of days from 1 Jan 1971 to 31 Dec 2000.

\begin{tabular}{|c|c|c|c|c|c|c|c|}
\hline \multicolumn{2}{|l|}{ Wind } & \multirow{2}{*}{$\begin{array}{c}\bar{T} \\
\left({ }^{\circ} \mathrm{C}\right)\end{array}$} & \multirow{2}{*}{$\begin{array}{r}\bar{q} \\
\left(\mathrm{~g} \mathrm{~kg}^{-1}\right)\end{array}$} & \multicolumn{2}{|c|}{ Precipitation } & \multicolumn{2}{|c|}{ Days } \\
\hline $\begin{array}{l}\text { Quadrant } \\
\left(\text { Min. }{ }^{\circ}, \text { Max. }{ }^{\circ}\right)\end{array}$ & $\begin{array}{l}|\overline{u+v}| \\
\left(\mathrm{m} \mathrm{s}^{-1}\right)\end{array}$ & & & $\begin{array}{r}p_{\max } \\
\left(\mathrm{mm} \mathrm{dy} \mathrm{dy}^{-1}\right)\end{array}$ & $\begin{array}{r}\text { NW Dist. } \\
(\mathrm{km})\end{array}$ & Num. & $(\%)$ \\
\hline Northwest $(270,360)$ & 9.4 & 6.5 & 5.0 & 53.2 & 78.1 & 3947 & 36.0 \\
\hline Northeast $(0,90)$ & 6.4 & 5.0 & 4.6 & 10.1 & 80.6 & 1356 & 12.4 \\
\hline Southwest $(180,270)$ & 8.9 & 3.2 & 3.6 & 10.7 & 77.3 & 4647 & 42.4 \\
\hline Southeast $(90,180)$ & 5.3 & 2.3 & 3.4 & 4.3 & 5.5 & 1008 & 9.2 \\
\hline North $(315,45)$ & 8.1 & 6.5 & 5.3 & 38.8 & 79.2 & 2269 & 20.7 \\
\hline South $(135,225)$ & 7.1 & 1.8 & 3.3 & 3.1 & 5.3 & 2213 & 20.2 \\
\hline West $(225,315)$ & 9.7 & 5.0 & 4.2 & 31.2 & 77.7 & 5567 & 50.8 \\
\hline East $(45,135)$ & 5.1 & 3.7 & 4.0 & 4.2 & 5.1 & 925 & 8.4 \\
\hline
\end{tabular}


sified by air temperature and specific humidity. However, the distinctions between the different precipitation profiles under such classifications were not as clear as those under classification by wind direction. On days during which the mean air temperature at $850 \mathrm{hPa} 42.5^{\circ} \mathrm{S} 170^{\circ} \mathrm{E}$ was less than $0{ }^{\circ} \mathrm{C}$, the spline fitted to the transect of precipitation observations reached a peak of just $6.7 \mathrm{~mm} \mathrm{dy}^{-1}, 77.0 \mathrm{~km} \mathrm{NW}$ of the baseline. However, the reduced air temperature and precipitation were accompanied by a notable change of the source wind direction toward the south. Thus to some extent air temperature appears to be a proxy for wind direction.

To further analyse the influence of air temperature, observations were limited to days on which the $850 \mathrm{hPa}$ wind blew from the northwest quadrant and the $850 \mathrm{hPa}$ mean air temperature was less than or equal to $0^{\circ} \mathrm{C}$ (Figure 5.6). The introduction of the upper temperature limit of $0{ }^{\circ} \mathrm{C}$ reduces the peak precipitation of the spline on northwesterly days from $53.2 \mathrm{~mm} \mathrm{dy}^{-1}$ to $21.6 \mathrm{~mm} \mathrm{dy}^{-1}$. Much of this reduction is likely to be due to the lower humidity of cold air. The location of the peak remains on the northwest flank of the Southern Alps, moving from $78.1 \mathrm{~km}$ to $79.4 \mathrm{~km}$ northwest of the baseline. A marked relationship between air temperature and spillover of precipitation southeast of the Main Divide is not obvious. However, the highest levels of precipitation are recorded at gauges southeast of the Main Divide, and precipitation is more evenly distributed in the centre of the profile. This could be caused by an increase in the southeastward drift of ice crystals during temperatures below freezing.

In order to investigate the influence of varying amounts of atmospheric moisture upon the distribution of precipitation, the observations of precipitation were classified by the amount of specific humidity at $850 \mathrm{hPa} 42.5^{\circ} \mathrm{S}$ $170^{\circ} \mathrm{E}$, with no limitation of wind direction or air temperature. The magnitude of the precipitation profile across the Southern Alps had a strong, positive correlation with the amount of specific humidity. However, variations in specific humidity did not correlate with changes in the location of peak precipitation to any great extent. Air temperature correlated positively with specific humidity.

Due to the covariances between wind direction, air temperature and spe- 


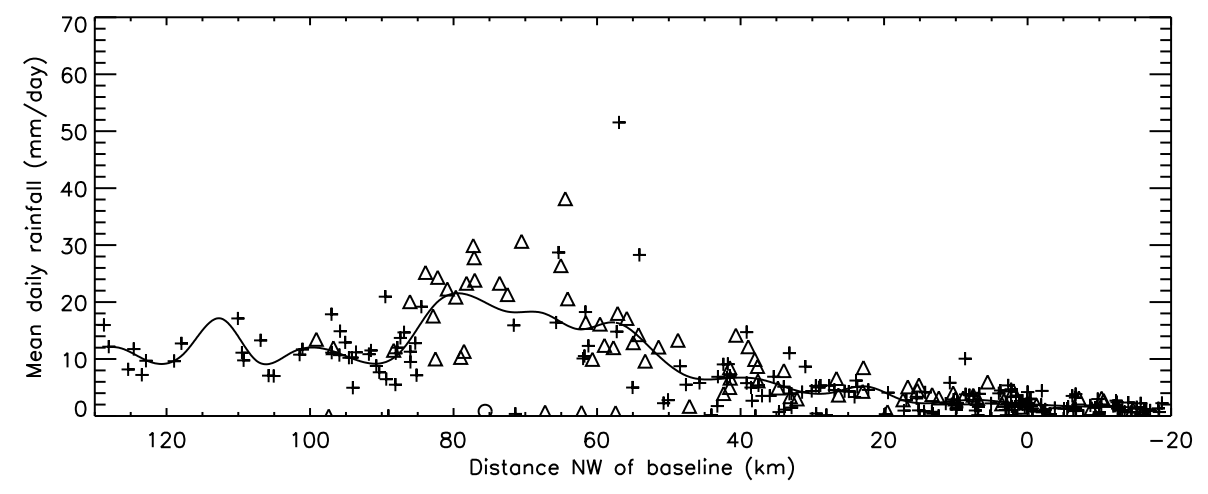

Figure 5.6 Mean daily precipitation $\left(\mathrm{mm} \mathrm{dy}^{-1}\right)$ in the Southern Alps on northwesterly days with $850 \mathrm{hPa}$ temperature less than or equal to $0{ }^{\circ} \mathrm{C}$, from 1971 to 2000 , versus distance northwest of baseline $(\mathrm{km})$. ' + ' symbols denote CliDB gauges, ' $\triangle$ ' symbols denote WRA gauges. The curved line shows the cubic spline fitted to the profile.

cific humidity, it was difficult to isolate the effect of any one of these variables upon the spatial distribution of precipitation in the Southern Alps. However, classification by wind direction produced the most distinct changes in the mean profile of rainfall. The wind-based classifications were therefore incorporated into the downscaling of precipitation simulated by the RCM in the Southern Alps.

\subsection{Surfaces of observed precipitation}

Surfaces of observed precipitation in the Southern Alps, constructed from the interpolated precipitation profiles, are described in this section. A new 30-year mean annual surface is compared with precipitation surfaces that have been independently developed by other researchers. The accuracy of the new 30-year surface is further assessed by its use within a model simulation of glacial flow in the central Southern Alps. Surfaces of mean daily precipitation, classified by wind direction, are then analysed. 


\subsubsection{Surface of mean annual precipitation}

The five two-dimensional transects of precipitation observed across the Southern Alps (northeast Hokitika, southwest Hokitika, Franz Josef, Haast and Milford, see Figure 5.2) were combined into a three-dimensional surface that extends across much of the South Island, as described in Section 4.1.2. Figure 5.7 is an oblique aerial view of this surface, hereafter referred to as Surf Obs.A. The surface in this image extends from 300 to $500 \mathrm{~km}$ northeast of the domain origin in Cape Providence, and from $20 \mathrm{~km}$ southeast of the baseline northwest to the Tasman Sea. This area encompasses all but the southwestern tip of the primary study region. The profile of precipitation across the Southern Alps is the dominant feature of the three-dimensional surface, as one would expect given the methodological approach of joining the two-dimensional transects. The ridge of peak rainfall along the axis of the Southern Alps is clearly visible, as is the rain shadow on the southeast side of the mountain range. Moving southwestward along the ridge, the surface initially rises a little and then dips significantly.

A plan view of Surf Obs.A $_{\text {a }}$ within the primary study region is shown in Figure 5.8. The surface peaks at $10.9 \mathrm{~m} \mathrm{a}^{-1}$ on the northwest flank of the central Southern Alps, around $74 \mathrm{~km}$ northwest of the baseline and approximately $11 \mathrm{~km}$ southeast of the Alpine Fault. The single maximum value of the surface is $10.93 \mathrm{~m} \mathrm{a}^{-1}$, on the upper region of the Fritz Range, which separates the Franz Josef and Fox glaciers. The location of this maximum is around $4 \mathrm{~km}$ northwest of the Main Divide, immediately northwest of the Pukaki catchment. In the context of the interpolative process, the location of peak precipitation is due to two factors. Firstly, of the 5 transects across the Southern Alps (northeast Hokitika, southwest Hokitika, Franz Josef, Haast and Milford), the magnitude of the interpolated profile was highest across the Franz Josef transect (10.9 $\mathrm{m} \mathrm{a}^{-1}$, see Figure 5.2d). Secondly, the Franz Josef profile was georeferenced so as to bisect the domain of the Franz Josef transect (Figure 4.1), and this bisecting line intersects the Franz Josef Glacier itself.

Throughout the central Southern Alps, the ridge of maximum precipita-

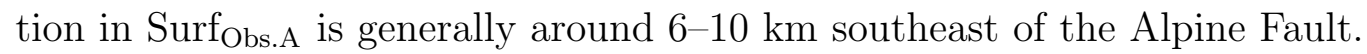




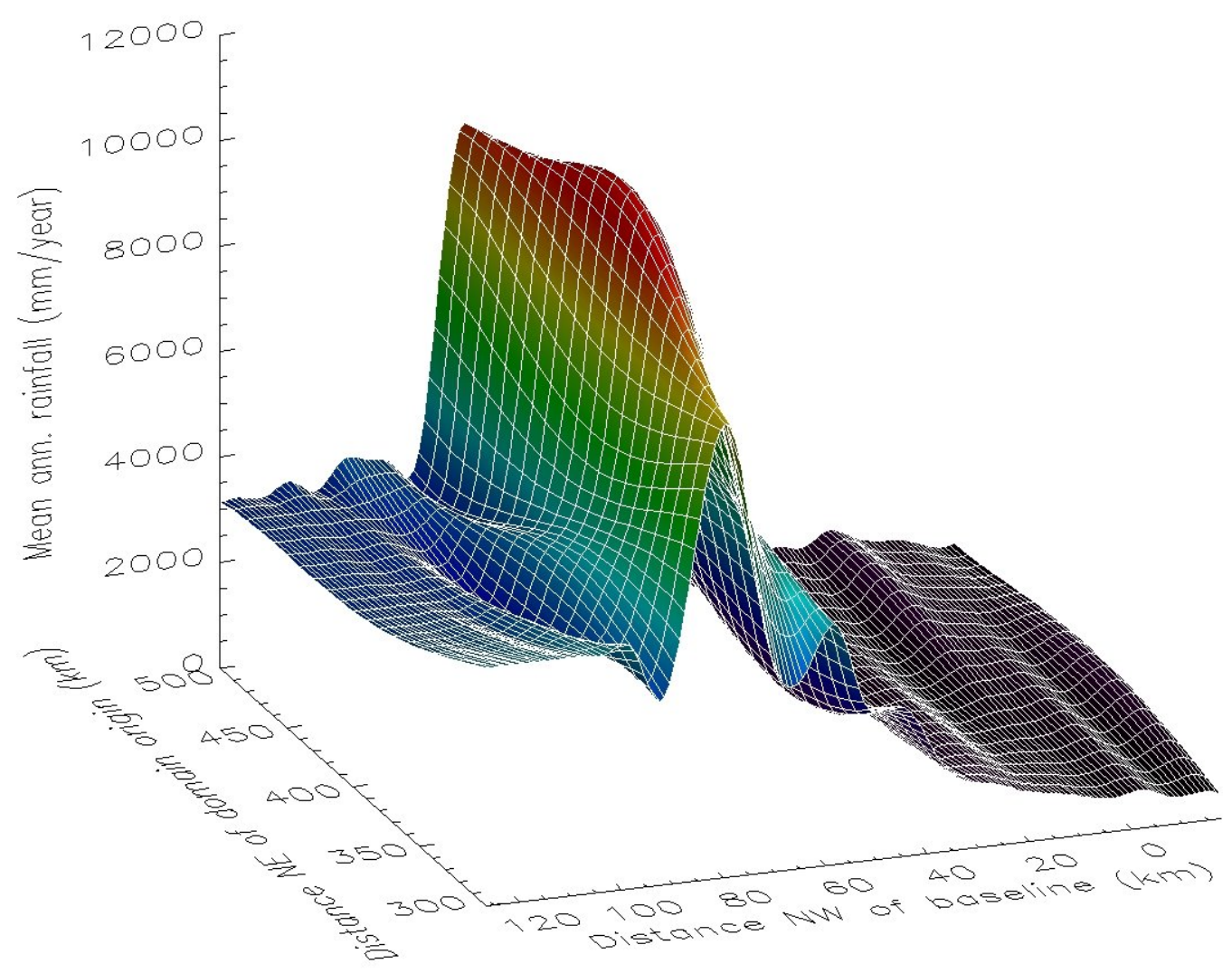

Figure 5.7 An oblique aerial view of the surface of observed mean annual precipitation $\left(\mathrm{mm} \mathrm{a}^{-1}\right)$ in the central Southern Alps from 1971 to 2000 (Surf Obs.A). The $\mathrm{x}$-axis is the distance $(\mathrm{km})$ northwest of the study baseline, the $y$-axis is the distance $(\mathrm{km})$ northeast of the domain origin in Cape Providence, and the $z$-axis is mean annual precipitation $\left(\mathrm{mm} \mathrm{a}^{-1}\right)$. 


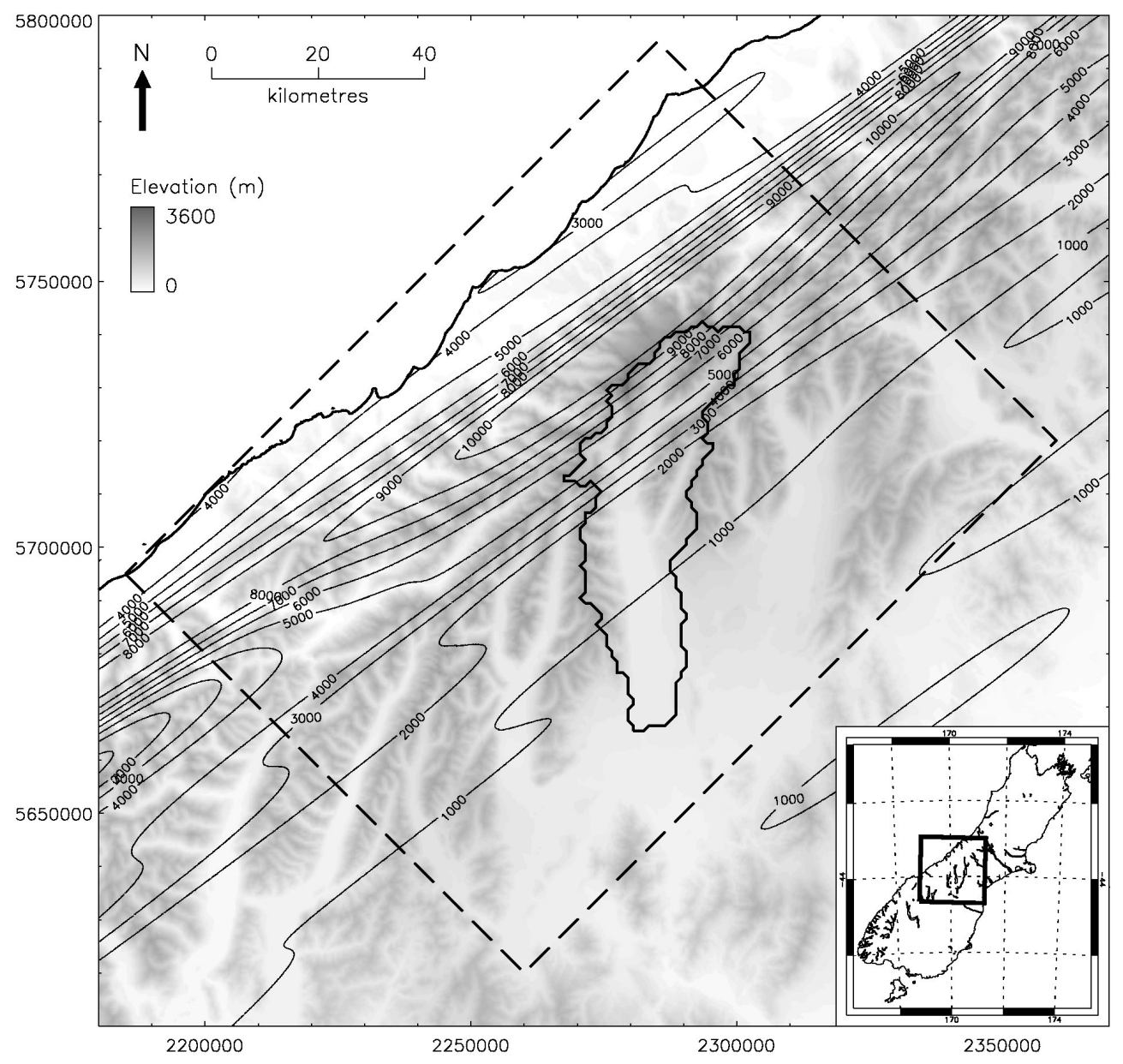

Figure 5.8 Isohyets of interpolated observations of mean annual precipitation $\left(\mathrm{mm} \mathrm{a}^{-1}\right)$ in the central Southern Alps from 1971 to 2000 (Surf Obs.A). The dashed line delineates the primary study region, within which Pukaki catchment is outlined. Shading indicates topographic elevations from a $500 \mathrm{~m}$ DEM. 
Due to the deformation of the main topographic ridge along the Southern Alps, the distance from the precipitation ridge to the Main Divide is more variable, ranging from just $4 \mathrm{~km}$ in the Franz Josef region, to a maximum of around $25 \mathrm{~km}$ in the Haast region, where the Main Divide lies further to the southeast.

\section{Comparison with other precipitation surfaces}

Scientists at the Antarctic Research Centre currently use a surface of mean annual precipitation in their simulations of the mass balance and flow of glaciers in the Southern Alps. Dr Brian Anderson, of the ARC, derived a

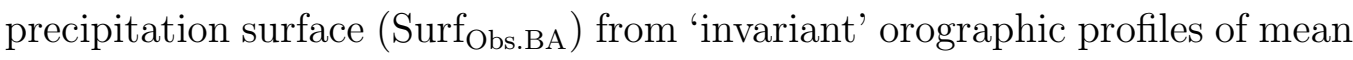
annual rainfall across the Southern Alps, which were subjectively estimated by Henderson and Thompson (1999). The magnitude of the profile of rainfall was slightly reduced during the construction of Surf $f_{\text {Obs.BA. }}$.

Dr Nick Golledge, a Post-Doctoral Fellow working with Dr Andrew Mackintosh at the ARC, compared Surf $f_{\text {Obs.BA }}$ to Surf ${ }_{\text {Obs.A }}$ within the domain of the Parallel Ice Sheet Model (PISM), which encompasses the central region of the Southern Alps. Figure 5.9 shows contours of the differences between the mean annual precipitation of the two surfaces in this region. The area of greatest difference lies on the northwest flank of the Southern Alps, northwest of the Pukaki catchment. In part of this region, Surf ${ }_{\text {Obs.A }}$ is over $3.0 \mathrm{~m} \mathrm{a}^{-1}$ wetter than $\operatorname{Surf}_{\text {Obs.BA. Surfobs.A }}$ is around $1.5-2.5 \mathrm{~m} \mathrm{a}^{-1}$ wetter than Surf $_{\text {Obs.BA }}$ in the northern part of Pukaki catchment, and around $1.5 \mathrm{~m} \mathrm{a}^{-1}$ wetter than Surf $_{\text {Obs.BA }}$ at the head of the Tekapo catchment. To the southeast of the Main Divide, Surf ${ }_{\text {Obs.A }}$ is generally $0-0.5 \mathrm{~m} \mathrm{a}^{-1}$ drier than Surf Obs.BA. $_{\text {. }}$.

Figure 5.10 compares Surf $f_{\text {Obs.A }}$ with two precipitation surfaces produced by Kerr (2009). These surfaces comprise estimated mean annual measured precipitation (Surf ${ }_{\text {Obs.TK.M) }}$ ) and estimated mean annual 'true' precipitation

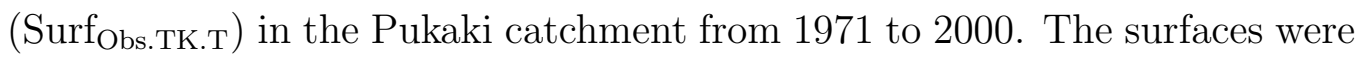
compared at a horizontal spatial resolution of $1 \mathrm{~km} \times 1 \mathrm{~km}$. Throughout most of the Pukaki catchment, mean annual precipitation in $\operatorname{Surf}_{\text {Obs.A }}$ is within $1.0 \mathrm{~m} \mathrm{a}^{-1}$ of both Surf Obs.TK.m and Surf Obs.TK.T. Across the whole catchment, the root mean square errors of the 1-km grid cells of Surfobs.A, 


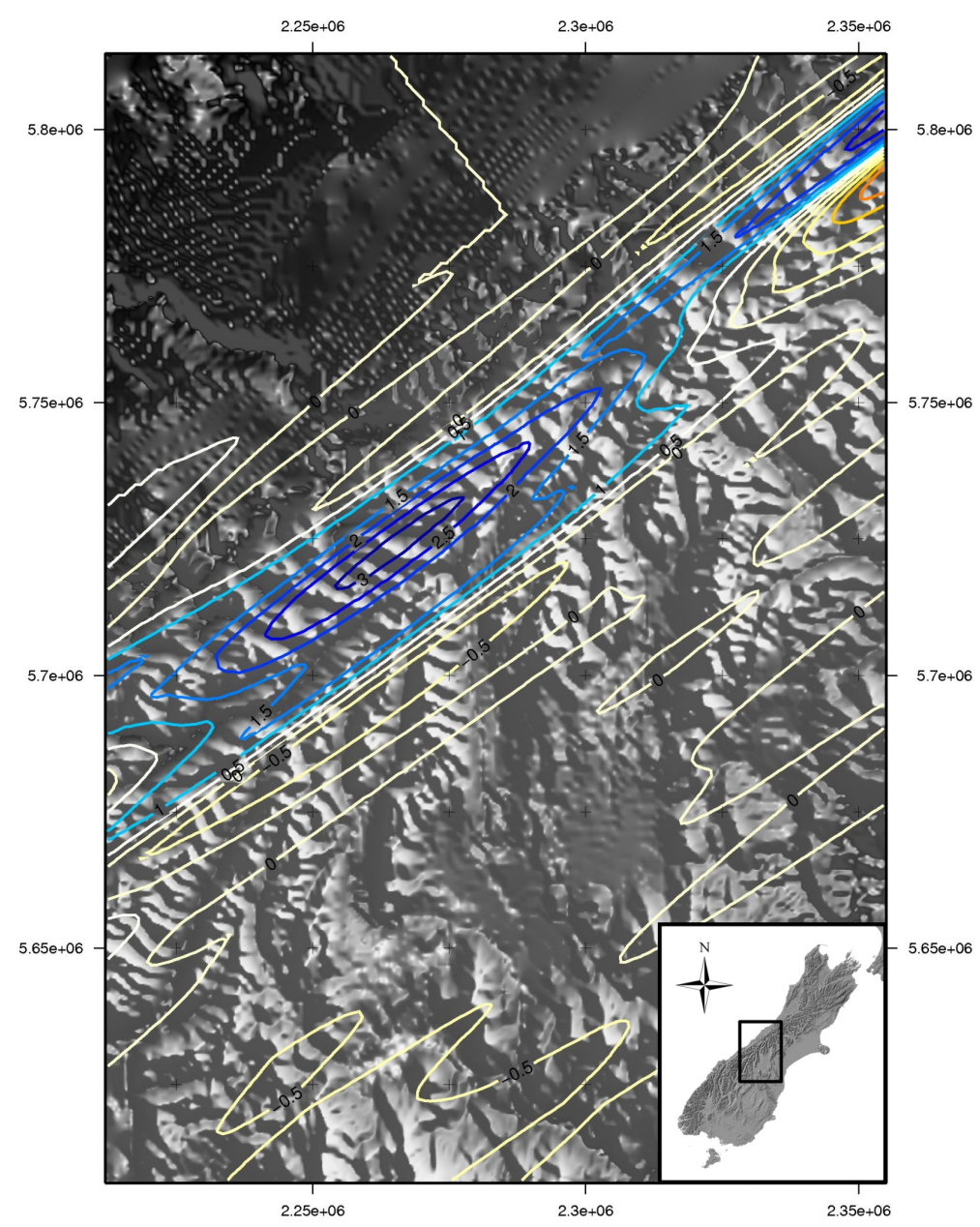

Figure 5.9 Contours of differences in mean annual precipitation $\left(\mathrm{m} \mathrm{a}^{-1}\right)$ in the cen-

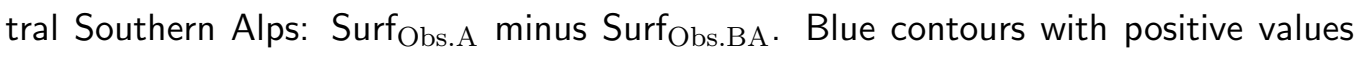

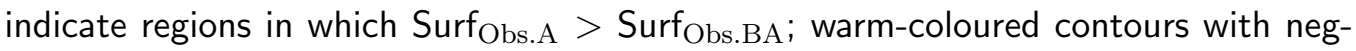
ative values indicate regions in which Surf Obs.A $<$ Surf Obs.BA. Image produced by Dr Nick Golledge of the Antarctic Research Centre, Victoria University of Wellington, New Zealand. 


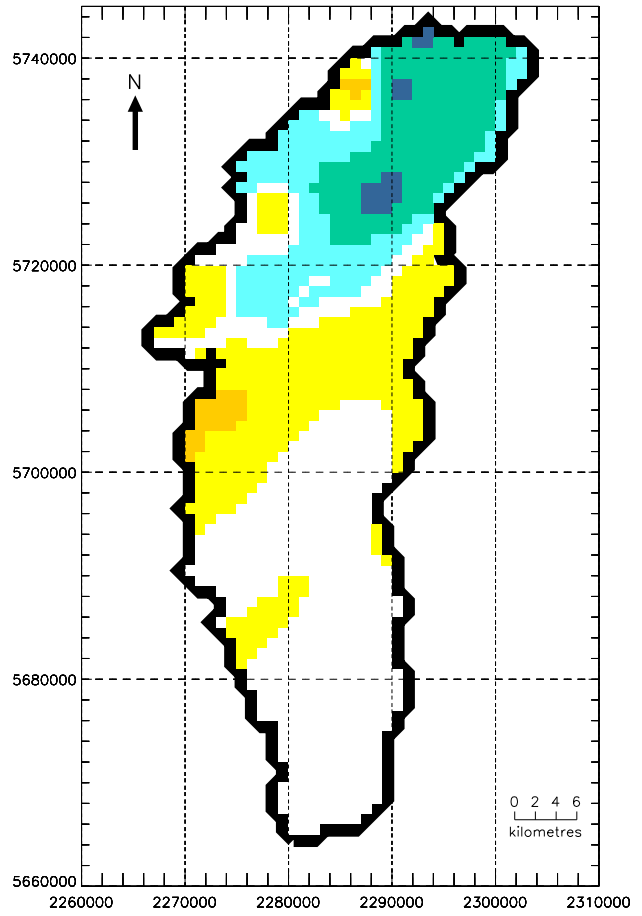

(a) Surf Obs.A minus Surf Obs.TK.M

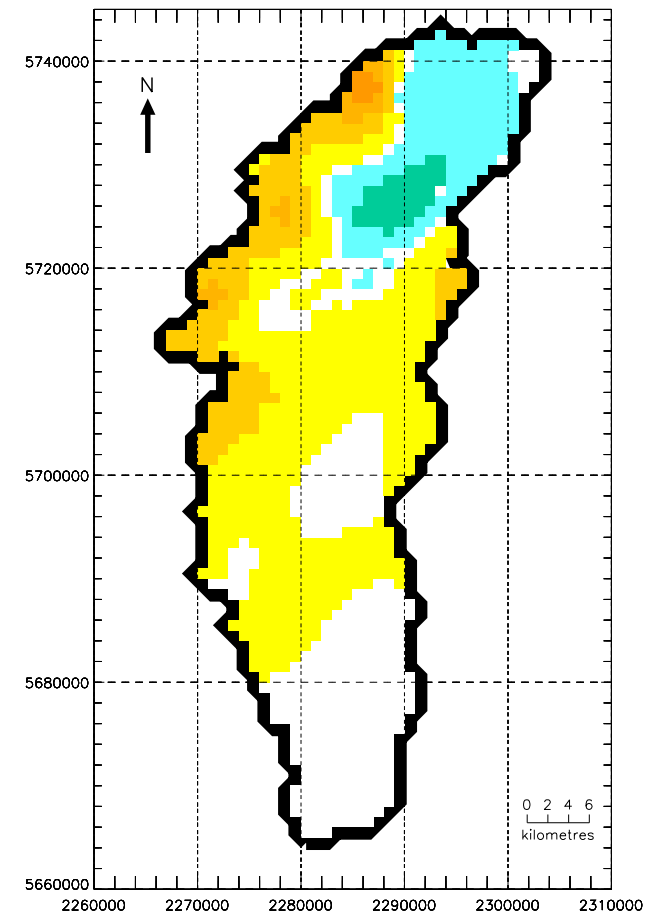

(b) Surf Obs.A minus Surf Obs.TK.T

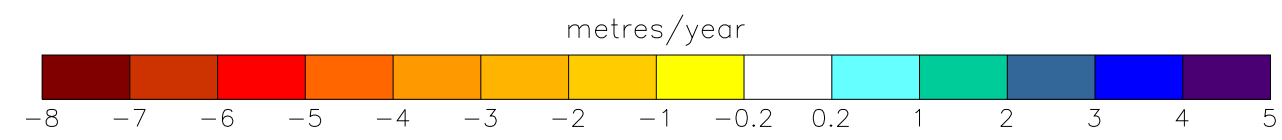

Figure 5.10 Differences in mean annual precipitation $\left(\mathrm{m} \mathrm{a}^{-1}\right)$ in the Pukaki catchment from 1971 to 2000: Surf Obs.A minus Surf Obs.TK.M (left image), and Surf Obs.A minus Surf ${ }_{\text {Obs.TK.T (right image). Surf }}$ Obs.TK.T is estimated 'true' precipitation, which takes into account the estimated undercatch by rain gauges; Surf Obs.TK.M does not consider undercatch. Cool colours indicate regions in which Surf Obs.A $>$ Surf $_{\text {Obs.TK.M }}$ and Surf Obs.A $^{>}$Surf $_{\text {Obs.TK.T; warm colours indicate regions in which Surf }}$ Obs.A $<$

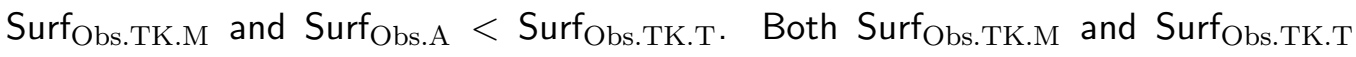
were produced by Kerr (2009). 
validated against Surf Obs.TK.m $_{\text {and }}$ Surf Obs.TK.T, are $0.7 \mathrm{~m} \mathrm{a}^{-1}$ and $0.8 \mathrm{~m} \mathrm{a}^{-1}$, respectively. Surf Obs.A is generally around $0.2-2.0 \mathrm{~m} \mathrm{a}^{-1}$ wetter than both Surf Obs.TK.M $_{\text {and }}$ Surf $_{\text {Obs.TK.T }}$ in the northeast part of the catchment.

Surf $_{\text {Obs.A }}$ is up to $4.0 \mathrm{~m} \mathrm{a}^{-1}$ drier than Surf Obs.TK.T $_{\text {on the northwest edge }}$ of the Pukaki catchment. This is due to the extremely steep horizontal precipitation gradient and high levels of precipitation in the very northwest region of Surf ${ }_{\text {Obs.TK.T, which are not represented to the same extent in Surf }}$ Obs.A. Variations between the surfaces from Kerr (2009) and the surface produced in the present analysis are due to the different interpolative techniques and data used in their construction. While Surf Obs.A was constructed via a spline of a series of transects, Surf Obs.TK.M $_{\text {and }}$ Surf $f_{\text {Obs.TK.T }}$ were produced by a direct two-dimensional interpolation of precipitation observed at rain gauges, via ordinary kriging. Surf $f_{\text {Obs.TK.M }}$ and Surf Obs.TK.T include additional observations from high-elevation gauges that were not present among the data used to build Surf Obs.A, and Surf $_{\text {Obs.TK.T }}$ also takes into account the amount of estimated undercatch. Kerr (2009) focused primarily on the Pukaki catchment - a much smaller region than that covered by Surf $_{\text {Obs.A }}$ - and Surf Obs.TK.M

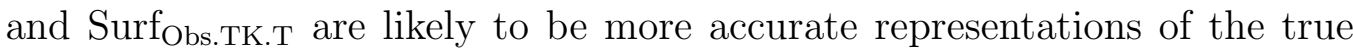
distribution of precipitation in this catchment. However, the overall similarities between Surf Obs.A $_{\text {and the Kerr (2009) surfaces indicate that Surf }}$ Obs.A provides a reasonably good representation of mean annual precipitation in the Pukaki catchment, and suggests that Surf Obs.A may provide a similarly good description of precipitation over the wider region of the central Southern Alps.

\section{Use of precipitation surface within the Parallel Ice Sheet Model}

Another way to assess the quality of a precipitation surface is to examine its performance within an independently developed model of palaeoclimatic processes. Dr Nick Golledge of the ARC currently uses the Parallel Ice Sheet Model to simulate the flow and extent of glaciers in the Southern Alps during the last 40,000 years. The precipitation fed into the glacial model is a single mean annual surface, which is then temporally divided into equal amounts according to the timestep of the model. In early simulations using other 
precipitation surfaces, the simulated extent of glaciers on the southeast side of the Southern Alps did not match geological evidence: the simulated ice did not extend far enough to the south.

Figure 5.11 shows the flux and extent of glacial ice in the central Southern Alps, as simulated by the PISM under possible cooling of $5-6{ }^{\circ} \mathrm{C}$ during the Last Glacial Maximum (LGM). This simulation uses the Surf Obs.A surface of observed precipitation, with the magnitude of the precipitation uniformly reduced by $50 \%$. It was not possible to simulate the mapped ice extent without this reduction in precipitation. A decrease in precipitation at the LGM is consistent with suggestions from the second phase of the Palaeoclimate Modelling Intercomparison Project (PMIP2) (Rojas et al. 2009). The horizontal spatial resolution of Surf Obs.A was set to $1 \mathrm{~km}$, which is the resolution of the PISM grid. The white lines delineate historical glacial extents inferred from geological evidence, provided courtesy of David Barrell from the Institute of Geological and Nuclear Sciences in New Zealand.

In Figure 5.11, the overall extent of simulated ice compares well to geological evidence, though the simlated ice extends a little beyond its geologicallyestimated boundaries in some areas northwest of the Main Divide. On the southern side of the Southern Alps, the tongues of ice stretch south to the estimated extents in the Ohau, Pukaki and Tekapo catchments. This particular image is a snapshot in time rather than a scenario of glacial equilibrium. The domain of the PISM has subsequently been enlarged so as to encompass the whole of the South Island; this precludes the use of Surf Obs.A in further simulations. However, the improved correlation between simulated glacial extents and those inferred from geological evidence suggests that Surf Obs.A provides a more accurate representation of mean annual precipitation in the central Southern Alps than previous surfaces.

\subsubsection{Surfaces of mean daily precipitation, categorised by wind direction}

The profile of mean daily precipitation across the Southern Alps, on all days from 1 January 1971 to 31 December 2000 (Figure 5.3), was split into the 


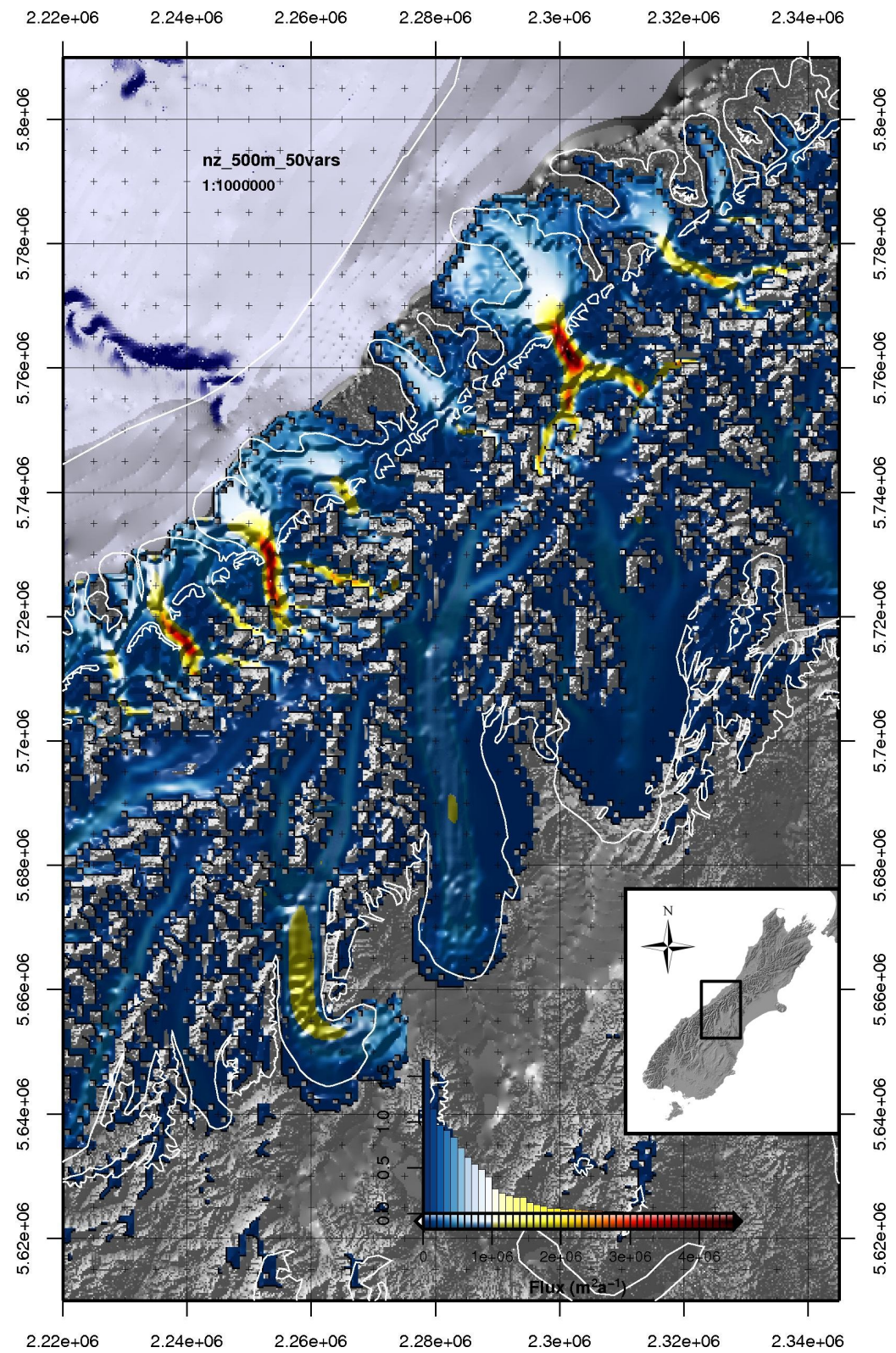

Figure 5.11 Snapshot of the flux $\left(\mathrm{m}^{2} \mathrm{a}^{-1}\right)$ and extent of glacial ice in the central Southern Alps, as simulated by the Parallel Ice Sheet Model under possible LGM cooling of $5-6{ }^{\circ} \mathrm{C}$. The simulation uses the Surf Obs.A surface of observed precipitation, with the magnitude of the precipitation uniformly reduced by $50 \%$. The white lines delineate glacial extents inferred from geological evidence, provided courtesy of David Barrell from the Institute of Geological and Nuclear Sciences in New Zealand. Image produced by Dr Nick Golledge of the Antarctic Research Centre, Victoria University of Wellington, New Zealand. 
5 transects of northeast Hokitika, southwest Hokitika, Franz Josef, Haast and Milford. These 5 daily transects were interpolated, again via a twodimensional tensor-product B-spline, to produce a surface of mean daily pre-

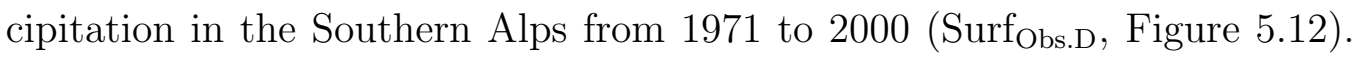

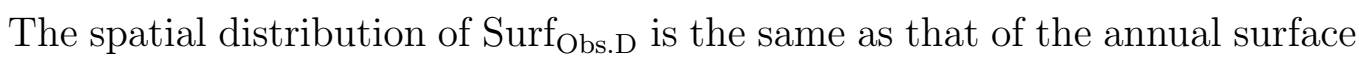
Surf Obs.A (Figure 5.8), but the units of the daily surface are millimetres of precipitation per day $\left(\mathrm{mm} \mathrm{dy}^{-1}\right)$, rather than millimetres of precipitation per annum $\left(\mathrm{mm} \mathrm{a}^{-1}\right)$. The northwest flank of the Southern Alps, northwest of the Pukaki catchment, experiences on average over $25 \mathrm{~mm}$ of precipitation each day. Mean daily precipitation peaks at just under $30 \mathrm{~mm} \mathrm{dy}^{-1}$ on the upper region of the Fritz Range, between the Franz Josef and Fox glaciers.

The wind-classified profiles of mean daily precipitation in the Southern Alps (Figure 5.5) were each split into the 5 transects of northeast Hokitika, southwest Hokitika, Franz Josef, Haast and Milford. These wind-classified daily transects were then interpolated to produce wind-classified surfaces of daily precipitation in the Southern Alps from 1971 to 2000. The surface of mean daily precipitation on northwesterly days (Surf Obs.D.NW) is shown in Figure 5.13.

The spatial pattern of precipitation in the central Southern Alps on northwesterly days is generally similar to the spatial pattern of precipitation on

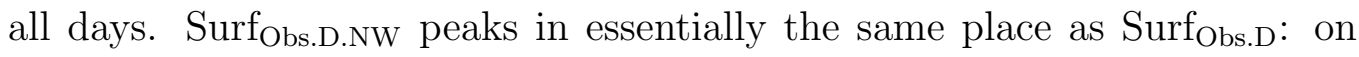
the upper northwest flank of the Southern Alps, near the Franz Josef and Fox glaciers. The similarities are unsurprising: since most of the annual precipitation in the Southern Alps falls on northwesterly days (see Figure 5.5 and Table 5.1), one would expect the annual climatology to be biased toward the northwesterly climatology. However, the magnitude of precipitation on northwesterly days is considerably higher than on all days, with Surf Obs.D.NW peaking at $65 \mathrm{~mm} \mathrm{dy}^{-1}$ on the upper regions of the Franz Josef and Fox glaciers. Another point of difference is that the horizontal precipitation gradient on northwesterly days is much steeper than on all days, as indicated by the tightly grouped $5-\mathrm{mm} \mathrm{dy}^{-1}$ isohyets in Figure 5.13. This is consistent with the increased precipitation one would expect from warmer, moister air encountering the mountains at an angle approximately perpendicular to the 


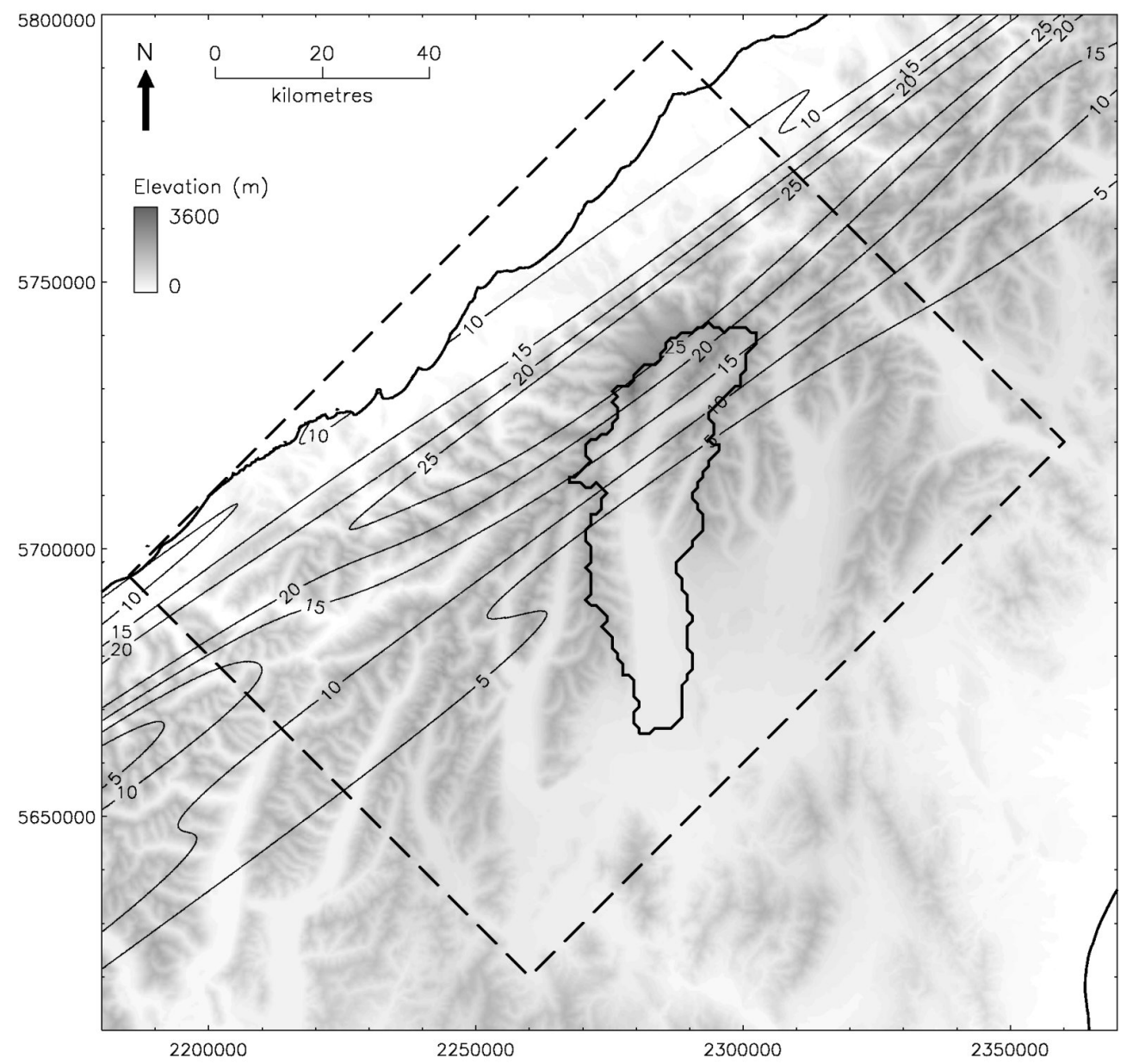

Figure 5.12 Isohyets of interpolated observations of mean daily precipitation $\left(\mathrm{mm} \mathrm{dy}^{-1}\right)$ in the central Southern Alps from 1971 to 2000 (Surf Obs.D). 


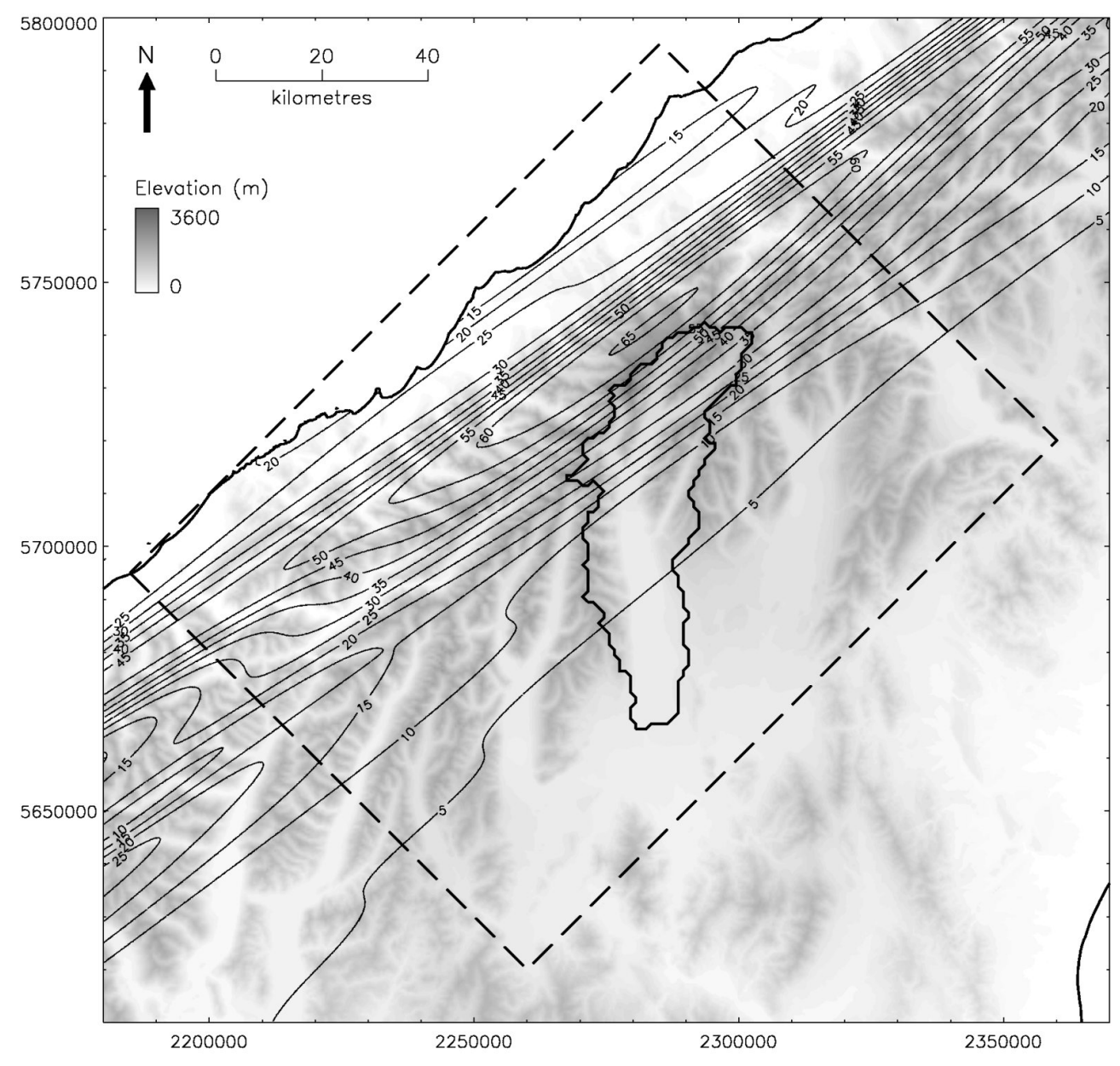

Figure 5.13 Isohyets of interpolated observations of mean daily precipitation $\left(\mathrm{mm} \mathrm{dy}^{-1}\right)$ in the central Southern Alps on northwesterly days from 1971 to 2000 (Surf Obs.D.NW), that is, days on which the mean horizontal wind at $850 \mathrm{hPa} 42.5^{\circ} \mathrm{S}$ $170^{\circ}$ E blew from bearings of $270-360^{\circ}$. 
main orographic axis.

The surface of mean daily precipitation on southwesterly days

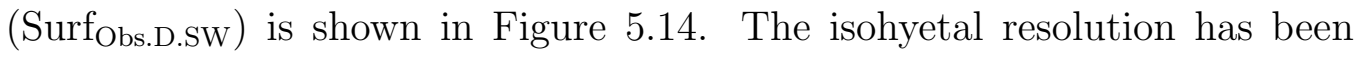
increased to $1 \mathrm{~mm} \mathrm{dy}^{-1}$ in this image, so as to distinguish the shallower precipitation gradients. Much less precipitation falls in the central Southern Alps on southwesterly days than on northwesterly days, which is consistent with cooler, drier air approaching the Southern Alps from a more oblique angle. The spatial pattern of Surfobs.D.sw is generally similar to that of

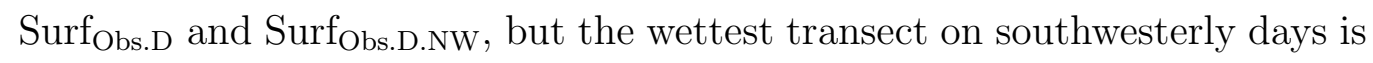
the Milford transect rather than the Franz Josef transect, which reflects the increased exposure of the Fiordland region to southwesterly winds.

The surface of mean daily precipitation on northeasterly days (Surf Obs.D.NE, not pictured) was distorted in the Milford region by lack of data. The overall magnitude of precipitation on northeasterly days was again low relative to that on northwesterly days. Surf Obs.D.NE is generally highest on the northwest flank of the Southern Alps, and, excluding the distorted Milford region, peaks at $13 \mathrm{~mm} \mathrm{dy}^{-1}$ on the northwest edge of the Pukaki catchment. The surface of mean daily precipitation on southeasterly days (Surf Obs.D.SE, not pictured) exhibits the lowest overall rainfall of the 4 precipitation surfaces classified by daily wind direction (northwesterly, southwesterly, northeasterly, southeasterly).

\subsection{Simulation of precipitation from 1971 to 2000}

To have a measure of confidence in downscaled global projections of future precipitation, the HadRM3P regional climate model should first be able to replicate the general spatial pattern of observed rainfall in the Southern Alps in recent decades. Significant differences between the spatial distributions of simulated and observed precipitation may indicate that certain aspects of HadRM3P, such as the model's orography or the parameterisation of meteorological processes, need to be recalibrated. This section examines the 


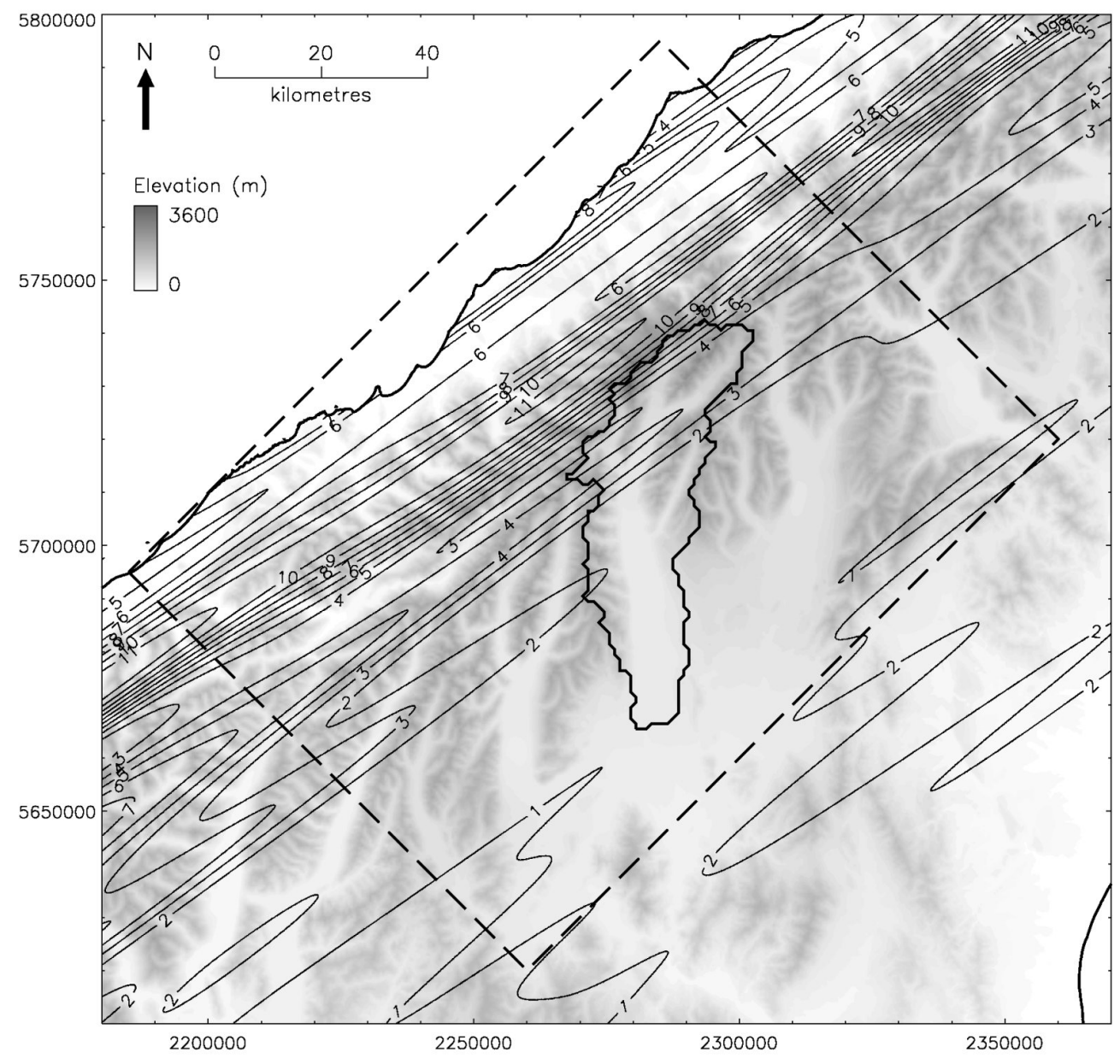

Figure 5.14 Isohyets of interpolated observations of mean daily precipitation $\left(\mathrm{mm} \mathrm{dy}{ }^{-1}\right)$ in the central Southern Alps on southwesterly days from 1971 to 2000 (Surf ${ }_{\text {Obs.D.SW }}$ ), that is, days on which the mean horizontal wind at $850 \mathrm{hPa} 42.5^{\circ} \mathrm{S}$ $170^{\circ} \mathrm{E}$ blew from bearings of $180-270^{\circ}$. 
spatial distribution of mean annual precipitation simulated in the central Southern Alps from 1971 to 2000, both at HadRM3P's original spatial resolution of $30 \mathrm{~km}$, and at downscaled resolutions of $100 \mathrm{~m}$ and $1 \mathrm{~km}$. To evaluate the skill of the downscaling method, the simulated precipitation is compared with observations from individual rain gauges, and also with an independently constructed surface of observed precipitation in the Pukaki catchment.

\subsubsection{Distribution of simulated precipitation}

Figure 5.15 shows mean annual precipitation in the central Southern Alps from 1971 to 2000, as simulated by HadRM3P at 30-km resolution; this surface will hereafter be referred to as $\operatorname{Surf}_{\mathrm{Rcm} \text {.A.Raw }}$. One can see a 'wall' of very high precipitation simulated along the West Coast of the South Island, ranging from $7.9 \mathrm{~m} \mathrm{a}^{-1}$ in the southwest near Haast, up to $9.5 \mathrm{~m} \mathrm{a}^{-1}$ in the northeast over the Whataroa catchment. By comparison with the Surf ${ }_{\text {Obs.A }}$ surface of observed precipitation (Figure 5.8), the amount of simulated precipitation appears to be too high on the edge of the West Coast. As mentioned in Chapter 1, at a spatial resolution of $30 \mathrm{~km}$, HadRM3P cannot accurately represent steep precipitation gradients, such as those that occur in the West Coast region. The excessive simulated precipitation in parts of the West Coast is also likely to be partly due to the representation of New Zealand orography within HadRM3P (Figure 2.5), in which the topography of the West Coast rises abrubtly at its boundary with the Tasman Sea. This sudden rise in the modelled topography is likely to exaggerate both the simulated orographic uplift of air and the consequent precipitation on the edge of the West Coast.

Moving southeastward away from the West Coast, the next NE-SW diagonal line of RCM grid cells generally lies over the most elevated region of the Southern Alps. HadRM3P simulates 5.4-6.8 $\mathrm{m} \mathrm{a}^{-1}$ of precipitation along this line of grid cells. Further to the southeast, in the rain shadow of the Southern Alps, the RCM simulates on average around $0.3-1.3 \mathrm{~m} \mathrm{a}^{-1}$ of precipitation.

The coarse simulated precipitation was then downscaled to a horizontal 


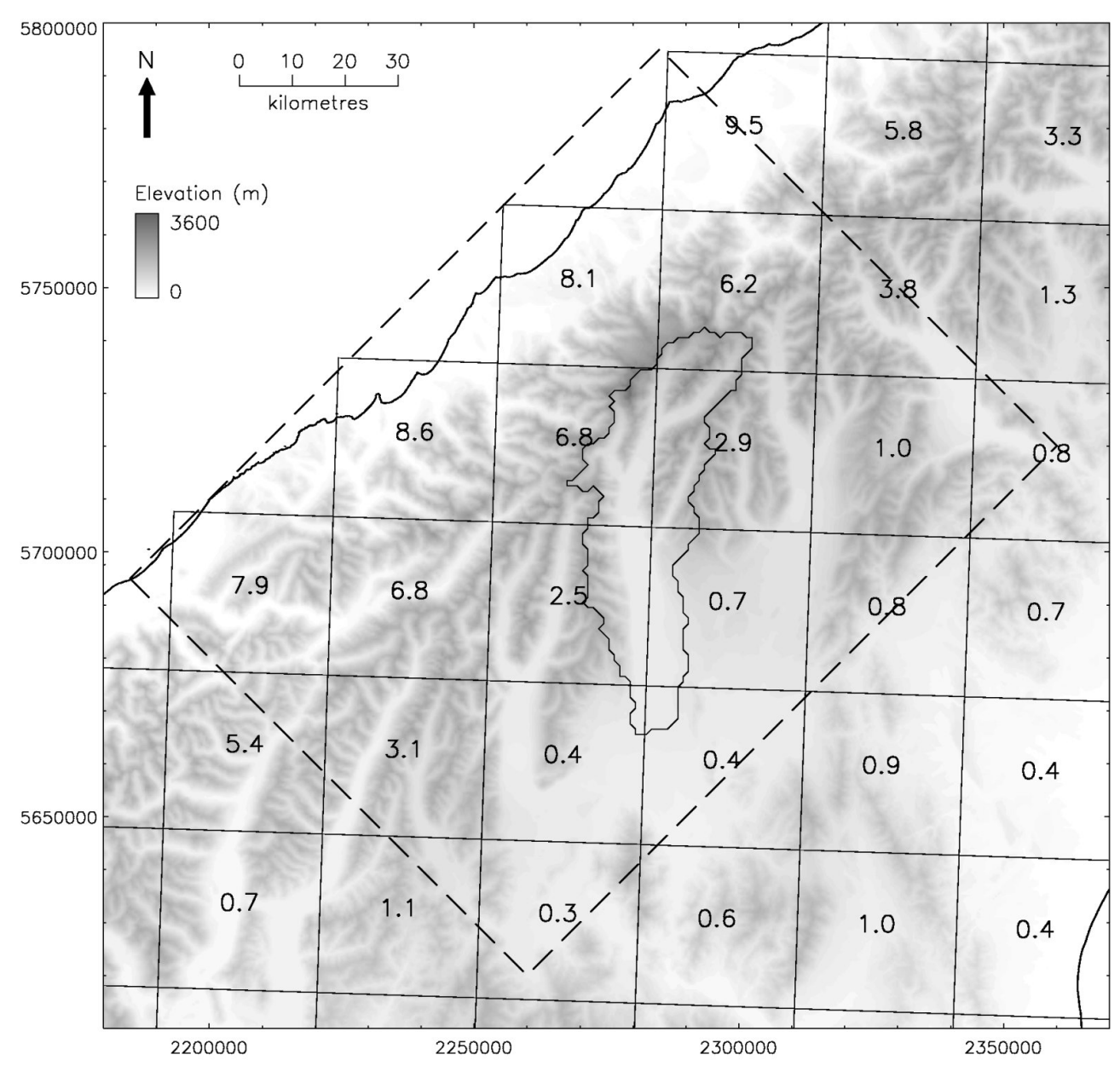

Figure 5.15 Mean annual precipitation $\left(\mathrm{m} \mathrm{a}^{-1}\right)$ in the central Southern Alps from 1971 to 2000 , as simulated by HadRM3P at 30-km resolution (Surf Rcm.A.Raw $_{\text {). Squares }}$ outline the grid cells of the RCM within the land mask of the model. 
spatial resolution of $100 \mathrm{~m}$. The downscaling was performed via a thin-plate

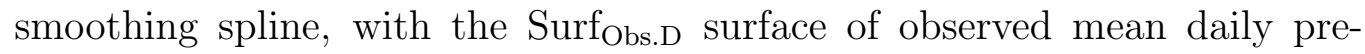
cipitation employed as an independent variable, as described in Section 4.2. Initially, a square-root transformation was applied during the trivariate interpolation, in order to reduce skewness within the frequency distribution of the simulated precipitation. Figure 5.16 shows isohyets of the simulated rainfall after being downscaled in this manner; this surface is hereafter referred to as Surf $_{\text {Rcm.A.DsT. }}$. The downscaled precipitation surface is represented by curved contour lines, and Surf $f_{\text {Rcm.A.DsT }}$ is a far smoother surface than $\operatorname{Surf}_{\text {Rcm.A.Raw }}$.

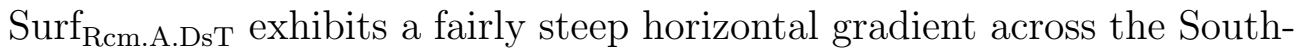
ern Alps. The surface rises from around $5 \mathrm{~m} \mathrm{a}^{-1}$ on the edge of the West Coast to more than $9 \mathrm{~m} \mathrm{a}^{-1}$ on the upper northwest flank of the Southern

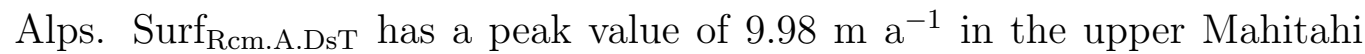
catchment, approximately $40 \mathrm{~km}$ southwest of Aoraki Mount Cook. Moving southeastward across the Pukaki catchment, the surface quickly drops away from around $8 \mathrm{~m} \mathrm{a}^{-1}$ to around $2-3 \mathrm{~m} \mathrm{a}^{-1}$, before falling below $1 \mathrm{~m} \mathrm{a}^{-1}$ on the southeast side of the South Island.

The smoothing parameter $\rho$ of the thin-plate smoothing spline fitted to Surf $\mathrm{Rcm}_{\text {.A.DsT }}$ was $1.56 \times 10^{-5}$, that is, almost zero. $\rho$ was determined by minimising the generalised cross validation (GCV). The spline's signal of 57 is equal to the total number of interpolated RCM grid points. This leads to a signal-to-error ratio of 57:0, which suggests that the surface-fitting procedure has failed to find a genuinely optimum value for $\rho$ (Hutchinson 2000). The low value of $\rho$ results in 'overfitting' of the surface to the grid points (represented by ' $\bullet$ 'symbols in Figure 5.16). The grid points are consequently given too much 'pull', causing concentric circles to form around the grid points in some regions.

Figure 5.17 shows isohyets of precipitation that has been simulated by HadRM3P and then downscaled, without transforming the simulated precipitation during the interpolation process. $\rho$ was again determined by minimising the GCV. This surface is hereafter referred to as $\operatorname{Surf}_{\text {Rcm.A.Ds }}$. Surf Rcm.A.Ds $_{\text {R }}$ is generally quite similar to $\operatorname{Surf}_{\mathrm{Rcm} \text {.A.DsT }}$, but it is more loosely fitted to the RCM grid points, resulting in a smoother surface with little distortion. This 


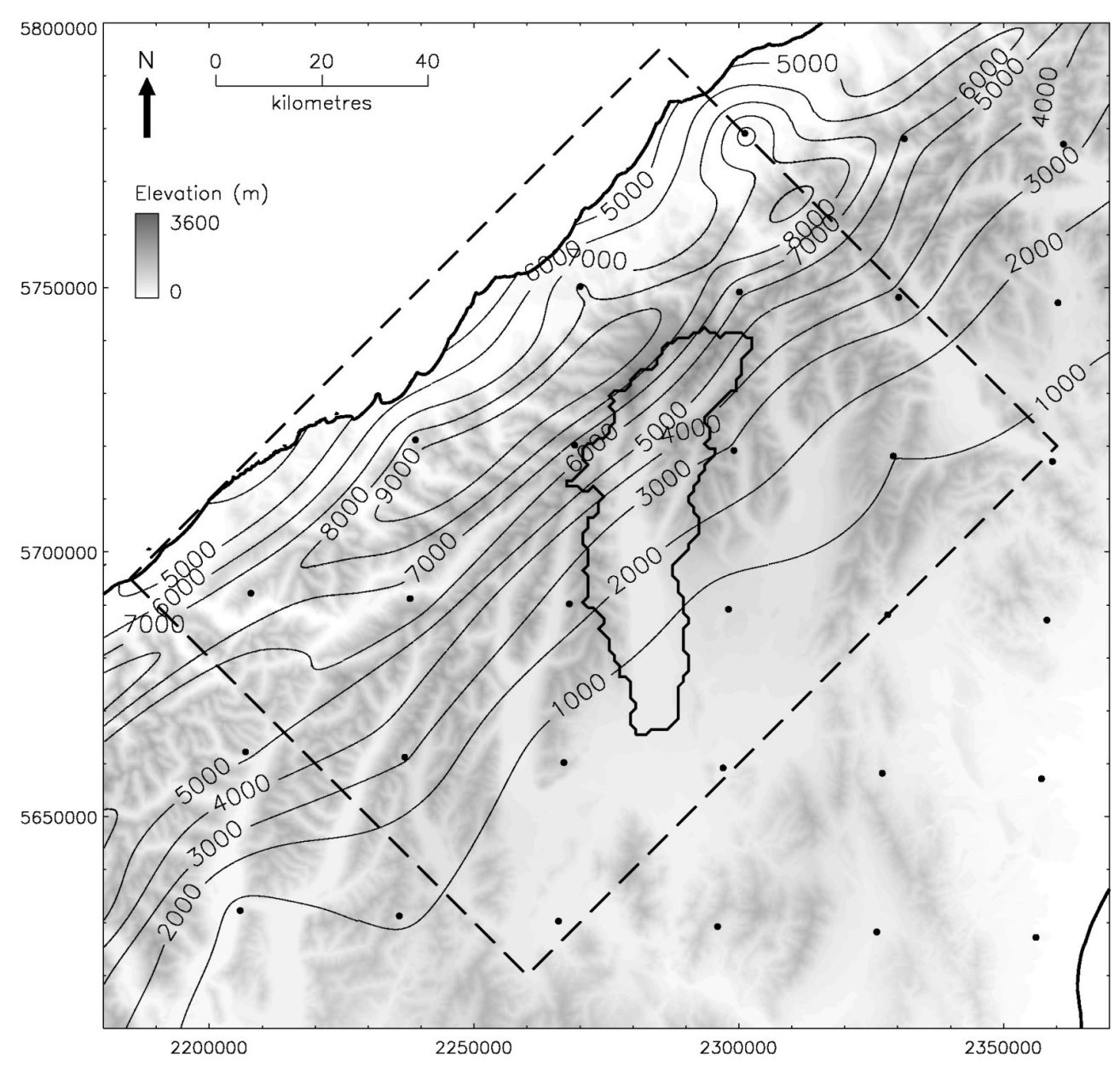

Figure 5.16 Isohyets of mean annual precipitation $\left(\mathrm{mm} \mathrm{a}^{-1}\right)$ the central Southern Alps from 1971 to 2000, simulated by HadRM3P and downscaled using a square-root

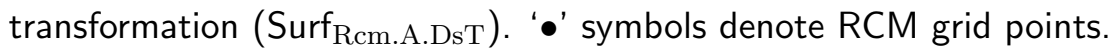




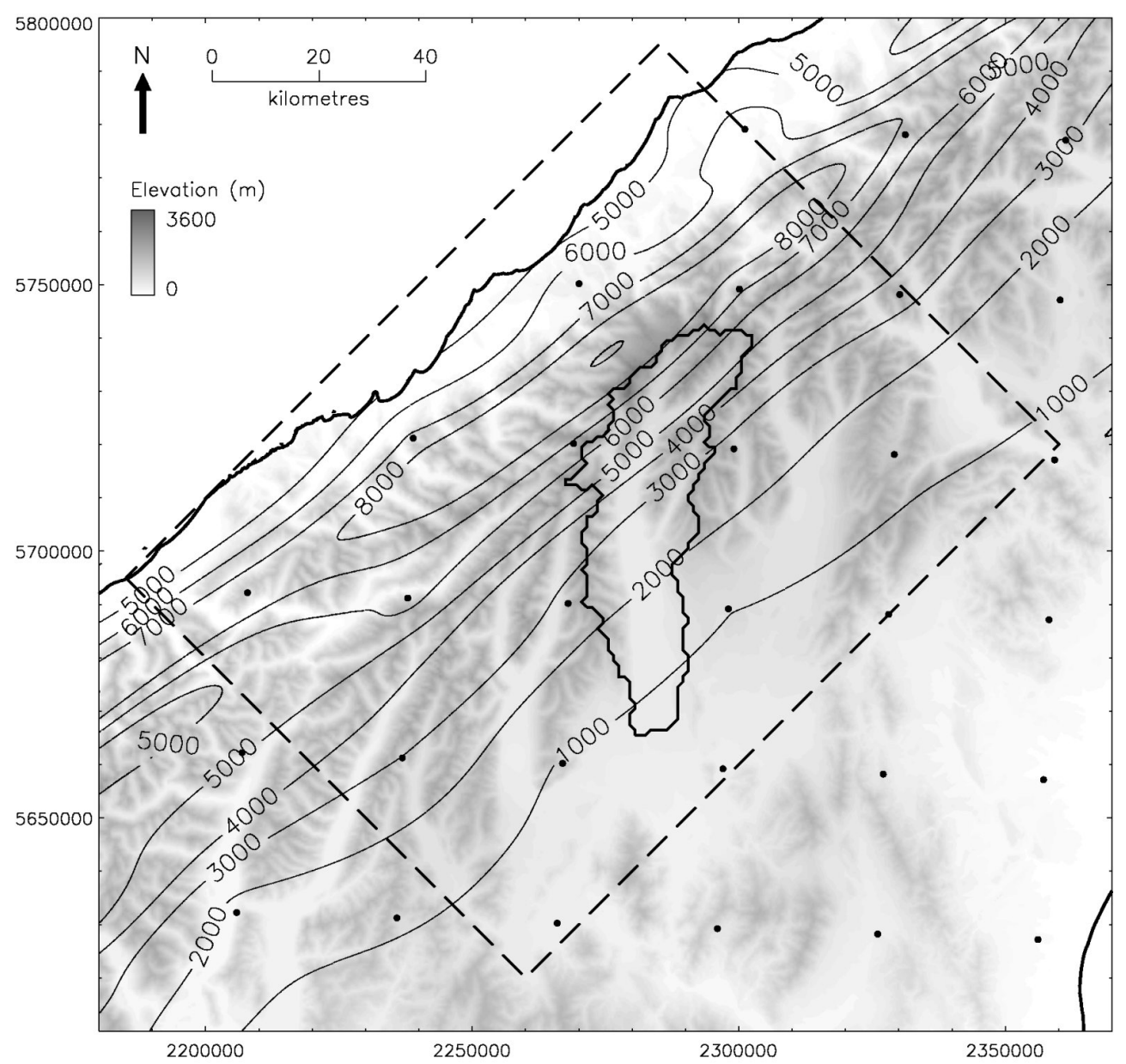

Figure 5.17 Isohyets of mean annual precipitation $\left(\mathrm{mm} \mathrm{a}^{-1}\right)$ in the central Southern Alps from 1971 to 2000, simulated by HadRM3P and downscaled without transforma-

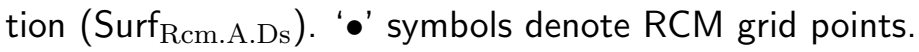


is reflected in the statistics of the spline. Surf $\mathrm{Rcm}$.A.Ds has a much larger value of $\rho$ (831) and a more optimal signal-to-error ratio of 34:23, which approximately equates to 1.5:1. Surf Rcm.A.Ds peaks at $9.02 \mathrm{~m} \mathrm{a}^{-1}$ on the upper Fox Range, around $6 \mathrm{~km}$ northwest of the Pukaki catchment boundary. Moving southeastward across the Pukaki catchment, this surface also drops quickly away from around $8 \mathrm{~m} \mathrm{a}^{-1}$ to around $2-3 \mathrm{~m} \mathrm{a}^{-1}$, though at a slightly lower rate than Surf Rcm.A.DsT. This slight shallowing of the horizontal precipitation

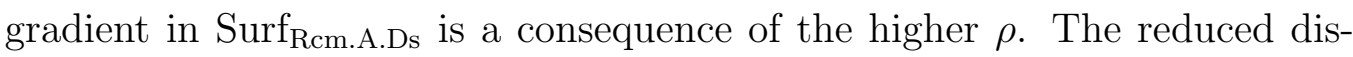
tortion present in Surf $_{\text {Rcm.A.Ds }}$ suggests that this surface describes the annual distribution of precipitation in the central Southern Alps more realistically than Surf $_{\text {Rcm.A.DsT. }}$.

\subsubsection{Comparison of simulated precipitation with observations}

\section{Validation of simulated precipitation against rain gauges}

The simulated and downscaled precipitation was compared with observations in order to assess its accuracy. HadRM3P was initially validated against longterm observations from individual rain gauges. These gauges were all located within the primary study region, and had each recorded at least 15 years of precipitation during the 30-year period from 1971 to 2000. The latter requirement was imposed to allow the mean annual precipitation at each gauge to be estimated with reasonable accuracy, although it did reduce to 17 the number of gauges available at elevations above $500 \mathrm{~m}$ a.s.l. Twenty-eight gauges within the Franz Josef and Haast transects fulfilled both selection criteria; the locations of these gauges are shown in Figure 5.18.

From 1971 to 2000, the average total period of observation at these stations was 24.3 years. The elevations of the stations range from 2 to $1027 \mathrm{~m}$ a.s.l, with a mean elevation of $461 \mathrm{~m}$ a.s.l. None of the long-term gauges are located in the wettest region of the Southern Alps, that is, the upper northwest flank. The wettest validation gauge is at Franz Josef Village (155 m a.s.l.), where an annual average of $5.9 \mathrm{~m}$ of rainfall was recorded during 18.4 years of observation between 1982 and 2000. 


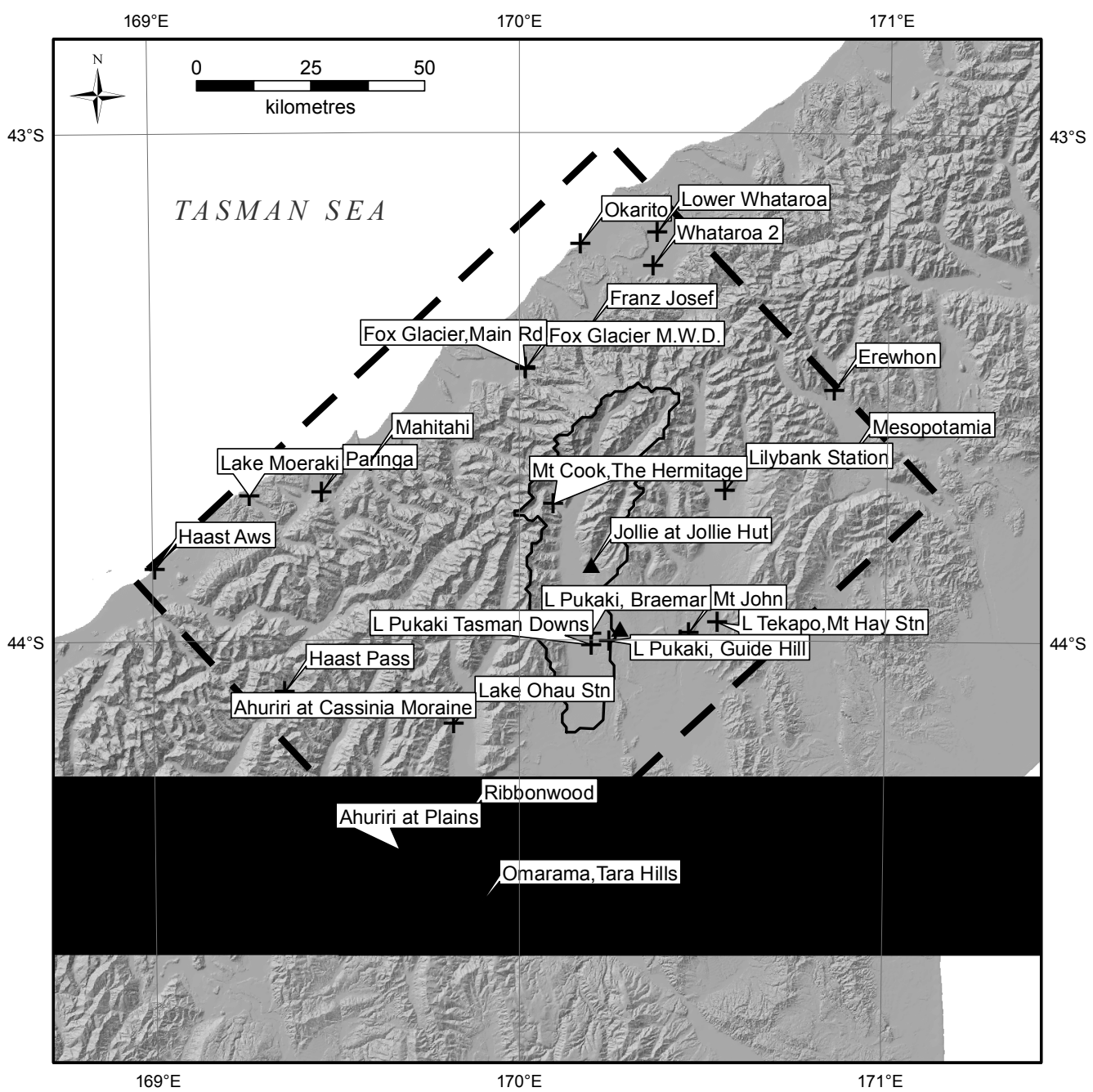

Figure 5.18 Stations in the central Southern Alps used to validate precipitation simulated by HadRM3P from 1971 to 2000 . '十' symbols denote CliDB gauges, 'A' symbols denote WRA gauges. The thick dashed line delineates the primary study region. The Pukaki catchment is outlined by a thin solid line within the primary study region. 
Table 5.2 Mean annual precipitation simulated by HadRM3P, minus observations from rain gauges, from 1971 to 2000 . Bias equates to the mean error of the simulated precipitation, by comparison with observations from 28 long-term rain gauges.

\begin{tabular}{lrrrr}
\hline Surface & $\begin{array}{r}\text { Max. Deficit } \\
\left(\mathrm{m} \mathrm{a}^{-1}\right)\end{array}$ & $\begin{array}{r}\text { Max. Surplus } \\
\left(\mathrm{m} \mathrm{a}^{-1}\right)\end{array}$ & $\begin{array}{r}\text { Bias } \\
\left(\mathrm{m} \mathrm{a}^{-1}\right)\end{array}$ & $\begin{array}{r}\text { RMSE } \\
\left(\mathrm{m} \mathrm{a}^{-1}\right)\end{array}$ \\
\hline Surf Rcm.A.Raw & 1.4 & 5.7 & 1.1 & 2.2 \\
Surf $_{\text {Rcm.A.DsT }}$ & 0.6 & 4.1 & 0.9 & 1.4 \\
Surf $_{\text {Rcm.A.Ds }}$ & 0.4 & 2.5 & 0.8 & 1.0 \\
\hline
\end{tabular}

Comparisons between HadRM3P and each individual validation gauge are presented in Table B.1 of Appendix B. These comparisons are summarised in the three scatter plots shown in Figure 5.19. Also displayed in each of these three plots is the coefficient of determination $\left(r^{2}\right)$, and a dashed line of equal simulated and observed precipitation, that is, the 'target line' for a perfect model. At 30-km resolution (Figure 5.19a), HadRM3P tends to overestimate precipitation at the sites of the validation gauges: $\operatorname{Surf}_{\text {Rcm.A.Raw }}$ has a wet bias (mean error) of $1.1 \mathrm{~m} \mathrm{a}^{-1}$, and a substantial root mean square error (RMSE) of $2.2 \mathrm{~m} \mathrm{a}^{-1}$ (Table 5.2). The greatest surpluses of simulated precipitation are on the West Coast, where the model orography is generally 400-800 $\mathrm{m}$ a.s.l. higher than the actual elevations of the validation sites. The maximum surplus occurs in the lower Whataroa catchment (30 m a.s.l.): here Surf $_{\text {Rcm.A.Raw }}$ Overestimates rainfall by $5.7 \mathrm{~m} \mathrm{a}^{-1}$. HadRM3P performs better in the rain shadow southeast of the Southern Alps, where both modelled and observed precipitation are generally less than $3 \mathrm{~m} \mathrm{a}^{-1}$. The mismatch between the model elevations and those of the validation sites is less pronounced in this region, and simulated precipitation is within $0.5 \mathrm{~m} \mathrm{a}^{-1}$ of observations.

Less excess precipitation on the West Coast is present in $\operatorname{Surf}_{\text {Rcm.A.DsT }}$, as can be seen by the improved correlation between simulated and observed precipitation in Figure 5.19b. The trivariate interpolation introduces a smooth 'downhill' gradient from the upper northwestern flank of the Southern Alps, northwest to the Tasman Sea. This results in less surplus rainfall on the West 


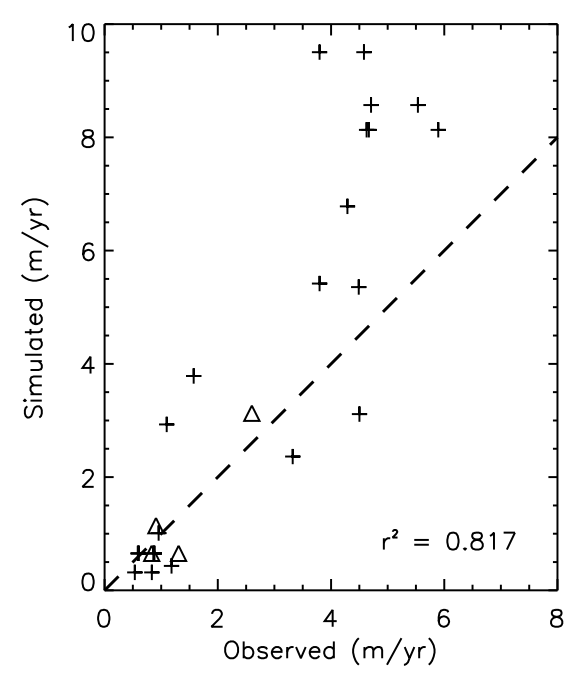

(a) Surf Rcm.A.Raw

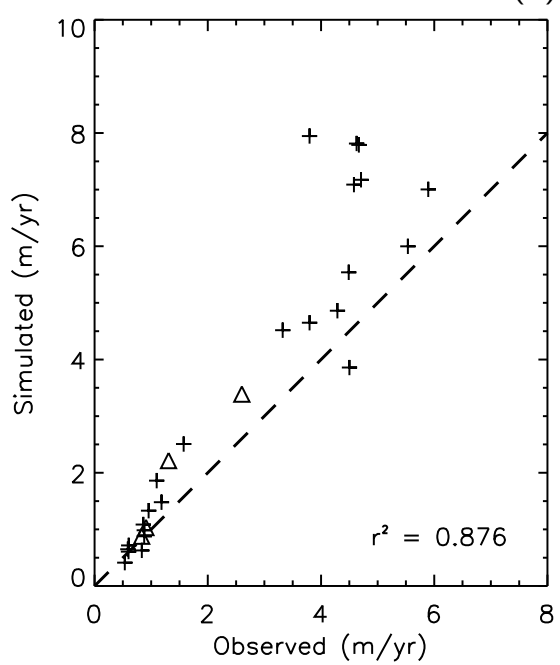

(b) Surf Rcm.A.DsT

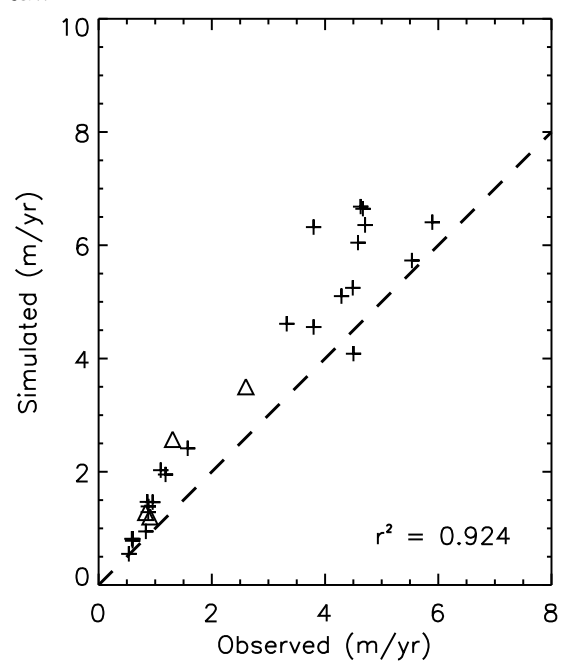

(c) Surf Rcm.A.Ds

Figure 5.19 Mean annual precipitation $\left(\mathrm{m} \mathrm{a}^{-1}\right)$ simulated by HadRM3P versus observations from rain gauges from 1971 to 2000 . ' + ' symbols denote CliDB gauges, ' $\triangle$ ' symbols denote WRA gauges. The dashed line indicates a perfect model, where simulated precipitation equals observed precipitation. Downscaling has improved the match between simulated and observed precipitation, as indicated by the higher coefficients of determination $\left(r^{2}\right)$ in (b) and (c). 
Coast and a lower RMSE of $1.4 \mathrm{~m} \mathrm{a}^{-1}$ in Surf Rcm.A.DsT. However, a wet bias of $0.9 \mathrm{~m} \mathrm{a}^{-1}$ still exists. The low smoothing parameter $\rho$ for $\operatorname{Surf}_{\text {Rcm.A.DsT }}$ causes the surface to be tightly fitted to the excessive precipitation simulated at the HadRM3P grid points on the West Coast. The maximum surplus of simulated precipitation, $4.1 \mathrm{~m} \mathrm{a}^{-1}$, is still in the lower Whataroa catchment.

The surplus rainfall is further reduced in Surf $\mathrm{Rcm}_{\text {R.As }}$ (Figure 5.19c), which has the highest $r^{2}(0.924)$ of the three surfaces, and a $53 \%$ reduction in RMSE to $1.0 \mathrm{~m} \mathrm{a}^{-1}$. This surface is not so tightly fitted to the excessive precipitation simulated at the RCM grid points on the West Coast, and the maximum surplus precipitation, again at Whataroa, decreases subtantially to $2.5 \mathrm{~m} \mathrm{a}^{-1}$. The wet bias also drops slightly to $0.8 \mathrm{~m} \mathrm{a}^{-1}$. The maximum deficit of simulated precipitation falls from $1.4 \mathrm{~m} \mathrm{a}^{-1}$ in $\operatorname{Surf}_{\text {Rcm.A.Raw }}$

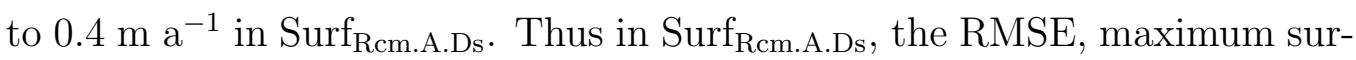
plus and maximum deficit of simulated precipitation are all at least $50 \%$ lower than in Surf $_{\text {Rcm.A.Raw }}$. By comparison with long-term observations from these 28 rain gauges in the Southern Alps, the downscaled surface $\operatorname{Surf}_{\text {Rcm.A.Ds }}$ is a significant improvement upon the precipitation simulated by HadRM3P at its original spatial resolution of $30 \mathrm{~km}$.

\section{Comparison between simulated and observed precipitation within the Pukaki catchment}

In order to further assess the accuracy of the precipitation simulated by HadRM3P, the simulated and downscaled precipitation surfaces were validated against a surface of estimated 'true' precipitation in the Pukaki catchment (Surf Obs.TK.T, Figure 3.6b), which was independently produced by Kerr (2009). Surf Obs.TK.T takes into account the estimated undercatch at rain gauges. The simulated and observed precipitation in the Pukaki catchment were compared at the 1-km resolution of the precipitation surfaces provided by Kerr (2010).

In Figure 5.20a, which compares the raw RCM (Surf Rcm.A.Raw) to Surf $_{\text {Obs.TK.T }}$, the differenced precipitation surface contains sharp steps at the edges of the $30-\mathrm{km}$ grid cells of HadRM3P. Within each RCM grid cell, the simulated precipitation tends toward a deficit in the northwest, and a surplus 


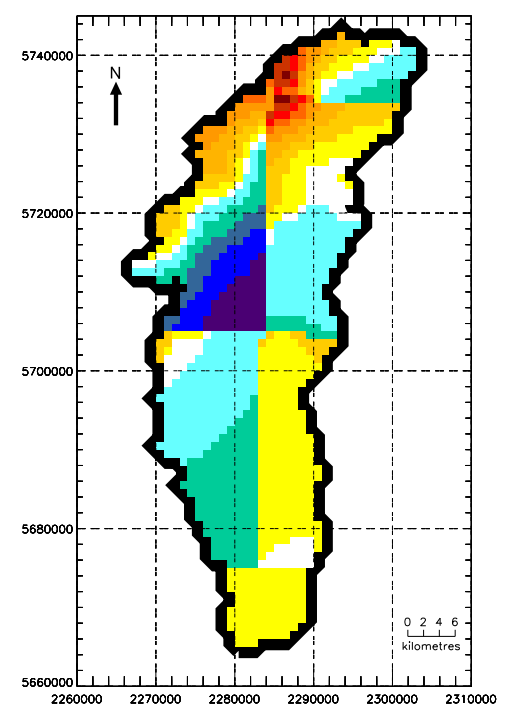

(a) Surf Rcm.A.Raw $_{\text {Rew }}$

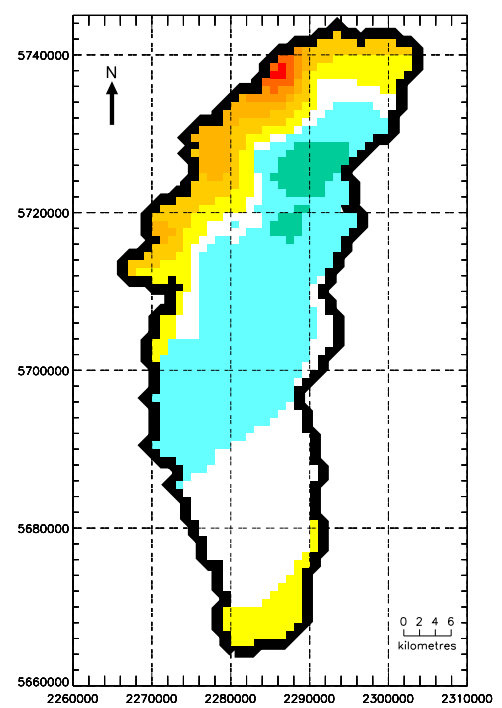

(b) Surf Rcm.A.DsT

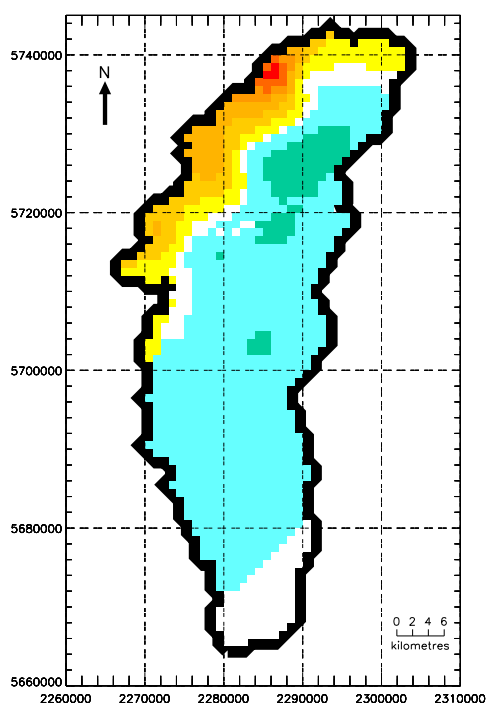

(c) Surf Rcm.A.Ds

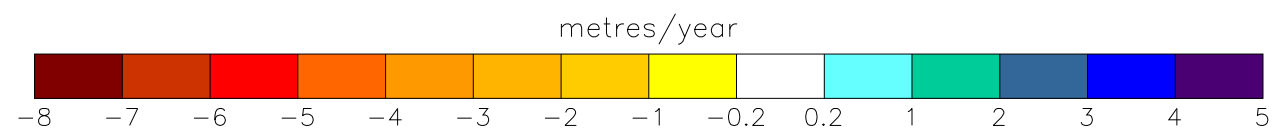

Figure 5.20 Mean annual precipitation $\left(\mathrm{m} \mathrm{a}^{-1}\right)$ simulated by HadRM3P, minus

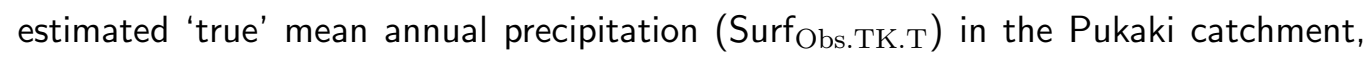
from 1971 to 2000. 'True' mean annual precipitation was estimated by Kerr (2009). Cool colours indicate a wet bias in HadRM3P; warm colours indicate a dry bias. 
in the southeast. This is indicative of the uniform rainfall simulated within each 30-km grid cell of the model, which cannot accurately represent the observed horizontal precipitation gradient at smaller spatial scales.

There is a deficit of simulated precipitation in the northwest of the Pukaki catchment, near its boundary with the Main Divide, where the topography is most elevated. HadRM3P underestimates precipitation by up to $7.6 \mathrm{~m} \mathrm{a}^{-1}$ in this region. In the middle of the catchment, HadRM3P overestimates precipitation by up to $5.0 \mathrm{~m} \mathrm{a}^{-1}$.

Figure 5.20b compares Surf Obs.TK.T with precipitation that has been simulated and downscaled using a square-root transformation ( $\operatorname{Surf}_{\mathrm{Rcm}}$.A.DsT $)$. This differenced surface is much smoother than Figure 5.20a, with most of Surf $_{\text {Rcm.A.DsT }}$ lying within $1.0 \mathrm{~m} \mathrm{a}^{-1}$ of the estimated 'true' mean annual precipitation. The downscaled surface still evidently underestimates precipitation in the northwest of the catchment, though the maximum deficit has dropped to $5.5 \mathrm{~m} \mathrm{a}^{-1}$. The precipitation deficit in this area of the downscaled surface is due to two main factors. Firstly, with respect to Surf Obs.TK.T (Figure 3.6b), HadRM3P simulates a relatively low amount of precipitation in the northwest catchment at its original $30-\mathrm{km}$ resolution (Figure 5.15). The second factor relates to the third independent variable of the trivariate interpolation used in the downscaling process, namely the Surf Obs.D $_{\text {sur- }}$ face of observed mean daily rainfall (Figure 5.12). The horizontal precipitation gradient of Surf Obs.D in the northwest Pukaki catchment is not as steep as that of Surf Obs.TK.T, as described earlier in Section 5.3.1. This contributes to the relative shallowness of the gradient in the downscaled surface Surf $_{\text {Rcm.A.DsT }}$, with respect to Surf Obs.TK.T. The maximum surplus of precipitation in Surf $_{\text {Rcm.A.DsT }}$ lies over the southern Liebig Range in the northeast part of the catchment, where precipitation is overestimated by $1.8 \mathrm{~m} \mathrm{a}^{-1}$.

Figure 5.20c shows the differences between Surf Obs.TK.T $_{\text {and }}$ the precipitation that was simulated and downscaled without any transformation of the dependent variable $\left(\operatorname{Surf}_{\mathrm{Rcm}}\right.$.A.Ds $)$. The general pattern of differences is similar that in Figure 5.20b, though a small wet bias of $0.2-1.0 \mathrm{~m} \mathrm{a}^{-1}$ is present throughout most of the southern part of the catchment. This wet bias is reflective of the shallower precipitation gradient in $\operatorname{Surf}_{\mathrm{Rcm} \text {.A.Ds }}-\mathrm{a}$ 
Table 5.3 Maximum deficit, maximum surplus, catchment bias and RMSE of mean annual precipitation simulated by HadRM3P in the Pukaki catchment from 1971 to 2000, when validated against estimated 'true' mean annual precipitation (Surf Obs.TK.T). 'True' mean annual precipitation in the Pukaki catchment was estimated by Kerr (2009). The formula used to calculate the catchment bias is shown in Equation 5.1.

\begin{tabular}{lrrrr}
\hline Surface & $\begin{array}{r}\text { Max. Deficit } \\
\left(\mathrm{m} \mathrm{a}^{-1}\right)\end{array}$ & $\begin{array}{r}\text { Max. Surplus } \\
\left(\mathrm{m} \mathrm{a}^{-1}\right)\end{array}$ & $\begin{array}{r}\text { Catchment Bias } \\
(\%)\end{array}$ & $\begin{array}{r}\text { RMSE } \\
\left(\mathrm{m} \mathrm{a}^{-1}\right)\end{array}$ \\
\hline Surf Rcm.A.Raw & 7.6 & 5.0 & +3.6 & 1.8 \\
Surf & 5.5 & 1.8 & -2.0 & 1.0 \\
Surf & & 2.0 & +5.3 & 1.0 \\
\hline
\end{tabular}

consequence of the smoother interpolation of the simulated precipitation.

The overall catchment bias of each of the three RCM surfaces was calculated as

$$
\text { Catchment Bias }=\frac{\sum\left(\operatorname{Surf}_{\mathrm{Rcm}}-\operatorname{Surf}_{\mathrm{TK} . \mathrm{T}}\right)}{\sum \operatorname{Surf}_{\mathrm{TK} . \mathrm{T}}}
$$

where $\left(\operatorname{Surf}_{\text {Rcm }}-\operatorname{Surf}_{\text {TK.T }}\right)$ is the difference between the simulated and estimated 'true' mean annual precipitation in each of the 1-km grid cells throughout the Pukaki catchment, and $\sum \operatorname{Surf}_{\mathrm{TK} . \mathrm{T}}$ is the sum of the estimated 'true' mean annual precipitation across all of the $1-\mathrm{km}$ grid cells throughout the catchment. Table 5.3 summarises the comparison of the simulated precipitation to observations in the Pukaki catchment. Surf $_{\text {Rcm.A.Raw }}$ has on average a wet bias of $3.6 \%$, while $\operatorname{Surf}_{\text {Rcm.A.DsT }}$ has a small dry bias of $2.0 \%$. Surf $f_{\text {Rcm.A.Ds }}$ has an overall wet bias of $5.3 \%$, which is indicative of the relatively small (generally $<1.0 \mathrm{~m} \mathrm{a}^{-1}$ ) wet bias of this surface in much of the catchment.

Across all of the 1-km grid cells within the Pukaki catchment, the RMSE of the simulated precipitation drops from $1.8 \mathrm{~m} \mathrm{a}^{-1}$ in Surf $\operatorname{Rcm}_{\text {R.A.Raw }}$ to $1.0 \mathrm{~m} \mathrm{a}^{-1}$ in both $\operatorname{Surf}_{\text {Rcm.A.DsT }}$ and $\operatorname{Surf}_{\text {Rcm.A.Ds }}$. This equates to RMSE reductions of $48 \%$ in $\operatorname{Surf}_{\mathrm{Rcm} . A . D s T}$ and $45 \%$ in $\operatorname{Surf}_{\mathrm{Rcm} . A . D s}$. (The reductions in RMSE are $3 \%$ different from one another when the calculations are performed to several significant figures.) With their higher spatial resolu- 
tion, the downscaled surfaces can more accurately represent the observed fall in precipitation associated with increasing distance from the Main Divide. These reductions in the RMSE represent a significant improvement in the accuracy of mean annual precipitation simulated by HadRM3P in the Pukaki catchment.

\subsection{Case study: precipitation on 5 November 1994}

The nesting of HadRM3P within reanalyses of historical atmospheric conditions allows past individual weather events to be recreated within the domain of the model, albeit at the model's relatively coarse resolution of $30 \mathrm{~km}$. This section contains an analysis of precipitation simulated during an intense northwesterly storm in November 1994, and compare the simulated precipitation to observations from rain gauges. Comparisons are made at the original $30-\mathrm{km}$ resolution of the $\mathrm{RCM}$, and at $100-\mathrm{m}$ resolution after the simulated precipitation has been downscaled via a trivariate thin-plate smoothing spline.

\subsubsection{Observed weather during the Guy Fawkes storm}

The 'Guy Fawkes storm' was an extended northwesterly storm from 4 to 9 November 1994, during which more than $1300 \mathrm{~mm}$ of rain was recorded in some areas near the Main Divide of the Southern Alps (Sinclair et al. 1997). The focus of the present analysis is the second day of the storm: 5 November UTC. Figure 5.21 shows mean sea level pressure and 850-hPa isotachs on 5 and 6 November 1994. An anticyclone to the east of New Zealand slowed the movement of a trough across the Tasman Sea, bringing a warm, moist northwesterly flow to the country. Blocking of low level air by the Southern Alps led to northeasterly barrier winds on the West Coast of the South Island from 4 to 6 November, but synoptic-scale airflow further upstream of the Southern Alps was from the northwestern quadrant throughout the period from 4 to 8 November. On 5 November, at the $42.5^{\circ} \mathrm{S} 170^{\circ} \mathrm{E}$ grid point of 

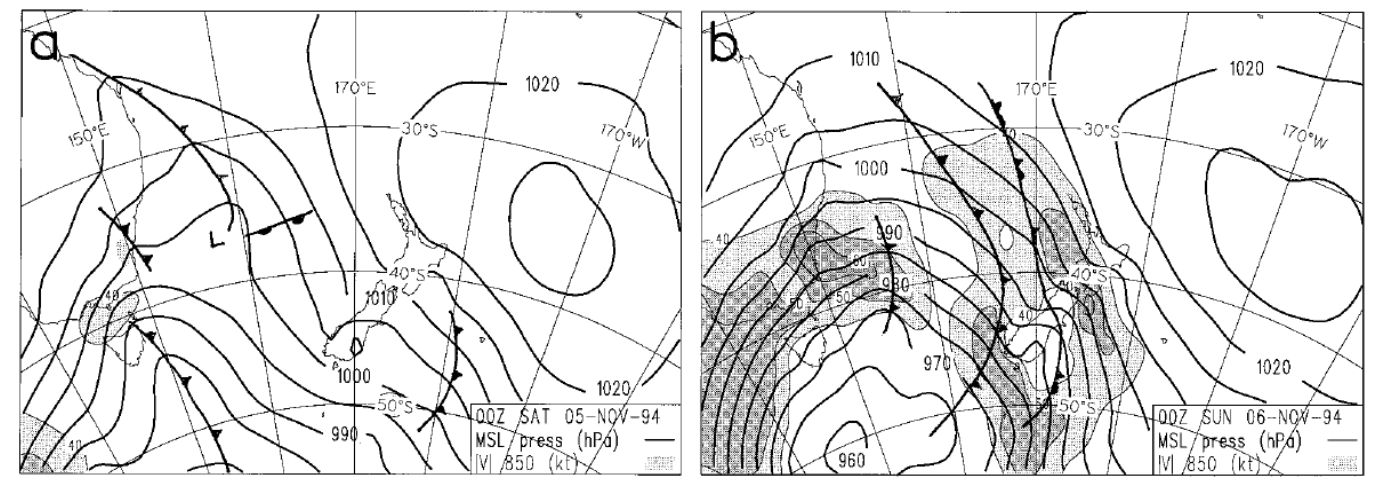

Figure 5.21 ECMWF mean sea level pressure (solid, every $5 \mathrm{hPa}$ ) and $850-\mathrm{hPa}$ isotachs, with values greater than $40 \mathrm{kt}$ and $50 \mathrm{kt}$ shaded $\left(1 \mathrm{kt}=0.514 \mathrm{~m} \mathrm{~s}^{-1}\right)$, at 00:00 5 Nov 1994 (left) and 00:00 6 Nov 1994 (right) UTC. Maps reproduced from Sinclair et al. (1997), including frontal positions from analyses by the Meteorological Service of New Zealand.

NCEP/NCAR Reanalysis 1, the mean horizontal wind velocity at $850 \mathrm{hPa}$ was $19 \mathrm{~m} \mathrm{~s}^{-1}$ from an approximately northwesterly bearing of $331^{\circ}$. An occluded front encountered the South Island on 5 November, and strong winds and heavy rainfall were recorded on the West Coast and in the Southern Alps. Sinclair et al. (1997) showed that the profile of observed precipitation moved southeastward across the mountains on 6 and 7 November, causing substantial spillover in catchments east of the Main Divide. This movement was associated with a reduction in static stability and an increase in the wind speed normal to the axis of the mountains, particularly above the freezing level.

\subsubsection{Simulated precipitation on 5 November 1994}

\section{Precipitation simulated at 30-km resolution on 5 November 1994}

The distribution of precipitation simulated by HadRM3P on 5 November 1994 UTC, at the original 30-km resolution of the model, is shown in Figure 5.22. This surface is hereafter referred to as Surf Rcm.D.Raw . Heavy orographic rainfall of 160-210 $\mathrm{mm}$ is simulated along the West Coast, with $210 \mathrm{~mm}$ falling in the Whataroa catchment in the northern corner of the primary study region. 
Moving inland from the West Coast and on to the highly elevated spine of the Southern Alps (see Figure 2.5 for topographic elevations of the HadRM3P grid cells), rainfall ranges from $134 \mathrm{~mm}$ in the southwest up to $227 \mathrm{~mm}$ in the northeast. Some precipitation spills over the Main Divide into southeast catchments, though the magnitude of rainfall suddenly drops further to the southeast, from $71-80 \mathrm{~mm}$ in the middle of the Pukaki catchment down to 0-1 mm over the Canterbury plains. The heaviest orographic rainfall is thus generally confined to the region upwind of and over the mountains, which is reasonably consistent with the observed blocking of low-level air northwest of the Main Divide during the first two days of the storm.

The simulated precipitation was compared with observations from rain gauges, in order to assess its accuracy. Only WRA gauges were used to validate the short-term precipitation, owing to the 4-hour difference between the observations periods of the CliDB gauges (20:00 to 20:00 UTC) and the days of the HadRM3P simulation (00:00 to 00:00 UTC). Nineteen WRA gauges recorded precipitation within the primary study region on 5 November 1994 (Figure 5.23). These gauges were generally situated at higher and more mountainous locations than the gauges used to validate the 30-year simulation. The topographic elevation of the short-term validation stations ranged from $58 \mathrm{~m}$ a.s.l. to $1509 \mathrm{~m}$ a.s.l., with a mean elevation of $728 \mathrm{~m}$ a.s.l.

At the location of each of the 19 validation gauges, the precipitation simulated by HadRM3P was compared to the observed precipitation. The result of each of these individual comparisons is presented in Table B.2 of Appendix B. A summary of these comparisons is presented in Table 5.4, which shows the maximum deficit, maximum surplus, bias and RMSE across all of the 19 locations. At 30-km resolution, the simulated precipitation differs greatly from observations at some of validation gauges. Surf Rcm.D.Raw overestimates precipitation by $199 \mathrm{~mm}$ at Panoroma Ridge (1509 m a.s.l.) in the upper Godley catchment. However, the observed $11 \mathrm{~mm}$ of rainfall at Panoroma Ridge looks suspiciously low compared to the $219 \mathrm{~mm}$ observed at Eade Hut (975 m a.s.l.), just $4 \mathrm{~km}$ to the south. Across all of the 19 validation gauges, Surf Rcm.D.Raw has a substantial RMSE of $78 \mathrm{~mm}$ and a wet bias of $29 \mathrm{~mm}$. The RCM generally appears to be too wet on the western 


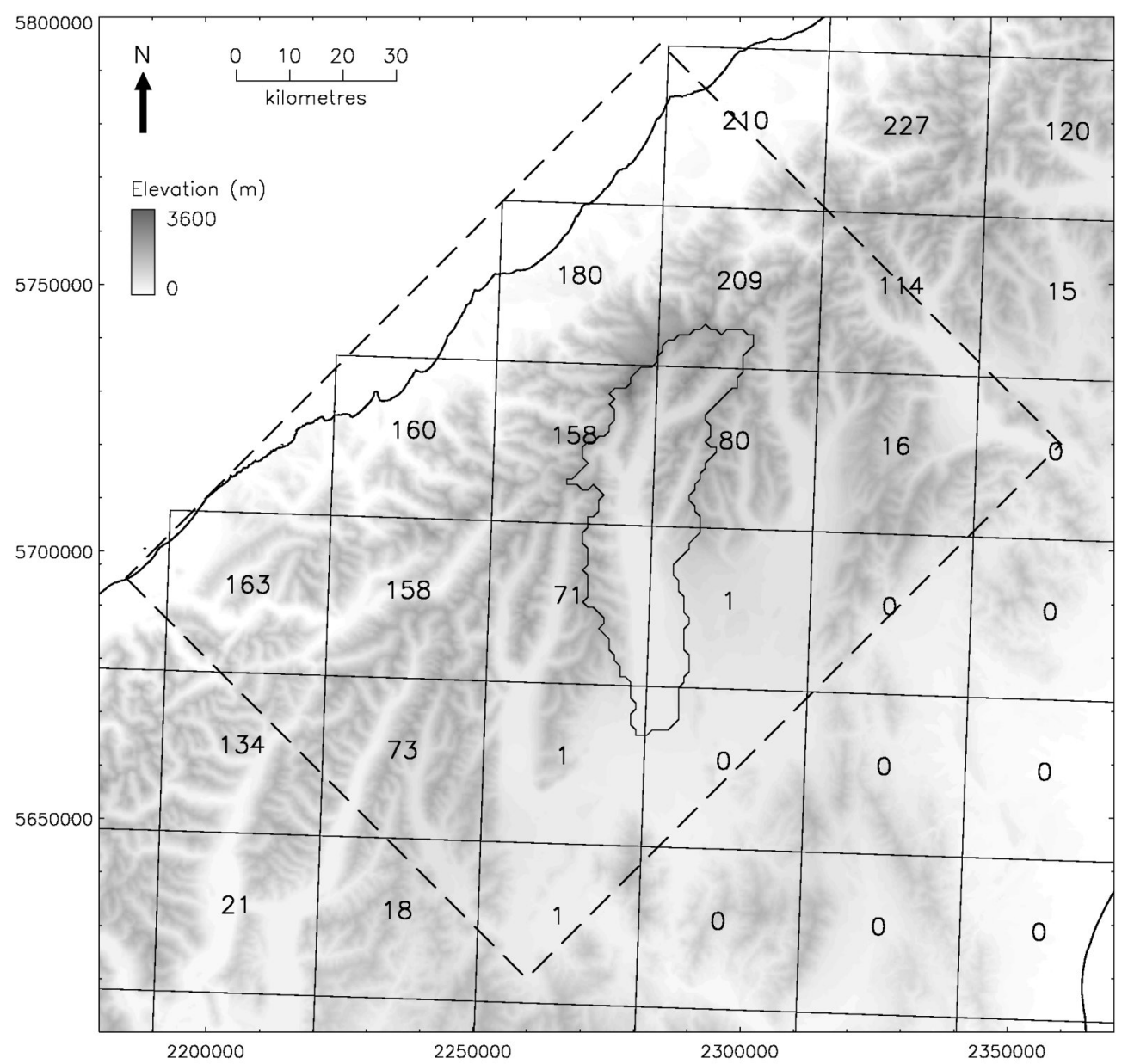

Figure 5.22 Precipitation $(\mathrm{mm})$ in the central Southern Alps on 5 Nov 1994 UTC, as simulated by HadRM3P at $30-\mathrm{km}$ resolution (Surf $\mathrm{Rcm}_{\text {.D.Raw }}$ ). Squares outline the grid cells of the RCM within the land mask of the model. 


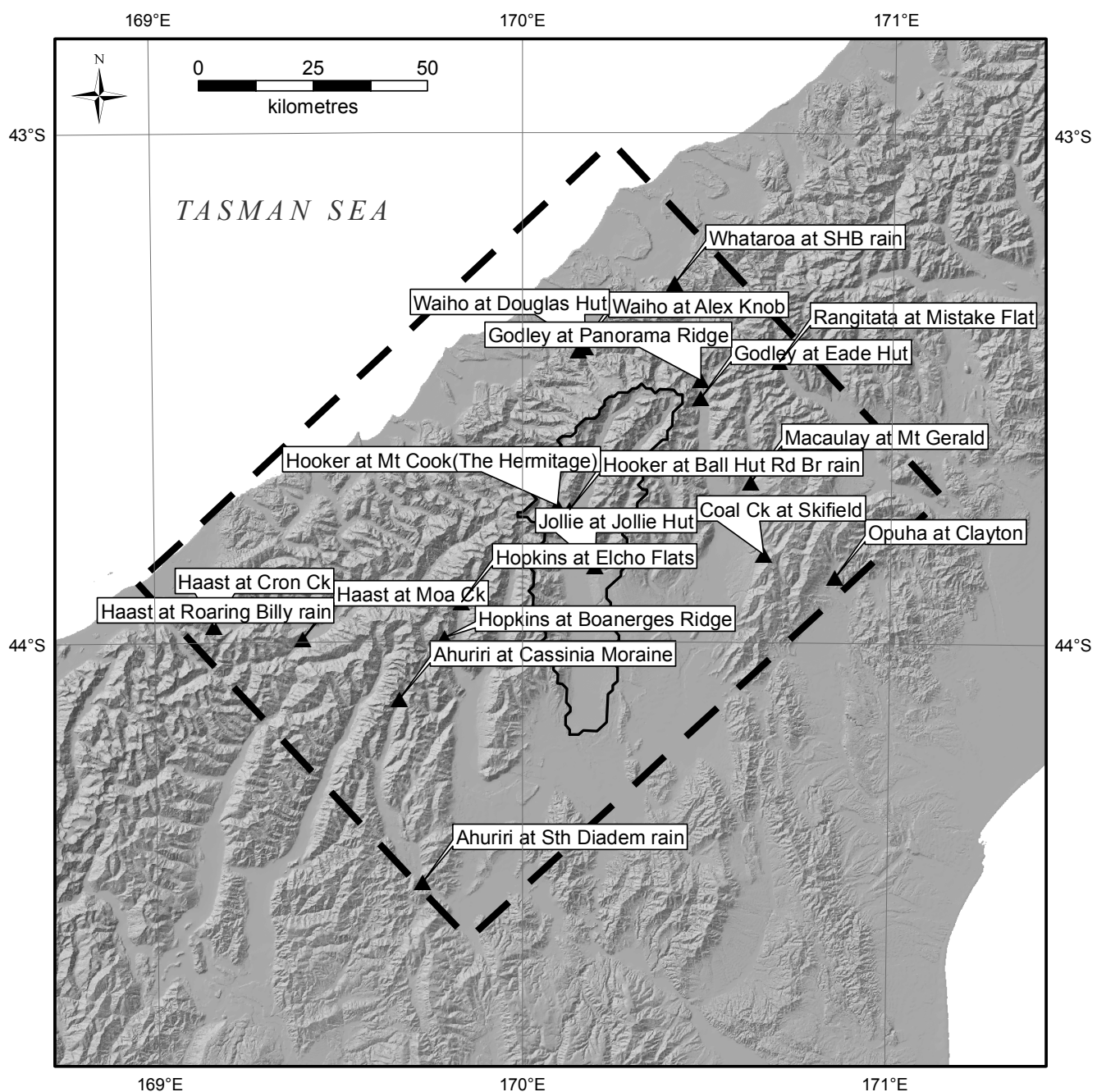

Figure 5.23 Stations in the central Southern Alps used to validate precipitation simulated by HadRM3P on 5 Nov 1994. '৯' symbols denote WRA gauges. 
Table 5.4 HadRM3P-simulated precipitation minus observations from rain gauges on 5 Nov 1994 UTC. Comparisons were performed at the location of each of the 19 gauges shown in Figure 5.23; the maximum deficit, maximum surplus, bias and RMSE of the simulated precipitation across all of these 19 locations are presented in the table below. Bias equates to the mean error of the simulated precipitation, when validated against the 19 rain gauges.

\begin{tabular}{lrrrr}
\hline Surface & $\begin{array}{r}\text { Max. Deficit } \\
(\mathrm{mm})\end{array}$ & $\begin{array}{r}\text { Max. Surplus } \\
(\mathrm{mm})\end{array}$ & $\begin{array}{r}\text { Bias } \\
(\mathrm{mm})\end{array}$ & $\begin{array}{r}\text { RMSE } \\
(\mathrm{mm})\end{array}$ \\
\hline Surf $_{\text {Rcm.D.Raw }}$ & 106 & 199 & 29 & 78 \\
Surf $_{\text {Rcm.D.Ds }}$ & 118 & 141 & 6 & 65 \\
Surf $_{\text {Rcm.D.Ds.Nw }}$ & 109 & 143 & 9 & 65 \\
\hline
\end{tabular}

flank of the Southern Alps, and too dry to the east of the Main Divide. This may be due to excessively high topography in this version of the RCM, which could exaggerate both orographic precipitation and lee-side drying. A new orographic model of New Zealand has been since been incorporated into HadRM3P. The topographic elevations of both the West Coast and the Southern Alps are significantly reduced in the updated version.

\section{Downscaled precipitation on 5 November 1994}

The precipitation simulated by HadRM3P on 5 November 1994 was first downscaled by using the Surf Obs.D surface of observed mean daily rainfall as the third independent variable of the trivariate interpolation, with no transformation of the simulated daily rainfall. Initially, the smoothing parameter $\rho$ was determined by minimising the GCV, but the resultant surface had a signal-to-error ratio of 57:0. This indicated that the downscaled surface fitted exactly to the precipitation simulated at the RCM grid points, with no 'error', that is to say, no residual. This surface was consequently somewhat distorted.

An alternative smoothing method was used, in which a fixed signal was supplied to the spline procedure. The resulting downscaled surface was validated against observations from the rain gauges. A square-root transforma- 
tion of the daily rainfall was disregarded because it increased the RMSE of the downscaled surface. A number of different fixed signals were tried; the lowest RMSE ( $65 \mathrm{~mm}$ ) was achieved by using a fixed signal-to-error ratio of 15:42. This RMSE is $17 \%$ less than that of the simulated precipitation at its original resolution of $30 \mathrm{~km}$. Figure 5.24a shows the simulated precipitation after being downscaled with the fixed signal value of 15 . This surface is hereafter referred to as Surf $_{\text {Rcm.D.Ds. }}$.

Surf $f_{\text {Rcm.D.Ds }}$ is a much-smoothed version of the precipitation simulated on 5 November 1994. In this surface, around 75-100 mm of rainfall falls on the edge of the West Coast, and rainfall peaks at over $250 \mathrm{~mm}$ in the region of the Franz Josef Glacier and upper Whataroa catchment. A ridge of 175+ mm rainfall extends southwest-to-northeast along the upper western flank of the Southern Alps. Spillover into the Pukaki catchment ranges from more than $225 \mathrm{~mm}$ in the northern tip, to less than $25 \mathrm{~mm}$ in the southern part of the catchment. By comparison with rain gauges, downscaling the simulated precipitation decreased the mean bias on 5 November from $29 \mathrm{~mm}$ to $6 \mathrm{~mm}$ - a reduction of $79 \%$. However, the high RMSE of $65 \mathrm{~mm}$ indicates that significant differences remain between HadRM3P and observations in some locations, with the same general trend of a wet bias in the west and a dry bias in the east.

Since the spatial distribution of rainfall observed in the Southern Alps varies significantly according to the mean daily wind direction (see Sections 5.2.2 and 5.3.2), it was hypothesised that downscaling skill could be improved by using the Surf Obs.D.Nw northwesterly surface (Figure 5.13) as the third independent variable of the trivariate interpolation. Figure 5.24b shows the simulated precipitation after being downscaled using Surf Obs.D.Nw as the third independent variable. The remaining parameters of the spline interpolation were not altered. This surface is hereafter referred to as $\operatorname{Surf}_{\text {Rcm.D.Ds.NW }}$.

There is very little difference between $\operatorname{Surf}_{\text {Rcm.D.Ds.NW }}$ and $\operatorname{Surf}_{\text {Rcm.D.Ds. }}$.

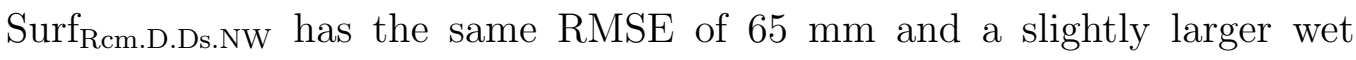
bias of $9 \mathrm{~mm}$. Therefore by comparison with observations from rain gauges, the use of the northwesterly surface during the trivariate interpolation did not improve the accuracy of the downscaled precipitation. One reason for 


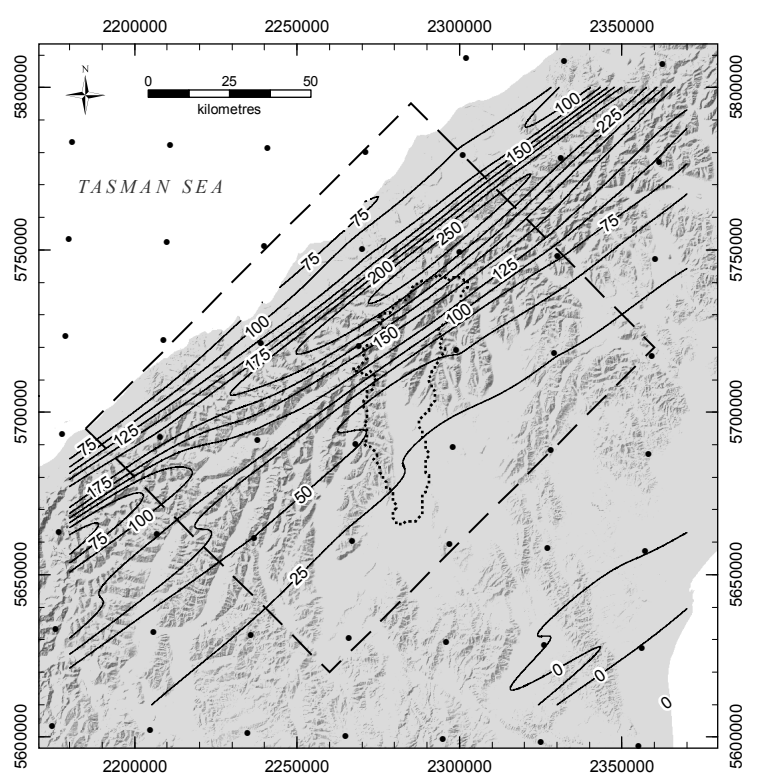

(a) Surf Rcm.D.Ds

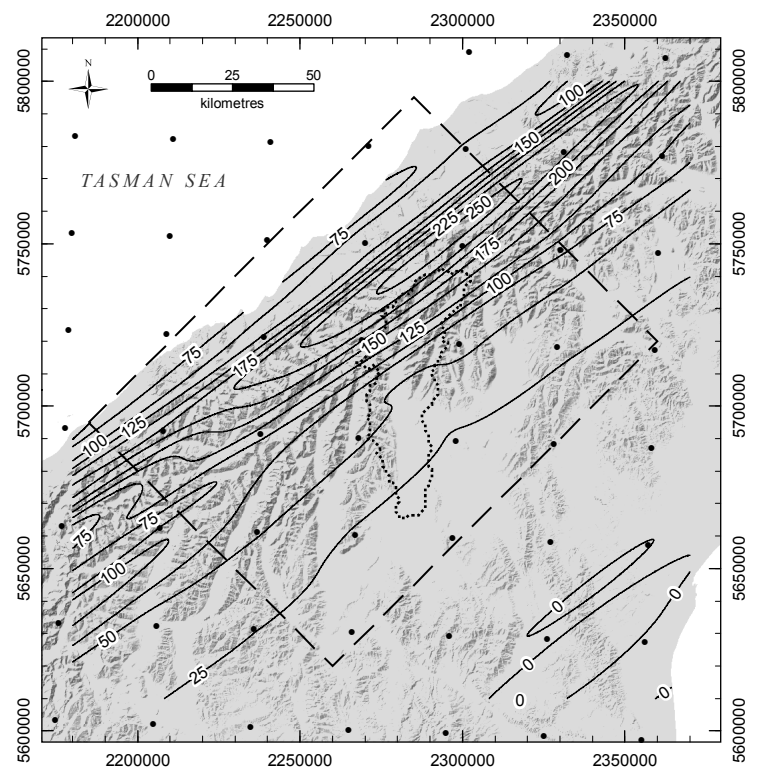

(b) Surf Rcm.D.Ds.NW

Figure 5.24 Isohyets of downscaled HadRM3P-simulated precipitation $(\mathrm{mm})$ in the central Southern Alps on 5 Nov 1994 UTC. '•' symbols denote RCM grid points.

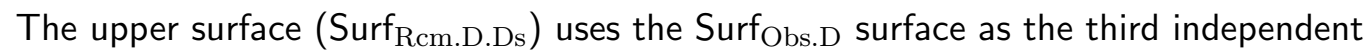
variable of the trivariate interpolation; the lower surface uses the Surf Obs.D.NW surface, as discussed in the text. Each contour represents $25 \mathrm{~mm}$ of precipitation. 
this may be that the mean daily surface $\left(\operatorname{Surf}_{\text {Obs.D }}\right)$ is reasonably similar in shape to the northwesterly surface (Surf Obs.D.Nw) - albeit substantially smaller in magnitude - and thus already reflects a climatology dominated by northwesterlies. However, downscaling skill might be improved by using, for example, a southeasterly surface to downscale precipitation simulated on a southeasterly day, since the climatology on southeasterly days differs more markedly from the mean daily climatology. More research is required to determine whether this approach will actually improve downscaling skill for precipitation simulated by the model during individual weather events.

\subsection{Summary of key results}

- Observations from rain gauges in the Southern Alps from 1971 to 2000 were objectively interpolated to produce mean annual profiles. Peak mean annual precipitation across the interpolated profiles ranges from $8.6 \mathrm{~m} \mathrm{a}^{-1}$ at Haast, to $9.0-9.4 \mathrm{~m} \mathrm{a}^{-1}$ in the Hokitika region, up to a maximum of $10.9 \mathrm{~m} \mathrm{a}^{-1}$ at Franz Josef.

- The profile of mean daily precipitation in the Southern Alps varies markedly according to the $850 \mathrm{hPa}$ wind direction north of the central Southern Alps. On days when the mean horizontal wind at $850 \mathrm{hPa}$ blows from the east, southeast or south quadrants, the daily precipitation peak across the Southern Alps is located approximately $80 \mathrm{~km}$ southeast of the Alpine Fault, well to the southeast of the Main Divide.

- A trivariate thin-plate smoothing spline, incorporating a surface of observed mean daily precipitation as a third independent variable, was used to downscale mean annual precipitation simulated in the central Southern Alps by the HadRM3P regional climate model from 1971 to 2000. Downscaling the simulated precipitation lead to large reductions in RMSE when validated against observations.

- Precipitation simulated by the HadRM3P RCM during an historic northwesterly storm exhibits a generally realistic spatial distribution, but still 
differs considerably from point-based observations by rain gauges in some locations. Substantial errors still remain after downscaling via a thin-plate smoothing spline, although the mean wet bias of the simulated precipitation was reduced by almost $80 \%$. 


\section{Chapter 6}

\section{Discussion}

Precipitation is a particularly difficult atmospheric phenomenon to simulate accurately, due to the numerous and complex meteorological interactions that contribute to its formation. The simulation of rainfall is even more difficult in regions of high topographic relief, such as the Southern Alps, where strong orographic forcing causes vigorous condensation of tropospheric moisture and extremely steep horizontal precipitation gradients at the surface. Future advances in computing power will inevitably lead to dynamic climate models with higher spatial resolution and more refined representations of the underlying physical processes that cause precipitation. For example, the newly installed IBM p575 supercomputer at NIWA, FitzRoy, is nearly 100 times more powerful than its Cray T3E1200e predecessor. NIWA is currently upgrading its regional climate model to a newer version of the UKMO Unified Model. This upgraded RCM may soon be simulating the New Zealand climate on FitzRoy at a horizontal resolution of $12 \mathrm{~km}$. However, precipitation simulated by the RCM, even at this increased resolution, is still too spatially coarse to be used in many downstream environmental models, such as the ARC energy-balance model of South Island glaciers, or the TopNet hydrological model currently being developed at NIWA (Clark et al. 2008). In the absence of a dynamic model that is able to accurately simulate long-term climate at a spatial resolution of less than $1 \mathrm{~km}$, some means of mathematical or statistical downscaling is still necessary.

The northeast-southwest axis of the Southern Alps lies across the domi- 
nant mid-latitude westerlies. Moisture-laden air blown in from the Tasman Sea encounters the very steep topography of this mountain range, producing a very distinct cross-mountain profile of precipitation. This is the dominant spatial characteristic of precipitation observed in the South Island. In Chapter 1, I asked the research question: what is the spatial distribution of precipitation in the central Southern Alps, and how is it influenced by topography and wind direction? Due to the shortage of available observations in the Milford transect, it is not possible to infer the magnitude and location of maximum rainfall in the Fiordland region from results in this thesis. Across the other objectively interpolated profiles, peak mean annual precipitation ranges from $8.6 \mathrm{~m} \mathrm{a}^{-1}$ at Haast, to $9.0-9.4 \mathrm{~m} \mathrm{a}^{-1}$ in the Hokitika region, up to a maximum of $10.9 \mathrm{~m} \mathrm{a}^{-1}$ at Franz Josef (Figure 5.2). The peak magnitudes of the interpolated profiles across the Hokitika and Franz Josef transects are somewhat lower than the $13 \mathrm{~m} \mathrm{a}^{-1}$ peak of the 'invariant' orographic profile subjectively estimated by Henderson and Thompson (1999). In this thesis, however, observations from short-term stations were not normalised to observations from nearby long-term stations, and no allowance was made for undercatch. The mean annual profiles developed in this thesis do support the hypothesis - put forward by Henderson and Thompson (1999) and implicit in Griffiths and McSaveney (1983) — that the peak magnitude of the precipitation profile is related to the elevation of the Main Divide in the vicinity of the profile.

The analysis presented in Section 5.2.1 indicates that orographic forcing causes mean annual precipitation to peak around $7-11 \mathrm{~km}$ southeast of the Alpine Fault in the Hokitika, Franz Josef (Figure 6.1) and Haast regions. This is again consistent with previous research by Henderson and Thompson (1999), which showed that rainfall during storms in the Southern Alps peaked within a slender zone approximately $10 \mathrm{~km}$ southeast of the Alpine Fault and 10-20 km northwest of the highest ground.

Peak precipitation thus occurs some considerable distance 'upwind' of the line of maximum topographic elevation. After much of the moisture in the atmospheric water column has condensed and precipitated northwest of the Main Divide, the consequent lee-side drying in the rain shadow of the 


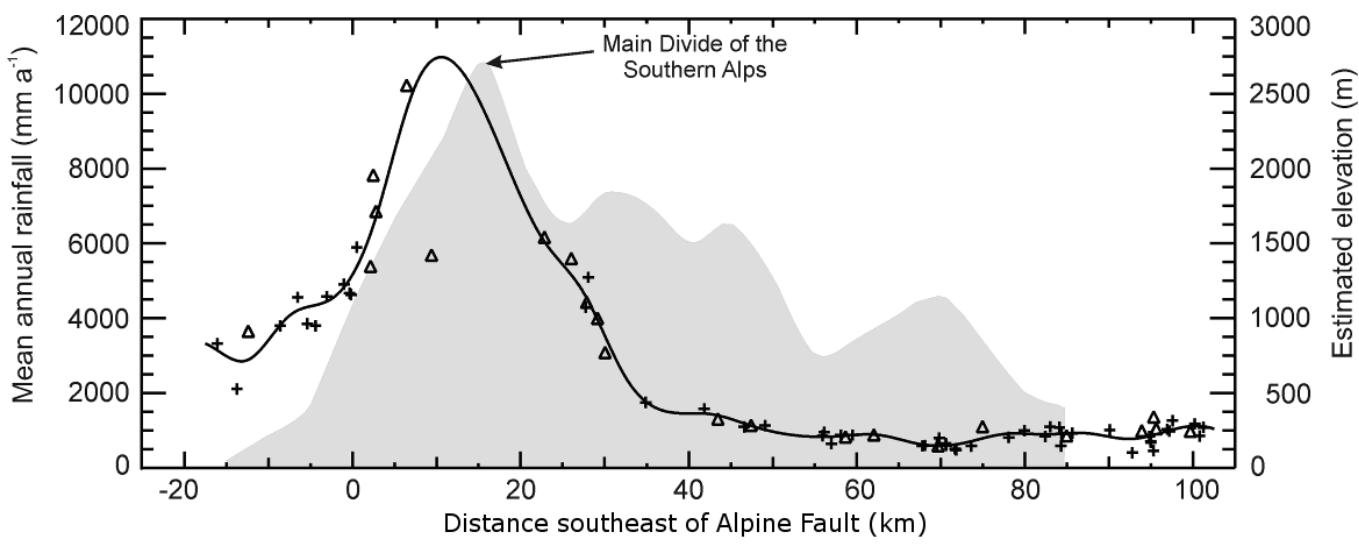

Figure 6.1 Mean annual precipitation $\left(\mathrm{mm} \mathrm{a}^{-1}\right)$ in the Franz Josef transect from 1971 to 2000, versus distance southeast of the Alpine Fault (km). '+' symbols denote CliDB gauges, ' $\triangle$ ' symbols denote WRA gauges. The curved line shows the cubic spline fitted to observations. Shading indicates topographic elevation ( $m$ a.s.l.) in the vicinity of Franz Josef, using the right-hand ordinate axis. Topographic elevations were added by Purdie (2011), using topographic data from Henderson and Thompson (1999).

mountains reduces the correlation between local topographic elevation and observed rainfall. As shown in previous research (Wratt et al. 2000; Tait et al. 2006) and in Section 5.1 of this thesis, local topographic elevation alone explains very little of the spatial variation in rainfall in the Southern Alps. Thus when interpolating point-based observations using mathematical techniques such as thin-plate smoothing splines, a direct dependence upon local topographic elevation does not produce particularly accurate surfaces of observed rainfall in the Southern Alps region (Leathwick et al. 2002; Tait et al. 2006). This also has implications for the downscaling of simulated rainfall: in order to increase the spatial resolution of rainfall simulated by the mesoscale HadRM3P regional climate model, an alternative approach is necessary.

The basic objective of the methodology in this thesis was to use the dominant spatial characteristic of observed rainfall in the Southern Alps - the precipitation profile across the whole mountain range - as a predictor of the distribution of precipitation at high spatial resolutions. In this approach, es- 
tablishing the observed profile becomes very important and one must consider the uncertainties involved. At high elevations in the heavily glaciated Aoraki Mount Cook region, observational data are scarce and the prevalence of both snow and strong winds makes rain gauges very susceptible to undercatch. If the anomalously low observations at Almer Hut are disregarded, then across the Franz Josef transect, the splined profile normal to the Alpine Fault is unguided by observational data for approximately $16 \mathrm{~km}$ between Luncheon Rock (680 m a.s.l.) and Panorama Ridge (1509 m a.s.l.) (Figure 6.1).

In research independent of the analysis in the present thesis, Kees (2011) used ground-penetrating radar (GPR) to measure snow thicknesses in highaltitude locations in the central Southern Alps during 2009. GPR readings were obtained at three points in the Davis Snowfield in the Franz Josef névé (2050, 2300 and 2450 m a.s.l.), one point in the Annette Plateau (2250 $\mathrm{m}$ a.s.l.) and one point in the Jollie Valley (approximately $2000 \mathrm{~m}$ a.s.l.). The snow thicknesses were converted to water equivalent using snow density measurements in associated snowpits. These water equivalents were then compared to 30-year norms (1971-2000) from nearby climate stations, in order to derive a precipitation index and estimates of mean annual precipitation at the GPR locations. Figure 6.2 shows the profile of observed mean annual precipitation across the Franz Josef transect, with a cubic spline fitted only to observations from rain gauges, as presented earlier in Figure 5.2d. The five GPR-based estimates of mean annual precipitation, provided by Kees (2011), have been added to Figure 6.2. It must be acknowledged that the Kees (2011) estimates are based on GPR measurements in just one accumulation year, and due to interannual variability it would be preferable to make this comparison in the year of measurement (2009). However, the three GPR-based estimates of $9.9-11.3 \mathrm{~m} \mathrm{a}^{-1}$ in the Franz Josef névé do compare well to the spline's $10.9 \mathrm{~m} \mathrm{a}^{-1}$ peak only $2-3 \mathrm{~km}$ to the northwest. The GPR measurements in the Franz Josef névé cast further doubt upon the validity of the relatively low $5.7 \mathrm{~m} \mathrm{a}^{-1}$ of precipitation observed at Almer Hut ('o' symbol in Figure 6.2) from 1991 to 1996, which was excluded from the fitted spline. All of the GPR-based estimates, including those for the Annette Plateau and the Jollie Valley east of the Main Divide, are within $0.5 \mathrm{~m} \mathrm{a}^{-1}$ 


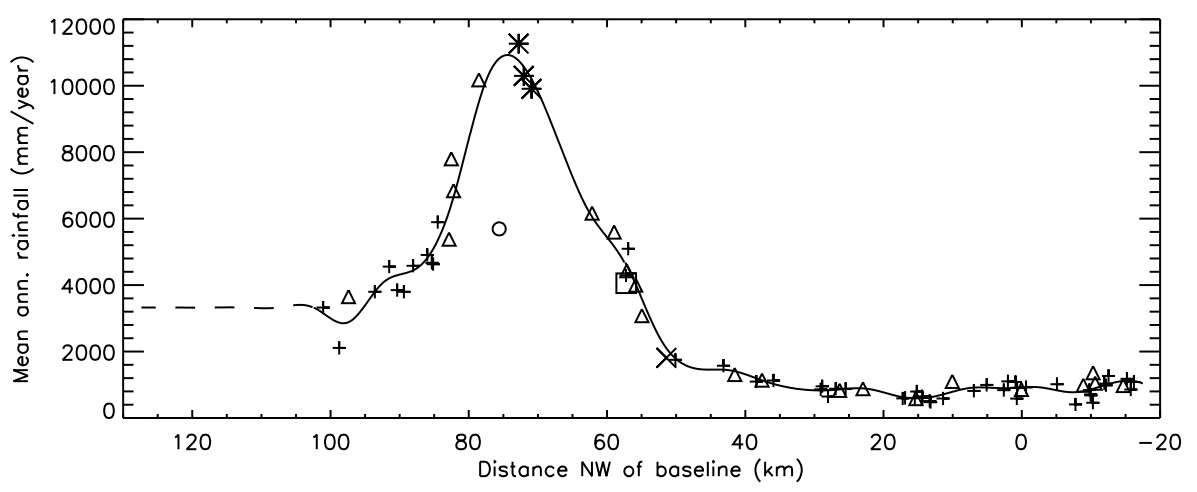

Figure 6.2 Mean annual precipitation $\left(\mathrm{mm} \mathrm{a}^{-1}\right)$ in the Franz Josef transect versus distance northwest of baseline $(\mathrm{km})$. The following symbols denote estimated precipitation, as derived from observations from rain gauges and ground-penetrating radar (GPR): '+' (CliDB gauges), ' $\triangle$ ' (WRA gauges), 'O' (Almer Hut gauge), '*' (Franz Josef névé GPR), ' $\square$ ' (Annette Plateau GPR), ' $\times$ ' (Jollie Valley GPR). The curved line shows the cubic spline fitted to observations from the CliDB gauges and WRA gauges, excluding Almer Hut. Mean annual precipitation at GPR sites was estimated by Kees (2011), based on GPR measurements in 2009.

of the spline fitted to observations from rain gauges.

Using additional rain gauges at high elevations, Kerr (2009) estimated mean annual precipitation in the northwesternmost part of the Pukaki catchment, along the southeast flank of the Main Divide, to be up to $13 \mathrm{~m} \mathrm{a}^{-1}$. Kerr (2009) suggested that the precipitation profile in the Aoraki Mount Cook region may exhibit a dual peak, with the second peak located near or slightly 'downwind' of the Main Divide. The data from rain gauges used in this thesis are insufficient to diagnose a second peak in Franz Josef region (Figure 6.1), but Figure 5.2b does suggest the presence of a second peak in the Hokitika region. Such a peak could be produced by orographic forcing of air that approaches the Southern Alps from the south or east. However, a comparison of the daily profile to reanalyses (Section 5.2.2) indicates that comparatively little precipitation falls near the Main Divide when the wind - diagnosed at a location north of the central Southern Alps — blows from the south or east (Figure 5.5). The use of data from additional reanalysis grid points southeast of the Main Divide would aid further analysis, to en- 
sure that the diagnosed wind direction is representative of airflow on both sides of the mountain range. Since the annual climatology is dominated by northwesterly and westerly precipitation, if a significant second peak does indeed exist in the central Southern Alps, this second peak may be formed primarily when wind approaches the mountain range from the northwest and west. Results from a high-resolution dynamic weather model of the European Alps suggest that an atmospheric freezing level near a mountain's summit may encourage the formation of a dual peak in the orographic precipitation profile (Zängl 2008), and Kerr (2009) suggested that such conditions may be present in the Aoraki Mount Cook region. Kerr et al. (2011) will begin a two-year campaign of precipitation observations in the late austral summer of 2011. Newly designed gauges, capable of recording high magnitudes of precipitation with reduced undercatch, will be installed in the wettest and most data-sparse areas of the central Southern Alps, east of Westland Tai Poutini National Park. With these new observations, Kerr et al. (2011) hope to refine the profile of mean annual precipitation in this region.

While there is still some uncertainty about the exact distribution of observed rainfall in the Aoraki Mount Cook region, the Surf Obs.A surface is within $0.6 \mathrm{~m} \mathrm{a}^{-1}$ of the five GPR-based estimates at high elevations independently produced by Kees (2011), with the caveat that the GPR readings were taken in the single year of 2009. Surf Obs.A also generally compares well to the surface of mean annual precipitation in the Pukaki catchment independently developed by Kerr (2009) (Figure 5.10). These results suggest that the merger of two-dimensional transects - a method used previously by Dr Brian Anderson of the Antarctic Research Centre - is a suitable way to develop surfaces of precipitation in this region.

Dr Nick Golledge of the ARC found that the use of Surf Obs.A within the Parallel Ice Sheet Model led to improved correlations between simulated glacial extent and geological evidence in the Southern Alps (Figure 5.11).

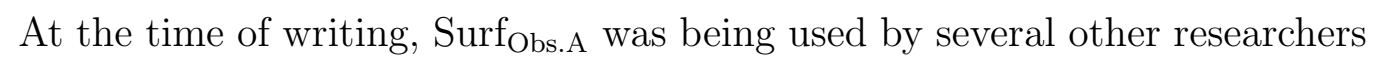
at the Victoria University of Wellington. Anderson and Mackintosh (2011) used Surf Obs.A within an energy-balance model, in order to analyse the sensitivity of maritime and debris-covered glaciers in the Southern Alps. Sat- 


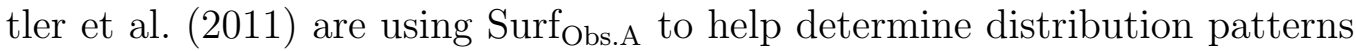
of rockglaciers in Canterbury and debris-flow activity across the Southern Alps. Doughty et al. (2011) aim to estimate late-glacial temperatures in New Zealand by replicating past glacial extents in the Ben Ohau and Arrow-

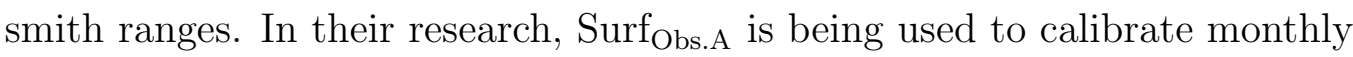
precipitation data fed into a coupled energy-balance/ice-flow model.

Having established that Surfobs.A provides a reasonably good representation of the observed spatial distribution of mean annual precipitation in the central Southern Alps, the surface was incorporated into the downscaling of precipitation simulated at $30-\mathrm{km}$ resolution by the HadRM3P regional climate model. The approach taken was a trivariate thin-plate smoothing spline interpolation, with Surf Obs.A employed as an independent variable. The use of a square-root transformation produced a downscaled surface ( $\operatorname{Surf}_{\mathrm{Rcm} . A . D s T}$ ) that was overfitted to the RCM grid points, and when validated directly against long-term rain gauges, Surf $f_{\text {Rcm.A.DsT }}$ had a higher RMSE than the surface downscaled without transformation $\left(\operatorname{Surf}_{\text {Rcm.A.Ds }}\right)$. The $\operatorname{Surf}_{\text {Rcm.A.Ds }}$ surface is therefore regarded as a better representation of mean annual precipitation in the Southern Alps from 1971 to 2000. As shown in Section 5.4.2, the downscaling without transformation reduced the RMSE of HadRM3Psimulated rainfall by $53 \%$ when compared directly with observations from long-term rain gauges in the central Southern Alps, and by $45 \%$ when compared with a precipitation surface for the Pukaki catchment produced by Kerr (2009).

The distribution of mean annual rainfall in the Southern Alps at spatial resolutions finer than $30 \mathrm{~km}$ can thus be estimated with some success by assuming a dependence upon historical spatial patterns of precipitation. This finding is consistent with research by Tait et al. (2006) into the production of historical daily precipitation surfaces for New Zealand; the present analysis may also represent an advance in interpolated precipitation surfaces within elevated regions of the Southern Alps. The trivariate spline interpolation could just as easily be applied to a future scenario of New Zealand rainfall, generated by the RCM nested within a GCM simulation. This method could be used to produce data for environmental models and other applications that 
require high-resolution annual surfaces of precipitation without day-to-day temporal variations.

In the context of downscaling future climatic projections, one must consider the implications of potential changes to the distribution of mean annual precipitation. GCM simulations for the IPCC Fourth Assessment Report (AR4) project enhanced warming in the tropical upper troposphere, accompanied by an expansion of the Hadley circulation (Meehl et al. 2007). In the Southern Hemisphere, the surface meridional temperature gradient is expected to steepen, accentuating a poleward movement of the primary storm tracks (Yin 2005). Descending air from the poleward limb of an expanded Hadley Cell is forecast to increase sea level pressure in the southern mid-latitudes. The AR4 GCM simulations have been downscaled in the New Zealand region, via both statistical regression and the HadRM3P RCM (Ministry for the Environment 2008). A steepening of the meridional sea level pressure gradient to the north of New Zealand is expected to increase westerlies over New Zealand during winter and spring, leading to increased precipitation west of the Southern Alps. This may exaggerate the current east-west gradient of mean annual rainfall across the South Island and reduce the skill of downscaling methods that make assumptions about its stationarity.

Downscaling techniques therefore often classify climatic variables according to the state of synoptic-scale meteorological predictors (Mullan et al. 2001; Wilby et al. 2004; Christensen et al. 2007). Kerr (2009) found that the spatial distribution of daily precipitation in the Pukaki catchment varied according to the horizontal wind direction at $850 \mathrm{hPa}$ north and south of the catchment. As shown in Section 5.2.2, variations in wind direction north of the central Southern Alps have a profound influence upon the shape of the daily precipitation profile across the whole mountain range. On days when the mean horizontal wind at $850 \mathrm{hPa}$ blows from the east, southeast or south quadrants, the daily precipitation peak along the Southern Alps is located approximately $80 \mathrm{~km}$ southeast of the Alpine Fault, well to the southeast of the Main Divide. Consequently, pressure-based indices of synoptic-scale circulation around New Zealand, such as those developed by Trenberth (1976) 
or Kidson (2000), are also likely to be good predictors of changes in the precipitation profile. The influence of atmospheric temperature upon the precipitation profile was difficult to isolate due to the strong correlation between temperature and wind direction. Greater insight into the influence of temperature variations may be gained by a more sophisticated statistical analysis or high-resolution numerical modelling.

Since wind direction appears to be the dominant atmospheric influence upon the spatial distribution of precipitation in the Southern Alps, a windbased surface was incorporated into the downscaling of daily precipitation simulated by HadRM3P during a northwesterly storm (Section 5.5). The general pattern of simulated precipitation appeared realistic and its mean bias was substantially reduced after being downscaled with surfaces of mean daily precipitation on all days (Surf Obs.D $_{\text {) }}$ and northwesterly days (Surf Obs.D.NW $_{\text {) }}$. However, the use of the northwesterly-based surface as a predictor did not improve downscaling skill, partly due to similarities between the Surf Obs.D

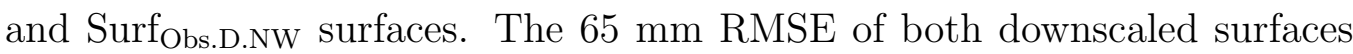
was still relatively high. Difficulties are posed by the complex spatial distribution of daily precipitation in highly elevated regions, which is considerably more patchy and 'noisy' than that of mean annual precipitation. Minimising the GCV during the downscaling resulted in a slightly distorted surface that fitted exactly to the RCM grid points; a low fixed signal was necessary to prevent such distortion. This probably indicates that the $30-\mathrm{km}$ grid of HadRM3P is too sparse to adequately represent the complexity of daily rainfall distributions in the Southern Alps during heavy precipitation events. This problem will be mitigated if the spatial resolution of the RCM is increased to $10-12 \mathrm{~km}$ in future versions of the model.

By using any historical precipitation surface as an independent variable during the downscaling of future climatic scenarios, one makes the implicit assumption that historical precipitation patterns will be a good predictor of future precipitation; one must ask whether this is a reasonable model. Regression models may encounter similar problems by assuming temporally constant relationships between local climatic variables and synoptic-scale circulation, which may not be valid in a future world climate perturbed by 
higher atmospheric concentrations of carbon dioxide and other greenhouse gases. Both of these downscaling techniques also require an accurate representation of historical precipitation, which can be difficult to ascertain in a rugged and isolated region such as the Southern Alps. A simpler approach might be to employ a predictor that is both known with certainty and essentially static for the next few centuries. While local topographic elevation has been shown to be a poor predictor of precipitation in the Southern Alps, the distinct cross-mountain profile of rainfall suggests that distance perpendicular to the main orographic axis could be a good alternative. The use of the Main Divide as a line of reference is problematic: it is too irregular and it does not always represent the line of highest ground, with higher ranges to the west at Mount Hooker and Mount Dechen, for example. The Alpine Fault, however, is approximately straight, and marks a clear change in topographic elevation across the Southern Alps.

A thin-plate smoothing spline does not require a temporally constant relationship between its independent and dependent variables. Each independent variable simply needs to be a good predictor of the dependent variable during the period being downscaled. Even if the exact relationship between rainfall and topography changes in the future, surface precipitation in the Southern Alps region will certainly still be greatly affected by its position with respect to the Alpine Fault. During a trivariate spline interpolation, a simple exponential or logarithmic transformation could be applied to the distance between each RCM grid point and the Alpine Fault, to help reproduce the observed east-west gradient of rainfall in the South Island. Any empirical calibration would still make some assumption of stationarity, but this is to some extent unavoidable; even dynamic climate models are tuned to accurately reproduce historical climate before being used to make future projections. This approach would have parallels with the logistic-growth model developed by Griffiths and McSaveney (1983) and is worth investigating in future research. 


\section{Chapter 7}

\section{Conclusion}

The central theme of this thesis has been the spatial distribution of precipitation in the central Southern Alps, and the manner in which it is influenced by topography and wind direction. The main axis of the Southern Alps runs parallel to the New Zealand Alpine Fault, at which point the topographic profile rises sharply and air moving horizontally is forced vigorously upward. The essence of the present analysis has been two-dimensional profiles of observed precipitation across the Southern Alps from 1971 to 2000, which were created objectively using a cubic spline interpolation. This analysis indicates that distance from the Alpine Fault is the most influential determinant of mean annual rainfall in the central Southern Alps, in agreement with previous work (Henderson and Thompson 1999). In 4 transects of the Hokitika, Franz Josef and Haast regions, the mean annual precipitation maxima of the objectively interpolated profiles are consistently located $7-11 \mathrm{~km}$ southeast of the Alpine Fault. Due to a shortage of available observations in the Milford transect, no conclusions are drawn for Fiordland.

Local topographic elevation explains very little $(0.3 \%)$ of the variation in mean annual precipitation recorded by individual rain gauges in the Southern Alps. Peak mean annual precipitation across the interpolated profiles ranges from $8.6 \mathrm{~m} \mathrm{a}^{-1}$ at Haast, to $9.0-9.4 \mathrm{~m} \mathrm{a}^{-1}$ in the Hokitika region, up to a maximum of $10.9 \mathrm{~m} \mathrm{a}^{-1}$ at Franz Josef, although higher levels were recorded by individual gauges. The magnitude of peak precipitation across 4 transects of the Southern Alps is thus related to the elevation of the Main Divide across 
each transect, in agreement with Henderson and Thompson (1999).

Peak mean annual precipitation is consistently located northwest of the Main Divide. The distance from the annual precipitation maxima southeast to the Main Divide ranges from $4-5 \mathrm{~km}$ in the Franz Josef region, up to a maximum of $25 \mathrm{~km}$ in the Haast region, where the Main Divide deviates significantly to the southeast. The magnitude and shape of the mean daily precipitation profile are strongly influenced by the wind direction north of the central Southern Alps, as evidenced by comparisons of observed daily rainfall to wind vectors from NCEP/NCAR Reanalysis 1 . On days when the mean horizontal wind at $850 \mathrm{hPa}$ blows from the east, southeast or south quadrants, the daily precipitation peak along the Southern Alps is located approximately $80 \mathrm{~km}$ southeast of the Alpine Fault, well to the southeast of the Main Divide.

Rain gauges are sparse in the Aoraki Mount Cook region. The interpolated profile of 1971-2000 mean annual precipitation across the Franz Josef transect is however supported by independent estimates from Kees (2011), which were based on GPR measurements at high elevations of the Aoraki

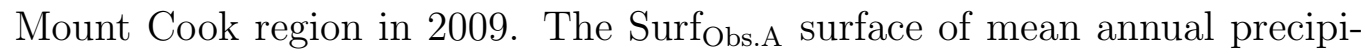
tation in the central Southern Alps, developed in this thesis, also generally compares well to an independently developed surface for the Pukaki catchment (Kerr 2009). The two-dimensional nature of its construction has made Surf Obs.A unrealistically smooth, but the sparsity of observations necessitates some form of idealised model in order to describe the spatial distribution of precipitation throughout the region. This surface is currently being used by several researchers at VUW, to gain further understanding of glacial behaviour in the central Southern Alps.

A trivariate thin-plate smoothing spline was used to interpolate mean annual precipitation simulated by the HadRM3P regional climate model in the central Southern Alps during the 30-year period from 1971 to 2000, with the Surf Obs.A surface being employed as an independent variable. This method of downscaling reduced the RMSE of HadRM3P-simulated rainfall by $53 \%$ when compared directly with observations from long-term rain gauges in the central Southern Alps, and by $45 \%$ when validated against an independently 
developed surface of mean annual precipitation in the Pukaki catchment (Kerr 2009). This result indicates that the observed rainfall profile across the Southern Alps can be successfully integrated into a trivariate thin-plate smoothing spline, in order to increase the spatial resolution and accuracy of mean annual precipitation simulated by a regional climate model. This approach may also be applicable in other north-south trending mountain ranges that intersect primarily zonal circulation and exhibit a similarly distinct profile of orographically enhanced rainfall.

The HadRM3P RCM generally simulated realistic spatial patterns of rainfall in the central Southern Alps during an historic and intense northwesterly storm. However, the $30-\mathrm{km}$ resolution of the RCM is too coarse to accurately represent the steep precipitation gradients of daily rainfall distributions in mountainous regions during heavy precipitation events. This led to only moderate improvements in the accuracy of the simulated daily rainfall after downscaling via a trivariate thin-plate smoothing spline. This issue will be mitigated in future versions of the RCM, which will run on a more powerful supercomputer and have a higher spatial resolution. 


\section{References}

Anagnostopoulou C., Tolika K., Maheras P., Kutiel H., Flocas H.A. (2008). Performance of the general circulation HadAM3P model in simulating circulation types over the Mediterranean region. International Journal of Climatology, 28(2):185.

Anderson B., Lawson W., Owens I., Goodsell B. (2008). Response of Franz Josef Glacier 'Ka Roimata o Hine Hukatere' to climate change. Global and Planetary Change, 63(1):23-30.

Anderson B., Mackintosh A. (2006). Temperature change is the major driver of late-glacial and Holocene glacier fluctuations in New Zealand. Geology, 34(2):121-124.

Anderson B., Mackintosh A. (2011). Controls on glacier sensitivity for maritime and debris-covered glaciers. Journal of Geophysical Research. In prep.

Anderson B., Mackintosh A., Stumm D., George L., Kerr T., Winter-Billington A., Fitzsimons S. (2010). Climate sensitivity of a high-precipitation glacier in New Zealand. Journal of Glaciology, 56(195):114-128.

Barry R.G. (2008). Mountain Weather and Climate. Cambridge University Press, 3rd edition.

Barry R.G., Chorley R.J. (2003). Atmosphere, Weather, and Climate. Routledge, 8th edition.

Batt G.E., Braun J., Kohn B.P., McDougall I. (2000). Thermochronological analysis of the dynamics of the Southern Alps, New Zealand. Geological Society of America Bulletin, 112(2):250-266.

Bueler E., Khroulev C., Aschwanden A., Joughin I., Smith B. (2010). Modeled and observed fast flow in the Greenland ice sheet. Geophysical Research Letters. Submitted.

Chater A., Sturman A. (1998). Atmospheric conditions influencing the spillover of rainfall to lee of the Southern Alps, New Zealand. International Journal of Climatology, 18(1):77-92. 
Chinn T., Winkler S., Salinger M.J., Haakensen N. (2005). Recent glacier advances in Norway and New Zealand: a comparison of their glaciological and meteorological causes. Geografiska Annaler. Series A, Physical Geography, 87(1):141-157.

Chinn T.J. (1979). How wet is the wettest of the wet West Coast? New Zealand Alpine Journal, 32:85-87.

Chinn T.J. (1996). New Zealand glacier responses to climate change of the past century. New Zealand Journal of Geology \& Geophysics, 39(3):415-428.

Chinn T.J. (2001). Distribution of the glacial water resources of New Zealand. Journal of Hydrology (NZ), 40(2):139-187.

Chinn T.J.H. (1995). Glacier fluctuations in the Southern Alps of New Zealand determined from snowline elevations. Arctic and Alpine Research, 27(2):187198.

Christensen J.H., Hewitson B., Busuioc A., Chen A., Gao X., Held I., Jones R., Kolli R.K., Kwon W.T., Laprise R., Rueda V.M., Mearns L., Menndez C.G., Risnen J., Rinke A., Sarr A., Whetton P. (2007). Regional climate projections. In Solomon S., Qin D., Manning M., Chen Z., Marquis M., Averyt K.B., Tignor M., Miller H.L., editors, Climate Change 200\%: The Physical Science Basis. Contribution of Working Group I to the Fourth Assessment Report of the Intergovernmental Panel on Climate Change, chapter 11, pages 847-940. Cambridge University Press, Cambridge, United Kingdom and New York, USA.

Clark M., Rupp D., Woods R., Zheng X., Ibbitt R., Slater A., Schmidt J., Uddstrom M. (2008). Hydrological data assimilation with the ensemble Kalman filter: Use of streamflow observations to update states in a distributed hydrological model. Advances in Water Resources, 31(10):1309-1324.

Craven P., Wahba G. (1979). Smoothing noisy data with spline functions: estimating the correct degree of smoothing by the method of generalized crossvalidation. Numerische Mathematik, 31(4):377-403.

da Rocha R.P., Morales C.A., Cuadra S.V., Ambrizzi T. (2009). Precipitation diurnal cycle and summer climatology assessment over South America: An evaluation of Regional Climate Model version 3 simulations. Journal of Geophysical Research-Atmospheres, 114, doi:10.1029/2008JD010212.

de Boor C. (1978). A Practical Guide to Splines, volume 27 of Applied Mathematical Sciences. Springer-Verlag, New York.

Doughty A., Mackintosh A., Anderson B., Kaplan M., Vandergoes M., Denton G., Barrell D., Schaefer J. (2011). Modelling late-glacial ice extent in the Ben 
Ohau Range to estimate past temperatures. In 2011 Annual Workshop of the New Zealand Snow and Ice Research Group (SIRG), Fox Glacier Township, New Zealand. 9-11 February 2011.

Dravitzki S.M. (2009). Precipitation in the Waikato River Catchment. Phd, School of Geography, Environment and Earth Sciences, Victoria University of Wellington, New Zealand.

Drost F., Renwick J., Bhaskaran B., Oliver H., McGregor J. (2007). Simulation of New Zealand's climate using a high-resolution nested regional climate model. International Journal of Climatology, 27(9):1153-1169.

Dykes R.C., Brook M.S. (2010). Terminus recession, proglacial lake expansion and 21st century calving retreat of Tasman Glacier, New Zealand. New Zealand Geographer, 66(3):203-217.

Eby M., Zickfeld K., Montenegro A., Archer D., Meissner K.J., Weaver A.J. (2009). Lifetime of Anthropogenic Climate Change: Millennial Time Scales of Potential $\mathrm{CO}_{2}$ and Surface Temperature Perturbations. Journal of Climate, 22(10):25012511, doi:10.1175/2008JCLI2554.1.

Fitzharris B.B., Chinn T.J., Lamont G.N. (1997). Glacier balance fluctuations and atmospheric circulation patterns over the Southern Alps, New Zealand. International Journal of Climatology, 17:745-763.

Fitzharris B.B., Hay J.E., Jones P.D. (1992). Behaviour of New Zealand glaciers and atmospheric circulation changes over the past 130 years. The Holocene, $2(2): 97106$.

Frei C., Schär C. (1998). A precipitation climatology of the Alps from highresolution rain-gauge observations. International Journal of Climatology, 18(8):873-900.

Fujiyoshi Y., Kondo H., Inoue J., Yamada T. (1987). Characteristics of precipitation and vertical structure of air temperature in the northern Patagonia. Bulletin of Glacier Research, 4:15-23.

Giorgi F., Shields Brodeur C., Bates G.T. (1994). Regional climate change scenarios over the United States produced with a nested regional climate model. Journal of Climate, 7(3):375-399.

Goodison B.E., Louie P.Y.T., Yang D. (1998). WMO Solid Precipitation Measurement Intercomparison - Final Report. Technical report, World Meteorological Organization. Instruments and Observing Methods - Report No. 67, WMO/TD - No. 872. 
Gordon N. (1986). The Southern Oscillation and New Zealand weather. Monthly Weather Review, 114(2):371-387.

Griffiths G.A., McSaveney M.J. (1983). Distribution of mean annual precipitation across some steepland regions of New Zealand. New Zealand Journal of Science, 26(2):197-209.

Hay J.E., Fitzharris B.B. (1988). The synoptic climatology of ablation on a New Zealand glacier. International Journal of Climatology, 8(2):201-215.

Haylock M.R., Cawley G.C., Harpham C., Wilby R.L., Goodess C.M. (2006). Downscaling heavy precipitation over the United Kingdom: a comparison of dynamical and statistical methods and their future scenarios. International Journal of Climatology, 26(10):1397-1415.

Hegerl G.C., Zwiers F.W., Braconnot P., Gillett N.P., Luo Y., Orsini J.A.M., Nicholls N., Penner J.E., Stott P.A. (2007). Understanding and attributing climate change. In Solomon S., Qin D., Manning M., Chen Z., Marquis M., Averyt K.B., Tignor M., Miller H.L., editors, Climate Change 200\%: The Physical Science Basis. Contribution of Working Group I to the Fourth Assessment Report of the Intergovernmental Panel on Climate Change, chapter 9. Cambridge University Press, Cambridge, United Kingdom and New York, NY, USA.

Henderson R.D. (1993). Extreme storm rainfalls in the Southern Alps, New Zealand. IAHS Publication, pages 113-120.

Henderson R.D., Thompson S.M. (1999). Extreme rainfalls in the Southern Alps of New Zealand. Journal of Hydrology (New Zealand), 38(2):309-330.

Hessell J.W.D. (1982). The climate and weather of Westland. Miscellaneous Publication 115 (10). Ministry of Transport, New Zealand Meteorological Service, Wellington, New Zealand.

Hessell J.W.D. (1983). Climatic effects on the recession of the Franz Josef Glacier. New Zealand Journal of Science, 26(2).

Holton J.R. (1992). An Introduction to Dynamic Meteorology. Academic Press, London, United Kingdom, 3rd edition.

Hooker B.L., Fitzharris B.B. (1999). The correlation between climatic parameters and the retreat and advance of Franz Josef Glacier, New Zealand. Global and Planetary Change, 22:39-48.

Hudson D.A., Jones R.G. (2002). Regional climate model simulations of presentday and future climates of southern Africa. Technical report, Hadley Centre, Met Office. 
Hutchinson M.F. (1995). Interpolating mean rainfall using thin plate splines. International Journal of Geographic Information Systems, 9(4):385-403.

Hutchinson M.F. (1998a). Interpolation of rainfall data with thin plate smoothing splines. Part I: Two dimensional smoothing of data with short range correlation. Journal of Geographic Information and Decision Analysis, 2(2):139-151.

Hutchinson M.F. (1998b). Interpolation of rainfall data with thin plate smoothing splines. Part II: Analysis of topographic dependence. Journal of Geographic Information and Decision Analysis, 2(2):152-167.

Hutchinson M.F. (2000). ANUSPLIN Version 4.1 User Guide. Centre for Resource and Environmental Studies, Australian National University, Canberra.

Hutchinson M.F. (2011). ANUSPLIN Version 4.3. http://fennerschool.anu. edu.au/publications/software/anusplin.php.

Hutchinson M.F., Gessler P.E. (1994). Splines - more than just a smooth interpolator. Geoderma, 62(1-3):45-67.

Hutchinson M.F., McKenney D.W., Lawrence K., Pedlar J.H., Hopkinson R.F., Milewska E., Papadopol P. (2009). Development and testing of Canada-wide interpolated spatial models of daily minimum-maximum temperature and precipitation for 1961-2003. Journal of Applied Meteorology and Climatology, 48(4):725-741.

Johns T.C., Durman C.F., Banks H.T., Roberts M.J., McLaren A.J., Ridley J.K., Senior C.A., Williams K.D., Jones A., Rickard G.J. et al. (2006). The new Hadley Centre climate model (HadGEM1): Evaluation of coupled simulations. Journal of Climate, 19(7):1327-1353.

Jones R.G., Murphy J.M., Noguer M. (1995). Simulation of climate change over Europe using a nested regional-climate model. I: Assessment of control climate, including sensitivity to location of lateral boundaries. Quarterly Journal of the Royal Meteorological Society, 121(526):1413-1449.

Jones R.G., Noguer M., Hassell D.C., Hudson D., Wilson S.S., Jenkins G.J., Mitchell J.F.B. (2004). Generating High Resolution Climate Change Scenarios Using PRECIS. Hadley Centre, United Kingdom Met Office, Exeter, United Kingdom.

Kalnay E. (2003). Atmospheric Modeling, Data Assimilation and Predictability. Cambridge University Press, Cambridge, United Kingdom.

Kalnay E., Kanamitsu M., Kistler R., Collins W., Deaven D., Gandin L., Iredell M., Saha S., White G., Woollen J. et al. (1996). The NCEP/NCAR 40-year 
reanalysis project. Bulletin of the American Meteorological Society, 77(3):437471.

Kees L. (2011). Assessment of a snow storage gradient across a maritime mountain environment; a GPR investigation. Master's thesis, Victoria University of Wellington, New Zealand.

Kerr T., Henderson R., Sood A. (2011). Design of a precipitation observation campaign to investigate the precipitation distribution in Westland Tai Poutini National Park, New Zealand. In 2011 Annual Workshop of the New Zealand Snow and Ice Research Group (SIRG), Fox Glacier Township, New Zealand. 9-11 February 2011.

Kerr T.R. (2009). Precipitation Distribution in the Lake Pukaki Catchment, New Zealand. Phd, University of Canterbury, New Zealand.

Kerr T.R. (2010). Personal communication. 16 March 2010, Christchurch, New Zealand.

Kidson J.W. (2000). An analysis of New Zealand synoptic types and their use in defining weather regimes. International Journal of Climatology, 20:299-316.

Kidson J.W., Thompson C.S. (1998). A comparison of statistical and modelbased downscaling techniques for estimating local climate variations. Journal of Climate, 11(4):735-753.

Kidston J., Renwick J.A., McGregor J. (2009). Hemispheric-Scale Seasonality of the Southern Annular Mode and Impacts on the Climate of New Zealand. Journal of Climate, 22(18):4759-4770, doi:10.1175/2009JCLI2640.1.

Kundzewicz Z.W., Mata L.J., Arnell N., Dll P., Kabat P., Jimnez B., Miller K., Oki T., Sen Z., Shiklomanov I. (2007). Freshwater resources and their management. In Parry M.L., Canziani O.F., Palutikof J.P., van der Linden P., Hanson C., editors, Climate Change 200\%: Impacts, Adaptation and Vulnerability. Contribution of Working Group II to the Fourth Assessment Report of the Intergovernmental Panel on Climate Change, pages 173-210. Cambridge University Press, Cambridge, UK.

Leathwick J.R., Wilson G., Stephens R.T.T. (2002). Climate Surfaces for New Zealand. Technical Report LC9798/126, Biodiversity and Conservation Division, Landcare Research.

Leyland, CAE (1998). Electricity Supply and Demand to 2015: On the Basis of Existing and Proposed Generating Capacities. Leyland Consultants and Centre for Advanced Engineering, University of Canterbury, New Zealand, 4th edition. 
McKerchar A.I., Pearson C.P., Fitzharris B.B. (1998). Dependency of summer lake inflows and precipitation on spring SOI. Journal of Hydrology, 205(1-2):66-80.

Meehl G.A., Stocker T.F., Collins W.D., Friedlingstein P., Gaye A.T., Gregory J.M., Kitoh A., Knutti R., Murphy J.M., Noda A., Raper S.C.B., Watterson I.G., Weaver A.J., Zhao Z.C. (2007). Global climate projections. In Solomon S., Qin D., Manning M., Chen Z., Marquis M., Averyt K.B., Tignor M., Miller H.L., editors, Climate Change 200\%: The Physical Science Basis. Contribution of Working Group I to the Fourth Assessment Report of the Intergovernmental Panel on Climate Change, chapter 10, pages 747-845. Cambridge University Press, Cambridge, United Kingdom and New York, USA.

Ministry for the Environment (2008). Climate change effects and impacts assessment: A guidance manual for local government in new zealand. Technical Report WLG2007/62, Ministry for the Environment, Wellington, New Zealand. $\mathrm{xviii}+149 \mathrm{p}$.

Mullan A.B., Wratt D.S., Renwick J.A. (2001). Transient model scenarios of climate changes for New Zealand. Weather and Climate, 21:3-34.

New Zealand Meteorological Service (1985). Climatic map series. part 6: annual rainfall. New Zealand Meteorological Service Miscellaneous Publication 175.

New Zealand Meteorological Service (2010). Understanding radar imagery. Website. http://vaac.metservice. com/default/index .php?alias=chradar.

NIWA (2007). Water Resources Archive: the backbone. Freshwater Update, 24. National Institute of Water \& Atmospheric Research, New Zealand.

NIWA (2010a). National Climate Database. Website. http://www.niwa.cri.nz/ services/clidb.

NIWA (2010b). Tideda - Time Dependent Data. Website. http://www.niwa.co . nz/our-services/software/tideda.

NOAA, NASA, USAF (1976). US Standard Atmosphere. National Oceanic and Atmospheric Administration, National Aeronautics and Space Administration, United States Air Force, Washington, D.C., United States.

Oerlemans J. (1997). Climate sensitivity of Franz Josef Glacier, New Zealand, as revealed by numerical modeling. Arctic and Alpine Research, 29(2):233-239.

Panziera L., Germann U. (2010). The relation between airflow and orographic precipitation on the southern side of the Alps as revealed by weather radar. Quarterly Journal of the Royal Meteorological Society, 136:222-238.

Pielke R.A., Cotton W.R., Walko R.L., Trembaek C.J., Lyons W.A., Grasso L.D., 
Nieholls M.E., Moran M.D., Wesley D.A., Lee T.J. (1992). A comprehensive meteorological modeling system - RAMS. Meteorology and Atmospheric Physics, 49:69-91.

Purdie H. (2011). Controls on spatial and temporal variation in snow accumulation on glaciers in the Southern Alps, New Zealand. PhD thesis, School of Geography, Environment and Earth Sciences, Victoria University of Wellington, New Zealand.

Randall D.A., Wood R.A., Bony S., Colman R., Fichefet T., Fyfe J., Kattsov V., Pitman A., Shukla J., Srinivasan J., Stouffer R.J., Sumi A., Taylor K. (2007). Climate models and their evaluation. In Solomon S., Qin D., Manning M., Chen Z., Marquis M., Averyt K., Tignor M., Millerw H., editors, Climate Change 2007: The Physical Science Basis. Contribution of Working Group I to the Fourth Assessment Report of the Intergovernmental Panel on Climate Change, chapter 8. Cambridge University Press, Cambridge, United Kingdom and New York, NY, USA.

Renwick J.A., Katzfey J.J., Nguyen K.C., McGregor J.L. (1998). Regional model simulations of New Zealand climate. Journal of Geophysical Research, 103:59735982.

Rew R., Davis G. (1990). NetCDF: an interface for scientific data access. IEEE Computer Graphics and Applications, 10(4):76-82.

Rojas M., Moreno P.I., Kageyama M., Crucifix M., Hewitt C., Abe-Ouchi A., Ohgaito R., Brady E.C., Hope P. (2009). The Southern Westerlies during the last glacial maximum in PMIP2 simulations. Climate Dynamics, 32(4):525-548, doi:10.1007/s00382-008-0421-7.

Saeed S., Liu Y., Rasul G. (2011). Multiyear hindcast simulations of summer monsoon over South Asia using a nested regional climate model-BCC_RegCM1.0. Theoretical and Applied Climatology, 103(1-2):249-264, doi:10.1007/s00704-0100297-4.

Salinger M.J. (1982). New Zealand climate: Scenarios for a warm high-C0 $\mathrm{C}_{2}$ world. Weather and Climate, 2:9-15.

Sattler K., Mackintosh A., Anderson B., de Roiste M. (2011). Debris-flow activity and the role of permafrost degradation in New Zealands Southern Alps. In 14th Biennial Meeting of the Australian $\&$ New Zealand Geomorphology Group. Australian \& New Zealand Geomorphology Group.

Schmidli J., Frei C., Vidale P.L. (2006). Downscaling from GCM precipitation: 
a benchmark for dynamical and statistical downscaling methods. International Journal of Climatology, 26(5):679-689.

Schneider C., Glaser M., Kilian R., Santana A., Butorovic N., Casassa G. (2003). Weather observations across the southern Andes at $53^{\circ}$ S. Physical Geography, 24(2):97-119.

Sevruk B. (1997). Regional dependency of precipitation-altitude relationship in the Swiss Alps. Climatic Change, 36(3):355-369.

Sinclair M.R. (1994). A diagnostic model for estimating orographic precipitation. Journal of Applied Meteorology, 33(10):1163-1175.

Sinclair M.R., Wratt D.S., Henderson R.D., Gray W.R. (1997). Factors affecting the distribution and spillover of precipitation in the Southern Alps of New Zealand - a case study. Journal of Applied Meteorology, 36(5):428-442.

Sturman A.P., Tapper N. (2006). The Weather and Climate of Australia and New Zealand. Oxford University Press, Victoria, Australia, 2nd edition.

Suggate R.P. (1990). Late Pliocene and Quaternary glaciations of New Zealand. Quaternary Science Reviews, 9(2-3):175-197.

Tait A., Turner R. (2005). Generating multiyear gridded daily rainfall over New Zealand. Journal of Applied Meteorology, 44(9):1315-1323.

Tait A., Zheng X. (2007). Analysis of the spatial interpolation error associated with maps of median annual climate variables. Technical report, National Institute of Water \& Atmospheric Research.

Tait A.B., Henderson R., Turner R., Zheng X. (2006). Thin plate smoothing spline interpolation of daily rainfall for New Zealand using a climatological rainfall surface. International Journal of Climatology, 26(14):2097-2115.

Thompson C.S., Sinclair M.R., Gray W.R. (1997). Estimating long-term annual precipitation in a mountainous region from a diagnostic model. International Journal of Climatology, 17:997-1007.

Trenberth K.E. (1976). Fluctuations and trends in indexes of southern hemispheric circulation. Quarterly Journal of the Royal Meteorological Society, 102(431):6575 .

Uddstrom M., Oliver H., Andrews P., Moore S., Sherlock V. (2007). Weathering the storm - from weather prediction to forecasting hazards. Water $\&$ Atmosphere, 15(3):10-11.

United Kingdom Met Office (1998). Unified Model User Guide. United Kingdom Met Office, Bracknell, United Kingdom. 
United Kingdom Met Office (2009). Atmospheric numerical model configurations. Website. http://www.metoffice.gov.uk/science/creating/ daysahead/nwp/um_config.h\%tml.

Uppala S., Kållberg P.W., Simmons A.J., Andrae U., Bechtold V.D.C., Fiorino M., Gibson J.K., Haseler J., Hernandez A., Kelly G.A. et al. (2005). The ERA-40 reanalysis. Quarterly Journal of the Royal Meteorological Society, 131(612):29613012 .

Wahba G. (1990). Spline Models for Observational Data. Society for Industrial Mathematics.

Walcott R.I. (1998). Modes of oblique compression: Late Cenozoic tectonics of the South Island of New Zealand. Reviews of Geophysics, 36(1):1-26.

Wallace J., Hobbs P. (2006). Atmospheric Science: An Introductory Survey. Academic Press, 2nd edition.

Walter K. (2000). Index to Hydrological Recording Sites in New Zealand. Technical Report 73, National Institute of Water \& Atmospheric Research, Wellington, New Zealand.

Weaver A.J., Eby M., Wiebe E.C., Bitz C.M., Duffy P.B., Ewen T.L., Fanning A.F., Holland M.M., MacFadyen A., Matthews H.D., Meissner K.J., Saenko O., Schmittner A., Wang H.X., Yoshimori M. (2001). The UVic Earth System Climate Model: Model description, climatology, and applications to past, present and future climates. Atmosphere-Ocean, 39(4):361-428.

Weaver A.J., Zickfeld K., Montenegro A., Eby M. (2007). Long term climate implications of 2050 emission reduction targets. Geophysical Research Letters, 34(19):L19703.

Webster S., Uddstrom M., Oliver H., Vosper S. (2008). A high-resolution modelling case study of a severe weather event over New Zealand. Atmospheric Science Letters, 9:119-128.

Weingartner R., Pearson C. (2001). A comparison of the hydrology of the Swiss Alps and the Southern Alps of New Zealand. Mountain Research and Development, 21(4):370-381.

Wilby R.L., Charles S.P., Zorita E., Timbal B., Whetton P., Mearns L. (2004). Guidelines for use of climate scenarios developed from statistical downscaling methods. Technical Report 2, IPCC Task Group on Data and Scenario Support for Impact and Climate Analysis (TGICA).

World Meteorological Organization (1983). Guide to Climatological Practices. Se- 
creteriat of the World Meteorological Organization, Geneva, Switzerland, 2nd edition. WMO-No. 100.

Wratt D.S., Revell M.J., Sinclair M.R., Gray W.R., Henderson R.D., Chater A.M. (2000). Relationships between air mass properties and mesoscale rainfall in New Zealand's Southern Alps. Atmospheric Research, 52(4):261-282.

Wratt D.S., Ridley R.N., Sinclair M.R., Larsen H., Thompson S.M., Henderson R., Austin G.L., Bradley S.G., Auer A., Sturman A.P. (1996). The New Zealand Southern Alps Experiment. Bulletin of the American Meteorological Society, 77(4):683-692.

Yin J.H. (2005). A consistent poleward shift of the storm tracks in simulations of 21st century climate. Geophysical Research Letters, 32(18), doi:10.1029/2005GL023684.

Zängl G. (2008). The temperature dependence of small-scale orographic precipitation enhancement. Quarterly Journal of the Royal Meteorological Society, 134(634):1167-1182.

Zhang L., Hickel K., Dawes W., Chiew F., Western A., Briggs P. (2004). A rational function approach for estimating mean annual evapotranspiration. Water Resources Research, 40(2):W02502. 


\section{Appendix A}

\section{Rain gauges in the Southern}

\section{Alps}

This appendix contains details of rain gauges in the Southern Alps that were operational between 1 January 1971 and 31 December 2000, including precipitation recorded during this period. The gauges are separated into five tables, which correspond to the five transects of the Southern Alps (see Figure 3.2): northeast Hokitika, southwest Hokitika, Franz Josef, Haast and Milford. Within each table, gauges are listed from northwest to southeast. Gauges more than $20 \mathrm{~km}$ southeast of the domain's baseline have been omitted. 
Table A.1 Rain gauges in the northeast Hokitika transect of the Southern Alps from 1 Jan 1971 to 31 Dec 2000. Total number of gauges: 84; CliDB gauges: 61; WRA gauges: 23. 'Begin Date' is the date of the first daily observation between 1 Jan 1971 and 31 Dec 2000; 'End Date' is the date of the last daily observation between 1 Jan 1971 and 31 Dec 2000; 'Obs. Years' is the number of years of observation by each gauge between 1 Jan 1971 and 31 Dec 2000. ' $\bar{p}$ Daily' is mean daily precipitation; ' $\bar{p}$ Annual' is mean annual precipitation.

\begin{tabular}{|c|c|c|c|c|c|c|c|c|c|c|c|}
\hline $\begin{array}{l}\text { Network/ } \\
\text { Site No. }\end{array}$ & Archive & Station Name & $\begin{array}{r}\text { Easting } \\
\text { (NZMG) }\end{array}$ & $\begin{array}{l}\text { Northing } \\
\text { (NZMG) }\end{array}$ & $\begin{array}{c}\text { Elevation } \\
\text { (ma.s.l.) }\end{array}$ & $\begin{array}{r}\text { NW Dist } \\
(\mathrm{km})\end{array}$ & $\begin{array}{r}\text { Begin } \\
\text { Date }\end{array}$ & $\begin{array}{l}\text { End } \\
\text { Date }\end{array}$ & $\begin{array}{r}\text { Obs. } \\
\text { Years }\end{array}$ & $\begin{array}{r}\bar{p} \text { Daily } \\
\left(\mathrm{mm} \mathrm{dy}^{-1}\right)\end{array}$ & $\begin{array}{r}\bar{p} \text { Annual } \\
\left(\mathrm{mm} \mathrm{a}^{-1}\right)\end{array}$ \\
\hline F21321 & $\mathrm{CDB}$ & Rapahoe 1 & 2365867 & 5869819 & 12 & 128.7 & $1 / 1971$ & $4 / 1972$ & 1.3 & 5.6 & 2032 \\
\hline F21322 & $\mathrm{CDB}$ & Rapahoe 2 & 2365640 & 5868814 & 10 & 128.1 & $5 / 1981$ & $12 / 2000$ & 18.7 & 8.1 & 2969 \\
\hline F21424 & $\mathrm{CDB}$ & Runanga Carroll St & 2366031 & 5865933 & & 125.5 & $1 / 1988$ & $12 / 1988$ & 1.0 & 8.0 & 2936 \\
\hline F21423 & $\mathrm{CDB}$ & Runanga & 2366439 & 5866053 & 6 & 125.4 & $5 / 1987$ & $8 / 1992$ & 5.2 & 8.1 & 2968 \\
\hline F21331 & $\mathrm{CDB}$ & Rewanui State Mine & 2370923 & 5868367 & 192 & 124.6 & $1 / 1971$ & $1 / 1985$ & 14.1 & 10.4 & 3792 \\
\hline $\mathrm{F} 21421$ & $\mathrm{CDB}$ & Greymouth $\mathrm{Hbr}$ & 2362272 & 5860631 & 3 & 123.4 & $1 / 1971$ & $6 / 1990$ & 19.3 & 6.8 & 2474 \\
\hline $\mathrm{F} 21422$ & $\mathrm{CDB}$ & Greymouth Aero & 2361234 & 5859164 & 4 & 122.9 & $1 / 1971$ & $12 / 2000$ & 30.0 & 6.8 & 2476 \\
\hline F21512 & $\mathrm{CDB}$ & Paroa & 2359638 & 5853130 & 11 & 118.9 & $1 / 1971$ & $12 / 2000$ & 30.0 & 7.5 & 2725 \\
\hline F21431 & $\mathrm{CDB}$ & Dobson & 2371248 & 5860373 & 14 & 117.9 & $1 / 1971$ & $12 / 2000$ & 29.3 & 7.9 & 2876 \\
\hline F21532 & $\mathrm{CDB}$ & Kokiri,Maori Gully Rd & 2375734 & 5853906 & 143 & 110.1 & $9 / 1980$ & $12 / 2000$ & 20.3 & 9.5 & 3484 \\
\hline F20794 & $\mathrm{CDB}$ & Hokitika Aws & 2344807 & 5830564 & 38 & 109.5 & $12 / 1981$ & $12 / 2000$ & 16.9 & 8.1 & 2943 \\
\hline F20793 & CDB & Hokitika Aero & 2345217 & 5830574 & 39 & 109.3 & $1 / 1971$ & $12 / 2000$ & 30.0 & 7.9 & 2875 \\
\hline F21541 & $\mathrm{CDB}$ & Arnold Power Station & 2379214 & 5852528 & 75 & 106.9 & $1 / 1971$ & $7 / 1995$ & 24.5 & 8.5 & 3121 \\
\hline F21701 & $\mathrm{CDB}$ & Kaniere & 2346284 & 5827044 & 8 & 105.8 & $1 / 1971$ & $5 / 1972$ & 1.4 & 6.5 & 2378 \\
\hline F21601 & $\mathrm{CDB}$ & Awatuna & 2351781 & 5830173 & 6 & 105.1 & $1 / 1971$ & $7 / 1981$ & 10.2 & 7.0 & 2545 \\
\hline F21711 & $\mathrm{CDB}$ & Kumara Reservoir & 2361884 & 5832843 & 151 & 101.2 & $1 / 1988$ & $10 / 1989$ & 1.4 & 11.9 & 4356 \\
\hline 216510 & WRA & Moana at Lake Brunner rain & 2384400 & 5846700 & 90 & 99.1 & $5 / 1989$ & $1 / 2001$ & 8.4 & 8.2 & 2990 \\
\hline F21631 & $\mathrm{CDB}$ & Mitchells & 2378471 & 5839737 & 130 & 97.0 & $4 / 1987$ & $1 / 1994$ & 6.8 & 10.7 & 3901 \\
\hline 218117 & WRA & Butchers Ck at Butchers Gully & 2354671 & 5821990 & 140 & 96.7 & $8 / 1972$ & $1 / 2001$ & 27.5 & 10.7 & 3892 \\
\hline F21812 & $\mathrm{CDB}$ & Lake Kaniere & 2357709 & 5821529 & 133 & 94.6 & $1 / 1971$ & $10 / 1989$ & 18.3 & 10.6 & 3885 \\
\hline F21641 & $\mathrm{CDB}$ & Inchbonnie & 2383093 & 5833824 & 116 & 89.5 & $1 / 1971$ & $12 / 2000$ & 30.0 & 13.7 & 5009 \\
\hline F21653 & $\mathrm{CDB}$ & Rotomanu 2 & 2393832 & 5838458 & 107 & 86.9 & $1 / 1971$ & $12 / 2000$ & 29.7 & 9.6 & 3519 \\
\hline 217411 & WRA & Taipo at SHB & 2379300 & 5826800 & 105 & 86.1 & $2 / 1987$ & $1 / 2001$ & 11.9 & 13.1 & 4773 \\
\hline $\mathrm{F} 21741$ & $\mathrm{CDB}$ & Taipo & 2380425 & 5827552 & 122 & 86.0 & $1 / 1971$ & $12 / 1971$ & 1.0 & 10.0 & 3638 \\
\hline 219211 & WRA & Styx at Mt Browning & 2371100 & 5809600 & 1160 & 77.0 & $3 / 1989$ & $10 / 2000$ & 6.6 & 25.3 & 9243 \\
\hline F21851 & $\mathrm{CDB}$ & Otira Substation & 2392534 & 5818548 & 383 & 71.6 & $1 / 1971$ & $10 / 1987$ & 16.8 & 13.9 & 5077 \\
\hline 310311 & WRA & Wilberforce at Clough Memorial & 2374835 & 5804244 & 975 & 70.5 & $2 / 1981$ & $8 / 1999$ & 14.8 & 23.2 & 8461 \\
\hline 310312 & WRA & Wilberforce at Cabot Ridge & 2370665 & 5797127 & 1450 & 67.2 & $4 / 1994$ & $10 / 1998$ & 3.4 & 26.6 & 9731 \\
\hline 310510 & WRA & Waimakariri at Carrington & 2383440 & 5803758 & 823 & 65.0 & $3 / 1989$ & $1 / 2001$ & 11.1 & 17.9 & 6538 \\
\hline 310314 & WRA & Wilberforce at Griffiths Confluenc & 2371448 & 5794215 & 700 & 64.4 & $4 / 1994$ & $3 / 1998$ & 3.5 & 19.1 & 6963 \\
\hline H21952 & $\mathrm{CDB}$ & Arthurs Pass Store & 2392495 & 5806548 & 748 & 61.9 & $1 / 1971$ & $11 / 1991$ & 16.3 & 12.5 & 4582 \\
\hline
\end{tabular}


Table A.1 (continued)

\begin{tabular}{|c|c|c|c|c|c|c|c|c|c|c|c|}
\hline $\begin{array}{r}\text { Network/ } \\
\text { Site No. }\end{array}$ & Archive & Station Name & $\begin{array}{r}\text { Easting } \\
\text { (NZMG) }\end{array}$ & $\begin{array}{l}\text { Northing } \\
\text { (NZMG) }\end{array}$ & $\begin{array}{c}\text { Elevation } \\
\text { (m a.s.l.) }\end{array}$ & $\begin{array}{r}\text { NW Dist } \\
(\mathrm{km})\end{array}$ & $\begin{array}{r}\text { Begin } \\
\text { Date }\end{array}$ & $\begin{array}{r}\text { End } \\
\text { Date }\end{array}$ & $\begin{array}{l}\text { Obs. } \\
\text { Years }\end{array}$ & $\begin{array}{r}\bar{p} \text { Daily } \\
\left(\mathrm{mm} \mathrm{dy}^{-1}\right)\end{array}$ & $\begin{array}{c}\bar{p} \text { Annual } \\
\left(\mathrm{mm} \mathrm{a}^{-1}\right)\end{array}$ \\
\hline H21954 & $\mathrm{CDB}$ & Arthurs Pass & 2392660 & 5806440 & 740 & 61.8 & $1 / 1971$ & $3 / 1991$ & 18.7 & 12.5 & 4555 \\
\hline H 21951 & $\mathrm{CDB}$ & Arthurs Pass & 2392723 & 5806310 & 738 & 61.6 & $1 / 1971$ & $12 / 2000$ & 29.8 & 12.2 & 4452 \\
\hline 219510 & WRA & Waimakariri at Arthurs Pass & 2392500 & 5806100 & 750 & 61.6 & $1 / 1971$ & $1 / 2001$ & 28.6 & 12.6 & 4605 \\
\hline 218810 & WRA & Waimakariri at Ranger Stm & 2416445 & 5814501 & 625 & 54.2 & 9/1978 & $1 / 2001$ & 20.7 & 6.8 & 2475 \\
\hline 311301 & WRA & Rakaia at Fang Hill & 2376928 & 5784436 & 625 & 53.3 & $5 / 1972$ & $8 / 1999$ & 24.0 & 6.4 & 2342 \\
\hline H31141 & $\mathrm{CDB}$ & Glenthorne & 2383521 & 5779863 & 610 & 45.7 & $1 / 1971$ & $12 / 2000$ & 29.8 & 4.1 & 1510 \\
\hline H31072 & $\mathrm{CDB}$ & Cass & 2408568 & 5796140 & 610 & 44.1 & $1 / 1971$ & $2 / 1975$ & 4.2 & 2.8 & 1014 \\
\hline H31241 & $\mathrm{CDB}$ & Harper River & 2384972 & 5776192 & 533 & 41.9 & $1 / 1971$ & $12 / 2000$ & 30.0 & 3.5 & 1273 \\
\hline 311810 & WRA & Waimakariri at Grasmere & 2409682 & 5793803 & 600 & 41.5 & $12 / 1988$ & $1 / 2001$ & 12.0 & 2.9 & 1077 \\
\hline 311610 & WRA & Harper at Cockayne rain & 2397600 & 5783900 & 740 & 40.7 & $4 / 1994$ & $12 / 1997$ & 3.6 & 4.7 & 1702 \\
\hline H31163 & $\mathrm{CDB}$ & Ski Basin Edl & 2402781 & 5785829 & 1554 & 39.2 & $5 / 1985$ & $8 / 1986$ & 1.3 & 4.0 & 1457 \\
\hline H31162 & $\mathrm{CDB}$ & Ski Basin & 2402781 & 5785829 & 1554 & 39.2 & $1 / 1971$ & $9 / 1986$ & 8.1 & 4.3 & 1578 \\
\hline 311710 & WRA & Camp Stream at Craigieburn rain & 2404343 & 5785568 & 1370 & 38.0 & $4 / 1978$ & $1 / 1994$ & 15.7 & 5.9 & 2150 \\
\hline H31173 & $\mathrm{CDB}$ & Camp Stream & 2404734 & 5785749 & 1433 & 37.9 & $1 / 1971$ & $7 / 1974$ & 3.2 & 4.2 & 1545 \\
\hline H31172 & $\mathrm{CDB}$ & Craigieburn Forest & 2405427 & 5783093 & 914 & 35.4 & $1 / 1971$ & $12 / 2000$ & 29.9 & 4.0 & 1467 \\
\hline H31171 & $\mathrm{CDB}$ & Flockhill & 2410108 & 5785608 & 655 & 34.6 & $1 / 1971$ & $3 / 1974$ & 3.0 & 3.0 & 1087 \\
\hline H31091 & $\mathrm{CDB}$ & Mt White Stn & 2423341 & 5794455 & 610 & 34.0 & $7 / 1971$ & $12 / 2000$ & 25.3 & 2.8 & 1031 \\
\hline 321710 & WRA & Waimakariri at Cheeseman & 2403600 & 5780000 & 880 & 34.0 & $6 / 1990$ & $1 / 2001$ & 10.5 & 3.8 & 1373 \\
\hline H31181 & $\mathrm{CDB}$ & Craigieburn Stn & 2417631 & 5788936 & 610 & 32.9 & $1 / 1971$ & $6 / 1972$ & 1.4 & 2.7 & 991 \\
\hline H31251 & $\mathrm{CDB}$ & Simois Creek & 2392096 & 5768430 & 549 & 31.4 & $1 / 1971$ & $12 / 1987$ & 17.0 & 2.5 & 918 \\
\hline H 31252 & $\mathrm{CDB}$ & Glenthorne Lower Station & 2391785 & 5767647 & 564 & 31.0 & $9 / 1985$ & $12 / 2000$ & 15.3 & 2.6 & 947 \\
\hline H31271 & $\mathrm{CDB}$ & Castle Hill & 2405607 & 5776651 & 715 & 30.1 & $1 / 1971$ & $12 / 2000$ & 28.1 & 2.7 & 972 \\
\hline 311910 & WRA & Waimakariri at Esk rain & 2425700 & 5787100 & 400 & 26.6 & $5 / 1990$ & $1 / 2001$ & 9.8 & 2.8 & 1021 \\
\hline H31351 & $\mathrm{CDB}$ & L Coleridge Homestead & 2395463 & 5761377 & 514 & 23.7 & $1 / 1971$ & $12 / 2000$ & 30.0 & 2.4 & 868 \\
\hline 314710 & WRA & Rakaia at Dry Acheron & 2401771 & 5755618 & 655 & 15.4 & $6 / 1985$ & $1 / 2001$ & 15.6 & 3.2 & 1165 \\
\hline 322110 & WRA & Ashley at Townshend & 2434180 & 5779062 & 470 & 15.1 & $2 / 1976$ & $1 / 2001$ & 24.5 & 3.7 & 1357 \\
\hline H31391 & $\mathrm{CDB}$ & Mt Torlesse & 2422902 & 5765118 & 378 & 10.6 & $1 / 1971$ & $11 / 1996$ & 25.4 & 2.8 & 1020 \\
\hline 313710 & WRA & Selwyn at 13 Mile Bush & 2411990 & 5756899 & 488 & 10.4 & $6 / 1973$ & $1 / 2001$ & 24.1 & 3.5 & 1262 \\
\hline H31471 & $\mathrm{CDB}$ & High Peak Station & 2407472 & 5750125 & 457 & 7.6 & $1 / 1971$ & $11 / 2000$ & 29.3 & 3.3 & 1196 \\
\hline 314701 & WRA & Selwyn at High Peak & 2407629 & 5750237 & 457 & 7.6 & $12 / 1987$ & $1 / 2001$ & 13.1 & 2.7 & 982 \\
\hline H32301 & $\mathrm{CDB}$ & View Hill & 2431636 & 5767447 & 335 & 7.3 & $1 / 1971$ & $5 / 1979$ & 8.3 & 3.0 & 1107 \\
\hline H31382 & $\mathrm{CDB}$ & Dalethorpe & 2418786 & 5757509 & 396 & 6.8 & $1 / 1971$ & $12 / 1980$ & 9.9 & 3.3 & 1206 \\
\hline H31482 & $\mathrm{CDB}$ & Steventon & 2416889 & 5754039 & & 5.2 & $1 / 1971$ & $12 / 1976$ & 5.0 & 1.9 & 701 \\
\hline 322210 & WRA & Ashley at Ashley Gorge No 1 & 2446168 & 5773516 & 247 & 3.6 & $1 / 1971$ & $1 / 1988$ & 15.2 & 3.2 & 1177 \\
\hline H31472 & $\mathrm{CDB}$ & Windwhistle,Rockwood & 2410276 & 5746611 & 366 & 3.1 & $1 / 1971$ & $10 / 1973$ & 2.5 & 2.7 & 983 \\
\hline H31571 & $\mathrm{CDB}$ & Waverley & 2407078 & 5744119 & 381 & 3.0 & $1 / 1971$ & $12 / 1984$ & 5.8 & 2.8 & 1010 \\
\hline H32213 & $\mathrm{CDB}$ & Glentui 2 & 2444191 & 5769802 & 274 & 1.8 & $2 / 1984$ & $12 / 1998$ & 14.9 & 2.7 & 991 \\
\hline H 32222 & $\mathrm{CDB}$ & Oxford & 2444515 & 5769917 & 259 & 1.7 & $1 / 1971$ & $3 / 1973$ & 2.2 & 2.3 & 843 \\
\hline H3148B & $\mathrm{CDB}$ & Glendore & 2415589 & 5748465 & 360 & 1.4 & $1 / 1972$ & $12 / 1976$ & 3.0 & 2.6 & 954 \\
\hline 324110 & WRA & Waimakariri at Waimakariri Gorge & 2433142 & 5760479 & 260 & 0.8 & $12 / 1987$ & $1 / 2001$ & 12.4 & 2.1 & 763 \\
\hline
\end{tabular}


Table A.1 (continued)

\begin{tabular}{|c|c|c|c|c|c|c|c|c|c|c|c|}
\hline $\begin{array}{l}\text { Network/ } \\
\text { Site No. }\end{array}$ & Archive & Station Name & $\begin{array}{r}\text { Easting } \\
(\mathrm{NZMG})\end{array}$ & $\begin{array}{l}\text { Northing } \\
\text { (NZMG) }\end{array}$ & $\begin{array}{c}\text { Elevation } \\
\text { (m a.s.l.) }\end{array}$ & $\begin{array}{r}\text { NW Dist } \\
(\mathrm{km})\end{array}$ & $\begin{array}{r}\text { Begin } \\
\text { Date }\end{array}$ & $\begin{array}{l}\text { End } \\
\text { Date }\end{array}$ & $\begin{array}{l}\text { Obs. } \\
\text { Years }\end{array}$ & $\begin{array}{r}\bar{p} \text { Daily } \\
\left(\mathrm{mm} \mathrm{dy}^{-1}\right)\end{array}$ & $\begin{array}{l}\bar{p} \text { Annual } \\
\left(\mathrm{mm} \mathrm{a}^{-1}\right)\end{array}$ \\
\hline H31592 & $\mathrm{CDB}$ & Woodlands & 2409210 & 5742151 & 366 & 0.1 & $1 / 1971$ & $12 / 1991$ & 15.0 & 3.0 & 1079 \\
\hline H32311 & $\mathrm{CDB}$ & Oxford 2 & 2444217 & 5767136 & 232 & -0.4 & $4 / 1973$ & $1 / 1984$ & 10.8 & 2.7 & 978 \\
\hline H32312 & $\mathrm{CDB}$ & Oxford, Matai & 2444243 & 5767028 & 237 & -0.5 & $6 / 1995$ & $12 / 2000$ & 5.6 & 2.4 & 886 \\
\hline 315910 & WRA & Selwyn at Whitecliffs rain & 2420369 & 5748637 & 280 & -1.2 & $5 / 1988$ & $1 / 2001$ & 12.6 & 2.6 & 947 \\
\hline H31581 & $\mathrm{CDB}$ & Hororata West & 2417613 & 5741154 & 287 & -5.7 & $1 / 1971$ & $12 / 2000$ & 30.0 & 2.5 & 919 \\
\hline H 32402 & $\mathrm{CDB}$ & Homebush & 2428443 & 5747710 & 244 & -6.8 & $1 / 1971$ & $12 / 2000$ & 26.9 & 2.4 & 888 \\
\hline H31591 & $\mathrm{CDB}$ & Hororata & 2420964 & 5739760 & 213 & -8.8 & $1 / 1971$ & $12 / 2000$ & 30.0 & 2.4 & 866 \\
\hline H31594 & $\mathrm{CDB}$ & Hororata, Illana & 2424831 & 5741786 & 196 & -9.4 & 9/1994 & $12 / 2000$ & 6.3 & 2.2 & 789 \\
\hline H31593 & $\mathrm{CDB}$ & Hororata Substation & 2427673 & 5739734 & 192 & -12.7 & $1 / 1971$ & $9 / 1993$ & 21.0 & 2.2 & 799 \\
\hline H 32424 & $\mathrm{CDB}$ & Eyrewell Forest & 2451530 & 5756649 & 158 & -13.2 & $1 / 1971$ & $12 / 1989$ & 19.0 & 2.1 & 776 \\
\hline H 32412 & $\mathrm{CDB}$ & Darfield & 2440217 & 5745875 & 195 & -15.2 & $1 / 1971$ & $12 / 2000$ & 30.0 & 2.2 & 798 \\
\hline H 32416 & $\mathrm{CDB}$ & Darfield Ews & 2441272 & 5745553 & 190 & -16.1 & $8 / 1999$ & $12 / 2000$ & 1.4 & 2.0 & 717 \\
\hline H32415 & CDB & Darfield Forest Plns & 2441114 & 5745218 & 184 & -16.3 & $4 / 1989$ & $12 / 1997$ & 8.8 & 2.2 & 803 \\
\hline
\end{tabular}


Table A.2 Rain gauges in the southwest Hokitika transect of the Southern Alps from 1 Jan 1971 to 31 Dec 2000. Total number of gauges: 54; CliDB gauges: 35; WRA gauges: 19. Column headers as per Table A.1.

\begin{tabular}{|c|c|c|c|c|c|c|c|c|c|c|c|}
\hline $\begin{array}{c}\text { Network/ } \\
\text { Site No. }\end{array}$ & Archive & Station Name & $\begin{array}{r}\text { Easting } \\
(\mathrm{NZMG})\end{array}$ & $\begin{array}{l}\text { Northing } \\
\text { (NZMG) }\end{array}$ & $\begin{array}{l}\text { Elevation } \\
\text { (m a.s.1.) }\end{array}$ & $\begin{array}{r}\text { NW Dist } \\
(\mathrm{km})\end{array}$ & $\begin{array}{r}\text { Begin } \\
\text { Date }\end{array}$ & $\begin{array}{l}\text { End } \\
\text { Date }\end{array}$ & $\begin{array}{c}\text { Obs. } \\
\text { Years }\end{array}$ & $\begin{array}{r}\bar{p} \text { Daily } \\
\left(\mathrm{mm} \mathrm{dy}^{-1}\right)\end{array}$ & $\begin{array}{r}\bar{p} \text { Annual } \\
\left(\mathrm{mm} \mathrm{a}^{-1}\right)\end{array}$ \\
\hline F20981 & $\mathrm{CDB}$ & Ross & 2331072 & 5810548 & 15 & 101.5 & $1 / 1971$ & $12 / 2000$ & 30.0 & 8.9 & 3267 \\
\hline F 30061 & $\mathrm{CDB}$ & Pukekura & 2320171 & 5797028 & 86 & 97.0 & $11 / 1982$ & $5 / 1995$ & 12.5 & 9.5 & 3458 \\
\hline F20892 & $\mathrm{CDB}$ & Kowhitirangi Fairhave & 2344564 & 5813556 & 30 & 95.9 & $1 / 1971$ & $12 / 2000$ & 30.0 & 9.2 & 3368 \\
\hline F21802 & $\mathrm{CDB}$ & Kokatahi & 2349729 & 5816346 & 24 & 95.1 & $6 / 1980$ & $6 / 1999$ & 18.9 & 9.4 & 3419 \\
\hline F21801 & $\mathrm{CDB}$ & Kowhitirangi No 2 & 2349262 & 5811890 & 30 & 91.8 & $1 / 1971$ & $12 / 2000$ & 30.0 & 9.4 & 3448 \\
\hline F30071 & $\mathrm{CDB}$ & Waitaha Valley & 2325390 & 5791059 & 70 & 89.1 & $1 / 1971$ & $7 / 1971$ & 0.6 & 6.2 & 2251 \\
\hline 301710 & WRA & Waitaha at Fergusons Farm & 2325700 & 5790375 & 90 & 88.3 & $11 / 1976$ & $1 / 1984$ & 6.3 & 13.2 & 4818 \\
\hline 209910 & WRA & Hokitika at Colliers $\mathrm{Ck}$ rain & 2346500 & 5800100 & 95 & 83.9 & $11 / 1987$ & $1 / 2001$ & 12.2 & 20.8 & 7591 \\
\hline 310010 & WRA & Hokitika at Rapid Ck & 2348160 & 5797546 & 152 & 80.9 & $1 / 1971$ & $1 / 2001$ & 28.4 & 21.1 & 7698 \\
\hline 301910 & WRA & Tuke at Tuke Hut & 2338166 & 5788770 & 975 & 79.7 & $5 / 1977$ & $1 / 2001$ & 23.5 & 29.1 & 10625 \\
\hline 301810 & WRA & Waitaha at MoonBeam Torrent & 2331412 & 5782978 & 410 & 79.0 & $6 / 1977$ & $4 / 1982$ & 3.6 & 18.0 & 6569 \\
\hline 311015 & WRA & Cropp at Waterfall & 2342803 & 5790316 & 975 & 78.2 & $6 / 1982$ & $1 / 2001$ & 17.5 & 32.4 & 11825 \\
\hline 301913 & WRA & Cropp at Cropp Hut & 2344271 & 5790069 & 860 & 77.1 & $7 / 1979$ & $1 / 2001$ & 21.0 & 29.8 & 10895 \\
\hline 311010 & WRA & Hokitika at Prices Flat & 2347983 & 5787026 & 427 & 72.5 & $4 / 1971$ & $1 / 2001$ & 27.9 & 20.4 & 7446 \\
\hline 303911 & WRA & Rakaia at Lake Ramsay & 2341113 & 5767332 & 945 & 60.6 & $7 / 1977$ & $1 / 2001$ & 22.1 & 13.2 & 4817 \\
\hline 312110 & WRA & Mathias at NZDSA Hut & 2358196 & 5778522 & 670 & 59.6 & $5 / 1978$ & $1 / 2001$ & 22.4 & 12.5 & 4559 \\
\hline 312111 & WRA & Talus at Talus Tarn rain & 2353640 & 5772495 & 1670 & 57.4 & $5 / 1979$ & $9 / 1986$ & 5.1 & 8.3 & 3032 \\
\hline 313210 & WRA & Rakaia at Glenfalloch & 2365795 & 5762746 & 610 & 42.4 & 3/1977 & $10 / 1982$ & 5.6 & 4.4 & 1604 \\
\hline H31321 & $\mathrm{CDB}$ & Double Hill & 2369930 & 5764675 & 561 & 41.5 & $1 / 1971$ & $12 / 2000$ & 30.0 & 3.7 & 1334 \\
\hline H31331 & $\mathrm{CDB}$ & Glenariffe & 2378037 & 5765060 & 457 & 37.0 & $1 / 1971$ & $10 / 1988$ & 14.4 & 2.4 & 860 \\
\hline $\mathrm{H} 3141 \mathrm{~A}$ & $\mathrm{CDB}$ & Upper Lake Heron & 2363261 & 5750421 & 686 & 33.9 & $1 / 1971$ & $5 / 1981$ & 10.3 & 2.7 & 993 \\
\hline H31341 & $\mathrm{CDB}$ & Peak Hill & 2384208 & 5764844 & 411 & 33.2 & $1 / 1971$ & $12 / 1985$ & 14.7 & 2.3 & 828 \\
\hline 314412 & WRA & Ashburton at Turtons Saddle rain & 2377500 & 5759800 & 1140 & 33.1 & $11 / 1994$ & $1 / 2001$ & 6.1 & 2.7 & 1003 \\
\hline 315010 & WRA & Sth Ashburton at Boundary Creek & 2353409 & 5741002 & 1120 & 32.1 & $12 / 1999$ & $1 / 2001$ & 1.1 & 3.8 & 1386 \\
\hline H31352 & $\mathrm{CDB}$ & Lake Coleridge & 2390795 & 5759407 & 364 & 24.9 & $1 / 1971$ & $12 / 2000$ & 28.5 & 2.2 & 820 \\
\hline H31611 & $\mathrm{CDB}$ & Hakatere Stn & 2361886 & 5731944 & 616 & 19.8 & $1 / 1971$ & $10 / 1982$ & 10.9 & 2.4 & 880 \\
\hline H31612 & $\mathrm{CDB}$ & Hakatere & 2362215 & 5731729 & 604 & 19.5 & $12 / 1984$ & $10 / 1991$ & 5.4 & 1.6 & 598 \\
\hline 314411 & WRA & Nth Ashburton at Cookies Hut & 2383388 & 5744625 & 1000 & 17.4 & $12 / 1999$ & $1 / 2001$ & 1.0 & 3.2 & 1180 \\
\hline H31451 & $\mathrm{CDB}$ & Mt Hutt Skifield & 2391688 & 5745423 & 1600 & 13.1 & $8 / 1989$ & $10 / 1993$ & 0.5 & 1.7 & 615 \\
\hline H31621 & $\mathrm{CDB}$ & Mt Possession & 2367168 & 5726613 & 610 & 12.4 & $1 / 1971$ & $11 / 1980$ & 8.3 & 2.4 & 874 \\
\hline 316310 & WRA & Sth Ashburton at Mt Somers rain & 2373675 & 5731337 & 807 & 12.4 & $2 / 1988$ & $1 / 2001$ & 12.6 & 2.8 & 1017 \\
\hline H31461 & $\mathrm{CDB}$ & Bayfields & 2399907 & 5747451 & 497 & 9.9 & $1 / 1971$ & $7 / 1979$ & 8.6 & 3.3 & 1222 \\
\hline 315510 & WRA & Pudding Hill Stm at Mt Hutt & 2391622 & 5740256 & 1066 & 9.0 & $2 / 1988$ & $1 / 2001$ & 12.3 & 4.6 & 1678 \\
\hline H31463 & $\mathrm{CDB}$ & Snowdon Ews & 2402568 & 5747938 & 560 & 8.7 & $6 / 1999$ & $12 / 2000$ & 1.5 & 3.5 & 1282 \\
\hline 315610 & WRA & Rakaia at Fighting Hill rain & 2399699 & 5743693 & 290 & 7.0 & $4 / 1988$ & $8 / 2000$ & 11.9 & 2.5 & 913 \\
\hline 317210 & WRA & Rangitata at Klondyke & 2366600 & 5714900 & 400 & 3.3 & $6 / 1991$ & $1 / 2001$ & 9.5 & 2.7 & 971 \\
\hline H31733 & $\mathrm{CDB}$ & Evandale & 2376411 & 5721768 & 396 & 3.0 & $1 / 1971$ & $12 / 2000$ & 29.5 & 2.7 & 1004 \\
\hline
\end{tabular}


Table A.2 (continued)

\begin{tabular}{|c|c|c|c|c|c|c|c|c|c|c|c|}
\hline $\begin{array}{l}\text { Network/ } \\
\text { Site No. }\end{array}$ & Archive & Station Name & $\begin{array}{r}\text { Easting } \\
(\mathrm{NZMG})\end{array}$ & $\begin{array}{l}\text { Northing } \\
\text { (NZMG) }\end{array}$ & $\begin{array}{l}\text { Elevation } \\
\text { (m a.s.l.) }\end{array}$ & $\begin{array}{r}\text { NW Dist } \\
(\mathrm{km})\end{array}$ & $\begin{array}{r}\text { Begin } \\
\text { Date }\end{array}$ & $\begin{array}{l}\text { End } \\
\text { Date }\end{array}$ & $\begin{array}{c}\text { Obs. } \\
\text { Years }\end{array}$ & $\begin{array}{r}\bar{p} \text { Daily } \\
\left(\mathrm{mm} \mathrm{dy}^{-1}\right)\end{array}$ & $\begin{array}{r}\bar{p} \text { Annual } \\
\left(\mathrm{mm} \mathrm{a}^{-1}\right)\end{array}$ \\
\hline H31642 & $\mathrm{CDB}$ & Staveley, Birchlands & 2385096 & 5727898 & 382 & 2.8 & $1 / 1971$ & $12 / 2000$ & 29.9 & 3.3 & 1220 \\
\hline H31721 & $\mathrm{CDB}$ & Mayfield, Temora & 2369416 & 5715751 & 468 & 2.3 & $5 / 1983$ & $12 / 2000$ & 17.6 & 2.6 & 953 \\
\hline H31641 & $\mathrm{CDB}$ & Mt Somers, Somer Downs & 2382045 & 5724912 & 372 & 2.2 & $4 / 2000$ & $12 / 2000$ & 0.8 & 3.6 & 1312 \\
\hline H31655 & $\mathrm{CDB}$ & Methven,Alaska & 2394016 & 5732351 & 402 & 1.2 & $1 / 1971$ & $12 / 2000$ & 30.0 & 3.2 & 1155 \\
\hline H31651 & $\mathrm{CDB}$ & Alford Forest 1 & 2391162 & 5729301 & 390 & 0.4 & $1 / 1971$ & $12 / 2000$ & 29.6 & 3.0 & 1078 \\
\hline H31736 & $\mathrm{CDB}$ & Mt Somers & 2381146 & 5721339 & 383 & -0.1 & $12 / 1980$ & $12 / 2000$ & 20.1 & 2.6 & 933 \\
\hline H31742 & $\mathrm{CDB}$ & Mt Somers,Motels & 2381002 & 5720447 & 366 & -0.7 & $1 / 1971$ & $7 / 1991$ & 16.8 & 2.5 & 918 \\
\hline H31734 & $\mathrm{CDB}$ & Mayfield,Brackley & 2373886 & 5713640 & 396 & -2.0 & $1 / 1971$ & $4 / 1979$ & 7.9 & 2.8 & 1024 \\
\hline H31643 & $\mathrm{CDB}$ & Springburn & 2387752 & 5723258 & 312 & -2.5 & $1 / 1971$ & $12 / 2000$ & 30.0 & 2.5 & 915 \\
\hline $\mathrm{H} 31572$ & $\mathrm{CDB}$ & Highbank Power Stn & 2407922 & 5736354 & 230 & -3.8 & $1 / 1971$ & $12 / 2000$ & 30.0 & 2.6 & 932 \\
\hline H31661 & $\mathrm{CDB}$ & Methven & 2400961 & 5729143 & 332 & -5.5 & $1 / 1971$ & $12 / 2000$ & 30.0 & 2.6 & 956 \\
\hline H31743 & $\mathrm{CDB}$ & Mt Somers,Buccleugh & 2387490 & 5718235 & 296 & -6.4 & $1 / 1971$ & 9/1992 & 21.7 & 2.3 & 847 \\
\hline H31671 & $\mathrm{CDB}$ & Rakaia, Greenfields & 2407705 & 5732621 & 305 & -6.7 & $1 / 1971$ & $12 / 2000$ & 30.0 & 2.4 & 894 \\
\hline H31771 & $\mathrm{CDB}$ & Lyndhurst Limewood Farm & 2406606 & 5722111 & 243 & -14.5 & $1 / 1971$ & $12 / 2000$ & 30.0 & 2.1 & 781 \\
\hline H31681 & $\mathrm{CDB}$ & Creeside & 2415498 & 5726131 & 226 & -16.5 & $1 / 1971$ & $6 / 1983$ & 12.5 & 2.3 & 825 \\
\hline H31851 & $\mathrm{CDB}$ & Hackthorne & 2395671 & 5710934 & 198 & -17.1 & $1 / 1971$ & $8 / 1998$ & 26.8 & 2.1 & 758 \\
\hline H31943 & $\mathrm{CDB}$ & Lismore,Midway & 2383078 & 5700151 & 213 & -18.3 & $1 / 1971$ & $12 / 1982$ & 12.0 & 2.2 & 800 \\
\hline
\end{tabular}


Table A.3 Rain gauges in the Franz Josef transect of the Southern Alps from 1 Jan 1971 to 31 Dec 2000. Total gauges: 73; CliDB gauges: 51; WRA gauges: 22. Column headers as per Table A.1.

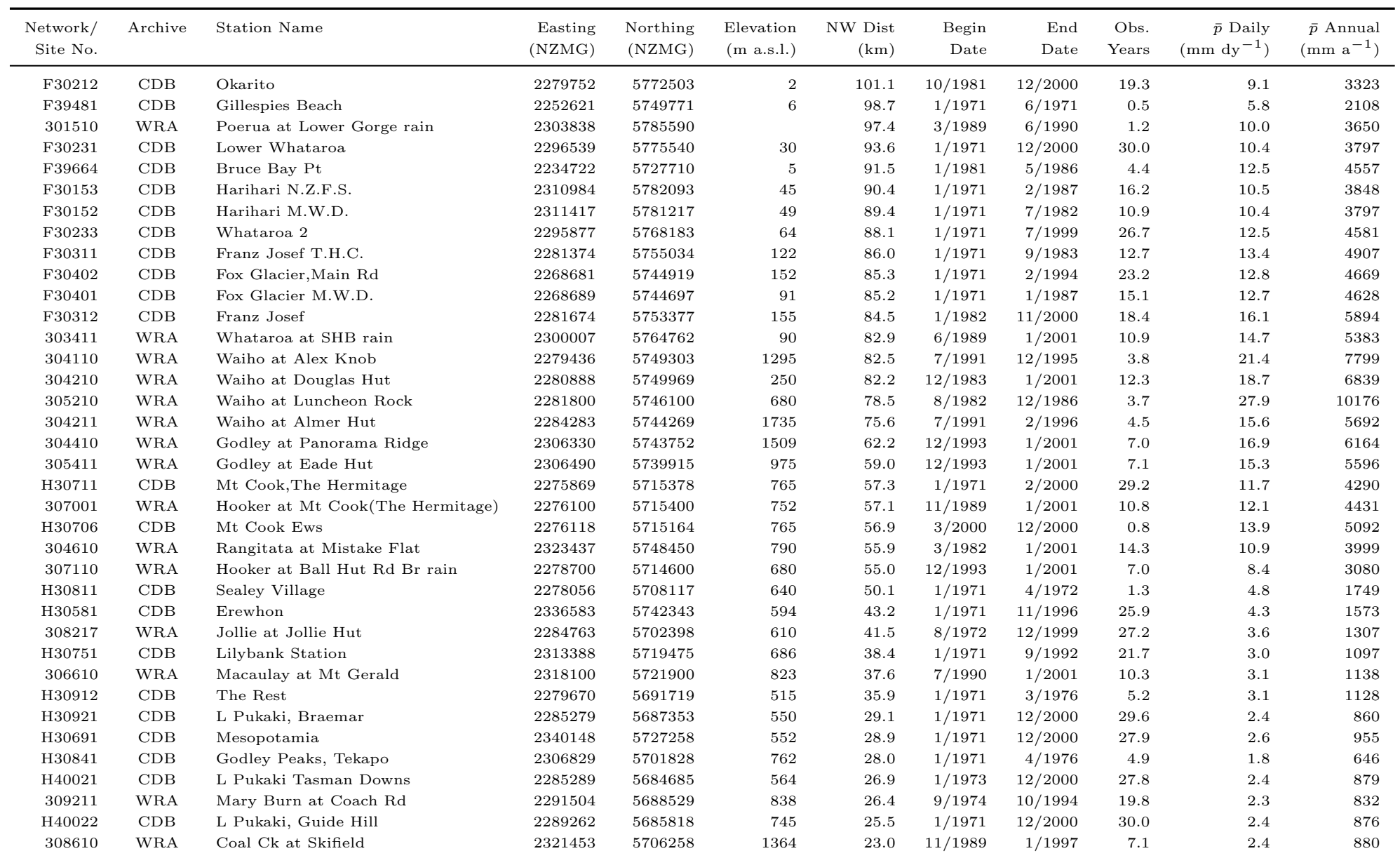


Table A.3 (continued)

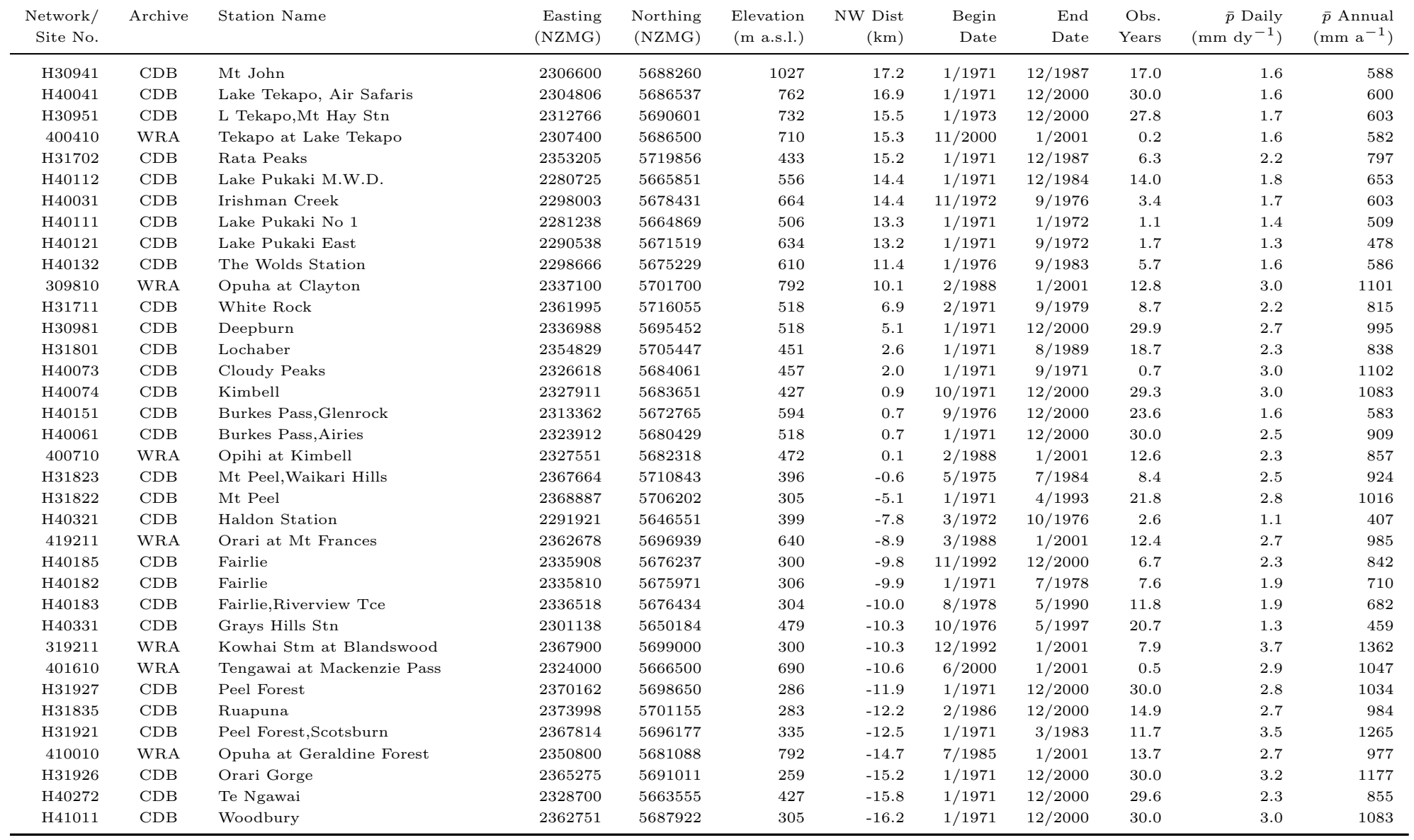


Table A.4 Rain gauges in the Haast transect of the Southern Alps from 1 Jan 1971 to 31 Dec 2000. Total number of gauges: 49; CliDB gauges: 39; WRA gauges: 10. Column headers as per Table A.1.

\begin{tabular}{|c|c|c|c|c|c|c|c|c|c|c|c|}
\hline $\begin{array}{c}\text { Network/ } \\
\text { Site No. }\end{array}$ & Archive & Station Name & $\begin{array}{r}\text { Easting } \\
(\mathrm{NZMG})\end{array}$ & $\begin{array}{l}\text { Northing } \\
\text { (NZMG) }\end{array}$ & $\begin{array}{c}\text { Elevation } \\
\text { (m a.s.l.) }\end{array}$ & $\begin{array}{r}\text { NW Dist } \\
(\mathrm{km})\end{array}$ & $\begin{array}{r}\text { Begin } \\
\text { Date }\end{array}$ & $\begin{array}{l}\text { End } \\
\text { Date }\end{array}$ & $\begin{array}{l}\text { Obs. } \\
\text { Years }\end{array}$ & $\begin{array}{r}\bar{p} \text { Daily } \\
\left(\mathrm{mm} \mathrm{dy}^{-1}\right)\end{array}$ & $\begin{array}{r}\bar{p} \text { Annual } \\
\left(\mathrm{mm} \mathrm{a}^{-1}\right)\end{array}$ \\
\hline F39721 & $\mathrm{CDB}$ & Lake Moeraki & 2209374 & 5714494 & 9 & 95.8 & $5 / 1985$ & $12 / 2000$ & 15.6 & 12.3 & 4502 \\
\hline F39803 & $\mathrm{CDB}$ & Haast Aws & 2189128 & 5697641 & 5 & 94.2 & $1 / 1982$ & $12 / 2000$ & 16.6 & 10.4 & 3798 \\
\hline F39801 & $\mathrm{CDB}$ & Haast & 2189213 & 5697533 & 4 & 94.0 & $1 / 1971$ & $8 / 1976$ & 5.7 & 9.0 & 3275 \\
\hline F38981 & $\mathrm{CDB}$ & Okuru,Carters & 2178286 & 5689097 & 6 & 93.7 & $3 / 1971$ & $3 / 1971$ & 0.1 & 7.9 & 2900 \\
\hline F39802 & $\mathrm{CDB}$ & Haast Township & 2191889 & 5695437 & 11 & 90.8 & $1 / 1981$ & $12 / 1989$ & 8.8 & 10.8 & 3927 \\
\hline F39741 & $\mathrm{CDB}$ & Paringa & 2225036 & 5716071 & 43 & 87.8 & $1 / 1971$ & $12 / 2000$ & 29.7 & 15.2 & 5534 \\
\hline F39662 & $\mathrm{CDB}$ & Mahitahi & 2235630 & 5723299 & 30 & 87.4 & $1 / 1971$ & $12 / 2000$ & 29.1 & 12.9 & 4707 \\
\hline 399210 & WRA & Haast at $\mathrm{Cron} \mathrm{Ck}$ & 2202129 & 5686188 & 58 & 77.3 & $12 / 1991$ & $1 / 2001$ & 9.0 & 22.6 & 8249 \\
\hline 399213 & WRA & Haast at Roaring Billy rain & 2212857 & 5689490 & 60 & 73.6 & $3 / 1989$ & $1 / 2001$ & 10.8 & 15.8 & 5766 \\
\hline F39932 & $\mathrm{CDB}$ & Haast,Macpherson Camp & 2214584 & 5688033 & 76 & 71.4 & $2 / 1971$ & $3 / 1980$ & 2.3 & 11.6 & 4230 \\
\hline 399410 & WRA & Haast at $\mathrm{Moa} \mathrm{Ck}$ & 2221639 & 5684164 & 105 & 64.1 & $11 / 1991$ & $1 / 2001$ & 9.1 & 10.8 & 3957 \\
\hline F49132 & $\mathrm{CDB}$ & Haast Pass & 2218661 & 5672086 & 524 & 56.1 & $1 / 1971$ & $11 / 1988$ & 17.9 & 12.3 & 4489 \\
\hline 399811 & WRA & Hopkins at Elcho Flats & 2255937 & 5693559 & 701 & 51.4 & $12 / 1993$ & $1 / 2001$ & 7.0 & 9.9 & 3611 \\
\hline I 49224 & $\mathrm{CDB}$ & Mt Albert Stn & 2207635 & 5657353 & 320 & 50.7 & $5 / 1972$ & $5 / 1973$ & 1.1 & 6.6 & 2400 \\
\hline 492203 & WRA & Makaroa at Makaroa Telemetry & 2208500 & 5655500 & 280 & 48.7 & $11 / 1997$ & $1 / 2001$ & 3.1 & 7.1 & 2586 \\
\hline I 49222 & $\mathrm{CDB}$ & Makarora Station & 2208534 & 5655170 & 320 & 48.4 & $1 / 1971$ & $12 / 2000$ & 30.0 & 6.6 & 2427 \\
\hline 399710 & WRA & Hopkins at Boanerges Ridge & 2252512 & 5685726 & 1402 & 47.1 & $12 / 1993$ & $1 / 2001$ & 7.0 & 9.7 & 3544 \\
\hline 491610 & WRA & Ahuriri at Cassinia Moraine & 2243162 & 5671844 & 980 & 41.4 & $1 / 1971$ & $1 / 2001$ & 29.5 & 7.1 & 2601 \\
\hline I49411 & $\mathrm{CDB}$ & Minaret Bay & 2200127 & 5636759 & 313 & 38.5 & $1 / 1971$ & $12 / 2000$ & 28.2 & 4.1 & 1490 \\
\hline 490810 & WRA & Hopkins at Huxley Lodge & 2257052 & 5677304 & 555 & 37.6 & $5 / 1988$ & $10 / 1994$ & 6.4 & 5.2 & 1900 \\
\hline H49182 & $\mathrm{CDB}$ & Lake Ohau Stn & 2255917 & 5666392 & 533 & 29.5 & $1 / 1971$ & $12 / 2000$ & 30.0 & 3.2 & 1182 \\
\hline I49432 & $\mathrm{CDB}$ & Hunter Valley 2 & 2216075 & 5634933 & 360 & 27.7 & $1 / 1971$ & $12 / 2000$ & 16.6 & 3.2 & 1178 \\
\hline I 49602 & $\mathrm{CDB}$ & West Wanaka Station & 2192661 & 5613151 & 300 & 23.9 & $7 / 1987$ & $1 / 1990$ & 2.6 & 2.6 & 957 \\
\hline I4928A & $\mathrm{CDB}$ & Ahuriri Catchment & 2255848 & 5657272 & 914 & 22.2 & $1 / 1971$ & $7 / 1972$ & 1.6 & 2.9 & 1051 \\
\hline I 49621 & $\mathrm{CDB}$ & Lake Hawea & 2211714 & 5615160 & 350 & 14.3 & $1 / 1971$ & $12 / 2000$ & 29.2 & 2.2 & 798 \\
\hline 494611 & WRA & Ahuriri at Plains & 2245132 & 5638418 & 747 & 13.3 & 9/1971 & $11 / 1994$ & 23.0 & 2.5 & 907 \\
\hline I49613 & $\mathrm{CDB}$ & Wanaka, Park Hq & 2204301 & 5605474 & 305 & 10.8 & $9 / 1990$ & $1 / 1994$ & 3.4 & 1.8 & 648 \\
\hline I 49381 & $\mathrm{CDB}$ & Ribbonwood & 2258028 & 5644123 & 634 & 10.3 & $1 / 1971$ & $12 / 2000$ & 27.0 & 2.3 & 834 \\
\hline H40211 & $\mathrm{CDB}$ & Twizel & 2277792 & 5658189 & 457 & 10.0 & $2 / 1972$ & $5 / 1986$ & 14.3 & 1.8 & 643 \\
\hline I 49612 & $\mathrm{CDB}$ & Albert Town & 2208035 & 5607094 & 293 & 9.9 & $1 / 1971$ & $8 / 1972$ & 1.6 & 1.8 & 659 \\
\hline I49711 & $\mathrm{CDB}$ & Wanaka & 2204664 & 5604490 & 314 & 9.8 & $1 / 1971$ & $8 / 1990$ & 19.7 & 1.9 & 703 \\
\hline I49631 & $\mathrm{CDB}$ & Hawea Flat & 2217018 & 5612063 & 335 & 8.6 & $1 / 1971$ & $12 / 2000$ & 30.0 & 2.0 & 733 \\
\hline H40213 & $\mathrm{CDB}$ & Twizel & 2278729 & 5656554 & 457 & 8.1 & $6 / 1989$ & $12 / 2000$ & 10.8 & 1.7 & 633 \\
\hline $\mathrm{H} 40212$ & $\mathrm{CDB}$ & Twizel Substation & 2278381 & 5655097 & 451 & 7.1 & $4 / 1985$ & 6/1993 & 8.2 & 1.6 & 573 \\
\hline I 49712 & $\mathrm{CDB}$ & Mt Barker & 2207676 & 5602850 & 305 & 6.7 & $1 / 1971$ & $9 / 2000$ & 29.7 & 1.9 & 678 \\
\hline 494711 & WRA & Ahuriri at Sth Diadem rain & 2249600 & 5632100 & 610 & 5.6 & $11 / 1992$ & $1 / 2001$ & 8.0 & 2.3 & 851 \\
\hline I 49723 & $\mathrm{CDB}$ & Wanaka Aero Aws & 2212519 & 5602739 & 352 & 3.8 & $4 / 1992$ & $12 / 2000$ & 8.6 & 1.8 & 670 \\
\hline
\end{tabular}


Table A.4 (continued)

\begin{tabular}{|c|c|c|c|c|c|c|c|c|c|c|c|}
\hline $\begin{array}{r}\text { Network/ } \\
\text { Site No. }\end{array}$ & Archive & Station Name & $\begin{array}{r}\text { Easting } \\
\text { (NZMG) }\end{array}$ & $\begin{array}{r}\text { Northing } \\
\text { (NZMG) }\end{array}$ & $\begin{array}{l}\text { Elevation } \\
\text { (m a.s.l.) }\end{array}$ & $\begin{array}{r}\text { NW Dist } \\
(\mathrm{km})\end{array}$ & $\begin{array}{r}\text { Begin } \\
\text { Date }\end{array}$ & $\begin{array}{c}\text { End } \\
\text { Date }\end{array}$ & $\begin{array}{l}\text { Obs. } \\
\text { Years }\end{array}$ & $\begin{array}{r}\bar{p} \text { Daily } \\
\left(\mathrm{mm} \mathrm{dy}^{-1}\right)\end{array}$ & $\begin{array}{r}\bar{p} \text { Annual } \\
\left(\mathrm{mm} \mathrm{a}^{-1}\right)\end{array}$ \\
\hline I 49721 & $\mathrm{CDB}$ & Luggate & 2214631 & 5601611 & 295 & 1.6 & $1 / 1971$ & $12 / 2000$ & 24.3 & 1.7 & 614 \\
\hline I 49651 & CDB & Morven Hills & 2232725 & 5612413 & 442 & -0.4 & $1 / 1971$ & $8 / 1996$ & 21.9 & 2.0 & 714 \\
\hline I 40401 & $\mathrm{CDB}$ & Chain Hills & 2271647 & 5633621 & 400 & -6.2 & $1 / 1993$ & $12 / 2000$ & 8.0 & 1.3 & 477 \\
\hline I 49592 & $\mathrm{CDB}$ & Tara Hills Aws & 2262833 & 5626625 & 488 & -6.7 & $5 / 1985$ & $12 / 2000$ & 14.9 & 1.4 & 529 \\
\hline I 49591 & $\mathrm{CDB}$ & Omarama,Tara Hills & 2262678 & 5626508 & 488 & -6.7 & $1 / 1971$ & $12 / 1985$ & 15.0 & 1.5 & 534 \\
\hline I $4975 \mathrm{~A}$ & $\mathrm{CDB}$ & Geordie Hill & 2235205 & 5606289 & 455 & -6.8 & $5 / 1987$ & $1 / 1990$ & 2.3 & 1.5 & 559 \\
\hline I 49822 & $\mathrm{CDB}$ & Queensbury Ews & 2217692 & 5586399 & 277 & -12.5 & $11 / 1978$ & $5 / 1992$ & 13.6 & 1.8 & 652 \\
\hline $\mathrm{H} 40421$ & CDB & Black Forest Stn & 2291272 & 5639638 & 366 & -13.0 & $11 / 1973$ & $1 / 1990$ & 10.7 & 1.3 & 462 \\
\hline I 49841 & $\mathrm{CDB}$ & Tarras & 2227530 & 5591170 & 290 & -14.4 & $1 / 1971$ & $7 / 1986$ & 15.4 & 1.3 & 487 \\
\hline I49931 & $\mathrm{CDB}$ & Bendigo 1 & 2219014 & 5583343 & 202 & -15.7 & $1 / 1971$ & $6 / 1979$ & 8.5 & 1.2 & 440 \\
\hline I49932 & $\mathrm{CDB}$ & Bendigo 2 & 2218290 & 5579694 & 200 & -18.2 & $5 / 1978$ & $5 / 1992$ & 14.1 & 1.1 & 416 \\
\hline I 40501 & $\mathrm{CDB}$ & Otamatapaio & 2277769 & 5622610 & 411 & -18.7 & $1 / 1971$ & $1 / 1986$ & 13.0 & 1.4 & 501 \\
\hline
\end{tabular}


Table A.5 Rain gauges in the Milford transect of the Southern Alps from 1 Jan 1971 to 31 Dec 2000. Total number of gauges: 46; CliDB gauges: 38; WRA gauges: 8. Column headers as per Table A.1.

\begin{tabular}{|c|c|c|c|c|c|c|c|c|c|c|c|}
\hline $\begin{array}{c}\text { Network/ } \\
\text { Site No. }\end{array}$ & Archive & Station Name & $\begin{array}{r}\text { Easting } \\
(\mathrm{NZMG})\end{array}$ & $\begin{array}{r}\text { Northing } \\
\text { (NZMG) }\end{array}$ & $\begin{array}{l}\text { Elevation } \\
\text { (m a.s.l.) }\end{array}$ & $\begin{array}{r}\text { NW Dist } \\
(\mathrm{km})\end{array}$ & $\begin{array}{r}\text { Begin } \\
\text { Date }\end{array}$ & $\begin{array}{l}\text { End } \\
\text { Date }\end{array}$ & $\begin{array}{c}\text { Obs. } \\
\text { Years }\end{array}$ & $\begin{array}{r}\bar{p} \text { Daily } \\
\left(\mathrm{mm} \mathrm{dy}^{-1}\right)\end{array}$ & $\begin{array}{r}\bar{p} \text { Annual } \\
\left(\mathrm{mm} \mathrm{a}^{-1}\right)\end{array}$ \\
\hline F48301 & $\mathrm{CDB}$ & Martins Bay & 2111801 & 5635326 & & 89.6 & $2 / 1971$ & $11 / 1974$ & 2.4 & 9.5 & 3471 \\
\hline F48302 & $\mathrm{CDB}$ & Lake Mckerrow & 2113817 & 5635003 & 6 & 88.1 & $3 / 1982$ & $3 / 1984$ & 1.1 & 14.7 & 5380 \\
\hline F48331 & $\mathrm{CDB}$ & Big Bay,Pyke River & 2136812 & 5640473 & 328 & 78.9 & $2 / 1971$ & $4 / 1971$ & 0.2 & 11.3 & 4128 \\
\hline F47691 & $\mathrm{CDB}$ & Milford Sound & 2107601 & 5602699 & 3 & 65.7 & $1 / 1971$ & $12 / 2000$ & 30.0 & 18.3 & 6699 \\
\hline F47693 & $\mathrm{CDB}$ & Milford Sound Aws & 2107695 & 5602341 & 3 & 65.4 & $7 / 2000$ & $12 / 2000$ & 0.4 & 18.3 & 6696 \\
\hline F47771 & $\mathrm{CDB}$ & Dumpling Hut & 2095771 & 5591235 & 120 & 63.4 & $1 / 1982$ & $3 / 1987$ & 1.7 & 31.4 & 11465 \\
\hline F48611 & $\mathrm{CDB}$ & Hidden Falls Hut & 2122830 & 5608269 & 50 & 61.2 & $4 / 1982$ & $1 / 1986$ & 1.4 & 17.6 & 6439 \\
\hline F 47872 & $\mathrm{CDB}$ & Mackinnon Pass & 2096715 & 5587620 & 1150 & 60.0 & $12 / 1987$ & $1 / 1988$ & 0.2 & 15.3 & 5576 \\
\hline F47871 & $\mathrm{CDB}$ & Lake Mintaro Hut & 2097331 & 5586658 & 640 & 58.8 & $1 / 1982$ & $2 / 1993$ & 2.1 & 23.9 & 8718 \\
\hline 477911 & WRA & Cleddau at No 3A & 2110191 & 5594696 & 457 & 57.7 & $1 / 1971$ & $9 / 1994$ & 11.5 & 16.7 & 6095 \\
\hline F47794 & $\mathrm{CDB}$ & Homer Tunnel Western & 2112322 & 5592939 & 823 & 55.0 & $11 / 1984$ & $11 / 1988$ & 4.0 & 14.1 & 5142 \\
\hline F47791 & $\mathrm{CDB}$ & Homer Tunnel, Eastern & 2113909 & 5592925 & 884 & 54.1 & $11 / 1984$ & $11 / 1988$ & 3.7 & 17.9 & 6552 \\
\hline I 48711 & $\mathrm{CDB}$ & Routeburn Falls Hut & 2129797 & 5597882 & 914 & 48.7 & $12 / 1971$ & $4 / 1973$ & 0.9 & 11.4 & 4147 \\
\hline F47881 & $\mathrm{CDB}$ & Clinton Forks Hut & 2105968 & 5579074 & 250 & 47.6 & $1 / 1982$ & $1 / 1993$ & 2.7 & 13.2 & 4810 \\
\hline I 48712 & $\mathrm{CDB}$ & Lake Mckenzie Hut & 2127594 & 5593523 & 914 & 46.5 & $3 / 1971$ & $4 / 1973$ & 1.1 & 11.0 & 4004 \\
\hline I 48713 & $\mathrm{CDB}$ & Lake Mckenzie Hut & 2128081 & 5593328 & 910 & 46.1 & $12 / 1981$ & $4 / 1990$ & 3.8 & 15.6 & 5682 \\
\hline I 48811 & $\mathrm{CDB}$ & Lake Howden Hut & 2125315 & 5587822 & 690 & 43.2 & $12 / 1981$ & $5 / 1991$ & 5.9 & 13.8 & 5032 \\
\hline I 48581 & $\mathrm{CDB}$ & Glenfinnan & 2179130 & 5626166 & 341 & 42.4 & $1 / 1971$ & $12 / 2000$ & 30.0 & 5.8 & 2100 \\
\hline I 48731 & $\mathrm{CDB}$ & Routeburn Stn & 2139104 & 5596082 & 381 & 41.8 & $3 / 1971$ & $12 / 2000$ & 27.3 & 6.2 & 2276 \\
\hline 487302 & WRA & Dart at "The Hillocks, Gelnorchy" & 2140100 & 5593300 & 310 & 38.9 & $8 / 1997$ & $1 / 2001$ & 3.2 & 5.2 & 1899 \\
\hline I 48741 & $\mathrm{CDB}$ & Earnslaw & 2146092 & 5595920 & 335 & 37.5 & $1 / 1971$ & $12 / 2000$ & 29.8 & 4.3 & 1575 \\
\hline 486610 & WRA & Shotover at 16 Mile rain & 2165081 & 5606458 & 610 & 34.8 & $2 / 1977$ & $4 / 1986$ & 8.3 & 4.0 & 1467 \\
\hline I 48833 & $\mathrm{CDB}$ & Rees Valley Station & 2145922 & 5590457 & 464 & 33.2 & 9/1987 & $1 / 1990$ & 2.3 & 4.3 & 1559 \\
\hline I 48901 & $\mathrm{CDB}$ & Knobs Flat & 2117333 & 5569197 & 375 & 32.9 & $1 / 1971$ & $11 / 1988$ & 17.3 & 6.4 & 2342 \\
\hline I 48831 & $\mathrm{CDB}$ & Glenorchy School & 2145182 & 5585296 & 311 & 29.5 & $1 / 1971$ & $5 / 1978$ & 6.5 & 3.0 & 1085 \\
\hline I 48771 & $\mathrm{CDB}$ & Shotover Branches & 2172205 & 5598440 & 503 & 24.1 & $6 / 1973$ & $12 / 2000$ & 27.6 & 2.8 & 1035 \\
\hline 486920 & WRA & Matutukituki at West Wanaka & 2192000 & 5611400 & 280 & 22.9 & $1 / 1998$ & $1 / 2001$ & 2.9 & 3.0 & 1099 \\
\hline 580110 & WRA & Mararoa at Mavora Lakes & 2124600 & 5557900 & 1433 & 19.5 & $3 / 1997$ & $1 / 2001$ & 3.8 & 4.2 & 1527 \\
\hline 488701 & WRA & Shotover at Peat's Hut & 2171200 & 5588500 & 460 & 16.7 & $12 / 1996$ & $1 / 2001$ & 3.7 & 2.6 & 961 \\
\hline I48961 & $\mathrm{CDB}$ & Arthurs Point & 2168430 & 5570758 & 607 & 4.0 & $1 / 1971$ & $12 / 2000$ & 30.0 & 2.6 & 950 \\
\hline I $4897 \mathrm{~A}$ & $\mathrm{CDB}$ & Hunter Heights & 2175738 & 5574477 & 488 & 2.7 & $4 / 1987$ & $9 / 1989$ & 2.1 & 2.2 & 804 \\
\hline I 48973 & $\mathrm{CDB}$ & Arrowtown, Zelkova & 2178428 & 5575950 & 413 & 2.3 & $4 / 1992$ & $4 / 2000$ & 8.0 & 2.4 & 892 \\
\hline I48981 & $\mathrm{CDB}$ & Arrowtown & 2180185 & 5577153 & 360 & 2.2 & $1 / 1971$ & $1 / 1991$ & 20.1 & 2.1 & 749 \\
\hline 489710 & WRA & Shotover at Middletons & 2172199 & 5571035 & 355 & 2.0 & $5 / 1985$ & $11 / 1995$ & 10.4 & 2.3 & 838 \\
\hline I 49801 & $\mathrm{CDB}$ & Cardrona & 2195575 & 5585703 & 518 & 0.0 & $1 / 1971$ & $12 / 2000$ & 29.7 & 1.8 & 672 \\
\hline I58061 & $\mathrm{CDB}$ & Queenstown & 2168377 & 5565748 & 329 & -0.0 & $1 / 1971$ & $12 / 2000$ & 30.0 & 2.5 & 913 \\
\hline I 58074 & $\mathrm{CDB}$ & Queenstown Aero & 2173968 & 5567487 & 349 & -1.9 & $1 / 1971$ & $8 / 1993$ & 21.8 & 1.9 & 695 \\
\hline
\end{tabular}


Table A.5 (continued)

\begin{tabular}{|c|c|c|c|c|c|c|c|c|c|c|c|}
\hline $\begin{array}{l}\text { Network/ } \\
\text { Site No. }\end{array}$ & Archive & Station Name & $\begin{array}{r}\text { Easting } \\
\text { (NZMG) }\end{array}$ & $\begin{array}{l}\text { Northing } \\
\text { (NZMG) }\end{array}$ & $\begin{array}{c}\text { Elevation } \\
\text { (m a.s.l.) }\end{array}$ & $\begin{array}{r}\text { NW Dist } \\
(\mathrm{km})\end{array}$ & $\begin{array}{r}\text { Begin } \\
\text { Date }\end{array}$ & $\begin{array}{l}\text { End } \\
\text { Date }\end{array}$ & $\begin{array}{l}\text { Obs. } \\
\text { Years }\end{array}$ & $\begin{array}{r}\bar{p} \text { Daily } \\
\left(\mathrm{mm} \mathrm{dy}^{-1}\right)\end{array}$ & $\begin{array}{l}\bar{p} \text { Annual } \\
\left(\mathrm{mm} \mathrm{a}^{-1}\right)\end{array}$ \\
\hline I58075 & $\mathrm{CDB}$ & Queenstown Aero Aws & 2174125 & 5567495 & 354 & -2.0 & $1 / 1982$ & $12 / 2000$ & 17.9 & 2.2 & 791 \\
\hline I58073 & $\mathrm{CDB}$ & Kawarau Falls & 2173536 & 5566686 & 320 & -2.3 & $1 / 1971$ & $2 / 1982$ & 10.9 & 2.0 & 721 \\
\hline I58161 & CDB & Cecil Peak & 2163795 & 5558494 & 351 & -3.2 & $1 / 1971$ & $2 / 1979$ & 5.5 & 2.0 & 725 \\
\hline I58311 & $\mathrm{CDB}$ & Mavora Lakes Park & 2131768 & 5530650 & 640 & -6.7 & $11 / 1985$ & $3 / 1989$ & 3.4 & 4.0 & 1451 \\
\hline 582210 & WRA & Oreti at Gorge $\mathrm{Ck}$ & 2138563 & 5535079 & 670 & -7.1 & $10 / 1974$ & $1 / 2001$ & 26.2 & 3.2 & 1153 \\
\hline I 49901 & $\mathrm{CDB}$ & Upper Meg Power Stn & 2199264 & 5573086 & 518 & -12.3 & $1 / 1971$ & $12 / 2000$ & 29.8 & 2.1 & 770 \\
\hline I58091 & $\mathrm{CDB}$ & Gibbston,Loop Rd & 2191135 & 5566573 & 533 & -12.8 & $1 / 1971$ & $12 / 1984$ & 14.0 & 1.8 & 666 \\
\hline I58171 & $\mathrm{CDB}$ & Wye Creek & 2176509 & 5554933 & 335 & -13.5 & $1 / 1971$ & $3 / 1981$ & 9.8 & 2.0 & 715 \\
\hline I58092 & $\mathrm{CDB}$ & Gibbston Nevis Bluff & 2193265 & 5566566 & 366 & -14.0 & $11 / 1984$ & $5 / 1987$ & 2.6 & 1.7 & 611 \\
\hline
\end{tabular}




\section{Appendix B}

\section{Simulated precipitation versus}

\section{rain gauges}

This appendix lists comparisons between precipitation simulated by the HadRM3P regional climate model and observations from rain gauges in the Southern Alps. Table B.1 lists comparisons during the 30-year period from 1 January 1971 to 31 December 2000, as described in Section 5.4. Table B.2 lists comparisons during the single day of 5 November 1994, as described in Section 5.5. 
Table B.1 Observations from 28 long-term rain gauges in the Southern Alps, compared with precipitation simulated by HadRM3P, from 1 Jan 1971 to 31 Dec 2000. 'Period' is the number of years of observation at each rain gauge. 'Precip.' is the amount of observed or simulated mean annual precipitation. 'Diff.' is the simulated precipitation minus the observed precipitation. Rain gauges are listed in descending order of the absolute difference between observations and Surf $\mathrm{Rcm}_{\text {.A.Raw }}$.

\begin{tabular}{|c|c|c|c|c|c|c|c|c|c|c|}
\hline \multirow{2}{*}{$\begin{array}{c}\text { Network/ } \\
\text { Site No. }\end{array}$} & \multirow[t]{2}{*}{ Station Name } & \multirow{2}{*}{$\begin{array}{l}\text { Elevation } \\
\text { (m a.s.l.) }\end{array}$} & \multicolumn{2}{|c|}{ Observed } & \multicolumn{2}{|c|}{ Surf $_{\text {Rcm.A.Raw }}$} & \multicolumn{2}{|c|}{ Surf $_{\text {Rcm.A.DsT }}$} & \multicolumn{2}{|c|}{ Surf $_{\text {Rcm.A.Ds }}$} \\
\hline & & & $\begin{array}{r}\text { Period } \\
\text { (Years) }\end{array}$ & $\begin{array}{r}\text { Precip. } \\
\left(\mathrm{mm} \mathrm{a}^{-1}\right)\end{array}$ & $\begin{array}{r}\text { Precip. } \\
\left(\mathrm{mm} \mathrm{a}^{-1}\right)\end{array}$ & $\begin{array}{r}\text { Diff. } \\
\left(\mathrm{mm} \mathrm{a}^{-1}\right)\end{array}$ & $\begin{array}{r}\text { Precip. } \\
\left(\mathrm{mm} \mathrm{a}^{-1}\right)\end{array}$ & $\begin{array}{r}\text { Diff. } \\
\left(\mathrm{mm} \mathrm{a}^{-1}\right)\end{array}$ & $\begin{array}{r}\text { Precip. } \\
\left(\mathrm{mm} \mathrm{a}^{-1}\right)\end{array}$ & $\begin{array}{r}\text { Diff. } \\
\left(\mathrm{mm} \mathrm{a}^{-1}\right)\end{array}$ \\
\hline F30231 & Lower Whataroa & 30 & 30.0 & 3797 & 9504 & 5707 & 7947 & 4150 & 6320 & 2523 \\
\hline F30233 & Whataroa 2 & 64 & 26.7 & 4581 & 9504 & 4923 & 7088 & 2507 & 6046 & 1465 \\
\hline F39662 & Mahitahi & 30 & 29.1 & 4707 & 8570 & 3863 & 7174 & 2467 & 6356 & 1649 \\
\hline F30401 & Fox Glacier M.W.D. & 91 & 15.1 & 4628 & 8133 & 3504 & 7815 & 3186 & 6682 & 2054 \\
\hline F30402 & Fox Glacier,Main Rd & 152 & 23.2 & 4669 & 8133 & 3464 & 7789 & 3121 & 6644 & 1975 \\
\hline F39741 & Paringa & 43 & 29.7 & 5534 & 8570 & 3036 & 5998 & 464 & 5731 & 196 \\
\hline H30711 & Mt Cook,The Hermitage & 765 & 29.2 & 4290 & 6781 & 2492 & 4862 & 572 & 5101 & 812 \\
\hline F30312 & Franz Josef & 155 & 18.4 & 5894 & 8133 & 2238 & 7004 & 1110 & 6406 & 512 \\
\hline H30581 & Erewhon & 594 & 25.9 & 1573 & 3786 & 2213 & 2507 & 934 & 2414 & 841 \\
\hline H30751 & Lilybank Station & 686 & 21.7 & 1097 & 2930 & 1834 & 1861 & 764 & 2028 & 931 \\
\hline F39803 & Haast Aws & 5 & 16.6 & 3798 & 5418 & 1620 & 4649 & 851 & 4556 & 758 \\
\hline F39721 & Lake Moeraki & 9 & 15.6 & 4502 & 3113 & -1389 & 3858 & -644 & 4085 & -417 \\
\hline F30212 & Okarito & 2 & 19.3 & 3323 & 2363 & -961 & 4518 & 1194 & 4613 & 1290 \\
\hline F49132 & Haast Pass & 524 & 17.9 & 4489 & 5356 & 867 & 5540 & 1051 & 5247 & 758 \\
\hline H49182 & Lake Ohau Stn & 533 & 30.0 & 1182 & 432 & -750 & 1480 & 298 & 1952 & 770 \\
\hline 308217 & Jollie at Jollie Hut & 610 & 27.2 & 1307 & 653 & -654 & 2215 & 908 & 2572 & 1265 \\
\hline 491610 & Ahuriri at Cassinia Moraine & 980 & 29.5 & 2601 & 3127 & 526 & 3389 & 788 & 3501 & 900 \\
\hline I49381 & Ribbonwood & 634 & 27.0 & 834 & 317 & -517 & 629 & -206 & 946 & 112 \\
\hline 494611 & Ahuriri at Plains & 747 & 23.0 & 907 & 1143 & 236 & 1033 & 126 & 1204 & 297 \\
\hline H40021 & L Pukaki Tasman Downs & 564 & 27.8 & 879 & 653 & -225 & 985 & 107 & 1387 & 509 \\
\hline H40022 & L Pukaki, Guide Hill & 745 & 30.0 & 876 & 653 & -223 & 879 & 3 & 1286 & 410 \\
\hline I 49591 & Omarama,Tara Hills & 488 & 15.0 & 534 & 317 & -217 & 412 & -121 & 550 & 16 \\
\hline
\end{tabular}


Table B.1 (continued)

\begin{tabular}{|c|c|c|c|c|c|c|c|c|c|c|}
\hline \multirow{2}{*}{$\begin{array}{c}\text { Network/ } \\
\text { Site No. }\end{array}$} & \multirow[t]{2}{*}{ Station Name } & \multirow{2}{*}{$\begin{array}{l}\text { Elevation } \\
\text { (m a.s.l.) }\end{array}$} & \multicolumn{2}{|c|}{ Observed } & \multicolumn{2}{|c|}{$\operatorname{Surf}_{\text {Rcm.Raw }}$} & \multicolumn{2}{|c|}{ Surf $_{\text {Rcm.A.DsT }}$} & \multicolumn{2}{|c|}{$\operatorname{Surf}_{\text {Rcm.A.Ds }}$} \\
\hline & & & $\begin{array}{l}\text { Period } \\
\text { (years) }\end{array}$ & $\begin{array}{r}\text { Precip. } \\
\left(\mathrm{mm} \mathrm{a}^{-1}\right)\end{array}$ & $\begin{array}{r}\text { Precip. } \\
\left(\mathrm{mm} \mathrm{a}^{-1}\right)\end{array}$ & $\begin{array}{r}\text { Diff. } \\
\left(\mathrm{mm} \mathrm{a}^{-1}\right)\end{array}$ & $\begin{array}{r}\text { Precip. } \\
\left(\mathrm{mm} \mathrm{a}^{-1}\right)\end{array}$ & $\begin{array}{r}\text { Diff. } \\
\left(\mathrm{mm} \mathrm{a}^{-1}\right)\end{array}$ & $\begin{array}{r}\text { Precip. } \\
\left(\mathrm{mm} \mathrm{a}^{-1}\right)\end{array}$ & $\begin{array}{r}\text { Diff. } \\
\left(\mathrm{mm} \mathrm{a}^{-1}\right)\end{array}$ \\
\hline H30921 & L Pukaki, Braemar & 550 & 29.6 & 860 & 653 & -207 & 1086 & 226 & 1468 & 607 \\
\hline 309211 & Mary Burn at Coach Rd & 838 & 19.8 & 832 & 653 & -178 & 880 & 48 & 1282 & 450 \\
\hline H30941 & Mt John & 1027 & 17.0 & 588 & 653 & 65 & 650 & 62 & 816 & 228 \\
\hline H30691 & Mesopotamia & 552 & 27.9 & 955 & 1011 & 57 & 1331 & 376 & 1463 & 508 \\
\hline $\mathrm{H} 40041$ & Lake Tekapo, Air Safaris & 762 & 30.0 & 600 & 653 & 53 & 608 & 8 & 781 & 181 \\
\hline H30951 & L Tekapo,Mt Hay Stn & 732 & 27.8 & 603 & 653 & 51 & 717 & 115 & 815 & 212 \\
\hline
\end{tabular}


Table B.2 Observations from 19 rain gauges in the Southern Alps, compared with precipitation simulated by HadRM3P, on 5 Nov 1994 UTC. Surf Rcm.D.Raw is simulated precipitation at 30-km resolution; Surf $f_{\text {Rcm.D.Ds }}$ is downscaled with the Surf $f_{\text {Obs.D }}$ surface of observed mean daily precipitation; Surf Rcm.D.Ds.NW is downscaled with the Surf Obs.D.NW surface of observed mean daily precipitation on northwesterly days. 'Precip.' is the amount of observed or simulated precipitation. 'Diff.' is the simulated precipitation minus the observed precipitation.

\begin{tabular}{|c|c|c|c|c|c|c|c|c|c|}
\hline \multirow{2}{*}{$\begin{array}{c}\text { Network/ } \\
\text { Site No. }\end{array}$} & \multirow[t]{2}{*}{ Station Name } & \multirow{2}{*}{$\begin{array}{l}\text { Elevation } \\
\text { (m a.s.l.) }\end{array}$} & \multirow{2}{*}{$\begin{array}{r}\text { Observed } \\
\text { Precip. } \\
(\mathrm{mm})\end{array}$} & \multicolumn{2}{|c|}{$\operatorname{Surf}_{\text {Rcm.D.Raw }}$} & \multicolumn{2}{|c|}{ Surf $_{\text {Rcm.D.Ds }}$} & \multicolumn{2}{|c|}{$\operatorname{Surf}_{\text {Rcm.D.Ds.NW }}$} \\
\hline & & & & $\begin{array}{r}\text { Precip. } \\
(\mathrm{mm})\end{array}$ & $\begin{array}{r}\text { Diff. } \\
(\mathrm{mm})\end{array}$ & $\begin{array}{r}\text { Precip. } \\
(\mathrm{mm})\end{array}$ & $\begin{array}{r}\text { Diff. } \\
(\mathrm{mm})\end{array}$ & $\begin{array}{r}\text { Precip. } \\
(\mathrm{mm})\end{array}$ & $\begin{array}{r}\text { Diff. } \\
(\mathrm{mm})\end{array}$ \\
\hline 304410 & Godley at Panorama Ridge & 1509 & 11 & 209 & 199 & 151 & 141 & 153 & 143 \\
\hline 303411 & Whataroa at SHB rain & 90 & 79 & 210 & 131 & 170 & 91 & 172 & 93 \\
\hline 399410 & Haast at Moa $\mathrm{Ck}$ & 105 & 44 & 163 & 119 & 105 & 61 & 124 & 80 \\
\hline 399811 & Hopkins at Elcho Flats & 701 & 177 & 71 & -106 & 58 & -118 & 67 & -109 \\
\hline 399210 & Haast at Cron $\mathrm{Ck}$ & 58 & 68 & 163 & 96 & 175 & 108 & 172 & 104 \\
\hline 304210 & Waiho at Douglas Hut & 250 & 100 & 180 & 81 & 167 & 67 & 167 & 67 \\
\hline 399213 & Haast at Roaring Billy rain & 60 & 89 & 163 & 74 & 146 & 57 & 151 & 62 \\
\hline 307110 & Hooker at Ball Hut $\mathrm{Rd} \mathrm{Br}$ rain & 680 & 89 & 158 & 69 & 91 & 2 & 91 & 1 \\
\hline 308217 & Jollie at Jollie Hut & 610 & 54 & 1 & -53 & 46 & -8 & 48 & -6 \\
\hline 399710 & Hopkins at Boanerges Ridge & 1402 & 114 & 158 & 44 & 55 & -59 & 61 & -52 \\
\hline 306610 & Macaulay at Mt Gerald & 823 & 57 & 16 & -41 & 36 & -21 & 39 & -18 \\
\hline 309810 & Opuha at Clayton & 792 & 26 & 0 & -25 & 15 & -10 & 14 & -11 \\
\hline 308610 & Coal Ck at Skifield & 1364 & 33 & 16 & -17 & 23 & -10 & 25 & -8 \\
\hline 304610 & Rangitata at Mistake Flat & 790 & 130 & 114 & -16 & 108 & -22 & 114 & -16 \\
\hline 307001 & Hooker at Mt Cook(The Hermitage) & 752 & 173 & 158 & -15 & 114 & -59 & 110 & -63 \\
\hline 304110 & Waiho at Alex Knob & 1295 & 170 & 180 & 10 & 160 & -10 & 160 & -10 \\
\hline 305411 & Godley at Eade Hut & 975 & 219 & 209 & -10 & 133 & -86 & 137 & -82 \\
\hline 491610 & Ahuriri at Cassinia Moraine & 980 & 64 & 73 & 9 & 60 & -4 & 63 & -1 \\
\hline 494711 & Ahuriri at Sth Diadem rain & 610 & 17 & 18 & 2 & 15 & -1 & 18 & 2 \\
\hline
\end{tabular}

